UNIVERSIDADE DE BRASÍLIA

FACULDADE DE TECNOLOGIA DEPARTAMENTO DE ENGENHARIA ELÉTRICA

IMPLEMENTAÇÕES EM PROCESSAMENTO DIGITAL DE SINAIS UTILIZANDO O TMS320C6711

\author{
KARINA MAHON MATTAR
}

ORIENTADORES: ALEXANDRE ZAGHETTO

TRABALHO DE CONCLUSÃO DO CURSO DE GRADUAÇÃO EM ENGENHARIA ELÉTRICA

BRASÍLIA/DF: DEZEMBRO/2006

UNIVERSIDADE DE BRASÍLIA 
FACULDADE DE TECNOLOGIA

DEPARTAMENTO DE ENGENHARIA ELÉTRICA

\title{
IMPLEMENTAÇÕES EM PROCESSAMENTO DIGITAL DE SINAIS UTILIZANDO O TMS320C6711
}

\author{
KARINA MAHON MATTAR
}

TRABALHO DE CONCLUSÃO DE CURSO SUBMETIDO AO DEPARTAMENTO DE ENGENHARIA ELÉTRICA DA FACULDADE DE TECNOLOGIA DA UNIVERSIDADE DE BRASÍLIA, COMO PARTE DOS REQUISITOS NECESSÁRIOS PARA A OBTENÇÃO DO GRAU DE ENGENHEIRO.

APROVADA POR:

Alexandre Zaghetto, M.Sc.

(Orientador)

Adson Ferreira Da Rocha, Ph.D., ENE/UnB

(Examinador)

Pedro de Azevedo Berger, Dr., CIC/UnB

(Examinador)

DATA: BRASÍLIA/DF, 07 DE DEZEMBRO DE 2006 


\section{FICHA CATALOGRÀFICA:}

\section{MATTAR, KARINA MAHON}

Implementações em Processamento Digital de Sinais Utilizando o TMS320C6711

[Distrito Federal] 2006.

xiv, 151 p., 297 mm (ENE/FT/UnB), Bacharel, Engenharia Elétrica, 2006). Trabalho de conclusão do curso de Graduação em Engenharia Elétrica - Universidade de Brasília. Faculdade de Tecnologia. Departamento de Engenharia Elétrica.

1. Aplicações em DSP utilizando o TMS3206711

2. Filtros com Resposta Impulsional Finita (FIR)

3. Filtros com Resposta Impulsional Infinita (IIR)

4. Transformada Rápida de Fourier (FFT)

5. Filtros Adaptativos

\section{REFERÊNCIA BIBLIOGRÁFICA:}

MATTAR, K.M. (2006). Implementações em Processamento Digital de Sinais Utilizando o TMS320C6711. Trabalho de conclusão de curso, Departamento de Engenharia Elétrica, Universidade de Brasília, Brasília, DF.

\section{CESSÃO DE DIREITOS}

AUTOR: Karina Mahon Mattar

TÍTULO: Implementações em Processamento Digital de Sinais Utilizando o TMS320C6711

GRAU: Bacharel

ANO: 2006

É concedida à Universidade de Brasília permissão para reproduzir cópias desse trabalho de conclusão de curso e para emprestar ou vender tais cópias somente para propósitos acadêmicos e científicos. $\mathrm{O}$ autor reserva outros direitos de publicação e nenhuma parte desse trabalho pode ser reproduzida sem a autorização por escrito do autor.

Karina Mahon Mattar

SHIS QL04 Conjunto 01, Casa 18

70510-310 - Brasília (DF) - Brasil 


\section{DEDICATÓRIA}

À minha filha, Isabella,

que a cada instante enche minha vida de alegria. 


\section{IMPLEMENTAÇÕES EM PROCESSAMENTO DIGITAL DE SINAIS UTILIZANDO O TMS320C6711}

\section{Autor: Karina Mahon Mattar \\ Orientador: Adson Ferreira Da Rocha e Alexandre Zaghetto \\ Programa de Graduação em Engenharia Elétrica \\ Brasília, Dezembro de 2006}

Este trabalho apresenta uma série de tutoriais, desenvolvidos para o DSK TMS320C6711 da Texas Instruments, que podem ser utilizados como material de suporte em cursos de Processamento Digital de Sinais (PDS). Tais tutoriais apresentam o kit TMS320C6711, bem como o ambiente de desenvolvimento Code Composer Studio, e conduzem o leitor na implementação de experimentos que aplicam na prática alguns tópicos em processamento digital de sinais, tais como filtros FIR, filtros IIR, transformada discreta de Fourier (DFT), transformada rápida de Fourier (FFT) e filtros adaptativos. Cada tutorial traz uma discussão teórica inicial seguida de práticas de laboratório que a consolida. 


\section{ABSTRACT \\ DIGITAL SIGNAL PROCESSING IMPLEMENTATIONS USING THE TMS320C6711}

\section{Author: Karina Mahon Mattar \\ Supervisor: Adson Ferreira Da Rocha e Alexandre Zaghetto \\ Programa de Graduação em Engenharia Elétrica \\ Brasília, December of 2006}

This work presents a set of tutorials developed to DSK TMS320C6711, a Texas Instruments digital signal processor starter kit, which can be used as a supplementary material for Digital Signal Processing (DSP) graduated and undergraduate course. Those tutorials presents the TMS320C6711 kit, as well as the integrated development environment Code Composer Studio, conducting the reader through the implementation of experiments which applies some topics of digital signal processing theory, such as FIR and IIR filters, Fourier Discrete Transform (FDT), Fourier Fast Transform (FFT) and adaptive filters. Each tutorial also brings a laconic theory discussion followed by practical laboratory experiments. 


\section{ÍNDICE}

Capítulo

Página

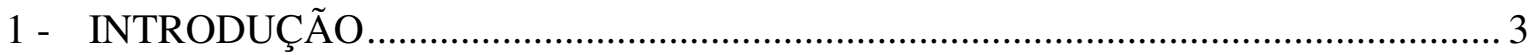

$1.1 \quad$ OBJETIVO

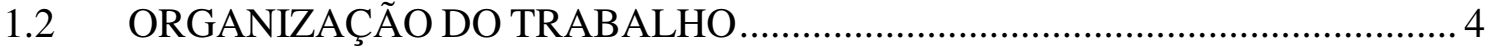

2 - TUTORIAL 1: APLICAÇÕES EM DSP UTILIZANDO O TMS3206711 …............. 5

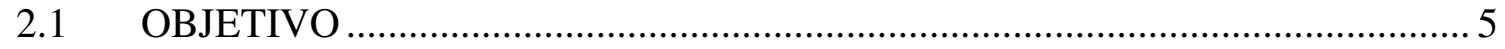

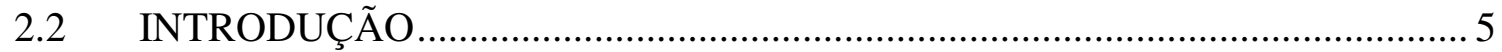

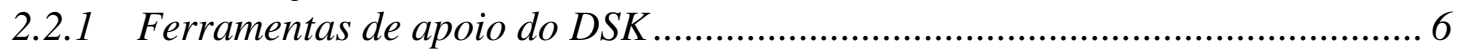

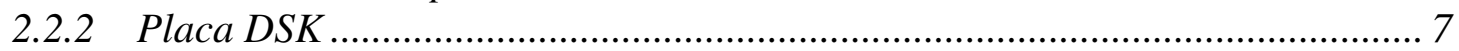

2.2.3 Processador Digital de Sinais TMS320C6711 …............................................ 8

2.2.4 Code Composer Studio ..................................................................................... 9

2.2.5 Instalação do Code Composer Studio v3.1 ..................................................... 9

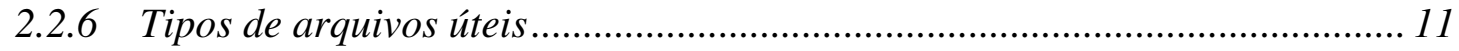

2.3 EXEMPLOS PARA TESTE DAS FERRAMENTAS DO DSK........................ 11

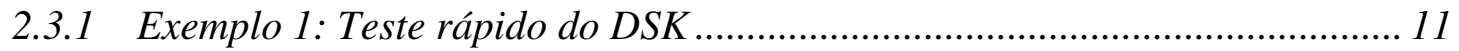

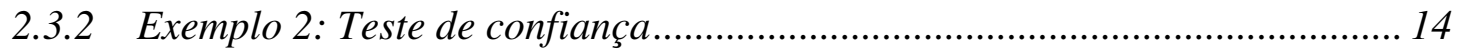

2.3.3 Exemplo 3: Geração de onda senoidal .......................................................... 16

2.3.4 Exemplo 4: Geração e Simulação de Gráficos de uma Senoide ...................... 25

2.3.5 Exemplo 5: Produto entre dois Vetores........................................................... 33

3 - TUTORIAL 2: FILTROS COM RESPOSTA IMPULSIONAL FINITA (FIR)......... 48

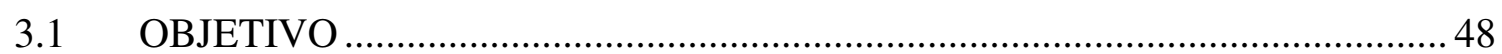

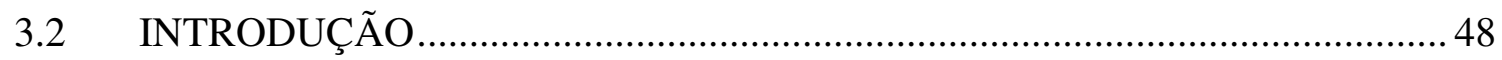

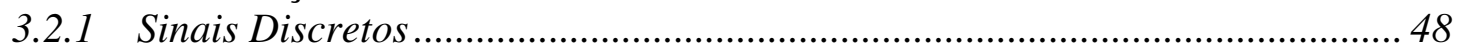

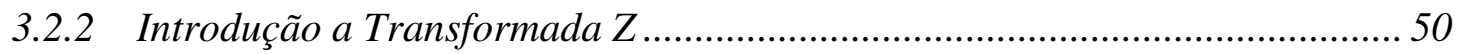

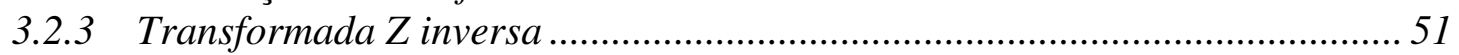

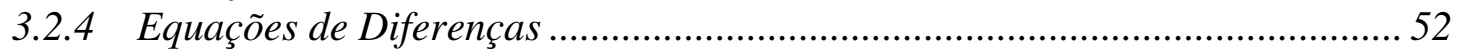

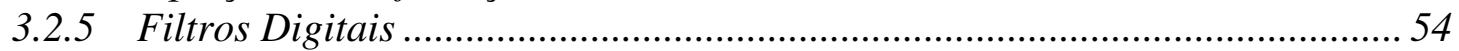

3.2.6 Filtros com Resposta Impulsional Finita (FIR) ........................................... 55

3.3 EXEMPLOS DE FILTROS COM RESPOSTAS IMPULSIONAL FINITA (FIR) 61

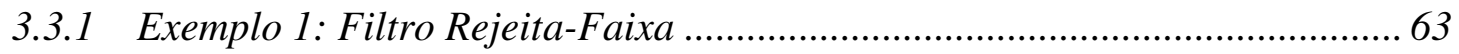

3.3.2 Exemplo 2: Filtro Passa-Faixa ...................................................................... 72

3.3.3 Exemplo 3: Implementação de dois filtros FIR rejeita-faixa para a

recuperação de uma entrada de voz corrompida ....................................................... 77

4 - TUTORIAL 3: FILTROS COM RESPOSTA IMPULSIONAL INFINITA (IIR) ..... 82

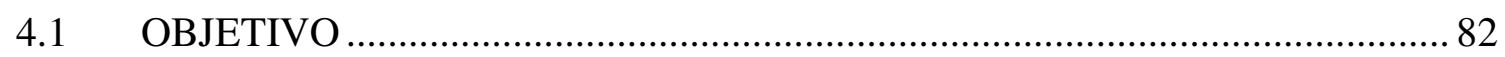

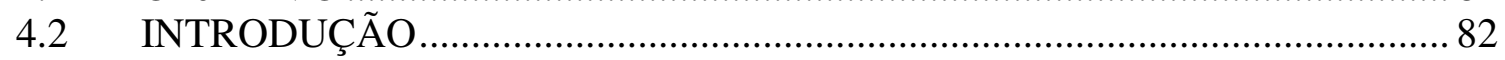

4.1 Filtros com Resposta Impulsional Infinita (IIR) ....................................... 82

4.2 Transformação Bilinear ......................................................................... 88

4.3 EXEMPLOS DE FILTROS COM RESPOSTA IMPULSIONAL INFINITA (IIR) 90

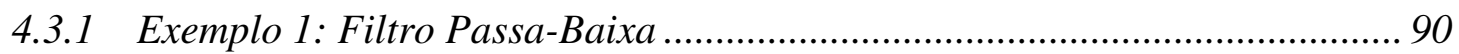


4.3.2 Exemplo 2: Filtro Passa-Faixa ................................................................... 93

5 - TUTORIAL 4: TRANSFORMADA RÁPIDA DE FOURIER (FFT) ......................... 98

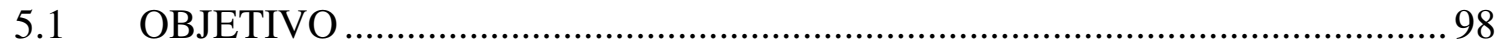

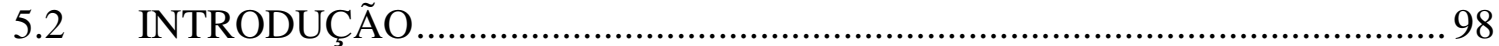

5.2.1 Transformada Discreta de Fourier (DFT) ................................................ 98

5.2.2 Desenvolvimento do algoritmo raiz-2 com decimação no tempo................... 101

5.2.3 Desenvolvimento do algoritmo raiz-2 com decimação na freqüência .......... 104

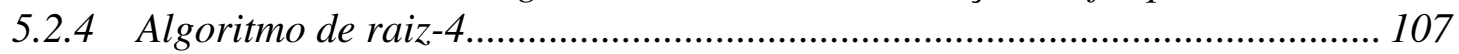

5.2.5 Transformada Inversa Discreta de Fourier (IDFT)................................... 108

5.3 EXEMPLOS DE TRANSFORMADA DISCRETA DE FOURIER (DFT) E

TRANSFORMADA RÁPIDA DE FOURIER (FFT) ....................................................... 109

5.3.1 Exemplo 1: DFT de uma Seqüência de números reais com saída para a janela

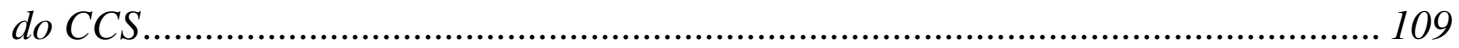

5.3.2 Exemplo 2: FFT formulada por Danielson -Lanczos.................................. 119

6 - TUTORIAL 5: FILTROS ADAPTATIVOS …........................................................ 128

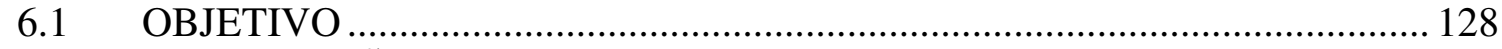

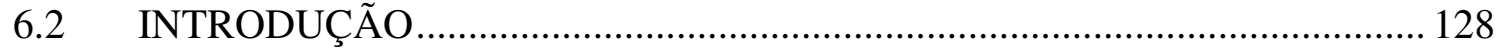

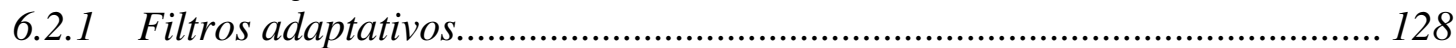

6.2.2 Algoritmo LMS - Least Mean Square ...................................................... 131

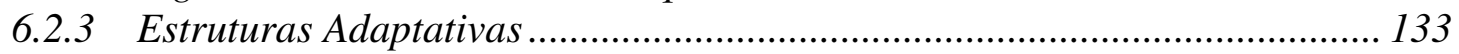

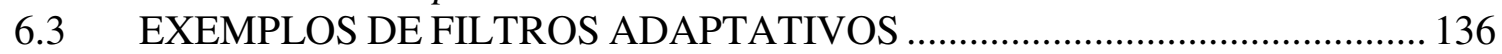

6.3.1 Exemplo 1: FIR adaptativo para identificação de sistemas.......................... 136

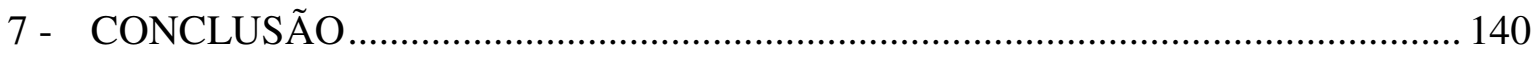

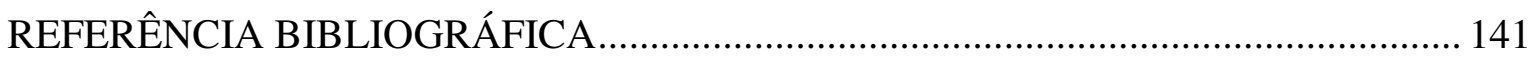

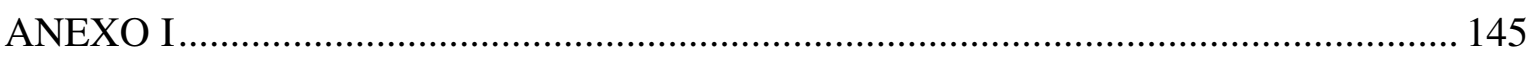




\section{LISTA DE TABELAS}

Tabela

Página

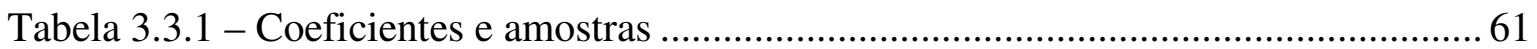

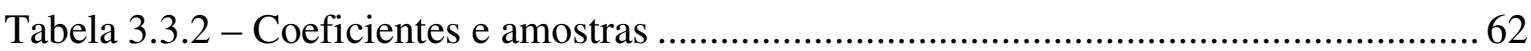

Tabela 5.3.1 - Reordenação utilizando a inversão de Bits .............................................. 122 


\section{LISTA DE FIGURAS}

Figura

Página

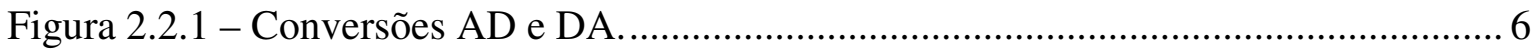

Figura 2.2.1.1 - Uma placa com o C6711 ................................................................ 7

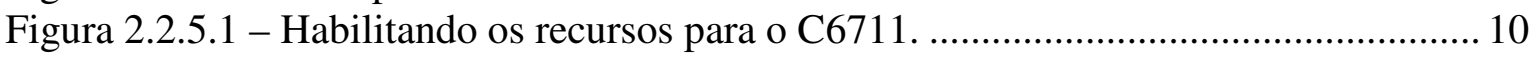

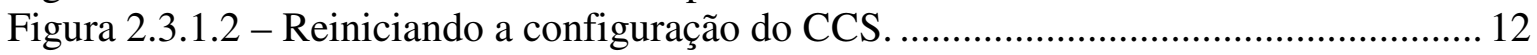

Figura 2.3.1.3 - Configurando a família e a plataforma...................................................... 12

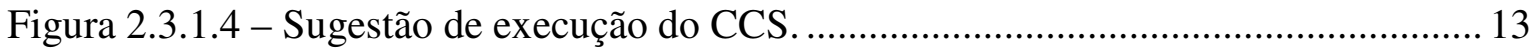

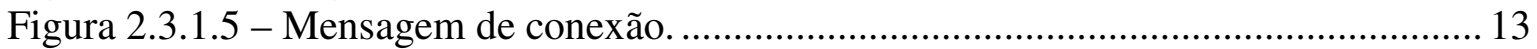

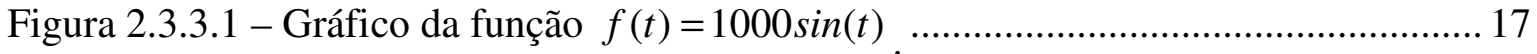

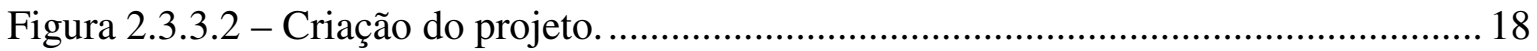

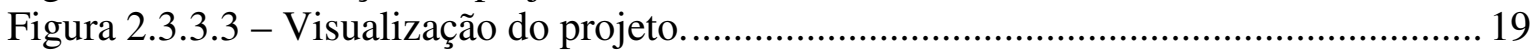

Figura 2.3.3.4 - Configuração do (a) compilador e do (b) linker....................................... 21

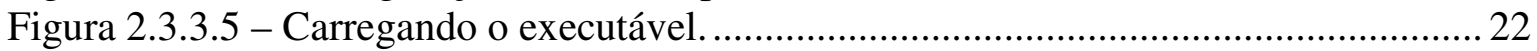

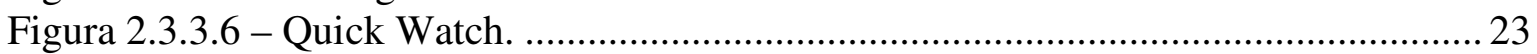

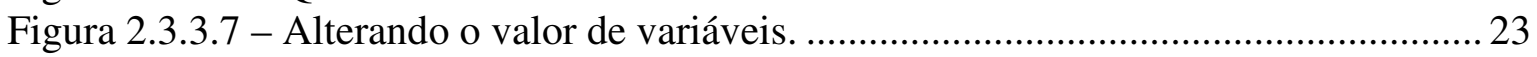

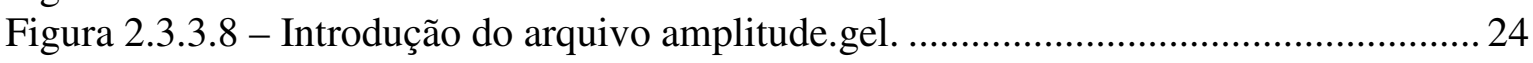

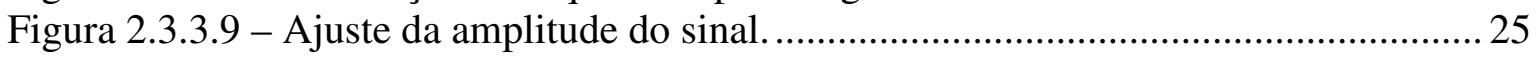

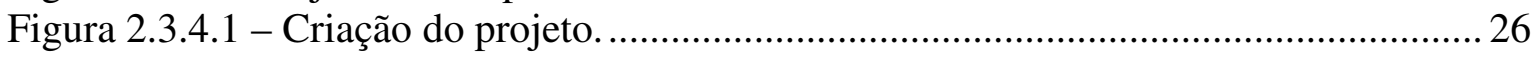

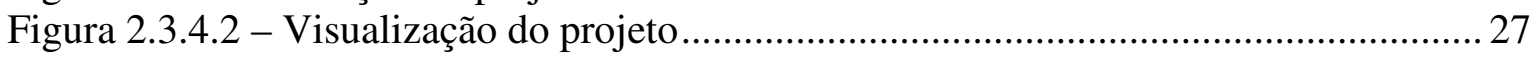

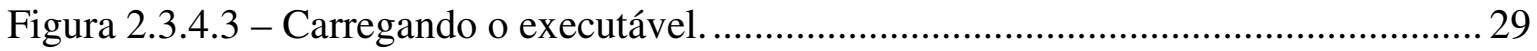

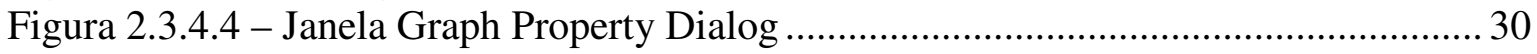

Figura 2.3.4.5 - Janela Graph Property Dialog com modificações.................................... 31

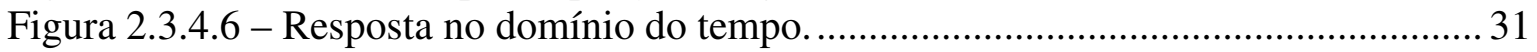

Figura 2.3.4.7 - Janela Graph Property Dialog com modificações .................................... 32

Figura 2.3.4.8 - Resposta no domínio da freqüência. ......................................................... 32

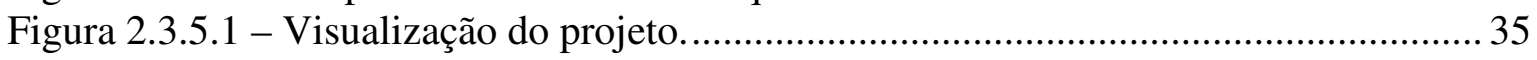

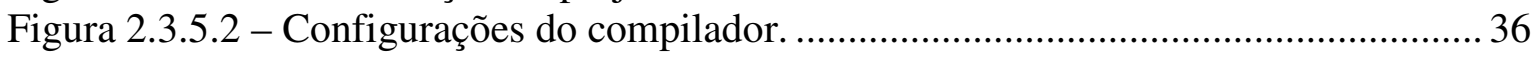

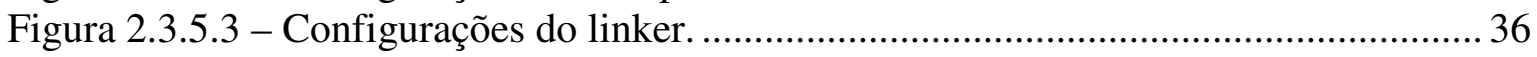

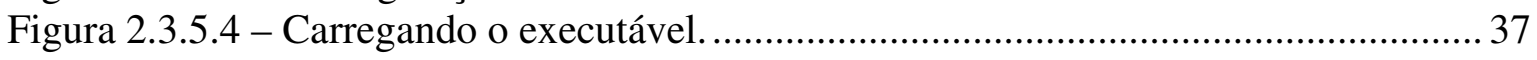

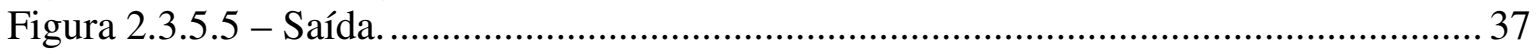

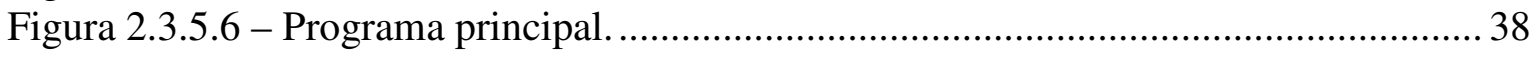

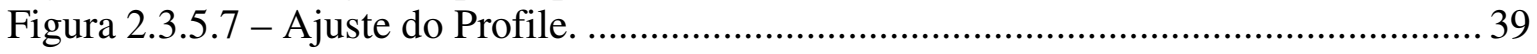

Figura 2.3.5.8 - Indicação de habilitação do Profile......................................................... 39

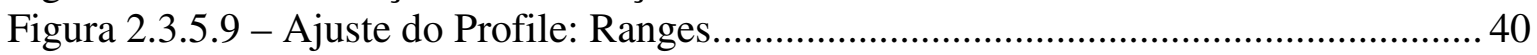

Figura 2.3.5.10 - Ajuste do Profile: Ranges................................................................. 41

Figura 2.3.5.11 - Ajuste do Profile: Custom/ Cycles........................................................ 41

Figura 2.3.5.12 - Configurações do compilador. ............................................................. 42

Figura 2.3.5.13 - Visualizador do Profile ....................................................................... 43

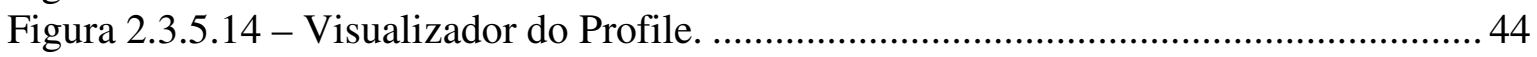

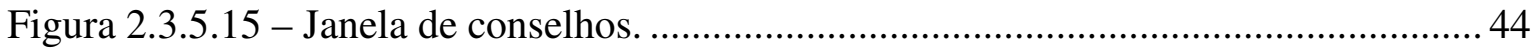

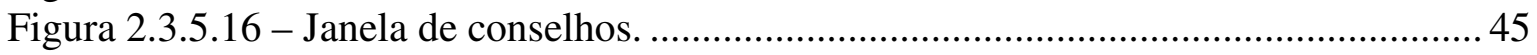

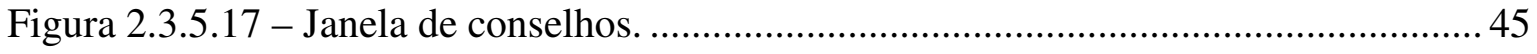

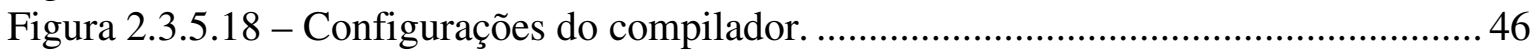

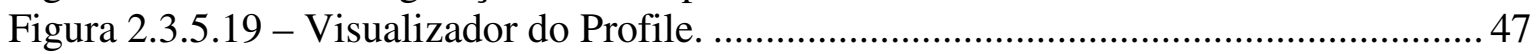


Figura 3.2.1.1 - Representação de um sistema no tempo discreto .................................. 49

Figura 3.2.6.1 - Forma direta para os filtros digitais FIR. ............................................... 57

Figura 3.2.6.2 - Função transferência desejada: (a) passa-baixas; (b) passa-altas; (c) passa-

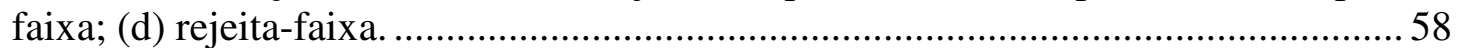

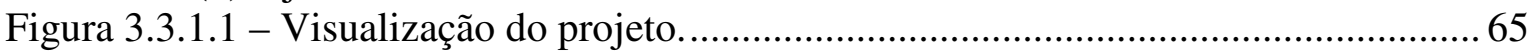

Figura 3.3.1.2 - Janela Graph Property Dialog com modificações................................... 67

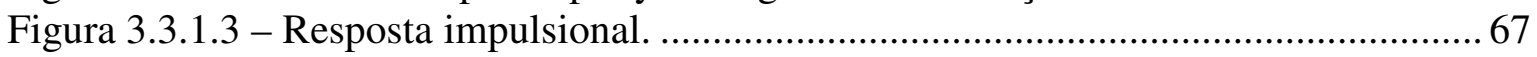

Figura 3.3.1.4 - Janela Graph Property Dialog com modificações para a FFT. ................. 68

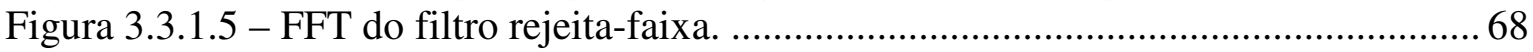

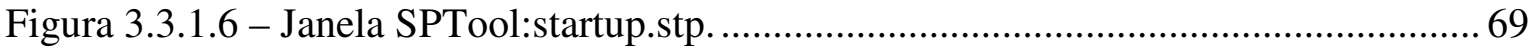

Figura 3.3.1.7 - Características do filtro FIR rejeita-faixa centrado em $2700 \mathrm{~Hz}$.............. 70

Figura 3.3.1.8 - Resposta em freqüência da saída do filtro FIR rejeita-faixa centrado em

$2700 \mathrm{~Hz}$, obtida com um osciloscópio. ................................................................ 71

Figura 3.3.1.9 - Resposta em freqüência da saída do filtro FIR rejeita-faixa centrado em

$2700 \mathrm{~Hz}$, obtido por meio da interpolação. ............................................................... 71

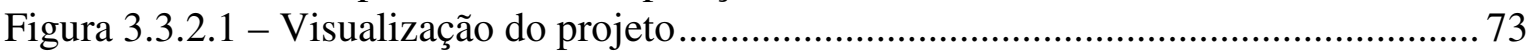

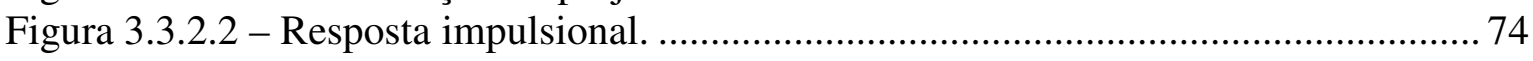

Figura 3.3.2.3 - FFT do filtro passa-faixa centrado em $1750 \mathrm{~Hz}$................................... 74

Figura 3.3.2.4 - Características do filtro FIR passa-faixa centrado em $1750 \mathrm{~Hz}$................. 75

Figura 3.3.2.5 - Resposta em frequiência da saída do filtro FIR passa-faixa centrado em

$1750 \mathrm{~Hz}$, obtido com um osciloscópio. .................................................................... 76

Figura 3.3.2.6 - Resposta em freqüência da saída do filtro FIR passa-faixa centrado em

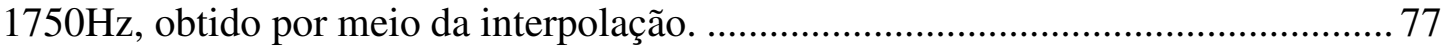

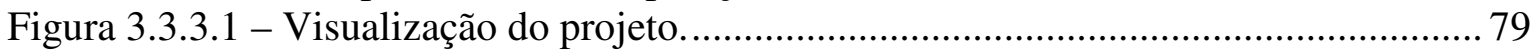

Figura 3.3.3.2 - Espectro do sinal de voz corrompido por dois sinais senoidais centrados

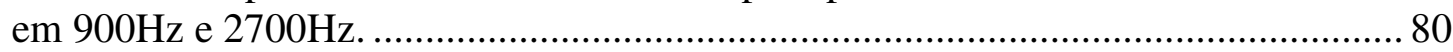

Figura 3.3.3.3 - Resposta em frequiência da saída dos filtros FIR rejeita-faixas em série

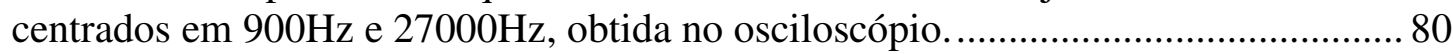

Figura 3.3.3.4 - Resposta em frequiência do sinal recuperado. ....................................... 81

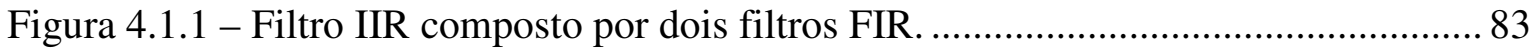

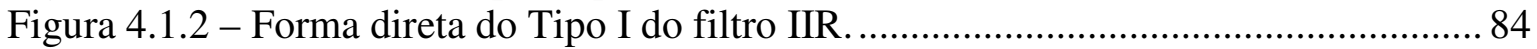

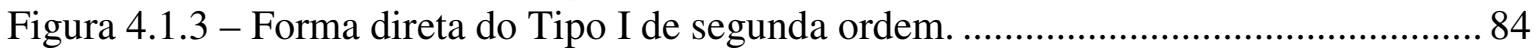

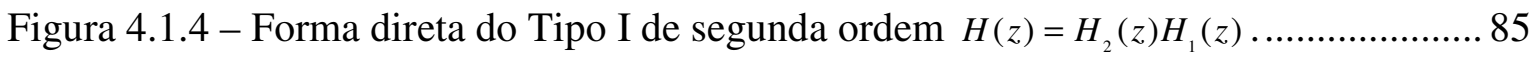

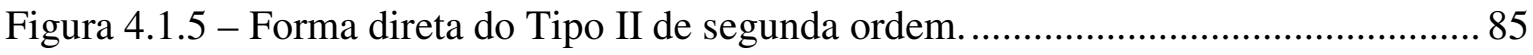

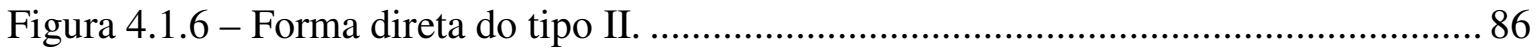

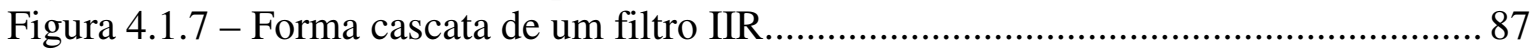

Figura 4.1.8 - Filtro IIR de quarta ordem com duas seções na forma direta do tipo II em

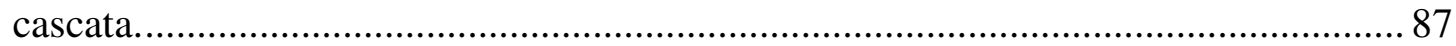

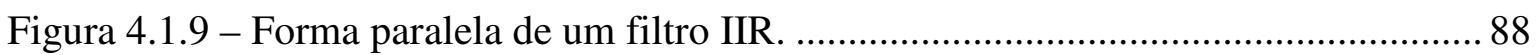

Figura 4.2.1. - Relação entre freqüências analógicas e digitais........................................ 89

Figura 4.3.1.1 - Visualização do projeto....................................................................... 92

Figura 4.3.1.2 - Resposta em freqüência da saída do filtro IIR passa-baixa com freqüência

de corte de $2000 \mathrm{~Hz}$, obtida no osciloscópio............................................................... 93

Figura 4.3.1.3 - Resposta em freqüência da saída do filtro IIR passa-baixa com freqüência

de corte de $2000 \mathrm{~Hz}$, obtida por meio da interpolação............................................. 93

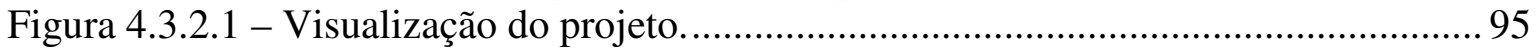

Figura 4.3.2.2 - Resposta em frequiência da saída do filtro IIR passa-faixa centrado em

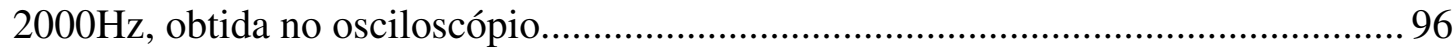

Figura 4.3.2.3 - Características do filtro IIR passa-faixa centrado em $2000 \mathrm{~Hz}$. ................ 97

Figura 5.2.1.1 - Comparação entre as funções $f(N)=N^{2}$ e $f(N)=N \log _{2} N \ldots \ldots \ldots \ldots \ldots . . .100$ 
Figura 5.2.1.2 - Visualização das propriedades de simetria e de periodicidade.

Figura 5.2.2.1 - Célula Básica do algoritmo de FFT com decimação no tempo.

Figura 5.2.2.2 - Decomposição de uma DFT com 8 pontos em duas DFTs de 4 pontos com decimação no tempo.

Figura 5.2.2.3 - Decomposição de duas DFTs de 4 pontos em quatro DFTs de 2 pontos com decimação no tempo.

Figura 5.2.2.4 - FFT de oito pontos usando decimação no tempo.................................... 104

Figura 5.2.3.1 - Célula Básica do algoritmo de FFT com decimação na freqüência........ 105

Figura 5.2.3.2 - Decomposição de uma DFT com 8 pontos em duas DFTs de 4 pontos . 106 com decimação na freqüência.

Figura 5.2.3.3 - Decomposição de duas DFTs de 4 pontos em quatro DFTs de 2 pontos com decimação na freqüência.

Figura 5.2.3.4 - FFT de oito pontos usando decimação na freqüência.

Figura 5.3.1.1 - Gráfico da função $x(n)=1000 * \cos \left(\frac{\pi}{4} n\right)$; Freqüência do sinal

$f=1000 \mathrm{~Hz}$ e Freqüência de amostragem $F_{s}=8000 \mathrm{~Hz}$.

Figura 5.3.1.2 - Valores da componente real (outRe) da DFT de $N=8$ gerada no MATLAB.

Figura 5.3.1.3 - Valores da componente imaginária (outIm) da DFT de $N=8$ gerada no MATLAB.

Figura 5.3.1.4 - Gráfico da função $x(n)=1000 \times \operatorname{sen}\left(\frac{\pi}{5} n\right)$; Freqüência do sinal

$f=800 \mathrm{~Hz}$ e Freqüência de amostragem $F_{s}=8000 \mathrm{~Hz}$

Figura 5.3.1.5 - Valores da componente real (outRe) da DFT de $N=20$ gerada no MATLAB.

Figura 5.3.1.6 - Valores da componente imaginária (outIm) da DFT de $N=20$ gerada no MATLAB.

Figura 5.3.1.7 - Visualização do projeto.

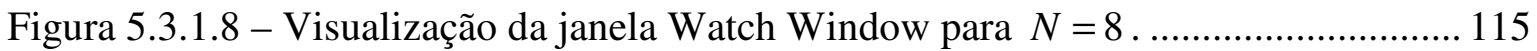

Figura 5.3.1.9 - Componentes real (outRe) e imaginária (outIm) da DFT de $N=8 \ldots \ldots .115$

Figura 5.3.1.10 - Componentes real (outRe) e imaginária (outIm) da DFT de $N=8$

geradas no MATLAB.

Figura 5.3.1.11 - Complexidade da função dft.c de uma DFT de comprimento $N=8 \ldots 116$

Figura 5.3.1.12 - Visualização da janela Watch Window para $N=20 \ldots \ldots \ldots \ldots \ldots \ldots \ldots \ldots \ldots . . . . .117$

Figura 5.3.1.13 - Valores da componente real (outRe) da DFT de $N=20$.................... 117

Figura 5.3.1.14 - Valores da componente imaginária (outIm) da DFT de $N=20 \ldots \ldots \ldots . .118$

Figura 5.3.1.15 - Componentes real (outRe) e imaginária (outIm) da DFT de $N=20$

geradas no MATLAB.

Figura 5.3.1.16 - Complexidade da função dft.c de uma DFT de comprimento $N=20.118$

Figura 5.3.2.1 -Gráfico da função $x(n)=1000 * \sin \left(\frac{\pi}{8} n\right)$; Freqüência do sinal

$f=500 \mathrm{~Hz}$ e Freqüência de amostragem $F_{s}=8000 \mathrm{~Hz}$

Figura 5.3.2.2 - Componentes real (outRe) e imaginária (outIm) da FFT de $N=32$

geradas no MATLAB.

Figura 5.3.2.3 - Componentes real (outRe) e imaginária (outIm) da FFT de $N=8 \ldots \ldots . .125$

Figura 5.3.2.4 - Complexidade da função fft.c de uma FFT de comprimento $N=8 \ldots \ldots 125$

Figura 5.3.2.5 - Valores da componente real (outRe) e da FFT de $N=32$. 126 
Figura 5.3.2.6 - Valores da componente imaginária (outIm) da FFT de $N=32 \ldots \ldots \ldots \ldots . .127$

Figura 5.3.2.7 - Complexidade da função fft.c de uma FFT de comprimento $N=32 \ldots 127$

Figura 6.2.1.1 - Forma geral de um combinador linear adaptativo............................... 129

Figura 6.2.1.2 - Diagrama de um filtro adaptativo FIR. ............................................... 129

Figura 6.2.1.3 - Estrutura Básica de um filtro Adaptativo.............................................. 130

Figura 6.2.3.1 - Identificação de Sistema utilizando filtro adaptativo............................... 133

Figura 6.2.3.2 - Sistema de modelamento de inversão utilizando um filtro adaptativo. .. 134

Figura 6.2.3.3 - Estrutura de um Cancelamento de Ruído................................................ 134

Figura 6.2.3.4 - Estrutura de Predição Adaptativa............................................................ 135

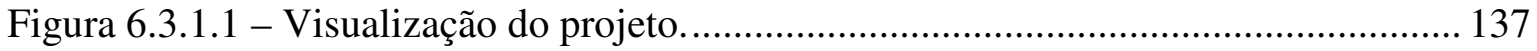

Figura 6.3.1.2 - Janela Graph Property Dialog com modificações................................. 138

Figura 6.3.1.3 - Sinal de cima: Sinal desejado (DESIRED); Sinal de baixo saída do filtro

(Y_out). 


\section{LISTA DE SÍMBOLOS, NOMENCLATURA E ABREVIAÇÕES}

$\begin{array}{ll}\text { ADC } & \text { Analog-to-digital Conversion } \\ \text { CCS } & \text { Code Composer Studio } \\ \text { CPU } & \text { Central Processing Unit } \\ \text { DSP } & \text { Digital Signal Processors } \\ \text { DSK } & \text { DSP start kit } \\ \text { DCA } & \text { Digital-to-analog Conversion } \\ \text { IDE } & \text { Integrated Development Environmet } \\ \text { ISR } & \text { Interrupt Service Routine } \\ \text { GEL } & \text { General Extension Language } \\ \text { McBSPs } & \text { Multichannel Buffered Serial Ports } \\ \text { PCHIP } & \text { Piecewise Cubic Interpolating Polynomial } \\ \text { RTDX } & \text { Real-time Data Exchange } \\ \text { SDRAM } & \text { Synchronous Dynamic RAM } \\ \text { SLR } & \text { Source Line Reference } \\ \text { TI } & \text { Texas Instruments } \\ \text { VLIW } & \text { Very-Long-Instruction-Word }\end{array}$




\section{1 - INTRODUÇÃO}

DSPs (Digital Signal Processors) ou Processadores Digitais de Sinais são utilizados em diversas áreas, tais como telecomunicações, controle, segurança, medicina, processamento de imagens, vídeo e áudio, entre outras. Podem ser encontrados em sistemas de transmissão sem fio, de identificação e classificação biométrica, de navegação, de monitoramento biofísico, em soluções DSL (Digital Subscriber Line), VoIP (Voice over Internet Protocol), em câmeras de foto e vídeo digitais, ou seja, em uma gama bastante abrangente de aplicações.

Esses processadores também ocupam espaço dentro da sala de aula, nas universidades, oferecendo aos alunos de graduação e pós-graduação uma forma econômica de se estudar, em tempo real, tópicos em processamento digital de sinais.

A Texas Instruments disponibiliza como produto a família de processadores TMS320C6x, baseada na arquitetura VLIW (Very-Long-Instruction-Word). Essa arquitetura oferece recursos que facilitam o desenvolvimento de compiladores bastante eficientes para linguagem de alto nível. Apesar do assembly para o TMS320C6x produzir códigos rápidos, alguns problemas no que diz respeito à documentação e manutenção podem ocorrer. Ao longo deste trabalho, as linguagens $\mathrm{C}$ e $\mathrm{C}++$ serão simplesmente referenciadas por C. Com o compilador $\mathrm{C}$ que o ambiente de desenvolvimento disponibiliza o programador precisa apenas deixar que a ferramenta faça o trabalho.

\subsection{OBJETIVO}

Este projeto tem por objetivo oferecer a estudantes de engenharia elétrica ou de computação uma série de tutorias que apresentam uma dimensão prática da disciplina de processamento digital de sinais (PDS). É convicção que os princípios abordados em PDS podem mais facilmente ser apreciados por meio de implementações em tempo real. Assume-se que, como pré-requisito, os alunos tenham adquirido conhecimentos em sistemas lineares, processamento digital de sinais e algum conhecimento em linguagem $\mathrm{C}$.

Os tutoriais começam com uma discussão teórica, seguida de um ou mais exemplos práticos que a consolidam. Foram elaboradas treze práticas de laboratório, com a maior parte dos códigos escrita em $\mathrm{C}$ e poucas linhas escritas em assembly. Os tutoriais abordam tópicos bastante conhecidos em processamento digitais de sinais. 
O conteúdo desse projeto pode ser utilizado de diversas formas como, por exemplo, em complemento a um curso de PDS, em um curso específico de tópicos especiais em PDS ou em seminários e oficinas.

\subsection{ORGANIZAÇÃO DO TRABALHO}

O Capítulo 2 apresenta alguns aspectos da placa DSK, bem como cinco exemplos básicos, cujo objetivo é fazer o aluno explorar o Code Composer Studio (CCS), ferramenta que acompanha o TMS3206711 DSP Starter Kit.

O Capítulo 3 trata de filtros FIR (Finite Impulse Response), através da conceituação destes e posterior apresentação de 3 exemplos; filtro rejeita-faixa, filtro passa-faixa; e o último exemplo apresenta a implementação de dois filtros rejeita-faixa para a recuperação de uma entrada de voz corrompida.

O Capítulo 4 introduz os conceitos de filtros IIR (Infinit Impulse Response), e apresenta a implementação de dois exemplos; o primeiro constitui um filtro passa-baixa e o segundo apresenta um filtro passa-faixa.

O Capítulo 5 trata sobre FFT (Fast Fourier Transform), e é constituído por dois exemplos; Transformada Discreta de Fourier (DFT) e Transformada Rápida de Fourier.

O Capítulo 6 apresenta uma abordagem sobre filtros adaptativos e a implementação de um exemplo sobre filtro FIR adaptativo para sistemas de identificação.

Por fim, o Capítulo 7 traz a conclusão do trabalho. 


\section{2 - TUTORIAL 1: APLICAÇÕES EM DSP UTILIZANDO O TMS3206711}

\subsection{OBJETIVO}

- Teste do Code Composer Studio ${ }^{\mathrm{TM}}$ DSK v3.1 IDE

- Utilização do TMS320C6711 DSK

- Implementação de exemplos para testar as ferramentas de trabalho.

Esse tutorial trata das ferramentas que serão utilizadas ao longo do trabalho. Apresenta o popular Code Composer Studio (CCS), que oferece um ambiente de desenvolvimento integrado (Integrated Development Environment - IDE); o DSP starter kit (DSK), com o processador TMS320C6711 e completo suporte a entrada e saída. Cinco exemplos serão trabalhados com o objetivo de se testar as ferramentas de software e hardware que o DSK oferece.

\subsection{INTRODUÇÃO}

Processadores digitais de sinais como os da família TMS320C6x são como microprocessadores rápidos, de aplicação específica, com um tipo especializado de arquitetura e conjunto de instruções, apropriados ao processamento de sinais. A notação C6x é utilizada para se designar um membro da família de processadores TMS320C6000 da Texas Instruments (TI). A arquitetura do processador C6x é bastante adequada à realização de cálculos numéricos. Baseado na arquitetura que pode ser traduzida como muito-longa-palavra-de-instrução (very-long-instructio-word - VLIW), o C6x é considerado o mais poderoso processador da TI.

Processadores digitais de sinais são utilizados em uma gama bastante abrangente de aplicações, que vão de telecomunicações e controle ao processamento de imagem e voz. São encontrados em aparelhos de telefonia celular, fax/modems, drives de disco, rádios, DVDs, TVs digitais, e etc. Tais processadores apresentam-se como uma opção interessante para um número considerável de aplicações que atendem ao consumidor final, uma vez que 
diminuem o custo de produção de um determinado equipamento, aumentando o lucro obtido na venda do mesmo.

DSPs são mais freqüentemente utilizados no processamento em tempo real. Isso quer dizer que o processamento deve manter o passo com algum evento externo. Tal evento é normalmente uma entrada analógica. Enquanto sistemas analógicos apresentam maior sensibilidade à variação de condições ambientais, como a temperatura, por exemplo, sistemas baseados em DSPs apresentam maior robustez em relação à variação de tais condições. Dessa forma, os DSPs se beneficiam das mesmas vantagens que um microprocessador. São fáceis de usar, flexíveis e econômicos.

As aplicações mais comuns que utilizam esses processadores consideram sinais que estão entre as freqüências 0 e $20 \mathrm{kHz}$. A voz pode ser amostrada a $8 \mathrm{kHz}$, o que implica em um período de amostragem de $1 / 8 \mathrm{kHz}$ ou $0.125 \mathrm{~ms}$. Normalmente, a frequiência de amostragem utilizada em um compact disk (CD) é de $44.1 \mathrm{kHz}$.

O DSK inclui um codec, o TLC320AD535 (AD535), que é ao mesmo tempo um conversor AD (analógico-digital) e um conversor DA (digital-analógico). O conversor AD captura o sinal analógico de entrada e gera uma representação digital desse sinal, que é processada pelo DSP. O resultado do processamento é entregue ao conversor DA, que gera o sinal analógico de saída, conforme pode ser observado na Figura 2.1 [Chassaing \& Horning, 1990].

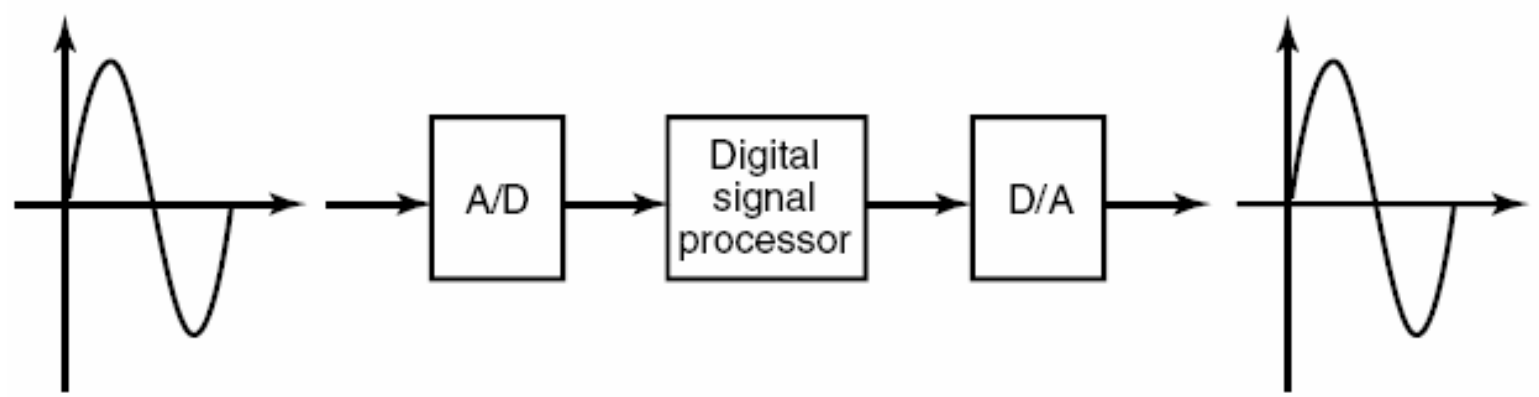

Figura 2.2.1 - Conversões AD e DA.

\subsubsection{Ferramentas de apoio do DSK}

Para que os experimentos possam ser realizados, (em todos os tutoriais), as ferramentas abaixo são necessárias: 
1. DSP starter kit (DSK) da TI. O pacote DSK inclui:

(a) O Code Composer Studio ${ }^{\mathrm{TM}}$ DSK v3.1 IDE.

(b) Uma placa com o processador TMS320C6711 (C6711), Figura 2.2.1.1.

(c) Um cabo paralelo (DB25) que conecta a placa ao PC.

(d) Uma fonte de tensão que alimenta a placa.

2. Um PC IBM-compatível

Todos os arquivos/ programas discutidos nos tutoriais foram incluídos em um CD que acompanha este volume.

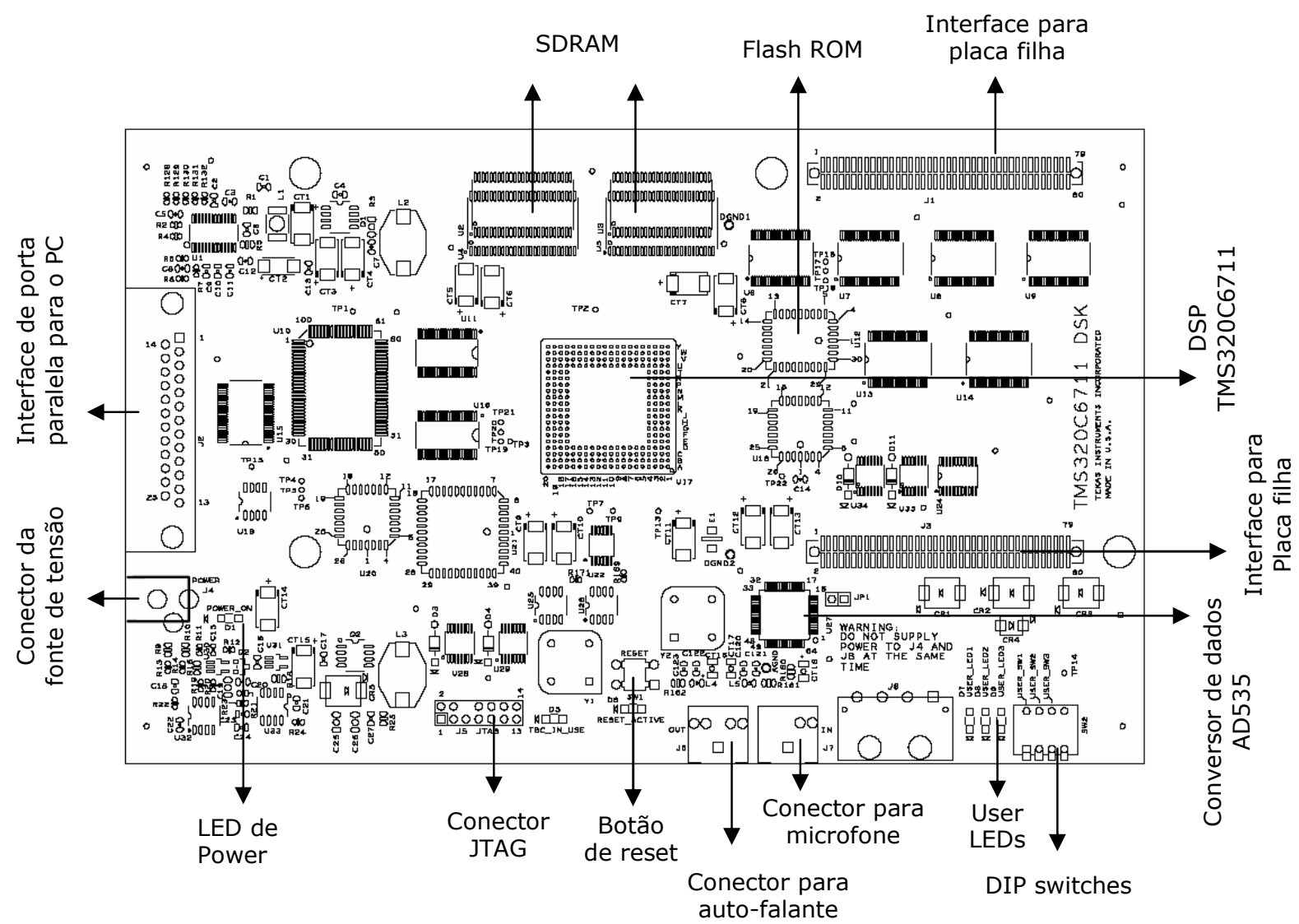

Figura 2.2.1.1 - Uma placa com o C6711.

\subsubsection{Placa DSK}

O pacote DSK, ainda relativamente caro, oferece as ferramentas de suporte de software e hardware necessários ao processamento digital de sinais em tempo real. É um sistema completo de DSP. A placa DSK, com dimensões aproximadas de 5x8 polegadas, 
inclui o processador digital de sinais C6711, que trabalha em ponto flutuante, e o codec de 16 bits , AD535, para entrada e saída [Kehtarnavaz \& Simsek, 2000].

O codec AD535 utiliza uma tecnologia sigma-delta [TMS320C6000C, 1998] que realiza as conversões analógico-digital (analog-to-digital conversion - ADC) e digitalanalógico (digital-to-analog conversion - DAC). A taxa de amostragem desse codec é fixa em $8 \mathrm{kHz}$.

A placa DSK também oferece uma expansão para placa filha. Em aplicações que requerem taxas de amostragem até $72 \mathrm{kHz}$, recomenda-se a utilização de uma placa de expansão baseada no codec stereo PCM3003, disponibilizado pela Texas Instruments.

A placa DSK ainda possui $16 \mathrm{MB}$ de SDRAM (synchronous dynamic RAM) e $128 \mathrm{kB}$ de flash ROM. Dois conectores possibilitam a entrada e saída dados e são identificados por IN (J7) e OUT (J6), respectivamente. Três dos quatro dip switches disponíveis podem ser lidos por um programa. O clock da placa é de $150 \mathrm{MHz}$.

\subsubsection{Processador Digital de Sinais TMS320C6711}

O TMS320C6711 (C6711) é baseado na arquitetura very-long-instruction-word (VLIW) [TMS320C6000, 1998], que é bastante apropriada para algoritmos numéricos intensivos. A memória interna de programa é estruturada de maneira a possibilitar a busca de oito instruções por ciclo. Por exemplo, com um clock de $150 \mathrm{MHz}$, o C6711 é capaz de buscar oito instruções de 32 bits a cada 1/150MHz ou 6.66ns [Dahnoum, 2000].

As especificações do C6711 incluem $72 \mathrm{~KB}$ de memória interna, oito unidades funcionais ou de execução, compostas por seis ALUs (Unidade Lógica e Aritmética), e duas unidades multiplicadoras, um barramento de endereço de 32 bits que pode endereçar 4GB, e dois conjuntos de registradores de 32 bits.

O C67xx (como o C6701 e o C6711) pertencem à família de processadores C6x que operam em ponto flutuante; já o C62xx e o C64xx pertencem à família C6x que operam em ponto fixo. O C6711 é capaz de realizar processamento tanto em ponto fixo como em ponto flutuante. 


\subsubsection{Code Composer Studio}

O Code Composer Studio (CCS) provê um ambiente de desenvolvimento integrado (integrated development environment - IDE) que incorpora os recursos de software. O CCS inclui ferramentas para geração de códigos, como um compilador C [TMS320C6000O, 1999], um assembler [TMS320C6000, 1999], e um linker. Apresenta ainda interface gráfica e possibilita o debug em tempo real [Chassaing, 1999].

O compilador C compila um programa com a extensão “.c" para produzir um código fonte assembly “.asm”. O assembler monta o arquivo fonte ".asm” e produz um objeto em linguagem de máquina com a extensão “.obj”. O linker combina arquivos de objetos com bibliotecas de objetos para produzir um arquivo executável com a extensão “.out". Esse arquivo executável pode ser carregado e executado diretamente no processador C6711 [TMS320C6000, 2000].

Para se criar uma aplicação, basta adicionar os arquivos apropriados ao projeto. $\mathrm{O}$ compilador e o linker oferecem uma série de parâmetros de configuração. Várias opções de debug são disponibilizadas, incluindo o uso de pontos de quebra (breakpoints), a observação do conteúdo de variáveis, da memória, de registradores, além de resultados gráficos. Pode-se ainda passear pelo programa de diferentes formas (step into, step over ou step out).

A análise em tempo real é facilmente implementada por meio do real-time data exchange (RTDX) associado ao DSP/BIOS. O RTDX permite a troca de dados e a análise sem que o DSK precise ser interrompido. Estatísticas e desempenho podem ser monitorados em tempo real [Kehtarnavaz \& Simsek, 2000].

\subsubsection{Instalação do Code Composer Studio v3.1}

Para se instalar o CCS, inicialmente deve-se conectar a interface J2 da placa DSK à porta paralela do PC (LTP1 ou LTP2) por meio do cabo paralelo (DB25). A fonte de tensão que acompanha o kit deve ser ligada ao conector J4 da placa DSK. Em seguida, deve-se instalar o CCS. Recomenda-se utilizar o diretório padrão "C:ICCStudio_v3.1".

É preciso garantir que os recursos para o processador C6711 serão instalados. Para isso, deve-se escolher o modo de instalação customizado (Custom Install). Em seguida 
seleciona-se a opção "Entire feature will be installed on local drive" para a plataforma TMS320C6000, conforme ilustrado na Figura 2.2.5.1.

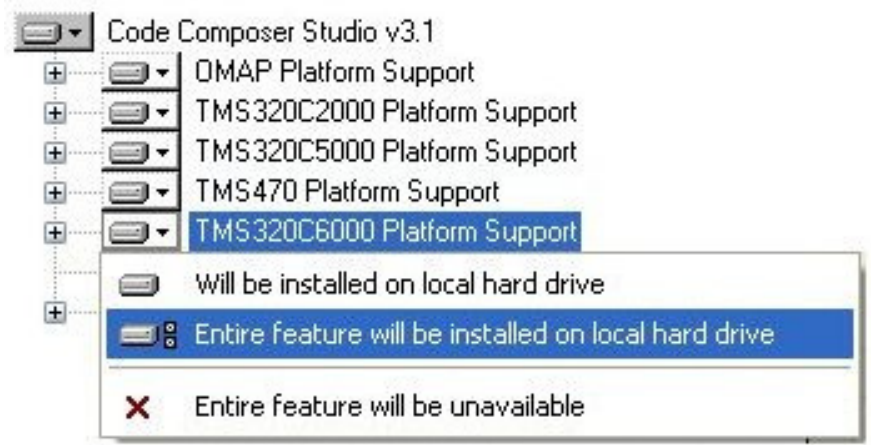

Figura 2.2.5.1 - Habilitando os recursos para o C6711.

Ao final da instalação, dois ícones são adicionados na área de trabalho do Windows. O ícone "CCStudio 3.1" é utilizado para iniciar o CCS e o ícone "Setup CCStudio v3.1" é utilizado para configurá-lo.

Quando a placa DSK é ligada, os LEDs localizados próximo aos quatro dip switches devem contar de 1 a 7 em binário.

Há uma grande quantidade de material de suporte (arquivos pdf) que acompanha o CCS, além de alguns exemplos e tutoriais.

O CCS 3.1 foi utilizado na elaboração e teste dos tutoriais desenvolvidos no presente trabalho. Uma série de arquivos, que se encontram nos subdiretórios dentro do diretório C:ICCStudio_v3.1, podem ser de grande utilidade. Alguns desses subdiretórios são:

- docs: contém documentação e manuais.

- MyProjects: todos os programas e projetos podem ser colocados dentro desse subdiretório.

- bin: contém vários tulitários.

- tutorial: contém tutoriais incluídos no CCS

- C6000入cgtools: contém ferramentas de geração de código.

- C6000`exemples: contém exemplos incluídos no CCS.

- C6000 RTDX: contém arquivos de suporte para transferência de dados em tempo real. 
- C6000 bios: contém arquivos de suporte para DSP/BIOS.

\subsubsection{Tipos de arquivos úteis}

Estar-se-á trabalhando com vários arquivos de extensões diferentes. Entre eles estão:

- arquivo.pjt: arquivo de projeto.

- arquivo.c: código fonte $\mathrm{C}$.

- arquivo.asm: código fonte assembly criado pelo usuário, pelo compilador $\mathrm{C}$ ou pelo otimizador linear.

- arquivo.sa:código fonte assembly linear. O otimizador linear utiliza o arquivo.sa como entrada para produzir um código assembly arquivo.asm.

- $\quad$ arquivo.h: arquivo de cabeçalho.

- arquivo.lib: arquivo de biblioteca.

- arquivo.cmd: arquivo de comando do linker que mapeia seções na memória.

- arquivo.obj: arquivo de objeto criado pelo assembler.

- arquivo.out: arquivo executável criado pelo linker que pode ser carregado e executado no processador.

\subsection{EXEMPLOS PARA TESTE DAS FERRAMENTAS DO DSK}

Com o objetivo de desenvolver um material de suporte para cursos de PDS, foram elaborados cinco exemlos que ilustram algumas das características do CCS e da placa DSK. O foco principal é familiarizar o usuário com as ferramentas de software e hardware disponíveis. Sugere-se que não se passe aos próximos tutoriais sem antes ter completado os dois primeiros exemplos que compõe este tutorial.

\subsubsection{Exemplo 1: Teste rápido do DSK}

Abra o CCS. Se for a primeira vez que você estiver rodando o programa, uma mensagem é apresentada solicitando a configuração do dispositivo: 


\section{Code Composer Studio}

1) You are attempting to start Code Composer Studio without a target configuration.

Code Composer Studio requires at least one target configuration to function properly.

would you like to enter the setup program and select the appropriate target configuration?

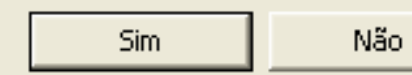

Figura 2.3.1.1 - Mensagem solicitando a configuração do CCS.

Clique em "Sim”. O programa de configuração "Code Composer Studio Setup" será aberto. Caso seja necessário rodar o programa de configuração novamente, basta clicar no ícone que a instalação disponibiliza na área de trabalho do Windows:

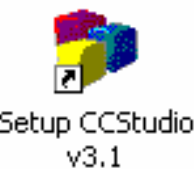

Figura 2.3.1.2 - Reiniciando a configuração do CCS.

No programa de configuração, para Family selecione "C67XX" e para Platform selecione "dsk".

\begin{tabular}{|c|c|c|}
\hline \multirow{2}{*}{ Available Factory Boards } & Family & Plat... \\
\hline & $667 \times x$ & dsk $\mathbf{T}$ \\
\hline 댐:C6711 DSK Port 278 EPP Mode & $667 \times x$ & $d s k$ \\
\hline 몀:C6711 DSK Port 278 SPP Mode & $667 x x$ & $d s k$ \\
\hline 몀:C6711 DSK Port 378 EPP Mode & $667 x x$ & dsk \\
\hline 댐:C6711 DSK Port 378 SPP Mode & $667 \times x$ & $d s k$ \\
\hline 땜ㅁㅁㄷ6711 DSK Port 3BC EPP Mode & $667 \times x$ & $d s k$ \\
\hline ㅁㅁㅁ:C6711 DSK Port 3BC SPP Mode & $667 \times x$ & dsk \\
\hline
\end{tabular}

Figura 2.3.1.3 - Configurando a família e a plataforma.

Em seguida, escolha a placa de acordo com a configuração da porta paralela na BIOS do computador. Uma configuração comum é "C6711 DSK Port 378 EPP Mode". Clique no botão "Add" e depois em "Save \& Quit". O "Code Composer Studio Setup" irá sugerir a execução do CCS. Clique em "Sim". 


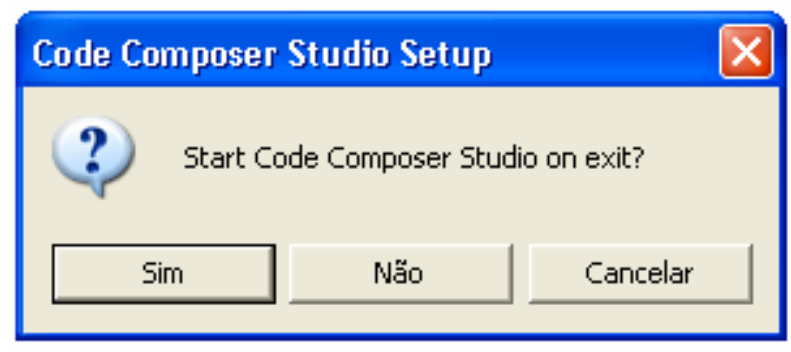

Figura 2.3.1.4 - Sugestão de execução do CCS.

Antes de se estabelecer à conexão com a placa DSK sugere-se a realização de um reset no emulador. Clique em Debug $\rightarrow$ Reset Emulator ou pressione as teclas CTRL+Shift+R.

Para conectar-se à placa DSK, dentro do CCS clique em Debug $\rightarrow$ Connect ou pressione $\mathrm{ALT}+\mathrm{C}$. Se a conexão for bem-sucedida a seguinte mensagem aparecerá no canto inferior esquerdo da tela principal do Code Composer Studio:

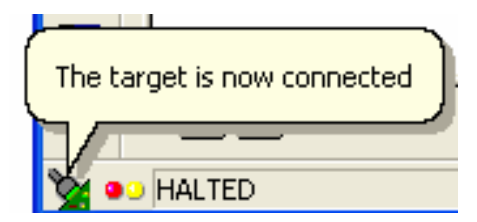

Figura 2.3.1.5 - Mensagem de conexão.

Agora você está pronto(a) para executar o teste rápido.

Clique em GEL $\rightarrow$ Check $D S K \rightarrow$ Quik Test. O teste rápido pode ser utilizado para confirmar a instalação e a operação correta da placa DSK. A seguinte mensagem é mostrada:

\author{
Switches: 7 Revision: 2 \\ $* * * * *$ Target is Okay $* * * * * * *$
}

Está assumido que os três primeiros dip switches, USER_SW1, USER_SW2 e USER_SW3, estão todos levantados (ON). Mude os switches para $(\mathbf{1 1 0 x})_{2}$, mantendo os dois primeiros switches levantados e abaixando o terceiro. O quarto switch não é utilizado.

Repita o procedimento: clique em GEL $\rightarrow$ Check $D S K \rightarrow$ Quik Test. O teste rápido verifica o novo valor dos dip switches e mostra "Switches: 3" na tela. Os dip switches 
podem ser ajustados para qualquer valor inteiro entre 0 e 7 . Dentro do seu programa você pode direcionar a execução do código baseando-se nesses oito valores.

\subsubsection{Exemplo 2: Teste de confiança}

Um programa de teste de confiança, incluído no DSK, verifica a operação apropriada da maioria de seus componentes, como interrupções, LEDs, temporizadores etc.

O programa original fornecido pela Texas Instruments teve que ser modificado com o objetivo de se contornar um problema apresentado pelo compilador do CCS. Logo todas as vezes que o código de origem apresentava a seguinte linha,

$$
\text { while (flag }==0) \text {; }
$$

Fora modificado para:

$$
\text { while (flag ==0) printf(“"”); }
$$

Assim, para que o teste de confiança possa ser executado sugere-se que, ao invés de se utilizar os arquivos instalados junto com o CCS, deva-se dar preferência aos arquivos contidos no diretório \Tutorial1〈Exemplo2lenfdsp_nohost\ do CD que acompanha o presente trabalho, copiando-os para um diretório local, como por exemplo:

\section{C:ICCStudio_v3.1\MyProjects\Tutorial1|Exemplo2lcnfdsp_nohost.}

Abra o arquivo de projeto cnfdsp_nohost.pjt a partir do menu Project $\rightarrow$ Open. Em seguida compile-o pressione a tecla F7. A seguinte mensagem aparecerá na janela Build do CCS:

$$
\begin{aligned}
& \text { Build Complete, } \\
& 0 \text { Errors, } 0 \text { Warnings, } 0 \text { Remarks. }
\end{aligned}
$$

É aconselhável realizar um reset na CPU antes de carregar o executável. Tal procedimento é executado pressionando-se as teclas CTRL+R. 
Para carregar o programa executável, pressione $\mathrm{CTR}+\mathrm{L}$, selecione o diretório Debug, clique no arquivo cnfdsp_nohost.out e no botão Abrir. O programa com o teste de confiança será transferido para o DSP. Execute-o pressionando F5.

Se o teste for bem sucedido, a seguinte saída será apresentada na janela Stdout do CCS:

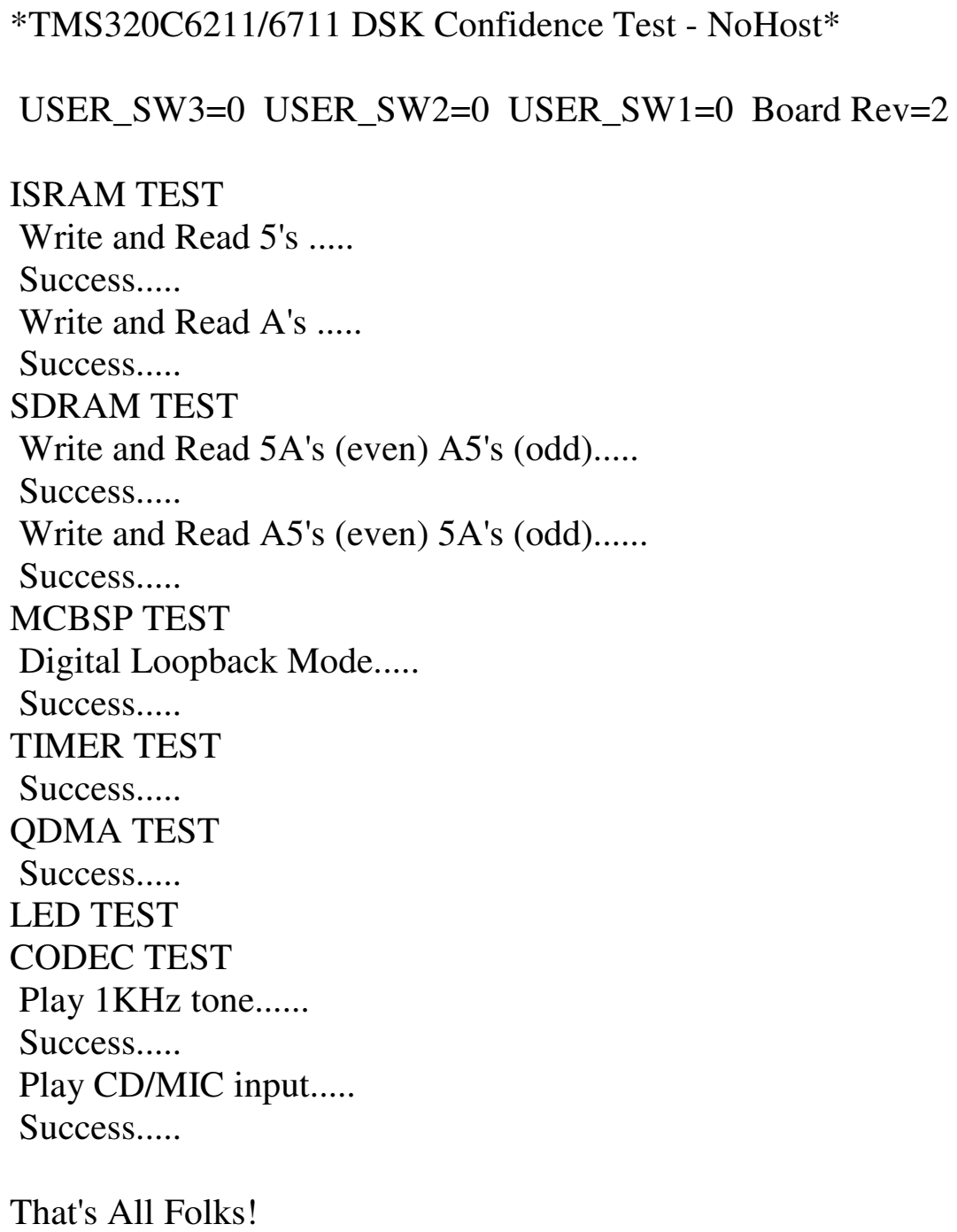

That's All Folks!

Caso ocorra algum erro, desconecte a alimentação do DSK, feche o CCS e comece novamente: reconecte a alimentação, abra o CCS, pressione $\mathrm{ALT}+\mathrm{C}$ para estabelecer a conexão com a placa, pressione $\mathrm{CTRL}+\mathrm{R}$ para reiniciar a $\mathrm{CPU}$, abra o projeto, carregue novamente o executável e execute o programa.

É interessante observar que durante a etapa LED TEST, os leds USER_LED1, USER_LED2 e USER_LED3 irão piscar. Durante o CODEC TEST é possível escutar um 
tom de $1 \mathrm{kHz}$ caso você tenha um fone de ouvido conectado à saída J6 (OUT) da placa DSK.

Verifica-se que a comunicação da placa DSK com o computador é bastante instável. Com freqüência a conexão é perdida, fazendo-se necessário reiniciar o processo de execução do programa.

\subsubsection{Exemplo 3: Geração de onda senoidal}

Esse exemplo gera uma senoide utilizando uma lookup-table. Além disso, ilustra com maiores detalhes alguns recursos do CCS, tais como a edição de um projeto, o acesso a ferramentas de geração de código e a execução de um programa no processador C6711. O código seno8_l.c implementa a geração da onda senoidal.

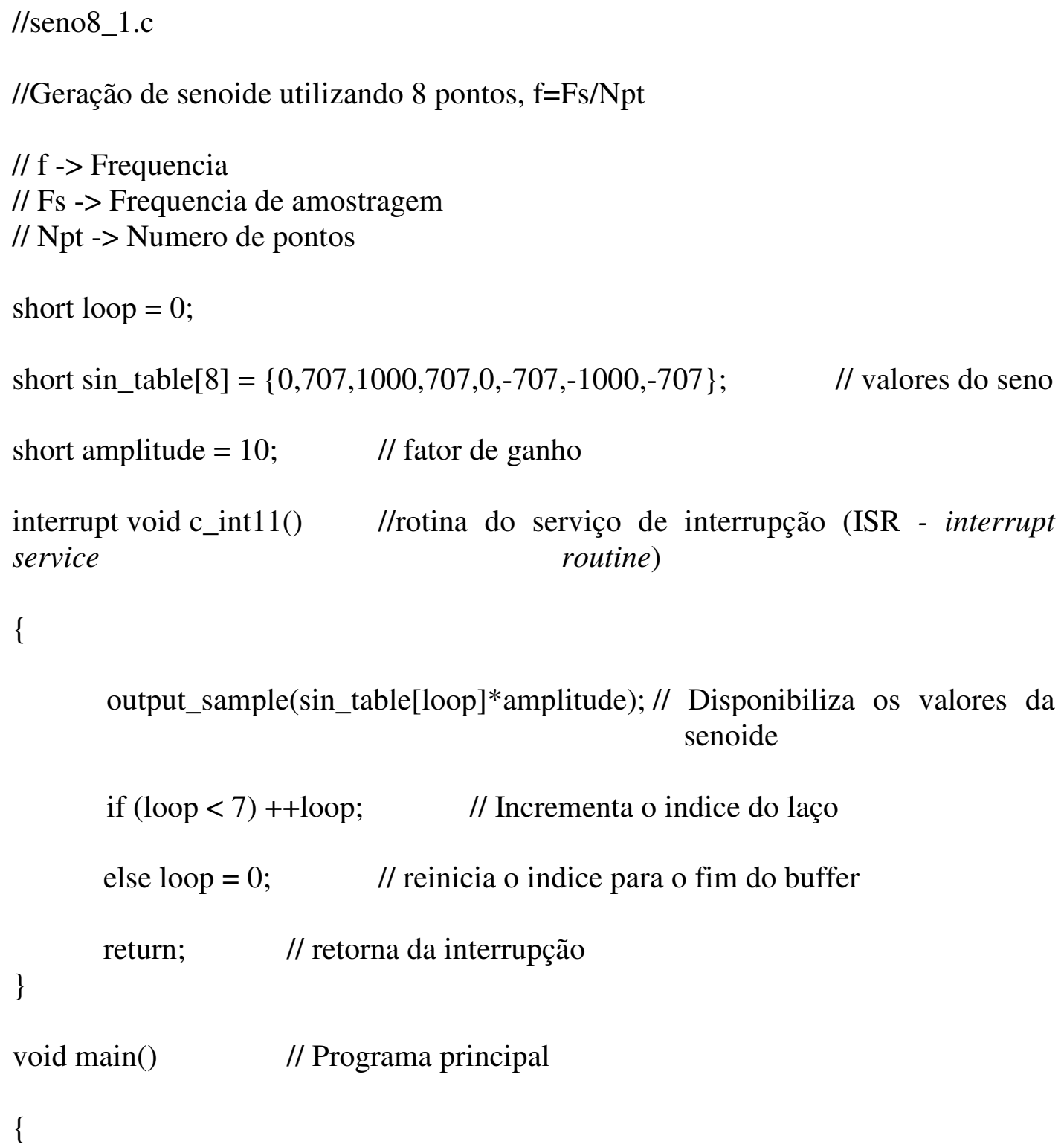




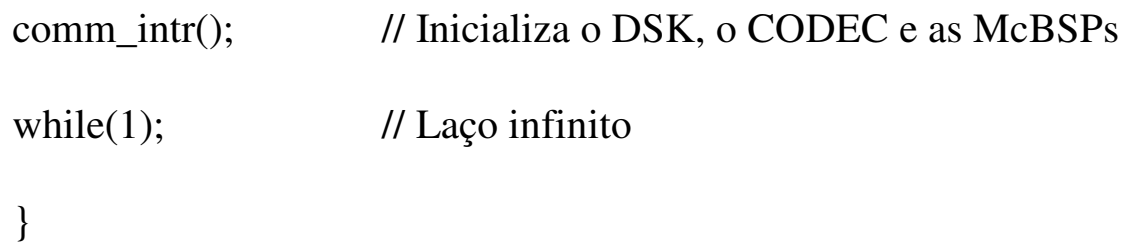

Apesar do objetivo principal desse exemplo ser ilustrar o uso de algumas ferramentas, pode ser útil entender o programa seno8_l.c.

Uma tabela (ou buffer) sin_table é criada e preenchida com oito pontos representando $f(t)=1000 \sin (t)$, onde $\mathrm{t}=0,45,90,135,80,225,270$ e 315 graus. $\mathrm{A}$ Figura 2.3.3.1 mostra o gráfico da função $f(t)$.

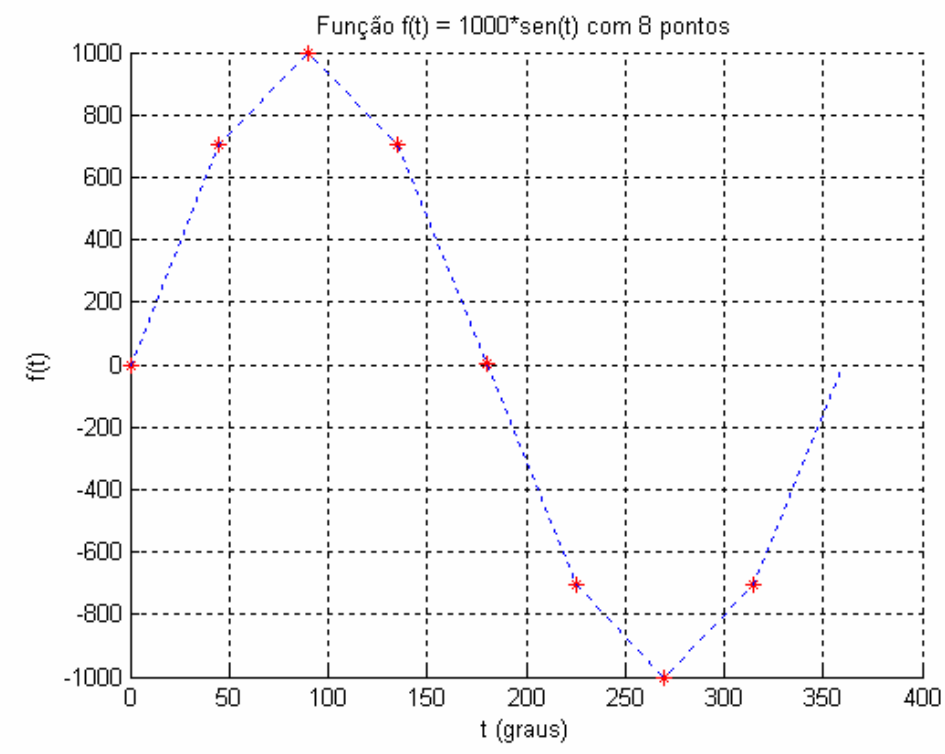

Figura 2.3.3.1 - Gráfico da função $f(t)=1000 \sin (t)$.

Dentro da função main, uma outra função, comm_intr, é chamada. Tal função está definida em um arquivo de suporte c6xdskinit.c. O papel dela é inicializar o DSK, o codec AD535 e as duas McBSPs (multichannel buffered serial ports).

O comando while(1) dentro da função main determina um laço infinito que aguarda a interrupção acontecer. Quando a interrupção ocorrer, a execução prossegue para a rotina do serviço de interrupção (ISR - interrupt service routine) $c \_i n t 11$.

Uma vez dentro da ISR a função output_sample, localizada no arquivo de suporte c6xdskinit.c, é chamada a disponibilizar o primeiro valor da tabela sin_table [0] $=0 . \mathrm{O}$ índice do laço é incrementado até se atingir o final da tabela, após o qual é reiniciado. A 
execução, então, retorna da ISR para o comando while(1) (laço infinito) até que a nova interrupção ocorra. Uma interrupção ocorre a cada período de amostragem $T_{s}$ :

$$
\begin{aligned}
& T_{s}=1 / F_{s} \\
& T_{s}=1 / 8000=0.125 \mathrm{~ms} .
\end{aligned}
$$

Ou seja, a cada período de amostragem de $0.125 \mathrm{~ms}$, uma interrupção ocorre, a ISR é acessada e o dado seguinte na tabela sin_table (multiplicado por amplitude $=10$ ) é enviado para a saída. Em um período da função f(t), oito valores espaçados de $0.125 \mathrm{~ms}$ no tempo são disponibilizados na saída para a geração de um sinal senoidal.

\section{Criação do projeto}

Para criar este projeto no Code Composer Studio ${ }^{\mathrm{TM}}$ IDE, é preciso adicionar os arquivos necessários à construção do projeto seno8_1:

1. Crie o arquivo denominado seno8_1.pjt clicando em Project $\rightarrow$ File. Ao abrir a janela Project Creation escreva o nome do projeto em Project Name. É importante observar em Location que o projeto em questão estará localizado em C:ICCStudio_v3.1\MyProjects\Tutorial1\seno8_1. Clique no botão Concluir.

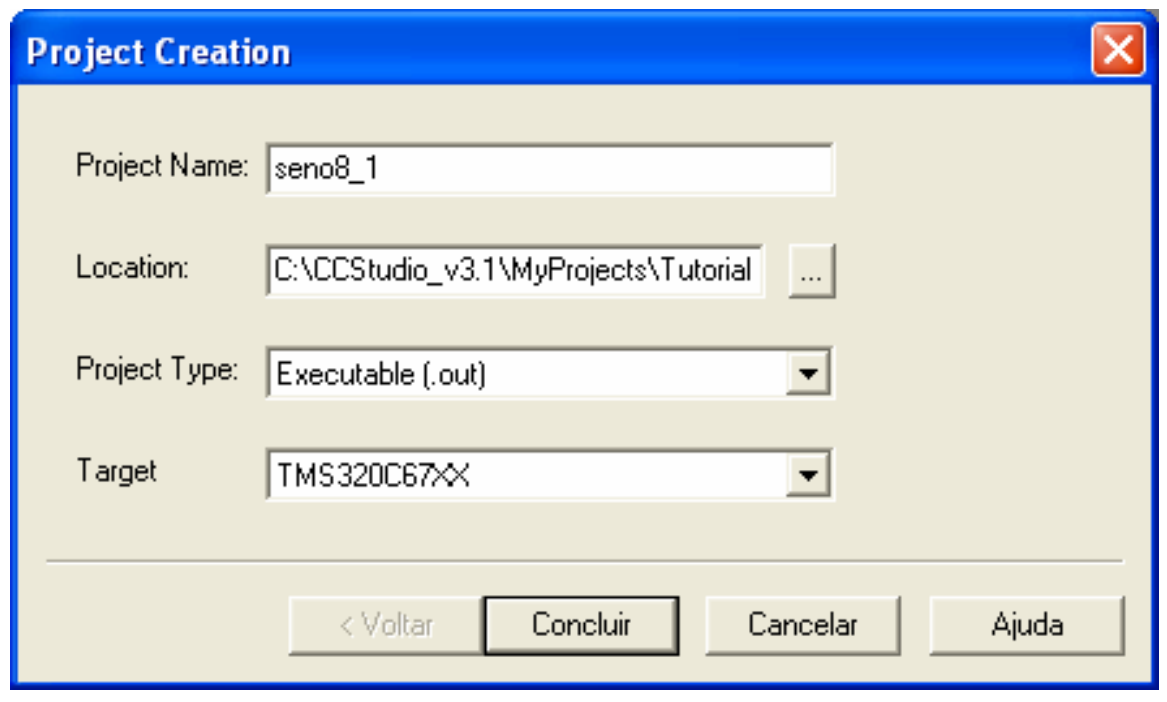

Figura 2.3.3.2 - Criação do projeto. 
2. Selecione Project $\rightarrow$ Add Files to Project no CCS. Abra a pasta seno8_1 do CD que acompanha o presente trabalho, e adicione ao projeto os dois arquivos ".c", sine8_1.c e c6xdskinit.c.

3. Novamente selecione Project $\rightarrow$ Add Files to Project. Abra a pasta sine8_1 e adicione o arquivo do tipo assembly, vectors_11.asm.

4. Repita o passo 3 e adicione o arquivo $c 6 x d s k . c m d$.

5. Repita o passo 3 e adicione na pasta Libraries do projeto o arquivo rts6700.lib, que suporta a arquitetura C67XX. Tal arquivo pode ser encontrado em $c: \backslash C C S t u d i o \_v 3.1 \backslash c 6000 \backslash c g t o o l s \backslash i b$.

6. Carregue na pasta Includes do projeto os arquivos de cabeçalho. Ou seja, clique em Project $\rightarrow$ Scan All File Dependecies e observe a adição dos seguintes arquivos; c6xdsk.h, c6xdskinit.h,c6xinterrupts.h, e c6x.h.

$\mathrm{O}$ arquivo Gel que inicializa o DSK, dsk6221_6711.gel, é adicionado automaticamente quando o projeto é criado.

Após a criação do projeto e a adição dos arquivos verifique no canto esquerdo da tela principal do Code Composer Studio a janela Project View, mostrada na Figura 2.3.3.3.

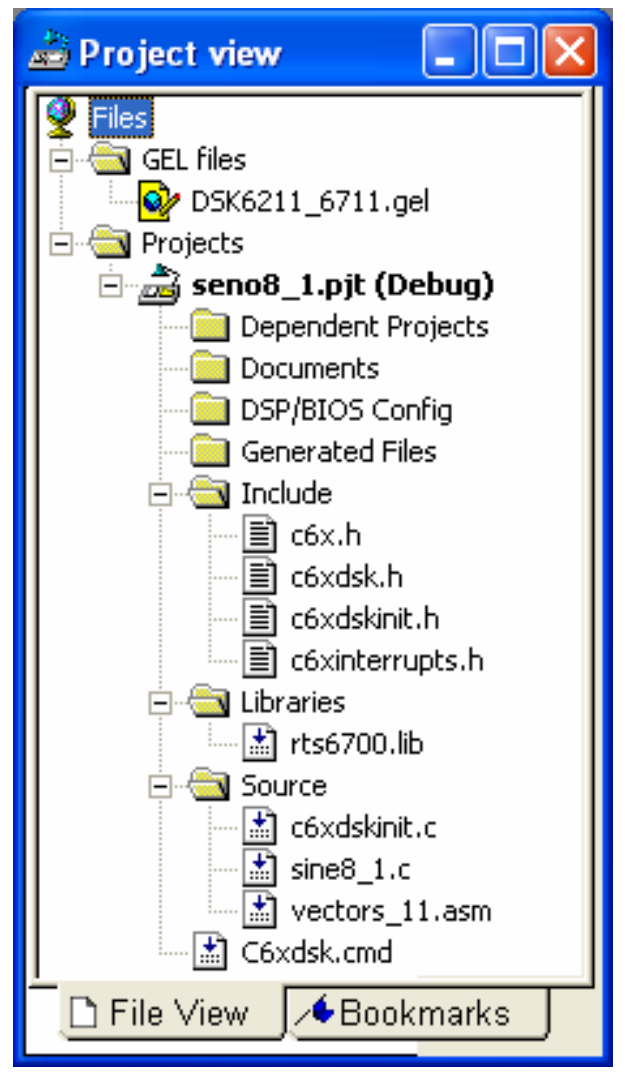

Figura 2.3.3.3 - Visualização do projeto. 


\section{Configuração do compilador e do linker}

Em seguida é necessário configurar os parâmetros do compilador e do linker:

1. Clique em Project $\rightarrow$ Build Options.

2. Na janela Build Options $\rightarrow$ Compiler (Figura 2.3.3.4(a)).

3. Na lista Category $\rightarrow$ Basic.

4. Em Basic escolha as seguintes opções:

- Target Version $\rightarrow$ Default, para selecionar a implementação em ponto fixo. No DSK baseado no C6711 pode-se optar pelo processamento em ponto fixo ou ponto flutuante.

- Generate Debug Info $\rightarrow$ Full Symbolic Debug (-g). Ao mesmo tempo em que o parâmetro $-g$ facilita o processo de debug, diminui a otimização do sistema.

- Opt Speed vs Size $\rightarrow$ Speed Most Critical (no ms).

- Opt Level $\rightarrow$ None.

- Program Level Opt $\rightarrow$ None.

Verifique na janela Buil Options a seleção dos parâmetros $-g-k-s$.

5. Clique em Linker na janela Build Options (Figura 2.3.3.4 (b)).

6. Na lista Category $\rightarrow$ Basic.

7. Em Basic ajuste as seguintes opções:

- Habilite Suppress Banner (-q).

- Habilite Exhaustively Reas Libraries (-x)

- Em Otput Filename (-o) coloque o nome do arquivo de saída, ou seja, seno8_1.out.

- Em Autoint Model selecione Run-Time Autoinitialization (-c). Este parâmetro inicializa as variáveis de tempo.

8. Clique em Ok e feche a janela Build Options. 


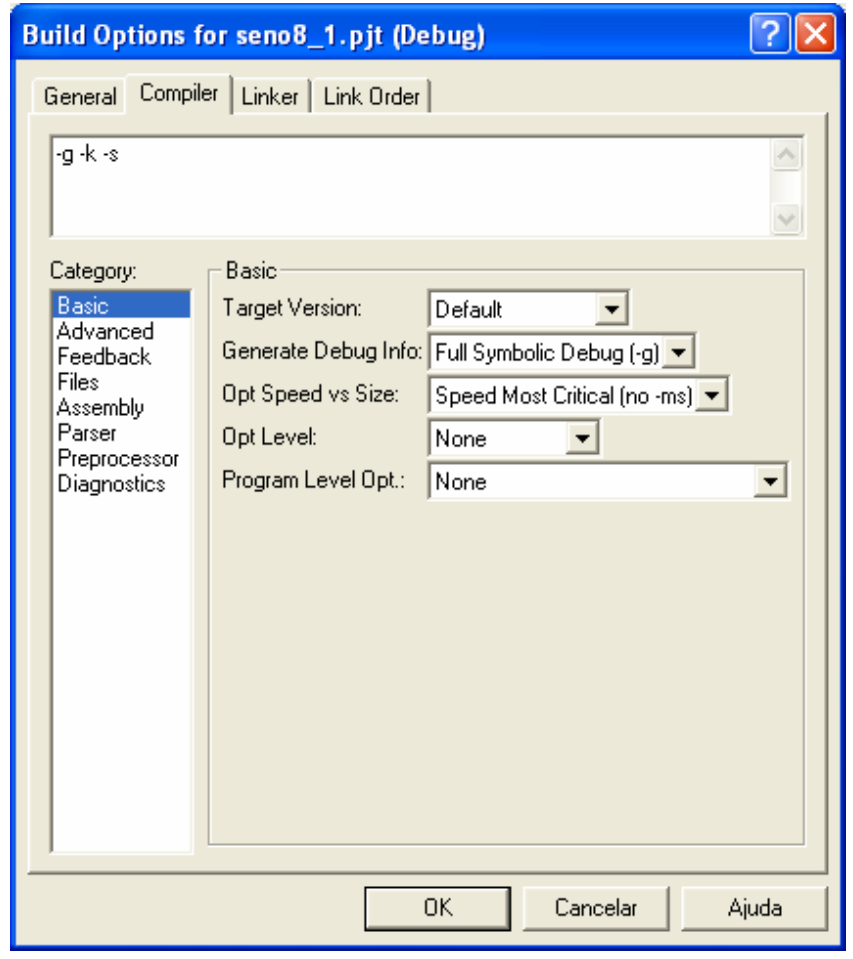

(a)

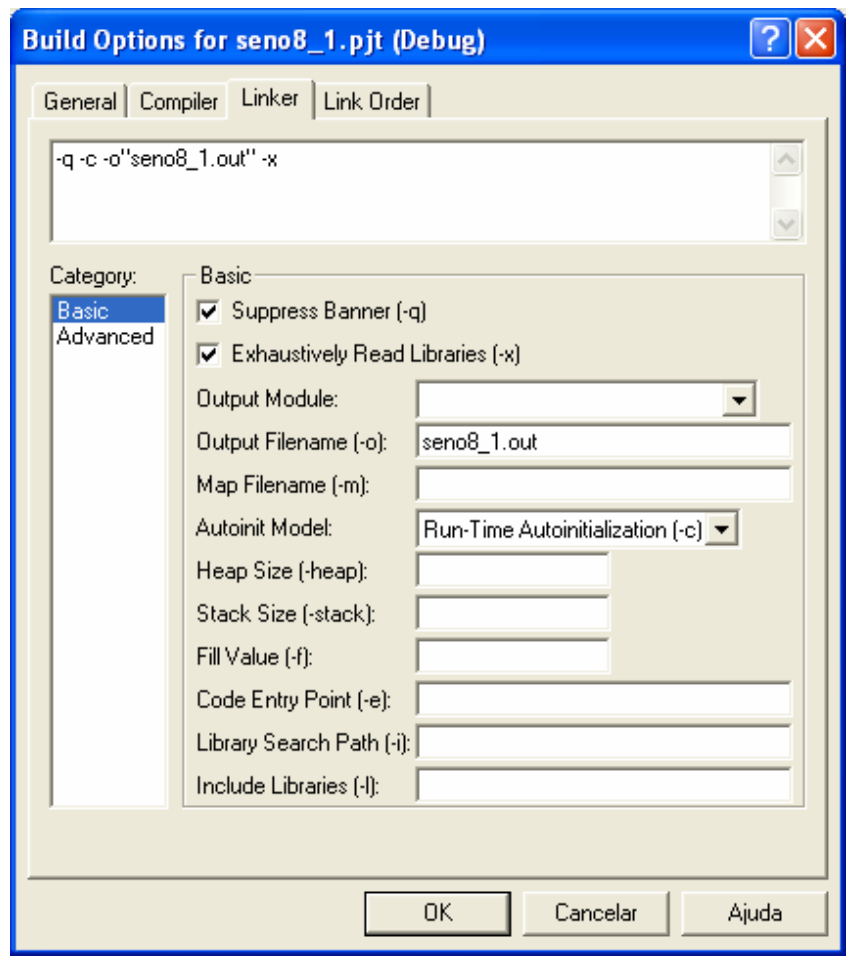

(b)

Figura 2.3.3.4 - Configuração do (a) compilador e do (b) linker. 


\section{Geração do executável e carregamento do programa}

1. Selecione Project $\rightarrow$ Build, ou clique no ícone para que o projeto possa ser construído.

2. Carregue o executável através do comando File $\rightarrow$ Load Program, selecionando o arquivo seno8_1.out (Figura 2.3.3.5).

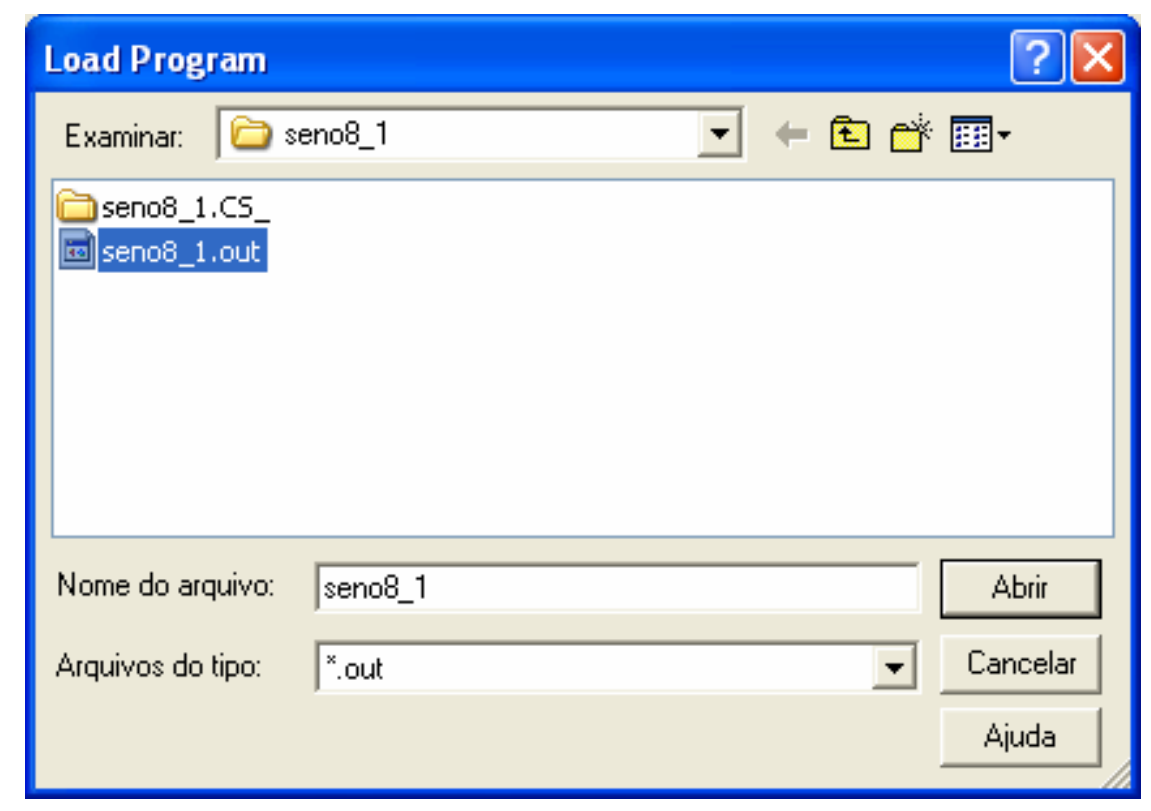

Figura 2.3.3.5 - Carregando o executável.

\section{Execução do programa}

Por fim, execute o programa por meio de Debug $\rightarrow$ Run, ou clique no ícone que se encontra no canto esquerdo do CCS. Conectando-se um fone na saída J6 da placa DSK é possível ouvir um tom.

A freqüência de amostragem $F_{s}$ do codificador é fixa em $8 \mathrm{kHz}$. A freqüência gerada pelo sinal será $f=F_{s} /($ número_de_pontos $)=8 \mathrm{kHz} / 8=1 \mathrm{kHz}$. Conecte a saída J6 da placa DSK em um osciloscópio e observe a onda senoidal gerada. Sua aplitude deve ser de aproximadamente $0.85 \mathrm{~V}$ (pico-a-pico).

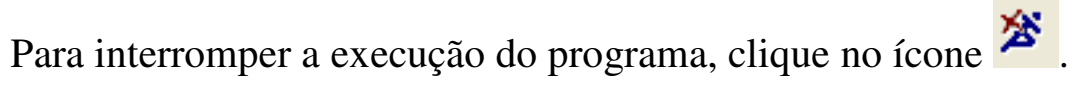




\section{Watch Window}

Certifique-se de que o processador ainda está rodando. A Watch Window permite o monitoramento ou a modificação do valor de uma variável:

1. Selecione a janela View $\rightarrow$ Quick Watch. Digite amplitude e, então, clique em Add to Watch. O valor 10 para a amplitude deve aparecer na janela.

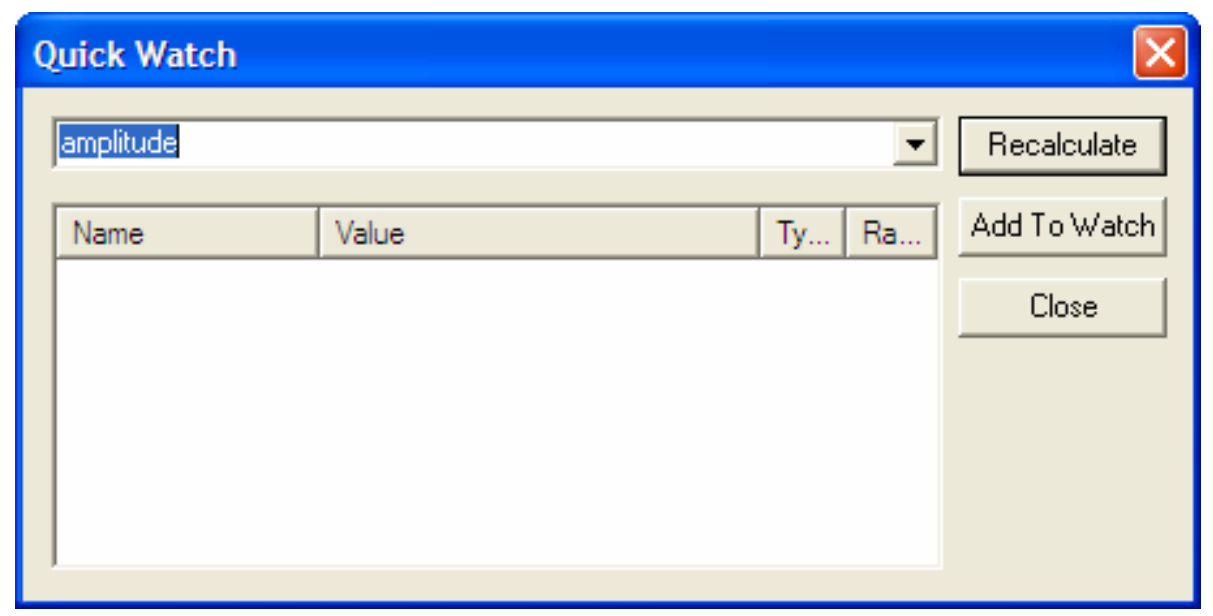

Figura 2.3.3.6 - Quick Watch.

2. Mude a amplitude para um valor (Value) entre 10 e 30.

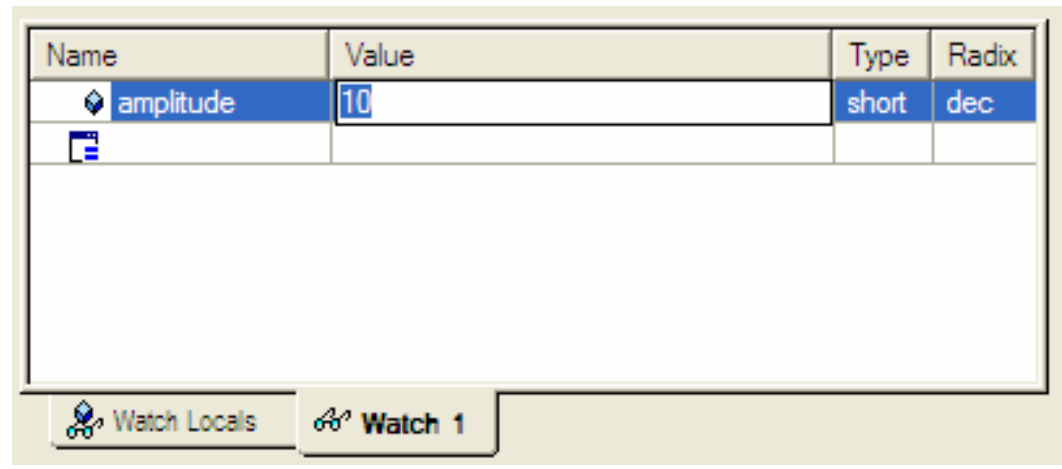

Figura 2.3.3.7 - Alterando o valor de variáveis.

3. Verifique que o volume do tom gerado varia de acordo com o valor ajustado. $\mathrm{O}$ valor da amplitude do sinal de saída deve ter variado entre $0.85 \mathrm{Vp}-\mathrm{p}$ e $2.6 \mathrm{Vp}-\mathrm{p}$.

4. Mude a amplitude para 33 (como no item anterior). Verifique a geração de um tom em alta frequiência, o que implica no fato de a mudança de frequiência ter ocorrido devido a variação da amplitude do sinal. Na verdade, o que ocorreu foi 
um overflow na capacidade de representação do codec de 16-bits AD535. Os valores da tabela são multiplicados por 33, fazendo com que estejam dentro do intervalo de +33.000 a -33.000 . O intervalo permitido para os valores de saída é definido pelos limites $-2^{15}$ e $-2^{15}-1$, ou seja, -32.768 e +32.767 , devido ao codec AD535, que utiliza a representação em complemento de 2.

\section{Aplicando um arquivo GEL}

A GEL (General Extension Language) é uma linguagem que permite ao projetista modificar o valor de variáveis por meio de uma barra deslizante enquanto o programa está rodando. Para isso, basta que, em primeiro lugar, as variáveis estejam definidas no programa.

No exemplo considerado, para amplificar o sinal de áudio por meio de uma barra deslizante, siga as seguintes instruções:

1. Selecione File $\rightarrow$ Load Gel e abra na pasta seno8_1 o arquivo amplitude.gel (Figura 2.3.3.8).

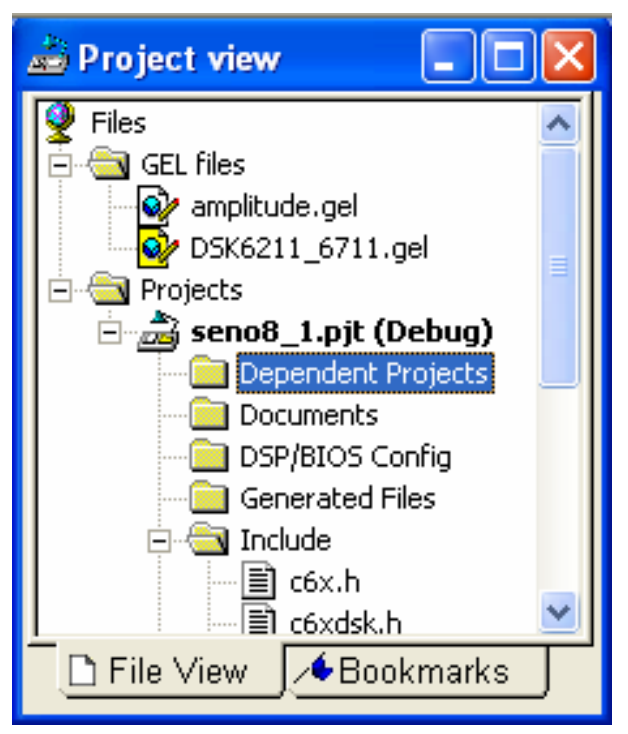

Figura 2.3.3.8 - Introdução do arquivo amplitude.gel.

2. Selecione em $\mathrm{Gel} \rightarrow$ Sine Amplitude $\rightarrow$ Amplitude. Aparecerá a seguinte janela, onde você poderá controlar manualmente o valor da amplitude do sinal de 10 a 35. 


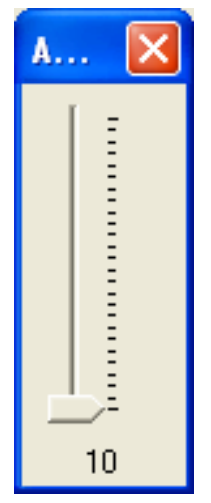

Figura 2.3.3.9 - Ajuste da amplitude do sinal.

3. Faça o debug do programa através de Debug $\rightarrow$ Run. Verifique novamente que, para amplitudes acima ou igual a 33, ocorre overflow na capacidade de representação do AD535.

\subsubsection{Exemplo 4: Geração e Simulação de Gráficos de uma Senoide}

Esse exemplo gera uma senóide com oito pontos e simula no próprio $C C S$ os gráficos no domínio do tempo e da freqüência. O código sine8_buf.c implementa a geração da onda senoidal.

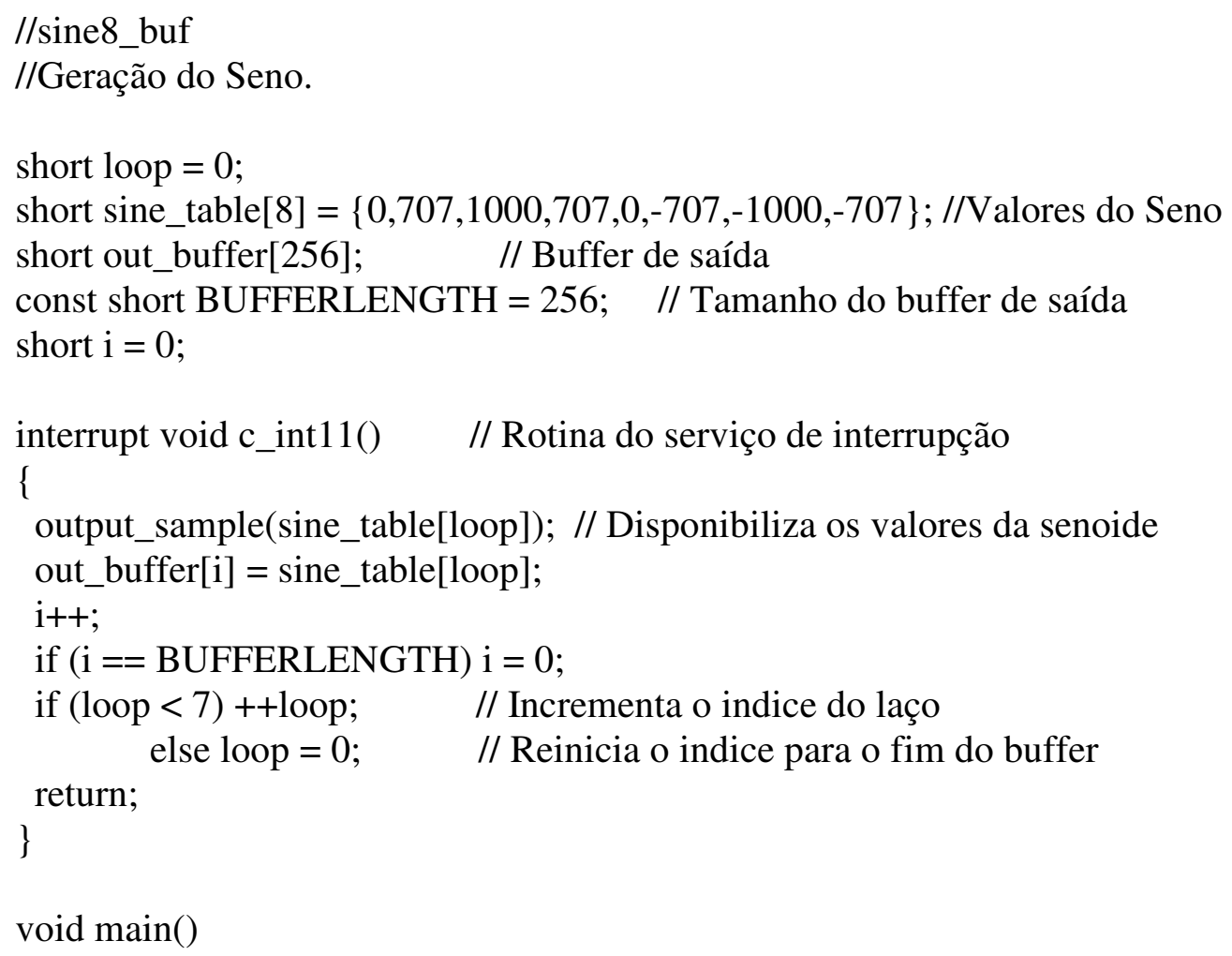


\{

comm_intr(); / Inicializa o DSK, o CODEC e as McBSPs

while(1); / Laço Infinito

\}

Verifica-se que o programa cria um buffer para armazenar os dados da saída na memória.

\section{Criação do projeto}

Para criar este projeto no Code Composer Studio, você deve adicionar os arquivos necessários para a construção do projeto seno8_buffer, assim:

1. Crie o arquivo denominado seno8_buffer.pjt clicando em Project $\rightarrow$ File. Ao abrir a janela Project Creation escreva o nome do projeto em Project Name. É importante observar em Location que o projeto em questão estará localizado em C:ICCStudio_v3.1\MyProjects\Tutorial1\seno8_buffer. Em seguida clique no botão Concluir.

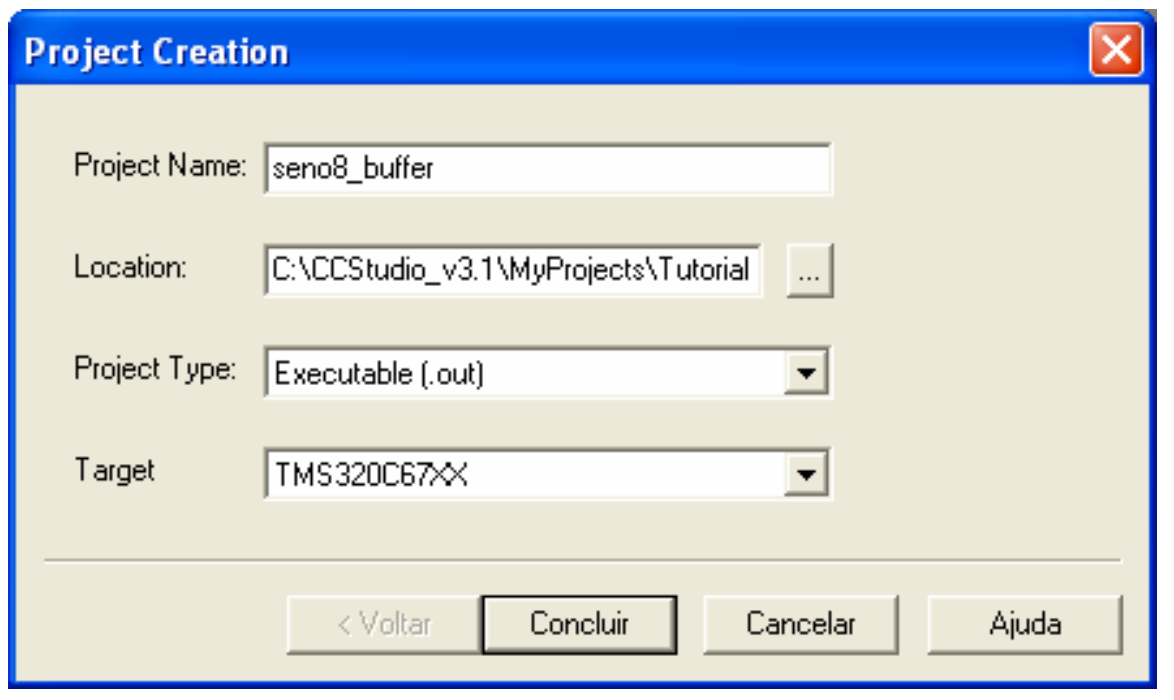

Figura 2.3.4.1 - Criação do projeto.

2. Selecione Project $\rightarrow$ Add Files to Project no CCS, abra a pasta seno8_buf do $\mathrm{CD}$ que acompanha o presente trabalho e adicione ao projeto os dois arquivos do tipo “.c", sine8_buf.c e c6xdskinit.c. 
3. Novamente selecione Project $\rightarrow$ Add Files to Project, abra a pasta sine8_buf e adicione o arquivo do tipo assembly, vectors_11.asm.

4. Repita o passo 3 e adicione o arquivo de comando do linker, ou seja, c6xdsk.cmd.

5. Repita o passo 3 e adicione na pasta Libraries o arquivo rts6700.lib, o qual suporta a arquitetura C67XX, que se encontra em c:\CCStudio_v3.1\c6000\cgtools \ib.

6. Carregue na pasta Includes do projeto os arquivos de cabeçalho. Ou seja, clique em Project $\rightarrow$ Scan All File Dependecies e observe a adição dos seguintes arquivos; c6xdsk.h, c6xdskinit.h,c6xinterrupts.h, e c6x.h.

Após a criação do projeto e a adição dos arquivos verifique no canto esquerdo da tela principal do Code Composer Studio a janela Project View, mostrada na Figura 2.3.4.2.

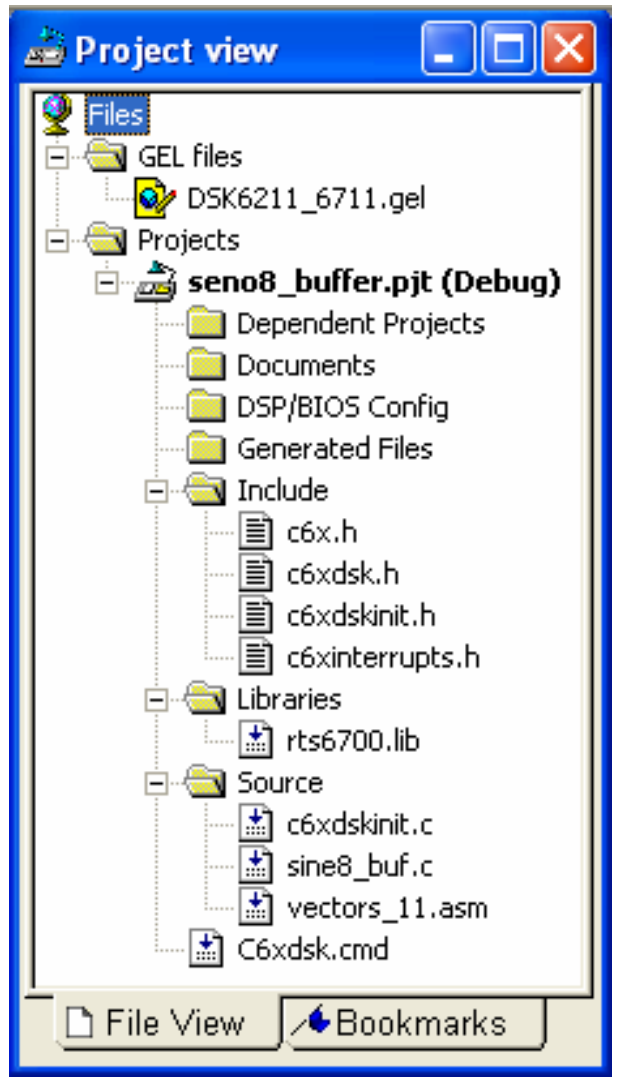

Figura 2.3.4.2 - Visualização do projeto 


\section{Configuração do compilador e do linker}

Defina para o seno8_buffer os mesmos parâmetros de compilação do exemplo seno8_1, e construa o projeto.

1. Clique em Project $\rightarrow$ Build Options.

2. Na janela Build Options $\rightarrow$ Compiler.

3. Na lista Category $\rightarrow$ Basic.

4. Em Basic escolha as seguintes opções:

- $\quad$ Target Version $\rightarrow$ Default

- Generate Debug Info $\rightarrow$ Full Symbolic Debug (-g).

- Opt Speed vs Size $\rightarrow$ Speed Most Critical (no ms).

- Opt Level $\rightarrow$ None.

- Program Level Opt $\rightarrow$ None.

Verifique na janela Buil Options a seleção dos parâmetros $-g-k-s$.

5. Clique em Linker na janela Build Options.

6. Na lista Category $\rightarrow$ Basic.

7. Em Basic ajuste as seguintes opções:

- Habilite Suppress Banner (-q).

- Habilite Exhaustively Reas Libraries (-x)

- Em Otput Filename (-o) coloque o nome do arquivo de saída, ou seja, seno8_buffer.out.

- $\quad$ Em Autoint Model selecione Run-Time Autoinitialization (-c). Clique em Ok e feche a janela Build Options.

8. Carregue o programa através dos comandos File $\rightarrow$ Load Program, abrindo o arquivo seno8_buf.out. 


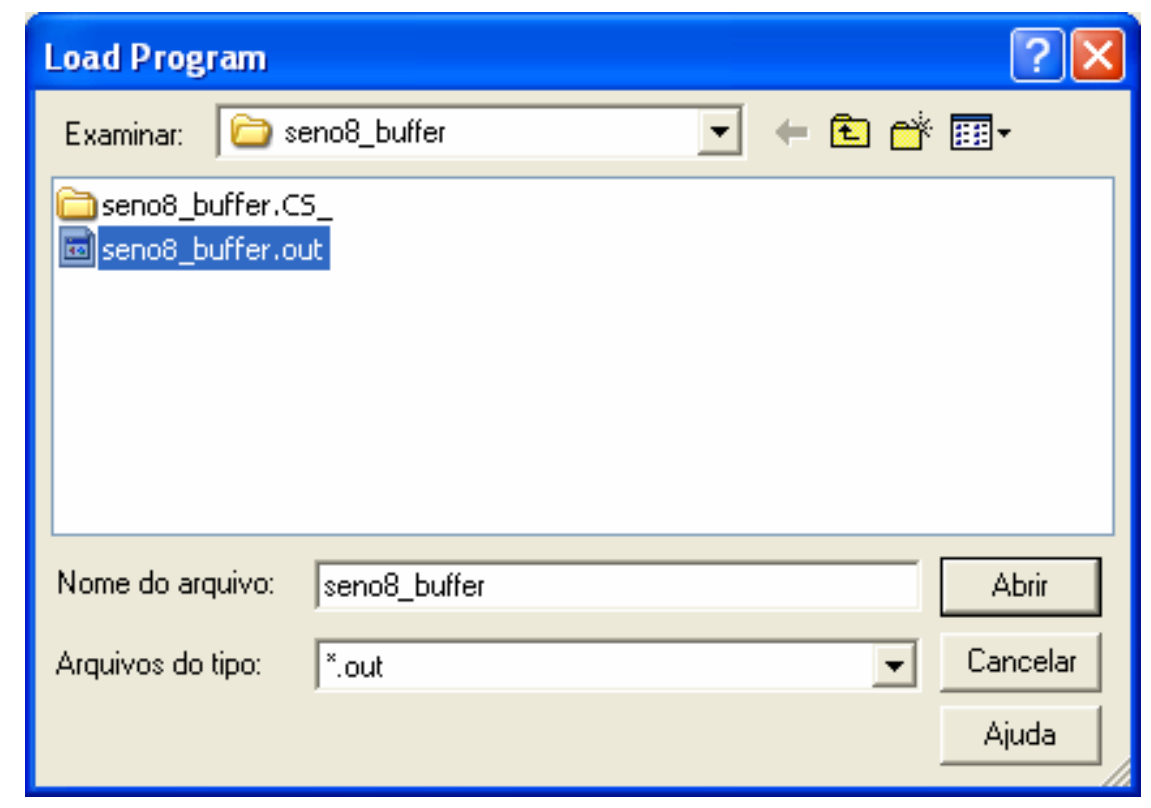

Figura 2.3.4.3 - Carregando o executável.

9. Faça o debug do programa através de Debug $\rightarrow$ Run.

Conectando-se um fone no Conector do Auto Falante J6 da placa do DSK você ouvirá um tom, como no exemplo passado.

\section{Construção gráfica}

Para construir os gráficos no domínio do tempo e da freqüência siga os passoa a seguir:

1. Selecione View $\rightarrow$ Graph $\rightarrow$ Time/Frequency. Logo a janela Graph Property Dialog abrirá (Figura 2.3.4.4). 


\begin{tabular}{|c|c|c|}
\hline \multicolumn{2}{|c|}{ (4) Graph Property Dialog } & $\mathrm{X}$ \\
\hline Display Type & Single Time & 亘 \\
\hline Graph Title & Graphical Display & \\
\hline Start Address & $0 \times 0030 E 000$ & \\
\hline Acquisition Buffer Size & 128 & \\
\hline Index Increment & 1 & \\
\hline Display Data Size & 200 & \\
\hline DSP Data Type & 32-bit signed integer & \\
\hline Q-value & 0 & \\
\hline Sampling Rate $[\mathrm{Hz}]$ & 1 & \\
\hline Plot Data From & Left to Right & \\
\hline Left-shifted Data Display & Yes & \\
\hline Autoscale & On & \\
\hline DC Value & 0 & \\
\hline Axes Display & On & \\
\hline Time Display Unit & $s$ & \\
\hline Status Bar Display & On & \\
\hline Magnitude Display Scale & Linear & \\
\hline Data Plot Style & Line & \\
\hline Grid Style & Zero Line & \\
\hline \multirow[t]{2}{*}{ Cursor Mode } & Data Cursor & \\
\hline & Cancel & Help \\
\hline
\end{tabular}

Figura 2.3.4.4 - Janela Graph Property Dialog

É necessário que você faça as seguintes modificações na janela Graph Property Dialog, (Figura 2.3.4.5):

- $\quad$ Start Adress $\rightarrow$ out_buffer.

- Acquisition Buffer Size $\rightarrow$ 256. Verifique no código fonte que o tamanho do buffer é 256.

- DisplayData Size $\rightarrow 64$.

- DSP Data Size $\rightarrow$ 16-bit signed integer.

- Sampling Rate $(\mathrm{Hz}) \rightarrow 8000$. 


\begin{tabular}{|c|c|c|}
\hline \multicolumn{2}{|c|}{ (4) Graph Property Dialog } & \multirow{2}{*}{$\frac{X}{x}$} \\
\hline Display Type & Single Time & \\
\hline Graph Title & Graphical Display & \\
\hline Start Address & out_buffer & \\
\hline Acquisition Buffer Size & 256 & \\
\hline Index Increment & 1 & \\
\hline Display Data Size & 64 & \\
\hline DSP Data Type & 16-bit signed integer & \\
\hline Q-value & 0 & \\
\hline Sampling Rate $[\mathrm{Hz}]$ & 8000 & \\
\hline Plot Data From & Left to Right & \\
\hline Left-shifted Data Display & Yes & \\
\hline Autoscale & On & \\
\hline DC Value & 0 & \\
\hline Axes Display & On & \\
\hline Time Display Unit & $s$ & \\
\hline Status Bar Display & On & \\
\hline Magnitude Display Scale & Linear & \\
\hline Data Plot Style & Line & \\
\hline Grid Style & Zero Line & \\
\hline \multirow[t]{2}{*}{ Cursor Mode } & Data Cursor & \\
\hline & Cancel & Help \\
\hline
\end{tabular}

Figura 2.3.4.5 - Janela Graph Property Dialog com modificações.

A Figura 2.3.4.6 mostra a resposta no domínio do tempo.

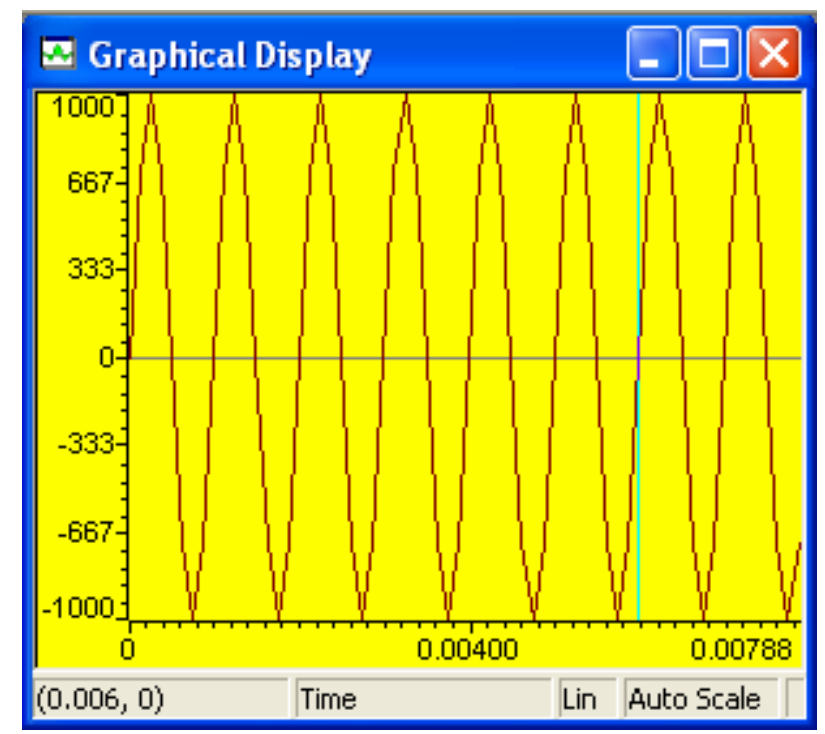

Figura 2.3.4.6 - Resposta no domínio do tempo.

Para o domínio da frequência você deve modificar algumas características na janela Graph Property Dialog (Figura 2.3.4.7): 
- Selecione em DisplayType $\rightarrow$ FFT Magnitude.

- $\quad$ FFT Framesize $\rightarrow 256$.

\begin{tabular}{|c|c|c|c|}
\hline \multicolumn{3}{|c|}{ (4) Graph Property Dialog } & \multirow{2}{*}{$\frac{x}{x}$} \\
\hline Display Type & FFT Magnitude & $\nabla$ & \\
\hline Graph Title & Graphical Display & & \\
\hline Signal Type & Real & & \\
\hline Start Address & out_buffer & & \\
\hline Acquisition Buffer Size & 256 & & \\
\hline Index Increment & 1 & & \\
\hline FFT Framesize & 256 & & \\
\hline FFT Order & 8 & & \\
\hline FFT Windowing Function & Rectangle & & \\
\hline Display Peak and Hold & Off & & \\
\hline DSP Data Type & 16-bit signed integer & & \\
\hline Q-value & 0 & & \\
\hline Sampling Rate [Hz) & 8000 & & \\
\hline Plot Data From & Left to Right & & \\
\hline Left-shifted Data Display & Yes & & \\
\hline Autoscale & On & & \\
\hline DC Value & 0 & & \\
\hline Axes Display & On & & \\
\hline Frequency Display Unit & $\mathrm{Hz}$ & & \\
\hline \multirow[t]{2}{*}{ Status Bar Display } & On & & $v$ \\
\hline & Cancel & Help & \\
\hline
\end{tabular}

Figura 2.3.4.7 - Janela Graph Property Dialog com modificações

A Figura 2.3.4.8 mostra a resposta no domínio da freqüência.

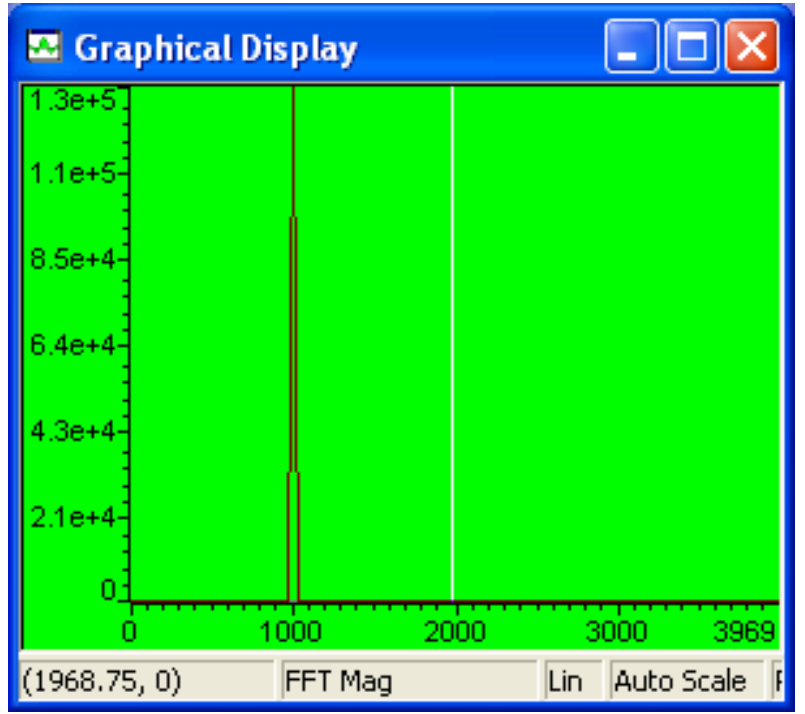

Figura 2.3.4.8 - Resposta no domínio da freqüência. 
No gráfico você pode verificar que o ponto de $1000 \mathrm{~Hz}$ representa a frequiência da senoide gerada.

\subsubsection{Exemplo 5: Produto entre dois Vetores}

Sabe-se que em um processador de sinais digitais as operações fundamentais são as de adição/subtração e multiplicação. A operação de multiplicação/acúmulo é muito utilizada em aplicações que requerem filtros digitais e análise espectral. Assim, tais operações são essenciais na maioria dos algoritmos de processamento de sinais digitais. Verifica-se que com o C6X pode-se executar duas operações de multiplicação/acúmulo em um único ciclo.

Neste exemplo o arquivo dotp4.c apresenta a soma do produto de dois vetores, onde cada vetor é composto por quatro números, como pode ser verificado no arquivo dotp4.h.

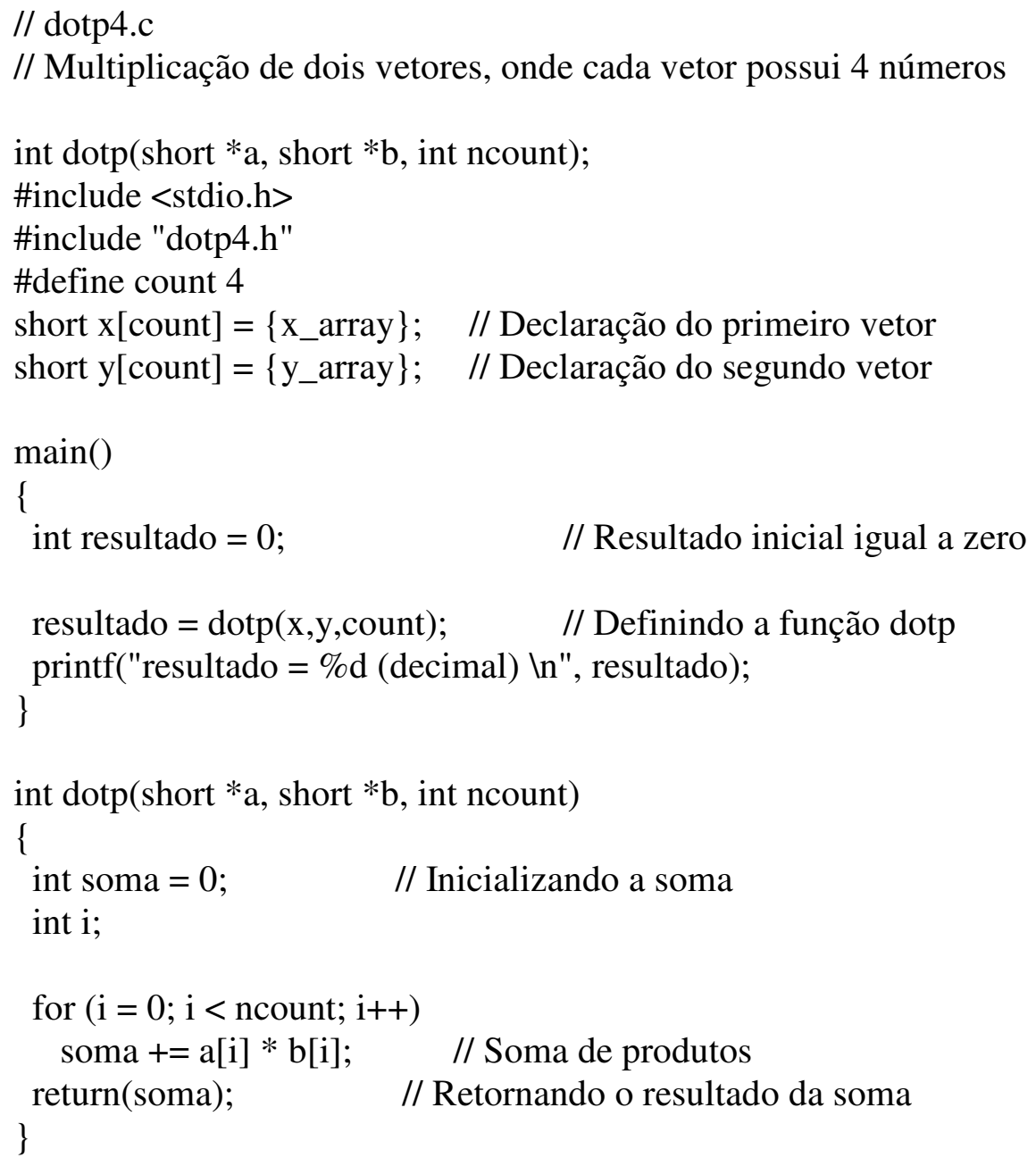


//dotp4.h

\#define $\mathrm{x} \_$array $1,2,3,4$

\#define y_array $0,2,4,6$

Dessa forma, a soma do produto será:

$$
(1 \times 0)+(2 \times 2)+(3 \times 4)+(4 \times 6)=40 .
$$

\section{Criação do projeto}

1. Crie o arquivo denominado dotp4.pjt clicando em Project $\rightarrow$ New.

2. Selecione Project $\rightarrow$ Add Files to Project no CCS, abra a pasta dotp4 e adicione ao projeto o arquivo dotp4.c.

3. Novamente selecione Project $\rightarrow$ Add Files to Project, abra a pasta dotp4 e adicione o arquivo vectors.asm.

4. Repita o passo 3 e adicione o arquivo c6xdsk.cmd.

5. Repita o passo 3 e adicione na pasta Libraries do projeto o arquivo rts6700.lib, que suporta a arquitetura C67XX, e se encontra em c:\CCStudio_v3.1\c6000\cgtools Vib.

6. Carregue na pasta Includes do projeto os arquivos de cabeçalho, clicando em Project $\rightarrow$ Scan All Dependecies, observando a adição do arquivo dotp4.h.

Após a criação do projeto e a adição dos arquivos, verifique no canto esquerdo da tela principal do Code Composer Studio a janela Project View, mostrada na Figura 2.3.5.1. 


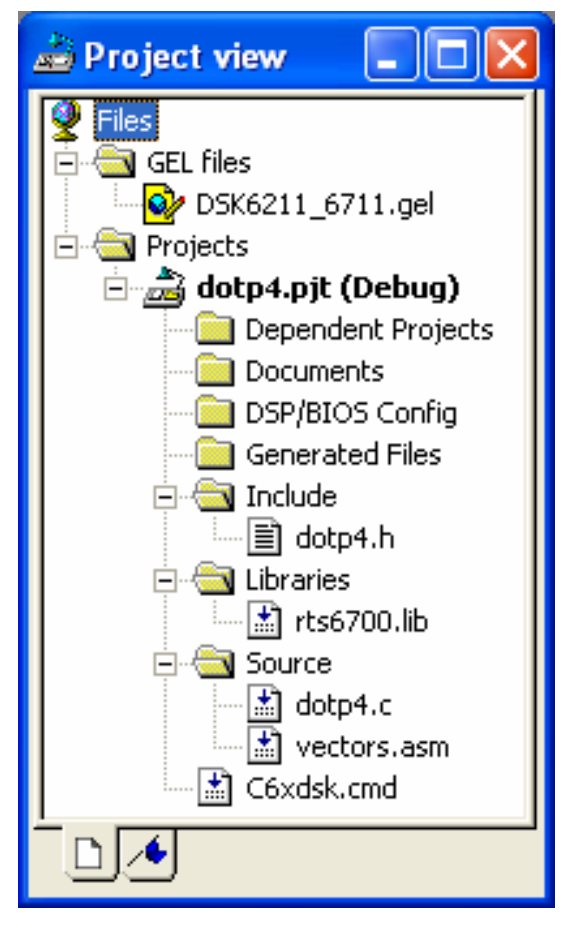

Figura 2.3.5.1 - Visualização do projeto.

Defina os parâmetros de configuração do compilador e do linker:

1. Clique em Project $\rightarrow$ Build Options.

2. Na janela Build Options $\rightarrow$ Compiler.

3. Na lista de Category $\rightarrow$ Basic.

4. No checkbox escolha as seguintes opções: 


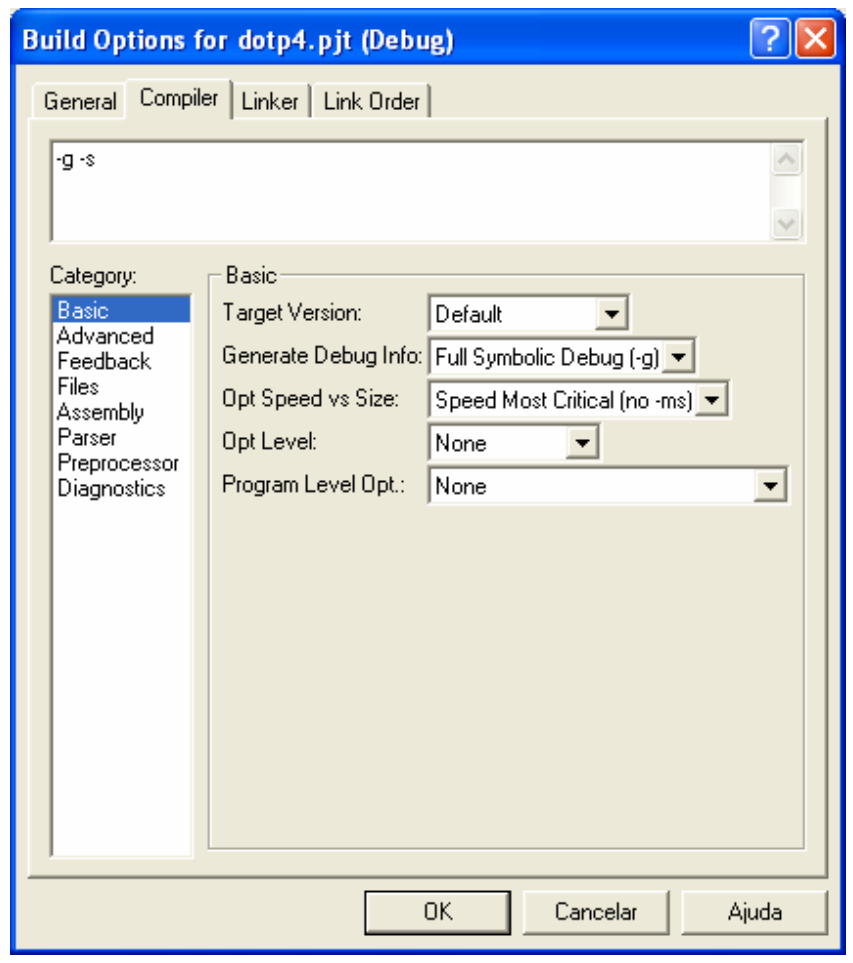

Figura 2.3.5.2 - Configurações do compilador.

5. Clique em Linker na janela Build Options.

6. Na lista de Category $\rightarrow$ Basic.

7. No checkbox escolha as opções apresentadas na Figura 2.3.5.3.

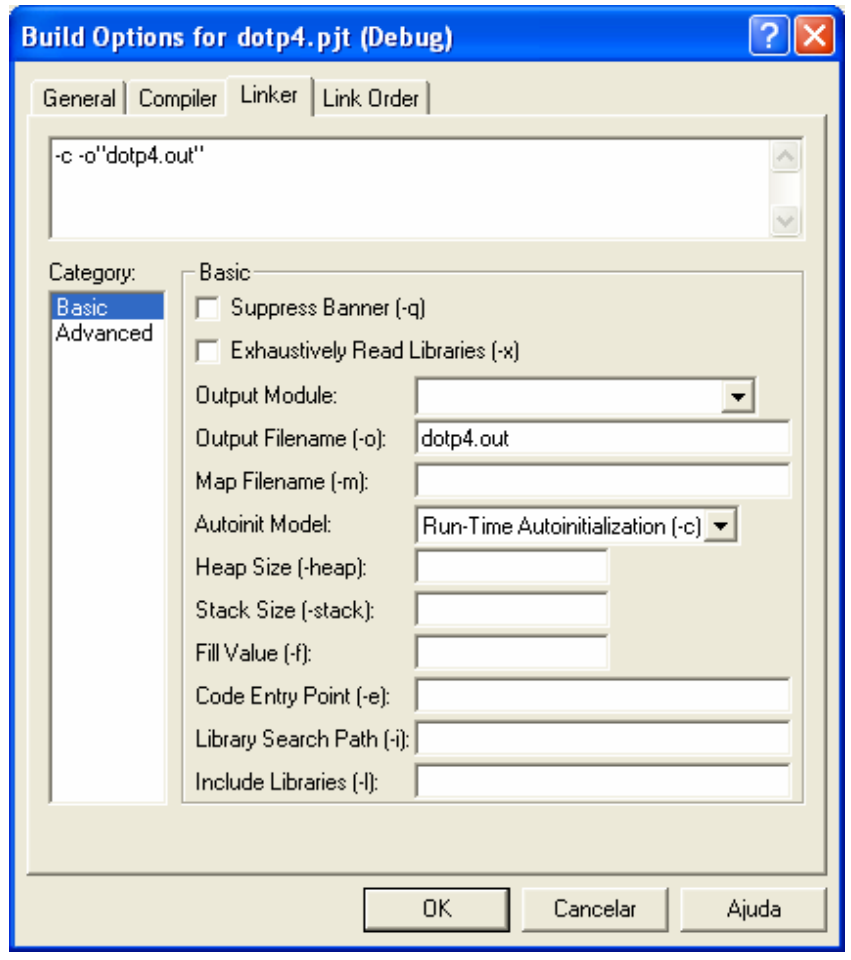

Figura 2.3.5.3 - Configurações do linker. 
8. Clique em $O k$ e feche a janela Build Options.

9. Selecione em Project $\rightarrow$ Build, ou clique no ícone para que o projeto possa ser construído.

10. Carregue o programa através dos comandos File $\rightarrow$ Load Program, abrindo o arquivo dotp4.out.

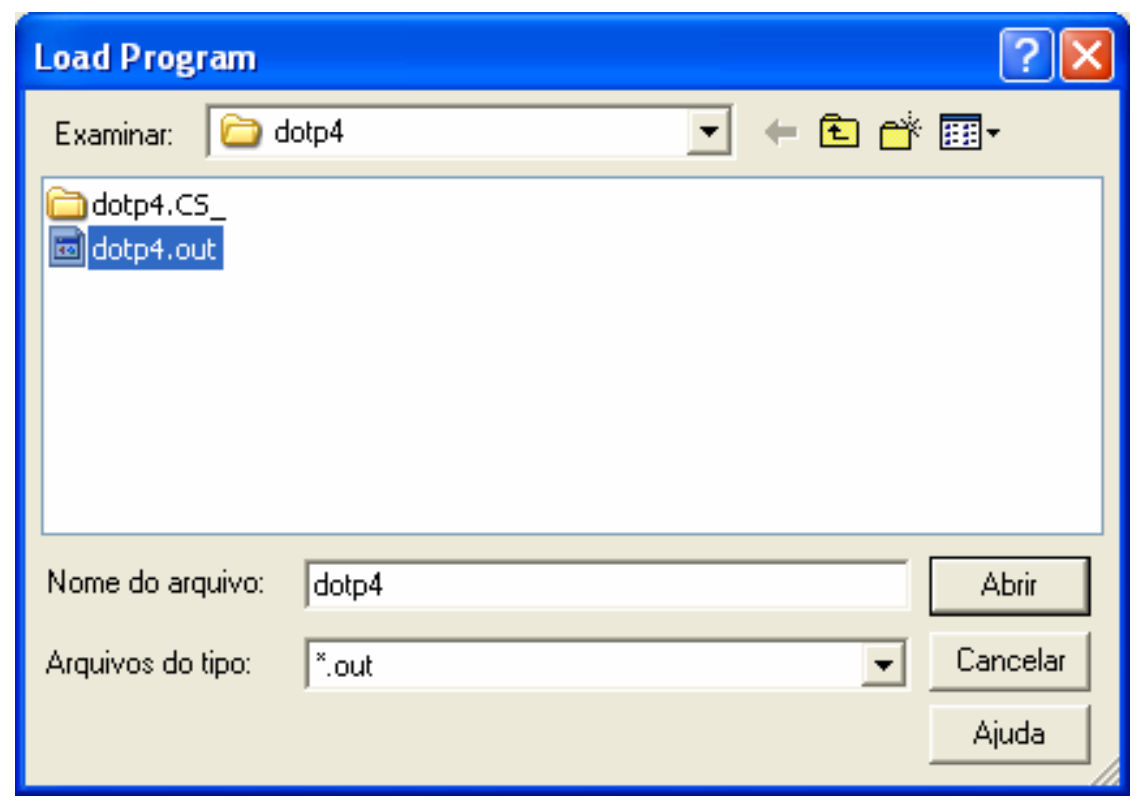

Figura 2.3.5.4 - Carregando o executável.

17. Faça o debug do programa através de Debug $\rightarrow$ Run. E o quadro mostrado na Figura 2.3.5.5 aparecerá:

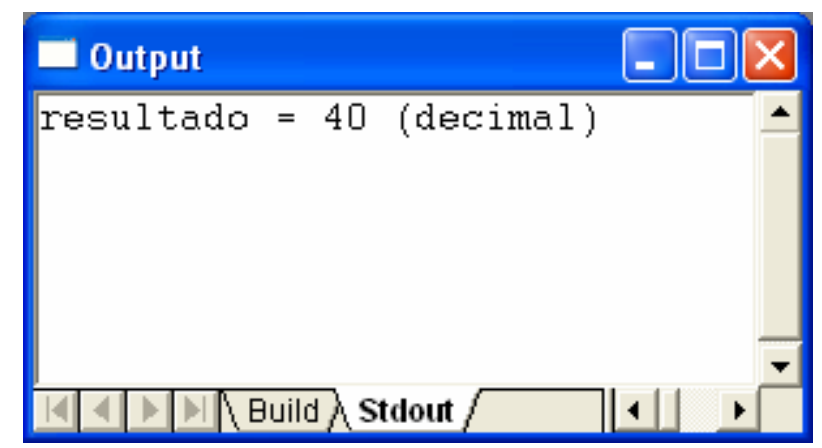

Figura 2.3.5.5 - Saída.

Sabe-se que o ajuste da otimização é um ponto bastante importante quanto ao desenvolvimento do projeto, podendo influenciar positivamente ou negativamente em outros parâmetros do sistema, e até mesmo no custo final do produto. A eficiência é 
comumente medida em termos da contagem do número de ciclos e o tamanho do código. $\mathrm{O}$ Code Composer Studio ${ }^{\mathrm{TM}}$ IDE fornece uma série de ferramentas de ajuda para que o programador alcance rapidamente a otimização do projeto.

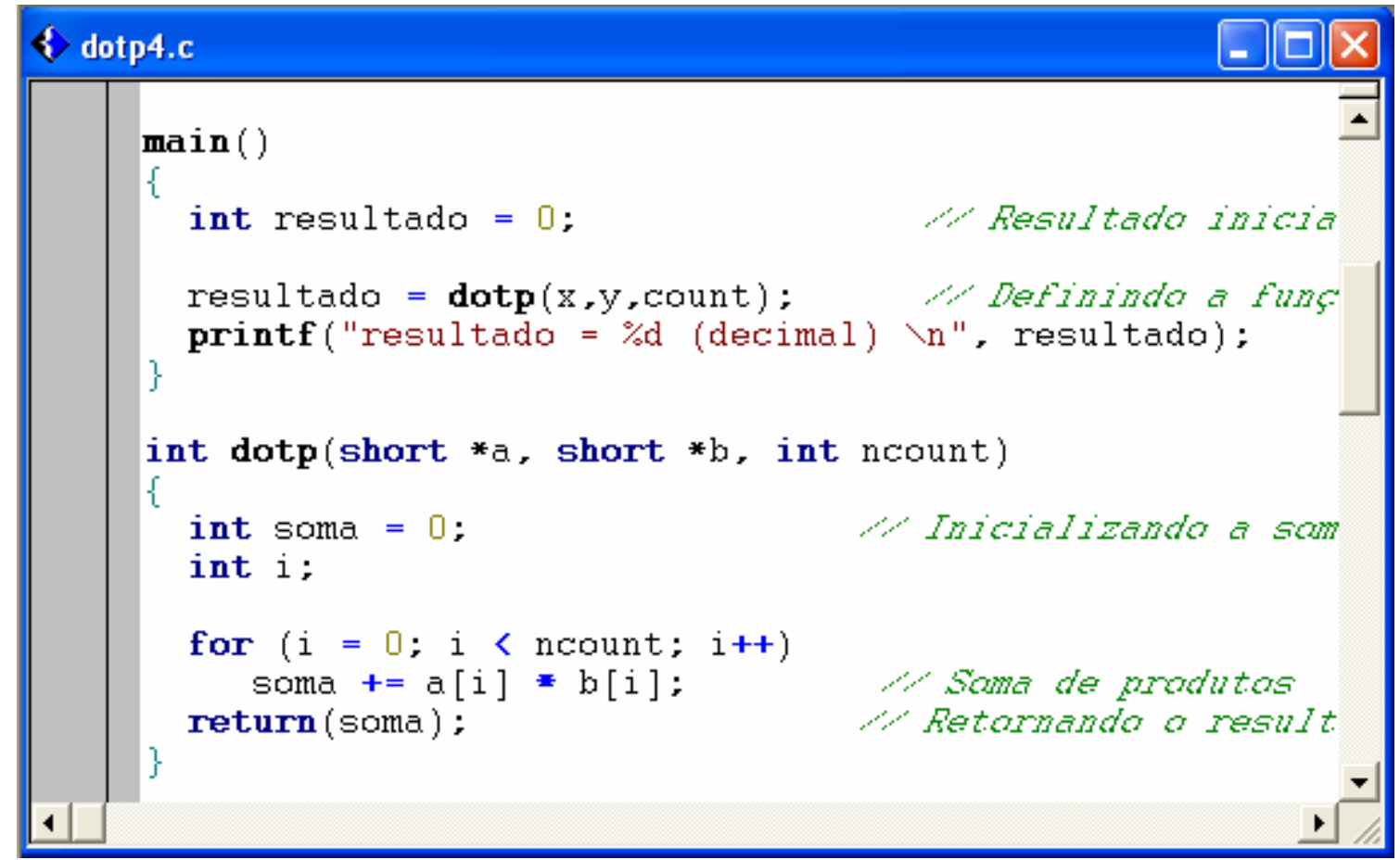

Figura 2.3.5.6 - Programa principal.

Nesta etapa do experimento serão utilizadas as janelas do Profile Setup para que o programador selecione a parte do código a ser analisada no Profile Viewer, e o Compiler Consultant Tool do compilador que apresentará conselhos quanto à otimização do projeto.

1. Clique em Profile $\rightarrow$ Setup para que janela Profile Setup seja aberta no lado direito da tela principal do Code Composer Studio. 


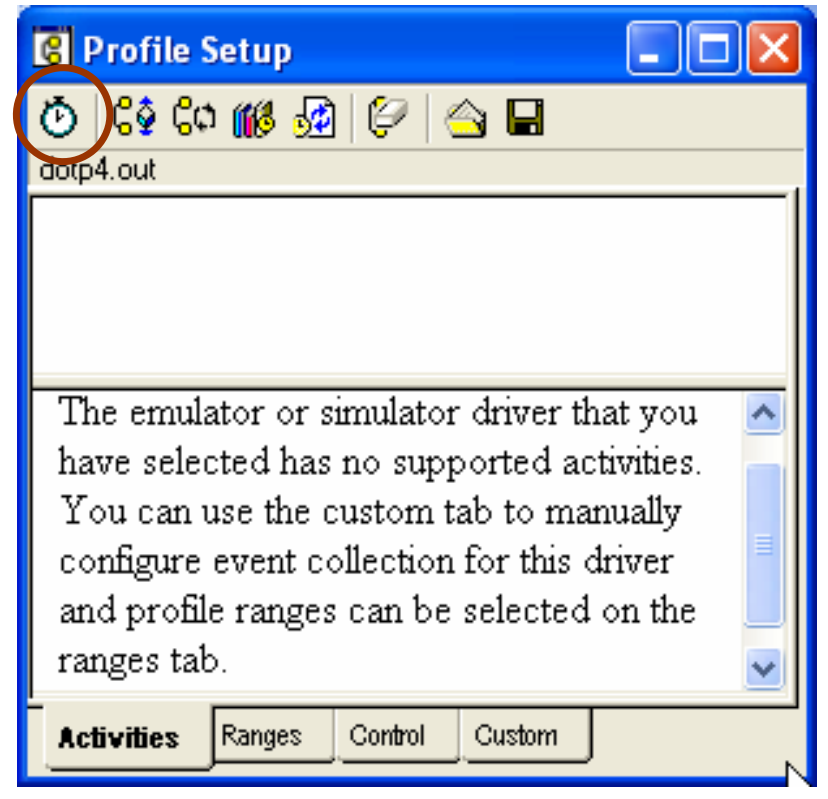

Figura 2.3.5.7 - Ajuste do Profile.

3. Clique no ícone que representa o relógio, o qual significa o comando de Enable/Disable Profiling, e observe que ao habilitá-lo será mostrado na parte central inferior da tela principal do Code Composer Studio a seguinte mensagem:

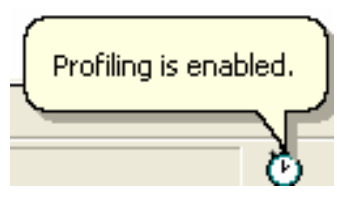

Figura 2.3.5.8 - Indicação de habilitação do Profile.

3. Clique na aba Ranges da janela Profile Setup: 


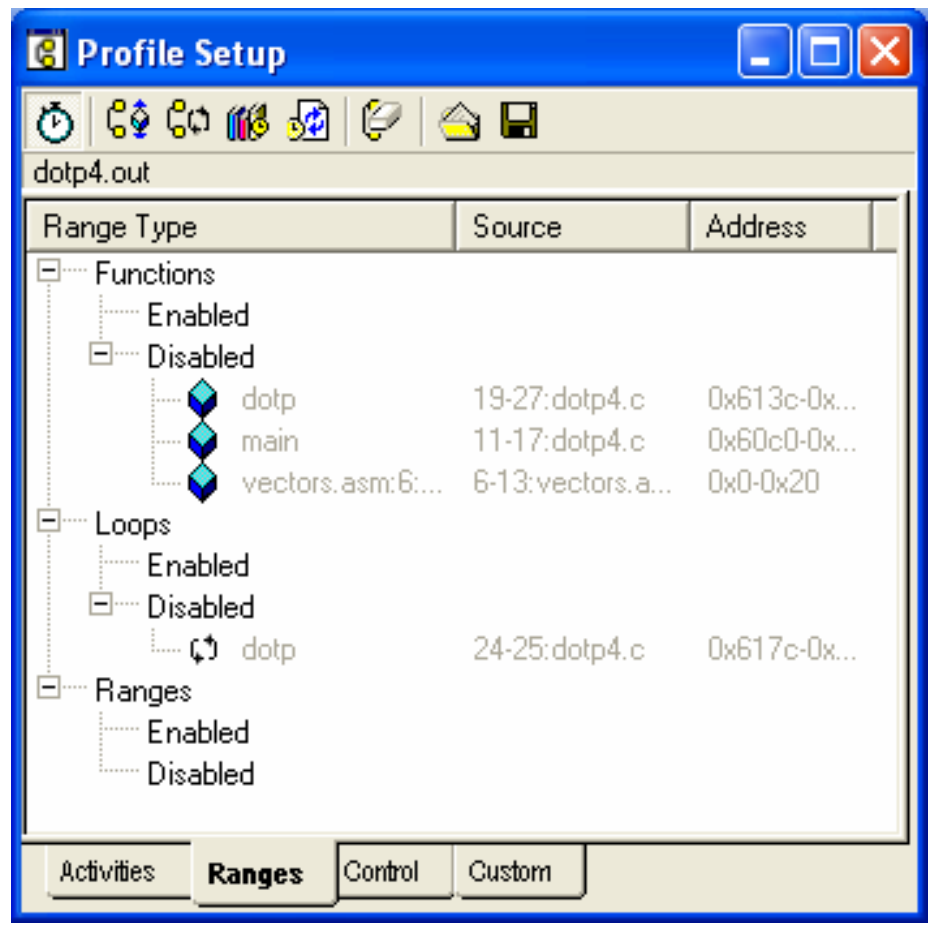

Figura 2.3.5.9 - Ajuste do Profile: Ranges.

4. Habilite as partes desejadas. Para habilitar uma única função basta arrastá-la para Functions $\rightarrow$ Enable. Todas as funções podem ser habilitadas simultaneamente clicando-se no ícone $\overline{b \hat{Q}}$. Da mesma maneira, todos os laços (loops) podem ser habilitados, clicando-se no ícone 


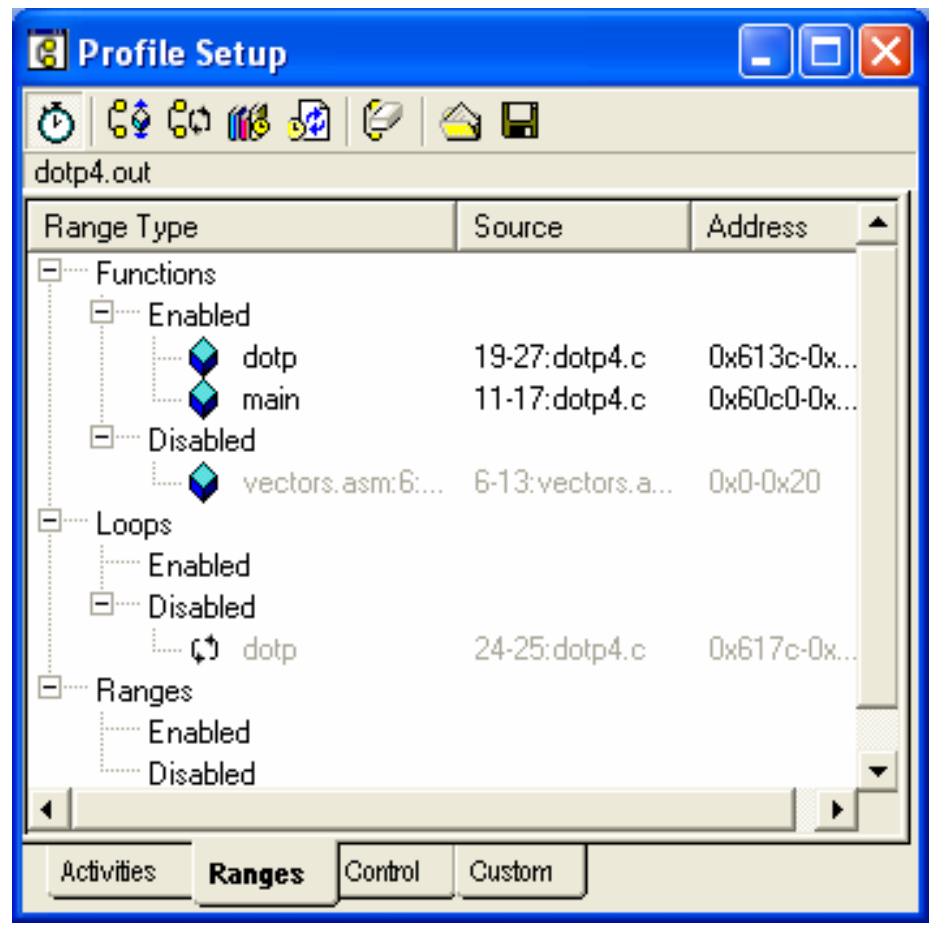

Figura 2.3.5.10 - Ajuste do Profile: Ranges.

Observa-se neste caso que foram habilitados às funções dotp e main.

5. Clique na aba Custom da janela Profile Setup e selecione Cycles.

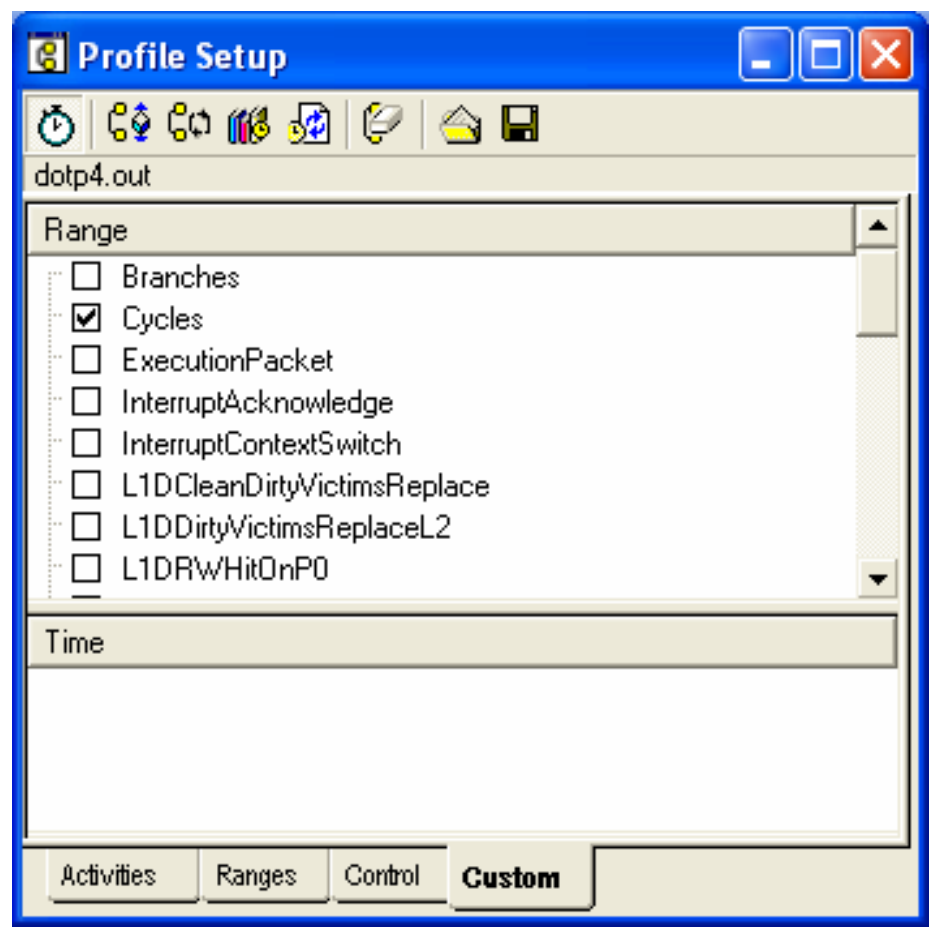

Figura 2.3.5.11 - Ajuste do Profile: Custom/ Cycles. 
Após esta primeira parte é necessário que você ajuste alguns parâmetros do compilador.

6. Clique em Project $\rightarrow$ Build Options.

7. Na janela Build Option $\rightarrow$ Compiler.

8. Na lista de Category $\rightarrow$ Feedback.

9. No checkbox clique em Generate Compiler Consultant.

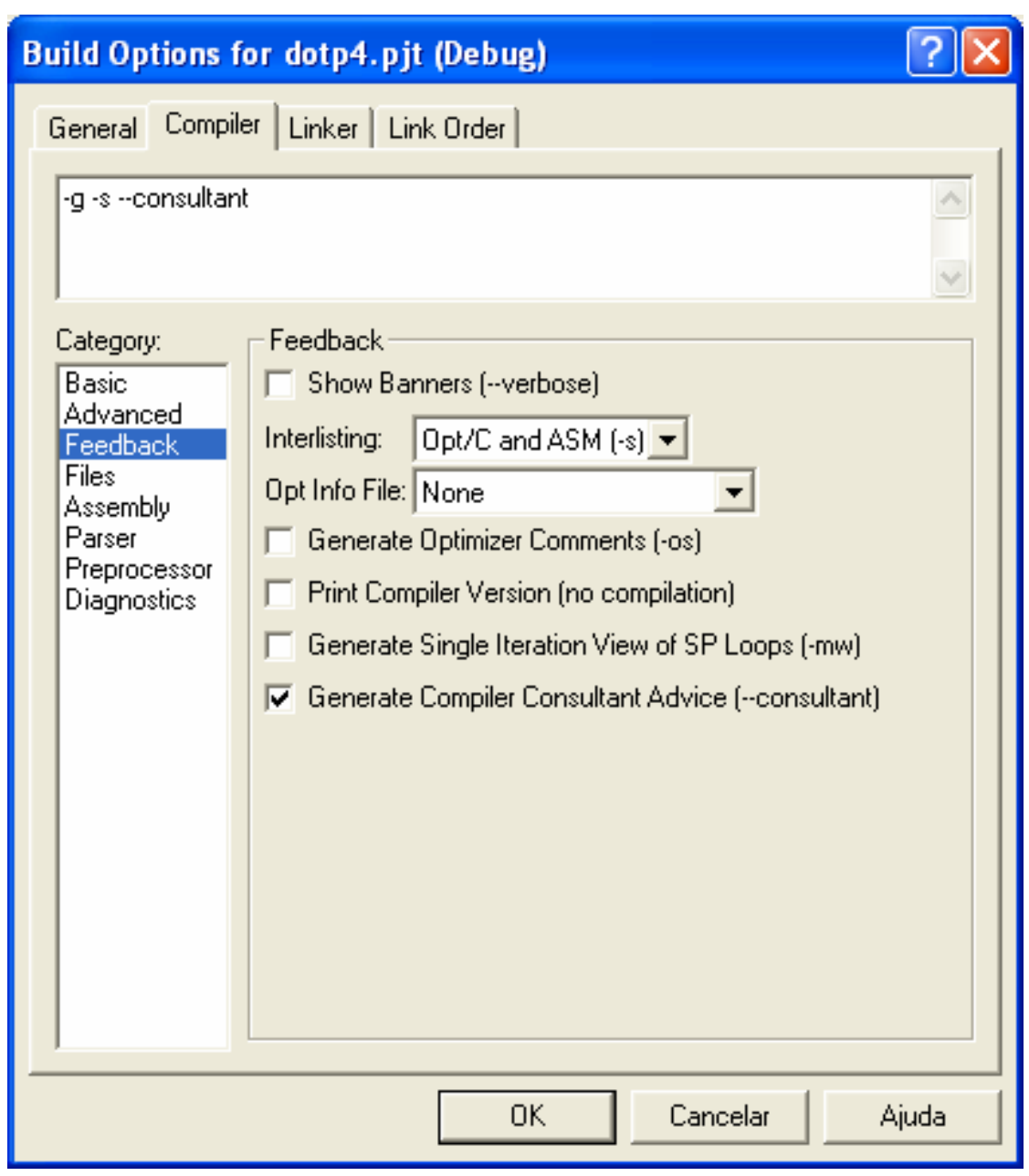

Figura 2.3.5.12 - Configurações do compilador.

10. Clique em OK e feche a janela Build Options.

11. No menu Project, selecione Build, para que as configurações feitas anteriormente sejam consideradas.

12. Clique em Debug $\rightarrow$ Reset $C P U$.

13. Carregue o programa através dos comandos File $\rightarrow$ Reload Program. 
14. Faça o debug do programa através de Debug $\rightarrow$ Run.

Nesta terceira parte verifique as análises das funções por meio da janela Profile Viewer.

15. Clique em Profile $\rightarrow$ Viewer, e a janela Profile Viewer será executado no canto inferior do lado direito da tela principal do Code Composer Studio (Figura 2.3.5.13):

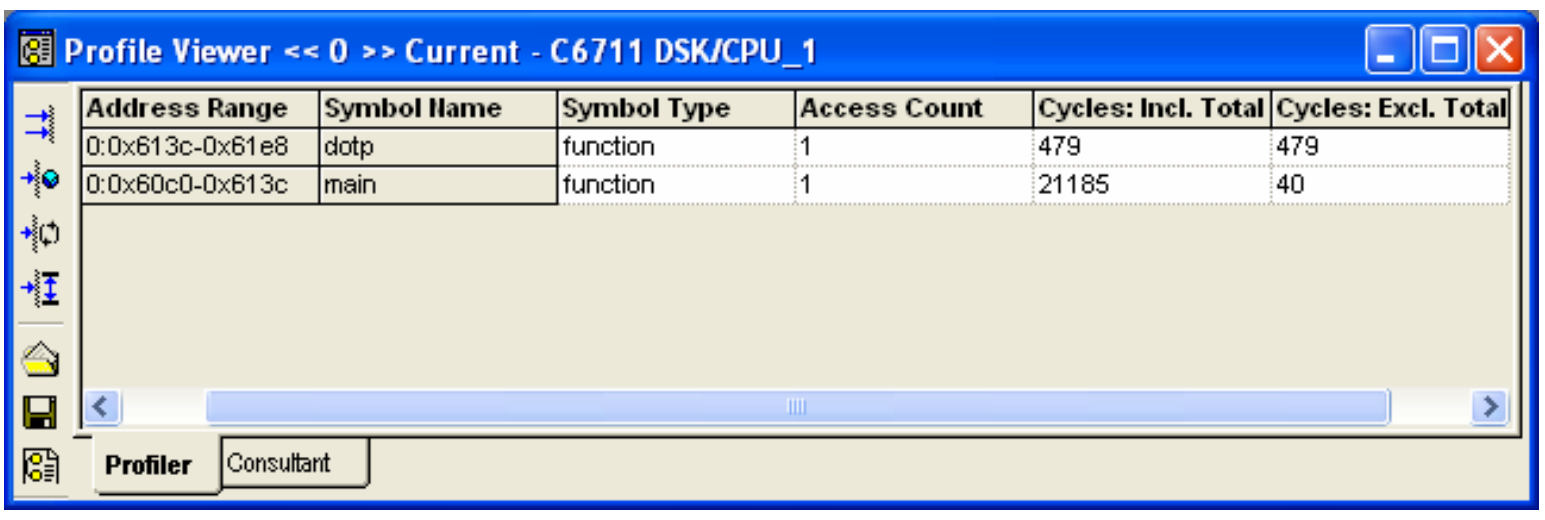

Figura 2.3.5.13 - Visualizador do Profile

Observe que o Address Range apresenta o endereço hexadecimal da função selecionada. Em SLR (Source Line Reference) verifique as linhas do código que definem o laço, a função ou o intervalo (range). Access Count significa o número de vezes que a função foi acessada. Cycles: Incl. Total indica a quantidade de ciclos total para a execução da função. Cycles: Excl. Total indica a quantidade de ciclos para que ocorra a execução da função, excluindo os ciclos das sub-rotinas contidas na mesma [TMS320C6000, 2000].

16. Clique na aba Consultant. A linha observada nesta janela representa o único laço presente no código do exemplo proposto. 


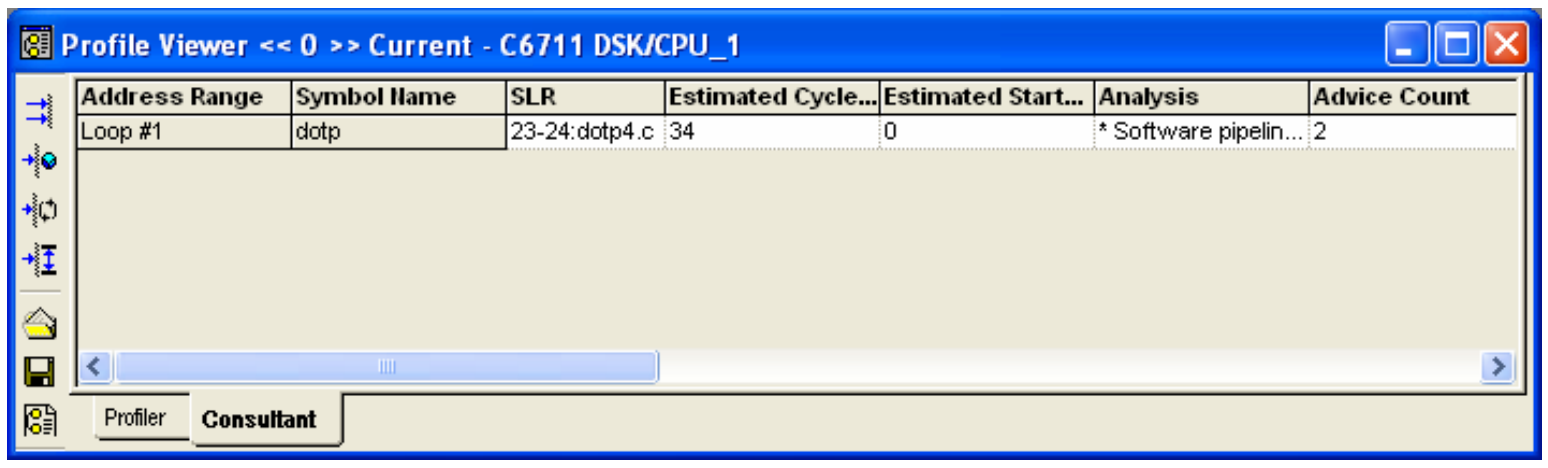

Figura 2.3.5.14 - Visualizador do Profile.

Em Advice Count observa-se a quantidade de conselhos oferecidos pelo Code Composer Studio ${ }^{\mathrm{TM}}$ IDE para a otimização do projeto, os quais podem ser verificados dando um duplo clique na linha correspondente as instruções.

Após o duplo clique, ou através dos comandos Profile $\rightarrow$ Tuning $\rightarrow$ Advice, verifica-se a abertura de uma janela de conselhos e análises do Compiler Consultant (Figura 2.3.5.15) no lado esquerdo da tela principal do Code Composer Studio.

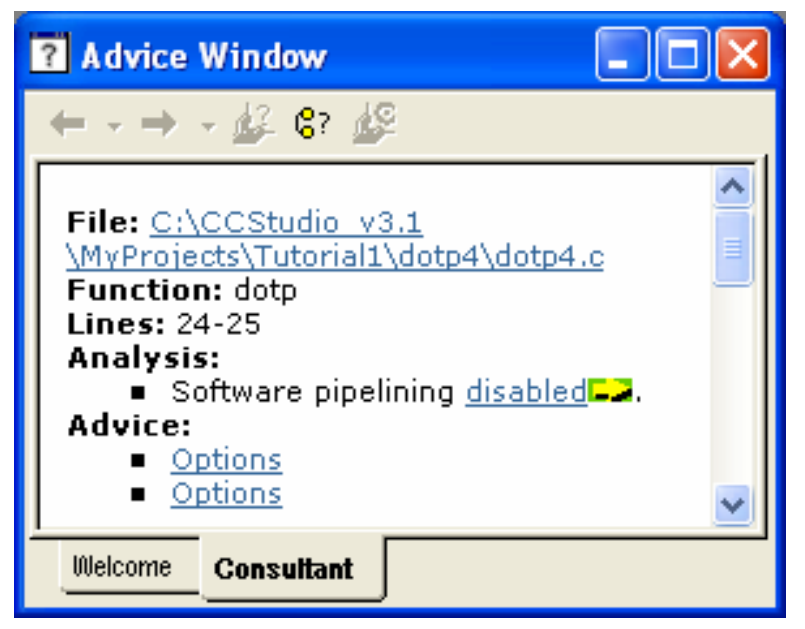

Figura 2.3.5.15 - Janela de conselhos.

Ao aparecer à janela Compiler Consultant verifique que no quadro Consultant aparece conselhos para a função dopt4. Em Analysis verifique que a otimização do Software pipelining está desabilitada. Em Advice aparecem duas opções de conselho. Para visualizá-los basta clicar em Options.

O primeiro conselho fornecido em Options indica que você está compilando o programa sem otimização. 


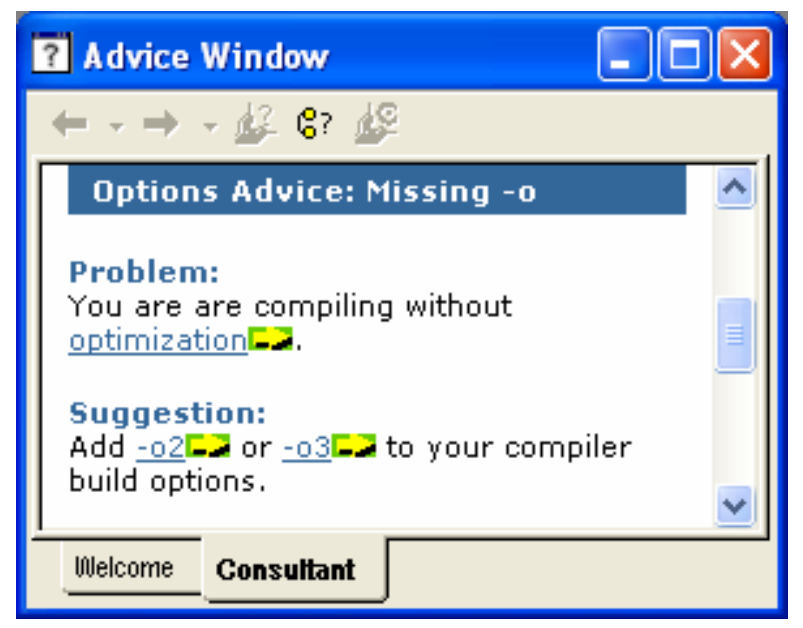

Figura 2.3.5.16 - Janela de conselhos.

Verifique que a palavra optimization encontra-se sublinhada, com uma cor diferente do texto inicial, e seguida pelo ícone [ב, o que significa que bastando clicar na mesma aparece uma janela de ajuda explicando os níveis de otimização.

Em Suggestion, na janela Consultant, verifique que a sugestão oferecida foi que o projetista deveria aplicar $-\mathrm{o} 2$ ou $-\mathrm{o} 3$ na opção do compilador.

Entretanto, antes de qualquer mudança observe na mesma janela o segundo conselho oferecido em Consultant $\rightarrow$ Advice $\rightarrow$ Options.

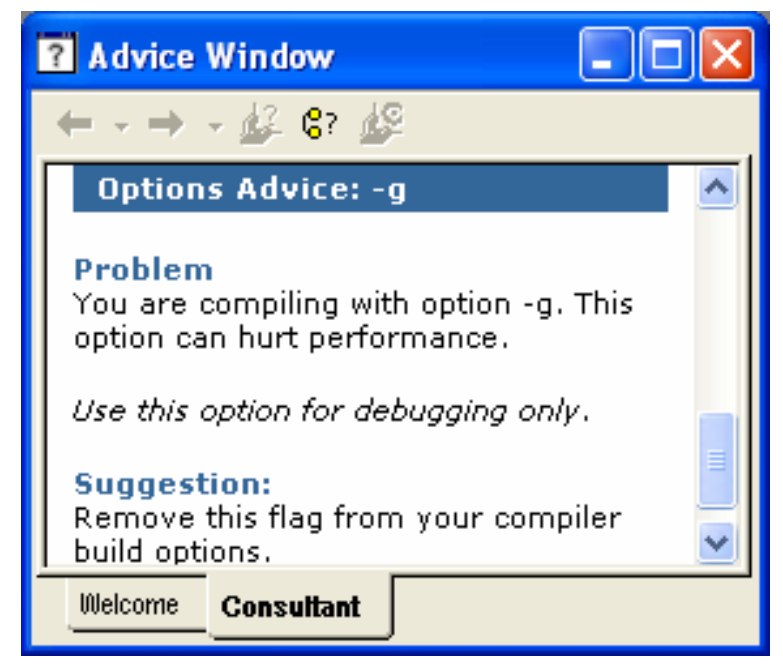

Figura 2.3.5.17 - Janela de conselhos.

Verifique em Problem que utilizar a opção -g na determinação dos parâmetros do Debug, pode interferir no desempenho do projeto. Sugere-se desta forma que o programador retire esta opção do seu Build Options. 
Seguindo os conselhos sugeridos para a otimização, é preciso configurar os novos parâmetros para o compilador.

1. Clique em Project $\rightarrow$ Build Options.

2. Na janela Build Option $\rightarrow$ Compiler.

3. Na lista de Category $\rightarrow$ Basic.

4. Em Generate Debug Info $\rightarrow$ No Debug.

5. Em Opt Level $\rightarrow$ File (-o3).

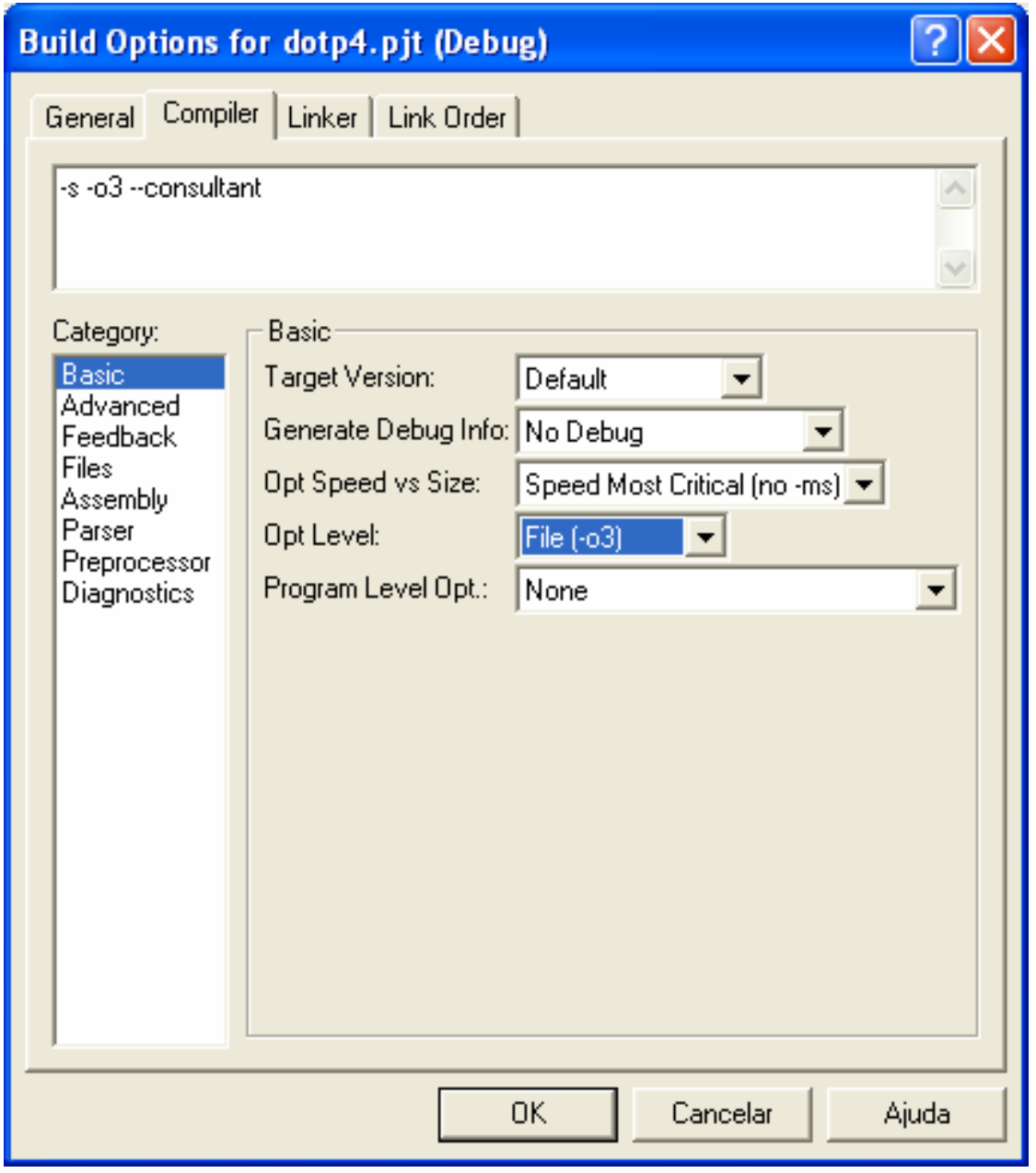

Figura 2.3.5.18 - Configurações do compilador.

6. Clique em $O K$ e feche a janela Build Options.

7. No menu Project selecione Rebuild All.

8. Clique em Debug $\rightarrow$ Reset $C P U$.

9. Carregue o pograma File $\rightarrow$ Reload Program. 


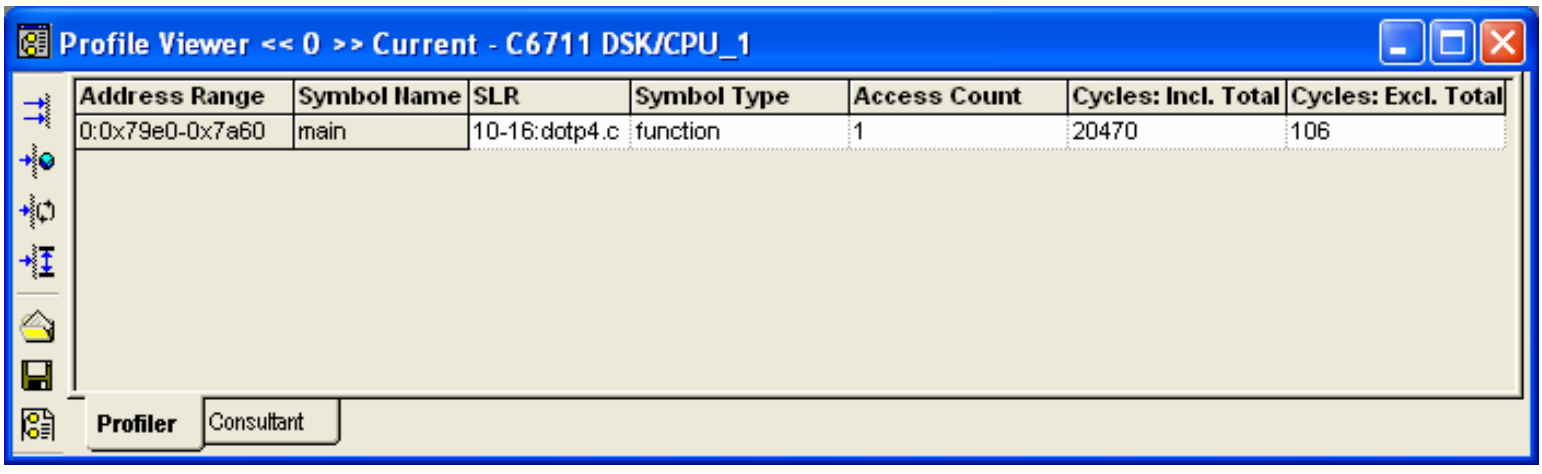

Figura 2.3.5.19 - Visualizador do Profile.

Observe na janela Profile Viewer que, após a determinação dos novos parâmetros para a otimização do projeto, a quantidade de Cycles: Incl. Total diminuiu, ou seja, a função main e suas sub-rotinas apresentaram um custo menor em termos de ciclos de relógio, após ter sido aplicada à ferramenta de otimização. 


\section{3 - TUTORIAL 2: FILTROS COM RESPOSTA IMPULSIONAL FINITA (FIR)}

\subsection{OBJETIVO}

- Estudo da transformada Z

- Projeto e implementação de filtros com resposta impulsional finita (FIR)

- Programação de exemplos usando C e o TMS320C6711 DSK

Esse tutorial tem por finalidade estudar a transformada $Z$ em conjunto com os sinais discretos. Projetar três exemplos de filtro FIR a partir do método da série de Fourier e implementá-los através da equação de convolução discreta.

\subsection{INTRODUÇÃO}

\subsubsection{Sinais Discretos}

Um sinal no tempo discreto é aquele que pode ser representado por uma seqüência de números, como,

$$
x(n)=\sum_{m=-\infty}^{\infty} x(m) \delta(n-m),
$$

onde $x(n)$ seria composto pela soma de sequiências de impulsos unitários $\delta(n)$ atrasados de $m$ amostras, e multiplicados por uma constante $x(m)$. Sabe-se que:

$$
\delta(n-m)= \begin{cases}1, & n=m \\ 0, & n \neq m\end{cases}
$$

Logo o somatório da Equação 3.1 seria representado por uma seqüência de valores $\mathrm{x}(1), \mathrm{x}(2), \ldots$, onde cada valor de amostra da seqüência corresponde a um valor de amostra no tempo $(n)$ determinado pelo intervalo de amostragem ou pelo período de amostragem, $T=1 / F_{S}$.

Dessa forma o sistema discreto aceita na sua seqüência de entrada, $x(n)$, sinais discretos e fornece na seqüência de saída, $y(n)$, também sinais discretos, a partir das relações existentes entre tais seqüências. 


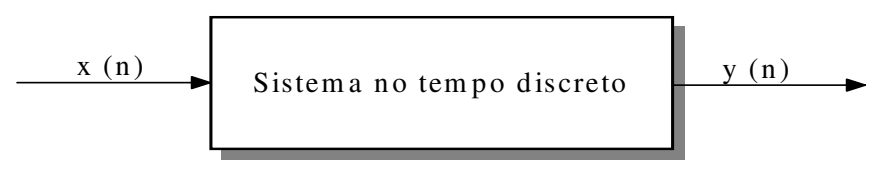

Figura 3.2.1.1 - Representação de um sistema no tempo discreto

Dependendo das relações, o sistema no tempo discreto pode ser classificado de várias formas, linear ou não linear, variante ou invariante no tempo (ao deslocamento) e causal ou não causal. Neste trabalho, porém, serão apenas considerados sistemas discretos lineares e invariantes ao deslocamento (LI).

Um sistema discreto é denominado linear se ao ser aplicada, uma entrada que seja uma combinação linear de duas outras, na saída será encontrada a mesma combinação linear relacionada às saídas correspondentes a essas entradas quando estas foram aplicadas separadamente [Oppenheim \& Schafer, 1989].

Assim se a entrada do sinal $x(n)$ corresponde à saída $y(n)$ :

$$
x(n) \rightarrow y(n)
$$

E se $a_{1} x_{1}(n) \rightarrow a_{1} y_{1}(n)$ e $a_{2} x_{2}(n) \rightarrow a_{2} y_{2}(n)$, então pela combinação linear:

$$
a_{1} x_{1}(n)+a_{2} x_{2}(n) \rightarrow a_{1} y_{1}(n)+a_{2} y_{2}(n) .
$$

A equação (3.4) representa o princípio da superposição, onde a seqüência de saída é a soma das respostas de cada entrada.

Se um sistema discreto é dito invariante ao deslocamento isto implica que se a entrada está atrasada de $m$ amostras a saída também estará, ou seja,

$$
x(n) \rightarrow y(n) \therefore x(n-m) \rightarrow y(n-m)
$$

Caso a resposta de saída ao impulso, $\delta(n)$, seja $h(n)$, então $\delta(n) \rightarrow h(n)$, e este sistema discreto seja considerado invariante no tempo então a seguinte relação torna-se verdadeira;

$$
\delta(n-m) \rightarrow h(n-m)
$$

Multiplicando o impulso por $x(m)$ e aplicando a linearidade obtém-se:

$$
x(m) \delta(n-m) \rightarrow x(m) h(n-m)
$$

Conseqüentemente a seqüência de saída será:

$$
y(n)=\sum_{m=-\infty}^{\infty} x(m) h(n-m)
$$

Esta operação entre os sinais discretos designa-se por convolução discreta. Fazendo $k=n-m$, tem-se: 


$$
y(n)=\sum_{k=0}^{\infty} h(k) x(n-k)
$$

\subsubsection{Introdução a Transformada $Z$}

A transformada $\mathrm{Z}$ é um instrumento matemático utilizado para a análise e síntese de sinais discretos no tempo, desempenhando um papel similar à transformada de Laplace para sinais contínuos no tempo [Gold \& Radere, 1969].

Considerando um sinal analógico idealmente amostrado $x(t)$,

$$
x_{s}(t)=\sum_{k=0}^{\infty} x(t) \delta(t-k T)
$$

A função impulso na equação está atrasada de $k T$ onde $T=1 / F_{s}$. Verifica-se que a função $x_{s}(t)$ será zero para qualquer valor exceto para $t=k T$.

A transformada de Laplace de $x_{s}(t)$ é:

$$
\begin{aligned}
X_{s}(s) & =\int_{0}^{\infty} x_{s}(t) e^{-s t} d t \\
& =\int_{0}^{\infty}\{x(t) \delta(t)+x(t) \delta(t-T) \ldots\} e^{-s t} d t
\end{aligned}
$$

Pela propriedade da função impulso tem-se:

$$
\int_{0}^{\infty} f(t) \delta(t-k T) d t=f(k T)
$$

Logo:

$$
X_{s}(s)=x(0)+x(T) e^{-s T}+x(2 T) e^{-2 s T}+\ldots=\sum_{n=0}^{\infty} x(n T) e^{-n s T}
$$

Fazendo $z=e^{s T}$ tem-se:

$$
X(z)=\sum_{n=0}^{\infty} x(n T) z^{-n}
$$

Considerando $x(n T)=x(n)$, obtém-se:

$$
X(z)=\sum_{n=0}^{\infty} x(n) z^{-n}=Z T\{x(n)\}
$$

O qual representa a transformada $\mathrm{Z},(Z T)$, de $x(n)$.

Verifica-se que a transformada em $\mathrm{Z}, X(z)$, de um sinal discreto $\mathrm{x}(\mathrm{n})$ é uma função complexa da variável complexa $z \in \mathbb{C}$. A transformada $X(z)$ só é definida para as regiões do plano complexo em que o somatório converge. 
Se, por exemplo, $x(n)=e^{n k}, n \geq 0$ e $k$ uma constante real, então a transformada $\mathrm{z}$ será:

$$
X(z)=\sum_{n=0}^{\infty} e^{n k} z^{-n}=\sum_{n=0}^{\infty}\left(e^{k} z^{-1}\right)^{n}
$$

Usando séries geométricas,

$$
\sum_{n=0}^{\infty} u^{n}=\frac{1}{1-u} \quad|\mathrm{u}|<1
$$

Onde $n \geq 0$. Assim,

$$
X(z)=\frac{1}{1-e^{k} z^{-1}}=\frac{z}{z-e^{k}}
$$

Para $\left|e^{k} z^{-1}\right|<1$ ou $|z|>\left|e^{k}\right|$. Se $k=0$, então $X(z)=z /(z-1)$.

\subsubsection{Transformada $Z$ inversa}

A transformada Z inversa é representada pela seguinte equação [Bellanger, 1989];

$$
x[n]=\frac{1}{2 \pi j} \oint_{c} X(z) z^{n-1} d z
$$

Onde a integral é realizada sobre um contorno $c$ fechado, anti-horário e ao redor da origem do plano $\mathrm{z}$.

Para se obter este resultado, tem-se a partir da teoria de funções complexas [Rabiner \& Gold, 1975],

$$
\oint_{c} z^{-k} d z=\left\{\begin{array}{r}
0 ; \mathrm{k} \neq 1 \\
2 \pi \mathrm{j} ; \mathrm{k}=1
\end{array}\right.
$$

Onde $k$ é um inteiro e $c$ é um contorno fechado, anti-horário e ao redor da origem do plano z. Logo ao considerar $c=r \exp (j \theta)$, onde $r=$ constante e $0 \leq \theta \leq 2 \pi$ na equação (3.20), obtém-se:

$$
\begin{aligned}
\oint_{c} z^{-k} d z & =\int_{0}^{2 \pi} r^{-k} e^{-j k \theta} j r e^{j \theta} d \theta \\
& =r^{-k+1} j \int_{0}^{2 \pi} e^{-j(k-1) \theta} d \theta
\end{aligned}
$$


Aplicando este resultado, equação (3.21), no cálculo da integral da Equação (3.19), com o contorno $c$ contido na região de convergência de $X(z)$. Usando a transformada $\mathrm{Z}$ para substituir $X(z)$ tem-se:

$$
\begin{aligned}
\oint_{c} X(z) z^{n-1} d z & =\sum_{k=-\infty}^{\infty} x[k] \oint_{c} z^{-(k-n+1)} d z \\
& =\sum_{k=-\infty}^{\infty} x[k]
\end{aligned}
$$

Obtendo desta forma a equação (3.18) que apesar de sua utilização não ser simples, esta equação permite obter a transformada inversa [Oppenheim, 1993].

\subsubsection{Equações de Diferenças}

A transformada de Laplace é utilizada para resolver equações diferenciais, no domínio s, no plano s, que representam filtros analógicos. Já a transformada $\mathrm{Z}$ resolve equações de diferenças, no domínio z, no plano z, representando filtros digitais. O plano s é um sistema com coordenadas retangulares enquanto que o plano z utiliza o formato polar [Rabiner \& Gold, 1975].

A entrada e a saída de um sistema descrito por uma equação de diferenças linear se relacionam genericamente por:

$$
y(n)=b x(n)-a y(n-1)
$$

Onde cada saída corrente $y(n)$ está relacionada com o sinal de entrada corrente $x(n)$, e com os sinais prévios da saída $y(n-1)$. Assumindo o sistema causal, ou seja, $y(n)=0$ para $n<0$ e $x(n)=\delta(n)$, a saída $y(n)$ pode ser escrita como:

$$
\begin{aligned}
y(n) & =b_{0} x(n)+b_{1} x(n-1)+\ldots+b_{L-1}(n-N+1)-a_{1} y(n-1)-\ldots-a_{M} y(n-M) \\
& =\sum_{k=0}^{N-1} b_{k} x(n-k)-\sum_{m=1}^{M} a_{m} y(n-m)
\end{aligned}
$$

O sistema representado pela equação (3.24) é dito recursivo, uma vez que a sua saída depende de suas entradas e das amostras passadas da própria saída. Um sistema discreto é denominado não-recursivo quando a resposta $y(n)$ do sistema pode ser calculada a partir exclusivamente de sua entrada $x(n)$, [Proakis \& Manolakis, 1996], assim:

$$
y(n)=\sum_{k=0}^{N-1} b_{k} x(n-k)
$$


Para resolver a equação de diferença faz-se necessário, como pode ser verificado a partir da equação (3.25), achar a transformada $\mathrm{Z}$ para a expressão do tipo $x(n-k)$, a qual corresponde a k-ésima derivada $d^{k} x(t) / d t^{k}$ de um sinal analógico $x(t)$.A ordem da equação de diferença, que é definida como o número de entradas prévias que devem ser armazenadas a fim de gerar uma dada saída, é determinada pelo maior valor de $k$. Assim, por exemplo, se $k=2$, o que corresponde à derivada de segunda ordem, a partir da equação (3.15) obtém-se primeiramente a transformada Z para $x(n)$ [Lyons, 1997]:

$$
X(z)=\sum_{n=0}^{\infty} x(n) z^{-n}=x(0)+x(1) z^{-1}+x(2) z^{-2}+\ldots
$$

A transformada $\mathrm{Z}$ para $x(n-1)$, que corresponde a derivada de primeira ordem $d x / d t$ é:

$$
\begin{aligned}
Z T[x(n-1)] & =\sum_{n=0}^{\infty} x(n-1) z^{-n} \\
& =x(-1)+x(0) z^{-1}+x(1) z^{-2}+x(2) z^{-3}+\ldots \\
& =x(-1)+z^{-1}\left[x(0)+x(1) z^{-1}+x(2) z^{-2}+\ldots\right] \\
& =x(-1)+z^{-1} X(z)
\end{aligned}
$$

Verifica-se que $x=(-1)$ representa a condição inicial associada com a equação de diferença de primeira ordem.

A transformada $\mathrm{Z}$ para $x(n-2)$, equivalente a segunda derivada $d^{2} x / d t^{2}$ será:

$$
\begin{aligned}
Z T[x(n-2)] & =\sum_{n=0}^{\infty} x(n-2) z^{-n} \\
& =x(-2)+x(-1) z^{-1}+x(0) z^{-2}+x(1) z^{-3}+\ldots \\
& =x(-2)+x(-1) z^{-1}+z^{-2}\left[x(0)+x(1) z^{-1}+\ldots\right] \\
& =x(-2)+x(-1) z^{-1}+z^{-2} X(z)
\end{aligned}
$$

Verifica-se na equação acima que x(-2) e x(-1) representam as condições iniciais necessárias para resolver a equação de diferença de segunda ordem. Assim:

$$
Z T[x(n-k)]=z^{-k} \sum_{m=0}^{k}\left\{x(-m) z^{m}+X(z)\right\}
$$

Considerando as condições iniciais nulas, tem-se:

$$
Z T[x(n-k)]=z^{-k} X(z)
$$

Se, por exemplo, considerar um sistema descrito pela seguinte equação da diferença:

$$
x[n]=y[n]-0.9 y[n-1]
$$


Tomando a transformada $\mathrm{Z}$ em ambos os lados da Equação 3.31, utilizando a propriedade de deslocamento, e considerando a entrada $x[n]=\mu[n]$ e a condição inicial $y[-1]=2$, obtém a seguinte saída:

$$
\begin{aligned}
& X[z]=Y[z]-0.9\left(y[-1]+z^{-1} Y[z]\right) \\
& X[z]+0.9 y[-1]=\left(1-0.9 z^{-1}\right) Y(z) \\
& Y(z)=\frac{X(z)}{1-0.9 z^{-1}}+\frac{0.9 y[-1]}{1-0.9 z^{-1}}
\end{aligned}
$$

Logo $Y(z)$ é representado pela soma de dois termos, um que depende da entrada e outro que depende da condição inicial. O termo dependente da entrada representa a resposta forçada do sistema. $\mathrm{O}$ termo dependente da condição inicial representa a resposta natural do sistema.

Fazendo $x(z)=1 /\left(1-z^{-1}\right)$ e $y[-1]=2$;

$$
Y(z)=\frac{1}{\left(1-0.9 z^{-1}\right)\left(1-0.9 z^{-1}\right)}+\frac{1.8}{1-0.9 z^{-1}}
$$

Expandindo em frações parciais obtém-se:

$$
Y(z)=\frac{-9}{1-0.9 z^{-1}}+\frac{10}{1-z^{-1}}+\frac{1.8}{1-0.9 z^{-1}}
$$

Tomando a transformada $\mathrm{Z}$ inversa:

$$
y[n]=-9(0.9)^{n} \mu[n]+10 \mu[n]+1.8(0.9)^{n} \mu[n]
$$

\subsubsection{Filtros Digitais}

Filtro digital é um dos grandes campos de aplicação de Processamento Digital de Sinal [Young, 1985]. Enquanto filtros analógicos operam com sinais contínuos e são tipicamente implementados com componentes discretos, ou seja, amplificadores, resistores e capacitores, os filtros digitais são algoritmos matemáticos implementados em hardware ou software que operam sobre um sinal discreto no tempo para produzir um sinal de saída desejado.

Os filtros digitais freqüentemente operam sobre sinais analógicos digitalizados. Logo sua implementação envolve o uso do conversor ADC (Analog to Digital Converter) que captura o sinal de entrada analógico amostrado periodicamente, convertendo-o numa série de amostras digitais, e envia o resultado para o conversor DAC (Digital to Analog Converter). Este converte o sinal de saída filtrado em valores analógicos que são então 
filtrados de uma forma analógica para suavizar e remover componentes indesejáveis de alta freqüência.

Os filtros digitais quando comparados com os analógicos são preferidos em muitas aplicações tais como compressão de dados, processamento de sinais biomédicos, processamento de imagens, transmissão de dados, áudio digital e cancelamento no eco do telefone. Esta preferência ocorre devido às vantagens oferecidas por estes filtros digitais. Estes podem oferecer uma resposta de fase linear exata, possuem uma maior acurácia; seu desempenho varia muito pouco com a mudança do meio, logo possuem menos sensibilidade à temperatura, o que elimina a necessidade de uma calibragem periódica; a freqüência dos filtros pode ser modificada quando são implementados num processador programável; diversos sinais podem ser filtrados por um único filtro sem a necessidade de replicar o hardware; os filtros digitais também podem ser utilizados em freqüências muito baixas e podem ser elaborados para trabalhar sobre um intervalo grande de freqüências por uma simples mudança nas freqüências amostradas.

\subsubsection{Filtros com Resposta Impulsional Finita (FIR)}

Um filtro FIR é aquele cujas respostas aos impulsos são de duração finita. Os filtros FIR são considerados ineficientes caso o sistema requeira uma função de transferência de ordem alta, quando comparada à ordem requerida por filtros digitais com resposta ao impulso de duração infinita. Entretanto os filtros FIR possuem vantagens quanto à possibilidade de terem fase linear exata na implementação, e de serem intrinsecamente estáveis quando realizados de forma não-recursiva.

Um sistema é dito estável quando uma entrada limitada em amplitude corresponde sempre a uma saída também limitada em amplitude. Sabe-se também que para um sistema causal estável a região de convergência da transformada $\mathrm{Z}$ à resposta impulsional tem que incluir a circunferência unitária [Porat, 1997].

Pode-se demonstrar que a condição necessária e suficiente de estabilidade é:

$$
\sum_{k=-\infty}^{\infty}|x(n)|<\infty
$$

Este resultado implica que $X(z)$ converge sobre a circunferência unitária, logo a transformada de Fourier de um sinal no tempo discreto existe. 
Logo, para o filtro FIR, uma nova amostra de saída $y(n)$ deve ser gerada a cada $n$ amostras de entrada. Portanto, para realizar o processamento necessário à implementação do filtro utiliza-se o processador DSP da família TMS320C6x que é projetado para realizar uma operação de multiplicação/acumulação a cada ciclo, leitura de operandos, e escrita na memória de dados. Isto acontece uma vez que o DSP em questão contempla as operações de multiplicação e adição em paralelo (MAC), acesso múltiplo à memória, possue registradores para armazenar dados temporários de instrução, gera de forma eficiente endereços para manipulação dos arrays, e possue características especiais como delays e modo de endereçamento circular.

Sabe-se que filtros não recursivos são caracterizados por uma equação de diferenças da forma:

$$
y(n)=b_{0} x(n)+b_{1} x(n-1)+\ldots+b_{L-1}(n-N+1)=\sum_{k=0}^{N-1} b_{k} x(n-k)
$$

Verifica-se desta forma que a convolução discreta, equação (3.27), quando constituída por termos finitos é bastante utilizada em projetos de filtros FIR.

$$
y(n)=\sum_{k=0}^{N-1} h(k) x(n-k)
$$

Os coeficientes $b_{k}$ se relacionam diretamente com as respostas ao impulso do sistema, $\operatorname{logo} b_{k}=h(k)$. A transformada $\mathrm{Z}$ da equação acima, considerando as condições iniciais nulas, é descrita como:

$$
Y(z)=h(0) X(z)+h(1) z^{-1} X(z)+h(2) z^{-2} X(z)+\ldots+h(N-1) z^{-(N-1)} X(z)
$$

Esta equação apresenta a multiplicação no domínio da frequiência entre os coeficientes e a amostra do sinal de entrada.

$$
Y(z)=H(z) X(z)
$$

Onde $H(z)=Z T[h(k)]$ é a função de transferência, ou seja, a relação entre a entrada e a saída [Orfanidis, 1996].

$$
H(z)=\frac{Y(z)}{X(z)}
$$

Logo,

$$
\begin{aligned}
H(z) & =\sum_{k=0}^{N-1} h(k) z^{-k}=h(0)+h(1) z^{-1}+h(2) z^{-2}+\ldots+h(N-1) z^{-(N-1)} \\
& =\frac{h(0) z^{(N-1)}+h(1) z^{(N-2)}+h(2) z^{(N-3)}+\ldots+h(N-1)}{z^{(N-1)}}
\end{aligned}
$$


Verifica-se que a equação de transferência possui N-1 pólos os quais estão localizados na origem, desta forma dentro da área de convergência, ou seja, dentro da circunferência de raio unitário. Logo, o filtro é considerável estável.

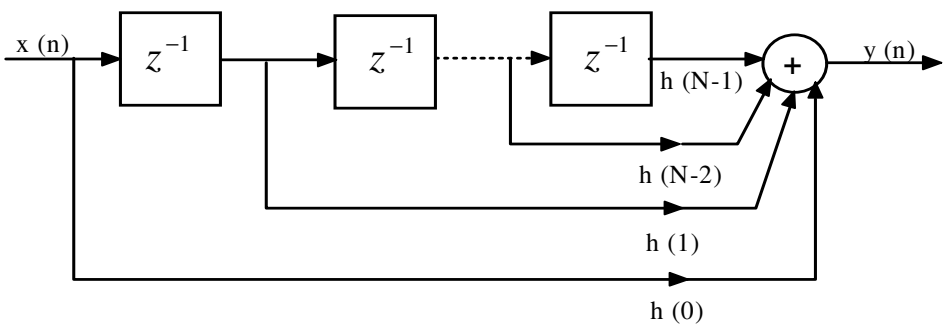

Figura 3.2.6.1 - Forma direta para os filtros digitais FIR.

O projeto de filtros FIR por meio de séries de Fourier é tal que a resposta em magnitude da função de transferência $H(z)$ é uma aproximação da resposta em magnitude desejada, uma vez que o comportamento de um filtro é melhor caracterizado por sua resposta em freqüência $H\left(e^{j w}\right)$. A função de transferência desejada é:

$$
H_{d}(\omega)=\sum_{n=-\infty}^{\infty} C_{n} e^{j n \omega T}|\mathrm{n}|<\infty
$$

Onde $C_{n}$ são os coeficientes da série de Fourier. Considerando $v=f / F_{N}$, onde $F_{N}$ corresponde à freqüência de $N y q u i s t$, ou seja, $F_{N}=F_{S} / 2$, e substituindo na equação acima, tem-se:

$$
H_{d}(v)=\sum_{n=-\infty}^{\infty} C_{n} e^{j n \pi v}
$$

Onde $\omega T=2 \pi f / F_{s}=\pi \nu$ e $|v|<1$. Os coeficientes de Fourier $C_{n}$ são definidos como:

$$
\begin{aligned}
& C_{n}=\frac{1}{2} \int_{-1}^{1} H_{d}(v) e^{-j n \pi v} d v \\
& =\frac{1}{2} \int_{-1}^{1} H_{d}(v)(\cos n \pi v-j \sin n \pi v) d v
\end{aligned}
$$

Considerando que $H_{d}(v)$ é uma função par, a Equação 3.45 fica reduzida a,

$$
C_{n}=\int_{0}^{1} H_{d}(v) \cos n \pi v d v, \mathrm{n} \geq 0,
$$


Logo $H_{d}(v) \sin n \pi v$ é uma função impar, ou seja, $\int_{-1}^{1} H_{d}(v) \sin n \pi v d v=0$. $\operatorname{Assim} C_{n}=C_{-n}$.

A Figura 3.2.6.2 representa idealmente as funções de transferência desejadas para os filtros seletores em freqüência: passa-baixas, passa-altas, passa-faixa, rejeita-faixa, de maneira que seus respectivos coeficientes $C_{n}$ são definidos por:

- Filtro passa-baixa ideal é determinado por $C_{0}=v_{1}$ e,

$$
C_{n}=\int_{0}^{1} H_{d}(v) \cos n \pi v d v=\frac{\sin n \pi v_{1}}{n \pi}
$$

- Filtro passa-alta ideal é determinado por $C_{0}=1-v_{1}$ e,

$$
C_{n}=\sum_{v_{1}}^{1} H_{d}(v) \cos n \pi v=-\frac{\sin n \pi \nu_{1}}{n \pi}
$$

- Filtro passa-faixa ideal é determinado por $C_{0}=v_{2}-v_{1} \mathrm{e}$,

$$
C_{n}=\int_{v_{1}}^{v_{2}} H_{d}(v) \cos n \pi v d v=\frac{\sin n \pi v_{2}-\sin n \pi v_{1}}{n \pi}
$$

- Filtro rejeita-faixa ideal é determinado por $C_{0}=1-\left(v_{2}-v_{1}\right)$ e,

$$
C_{n}=\int_{0}^{v_{1}} H_{d}(v) \cos n \pi v d v+\int_{v_{2}}^{1} H_{d}(v) \cos n \pi v d v=\frac{\sin n \pi v_{2}-\sin n \pi v_{1}}{n \pi}
$$

As freqüências de corte de cada filtro são determinadas pelos coeficientes $v_{1}$ e $v_{2}$.

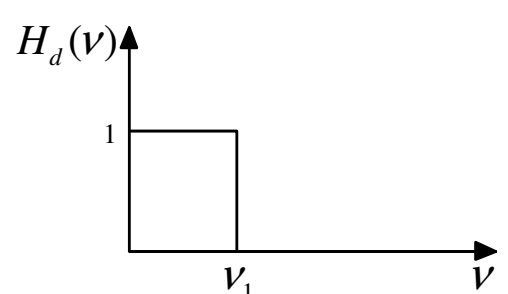

(a)

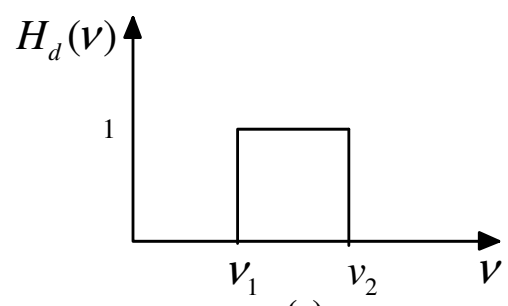

(c)

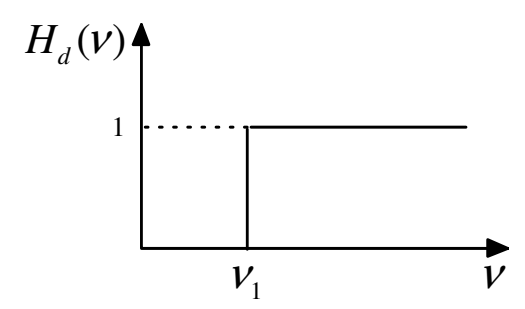

(b)

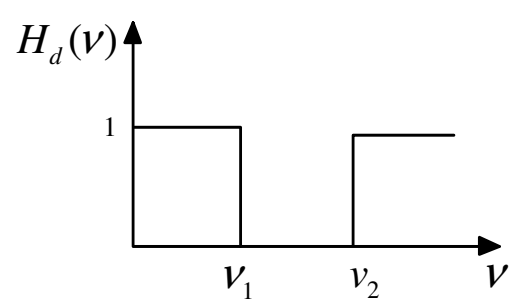

(d)

Figura 3.2.6.2 - Função transferência desejada: (a) passa-baixas; (b) passa-altas; (c) passa-faixa; (d) rejeita-faixa. 
Verifica-se que todos os filtros apresentados anteriormente possuem uma duração infinita, levando a filtros não-realizáveis. Um filtro causal de duração finita pode ser obtido truncando-se a resposta impulsiva de duração infinita $C_{n}$, isto é multiplicando-a por uma classe de funções do tempo conhecidas como função janela, $a(n)$.

$$
C^{\prime}(n)=C(n) a(n)
$$

E, posteriormente, tornando-a causal através da multiplicação da mesma por um fator de atraso.

Sabe-se que a lenta convergência da série de Fourier $C_{n}$ particularmente perto dos pontos de descontinuidade acarreta na introdução de ondulações, ou oscilações de Gibbs. Apesar do aumento do número dos coeficientes $C_{n}$ diminuir a amplitude das oscilações que encontram-se fora dos pontos de descontinuidades, este aumento não interfere nas outras amplitudes que permanecem inalteradas. Entretanto através da multiplicação no domínio do tempo, o que implica numa convolução no domínio da frequiência, entre os coeficientes e uma função janela finita, Equação 3.52, tal que sua transformada de Fourier tenha baixos níveis em seus lóbulos secundários com respeito ao pico do lóbulo principal, implica na redução da descontinuidade verificada anteriormente. Logo somente uma função janela adequada pode diminuir as ondulações. As funções janelas podem ser do tipo Retangulares, de Hanning, de Hamming, de Blackman e de Kaiser.

Caso a função janela utilizada seja a retangular, tem-se:

$$
a_{R}(n)= \begin{cases}1, & \text { para }|\mathrm{n}| \leq Q \\ 0, & \text { caso contrario }\end{cases}
$$

O truncamento da série infinita, equação (3.44), e uma janela retangular é:

$$
H_{a}(v)=\sum_{n=-Q}^{Q} C_{n} e^{j n \pi v}
$$

Onde $Q$ é positivo, finito e determina a ordem do filtro. Quanto maior o valor de $Q$, maior a ordem do filtro e melhor a aproximação da função de transferência desejada.

Substituindo na equação $e^{j \pi v}=z$ tem-se:

$$
H_{a}(z)=\sum_{n=-Q}^{Q} C_{n} z^{n}
$$

Ao introduzir uma amostra atrasada na equação anterior, obtém-se: 


$$
H_{a}(z)=z^{-Q} H_{a}(z)=\sum_{n=-Q}^{Q} C_{n} z^{n-Q}
$$

Se $n-Q=-i$ :

$$
H(z)=\sum_{i=0}^{2 Q} C_{Q-i} z^{-i}
$$

Fazendo $h_{i}=C_{Q-i}$ e $N-1=2 Q$ então:

$$
H(z)=\sum_{i=0}^{N-1} h_{i} z^{-i}
$$

Assim $H(z)$ é expressa em termos de coeficientes de respostas impulsionais $h_{i}$, e $h_{0}=C_{Q}, h_{1}=C_{Q-1}, \ldots, h_{Q}=C_{0}, h_{Q+1}=C_{-1}=C_{1}, \ldots, h_{2 Q}=C_{-Q}$.

Os coeficientes são simétricos com respeito a $h_{Q}, \operatorname{com} C_{n}=C_{-n}$.

A ordem do filtro é dada por $N=2 Q+1$. Por exemplo, se $Q=5$, o filtro terá 11 coeficientes,

$$
\begin{aligned}
& h_{0}=h_{10}=C_{5} \\
& h_{1}=h_{9}=C_{4} \\
& h_{2}=h_{8}=C_{3} \\
& h_{3}=h_{7}=C_{2} \\
& h_{4}=h_{5}=C_{1} \\
& h_{5}=C_{0}
\end{aligned}
$$

Por exemplo, vamos calcular os coeficientes de um filtro FIR passa-baixas de ordem, $N=11$, com freqüência de amostragem $F_{s}=10 \mathrm{kHz}$ e freqüência de corte $f_{c}=1 \mathrm{kHz}$.

Anteriormente foi definido $F_{N}$ como,

$$
F_{N}=F_{S} / 2 \text {. }
$$

Logo,

$$
F_{N}=10 / 2=5 \mathrm{kHz} .
$$

Considerando $v=f / F_{N}$, pode-se calcular $C_{0}$,

$$
C_{0}=v_{1}=\frac{f_{c}}{F_{N}}=\frac{1}{5}=0.2
$$

Os outros coeficientes podem ser calculados por meio da Equação 3.47,

$$
C_{n}=\frac{\sin 0.2 \pi n}{n \pi}, n= \pm 1, \pm 2, \ldots, \pm 5 .
$$




\subsection{EXEMPLOS DE FILTROS COM RESPOSTAS IMPULSIONAL FINITA (FIR)}

Três exemplos utilizando a equação discreta de convolução (Equação 3.48) serão desenvolvidos para ilustrar a implementação de filtros FIR.

$$
y(n)=\sum_{k=0}^{N-1} h(k) x(n-k)
$$

No CCS os coeficientes são organizados dentro do buffer (array), onde o primeiro coeficiente, $h(0)$, está no começo (na primeira localização) do buffer, endereço de memória mais baixo. O último coeficiente, $h(N-1)$, encontra-se na última localização do buffer, endereço de memória mais alto. As amostras atrasadas são organizadas na memória de modo que as amostras mais novas, $x(n)$, encontram-se no começo do buffer de amostras, enquanto as amostras antigas, $x(n-(N-1))$, estão localizadas no final do buffer. Inicialmente todas as amostras são setadas para zero.

\begin{tabular}{ccc}
\multicolumn{3}{c}{ Tabela 3.3.1 - Coeficientes e amostras } \\
\hline $\mathbf{i}$ & Coeficientes & Amostras \\
\hline $\mathbf{0}$ & $h(0)$ & $x(n)$ \\
$\mathbf{1}$ & $h(1)$ & $x(n-1)$ \\
$\mathbf{2}$ & $h(2)$ & $x(n-2)$ \\
$\cdot \boldsymbol{*}$ & $\cdot$ & $\cdot$ \\
$\cdot$ & $\cdot$ & $\cdot$ \\
$\cdot$ & $\cdot$ & $\cdot$ \\
$N-1$ & $h(N-1)$ & $x(n-(N-1))$ \\
\hline
\end{tabular}

No tempo $n$ a amostra mais nova que é adquirida após a geração de uma representação digital do sinal, ou seja, após a passagem do sinal pelo conversor $\mathrm{AD}$, é armazenada no começo do buffer de amostras. A saída do filtro no tempo $n$ é computado na equação de convolução, ou seja:

$$
y(n)=h(0) x(n)+h(1) x(n-1)+\ldots+h(N-2) x(n-(N-2))+h(N-1) x(n-(N-1))
$$

As amostras com atraso são então atualizadas, $\log 0 x(n-k)=x(n+1-k)$ podendo ser calculado a saída da unidade de tempo seguinte, $y(n+1)$, ou o período de amostragem 
$T_{S}$. Todas as amostras são armazenadas, exceto a amostra mais nova. Por exemplo, $x(n-1)=x(n)$, e $x(n-(N-1))=x(n-(N-2))$. Este processo de armazenamento tem o efeito de mover para baixo os dados na memória como pode ser observado na tabela abaixo:

Tabela 3.3.2 - Coeficientes e amostras

\begin{tabular}{cccc}
\hline $\mathbf{i}$ & Tempo $n$ & Tempo $n+1$ & Tempo $n+2$ \\
\hline $\mathbf{0}$ & $x(n)$ & $x(n+1)$ & $x(n+2)$ \\
$\mathbf{1}$ & $x(n-1)$ & $x(n)$ & $x(n+1)$ \\
$\mathbf{2}$ & $x(n-2)$ & $x(n-1)$ & $x(n)$ \\
$\boldsymbol{\cdot}$ & $\cdot$ & $\cdot$ & $\cdot$ \\
$\cdot$ & $\cdot$ & $\cdot$ & $\cdot$ \\
$\cdot$ & $\cdot$ & $\cdot$ & $\cdot$ \\
$N-3$ & $x(n-(N-3))$ & $x(n-(N-4))$ & $x(n-(N-5))$ \\
$N-2$ & $x(n-(N-2))$ & $x(n-(N-3))$ & $x(n-(N-4))$ \\
$N-1$ & $x(n-(N-1))$ & $x(n-(N-2))$ & $x(n-(N-3))$ \\
\hline
\end{tabular}

Verifica-se que no tempo $n+1$, a nova amostra $x(n+1)$ é adquirida e armazenada no topo do buffer de amostra, neste caso a saída $y(n+1)$ pode ser calculada como:

$$
y(n+1)=h(0) x(n+1)+h(1) x(n)+\ldots+h(N-2) x(n-(N-3))+h(N-1) x(n-(N-2))
$$

As amostras são, então, atualizadas para a unidade de tempo seguinte.

No tempo $n+2$, a nova amostra de entrada, $x(n+2)$, é adquirida. A saída seria:

$$
y(n+2)=h(0) x(n+2)+h(1) x(n+1)+\ldots+h(N-1) x(n-(N-3))
$$

Este processo continua a calcular a saída do filtro e a atualizar amostras atrasadas em cada unidade de tempo. 


\subsubsection{Exemplo 1: Filtro Rejeita-Faixa}

Esse exemplo analisa as características respectivas do filtro FIR do tipo rejeitafaixa através da implementação do código fir.c e da utilização de alguns recursos do CCS.

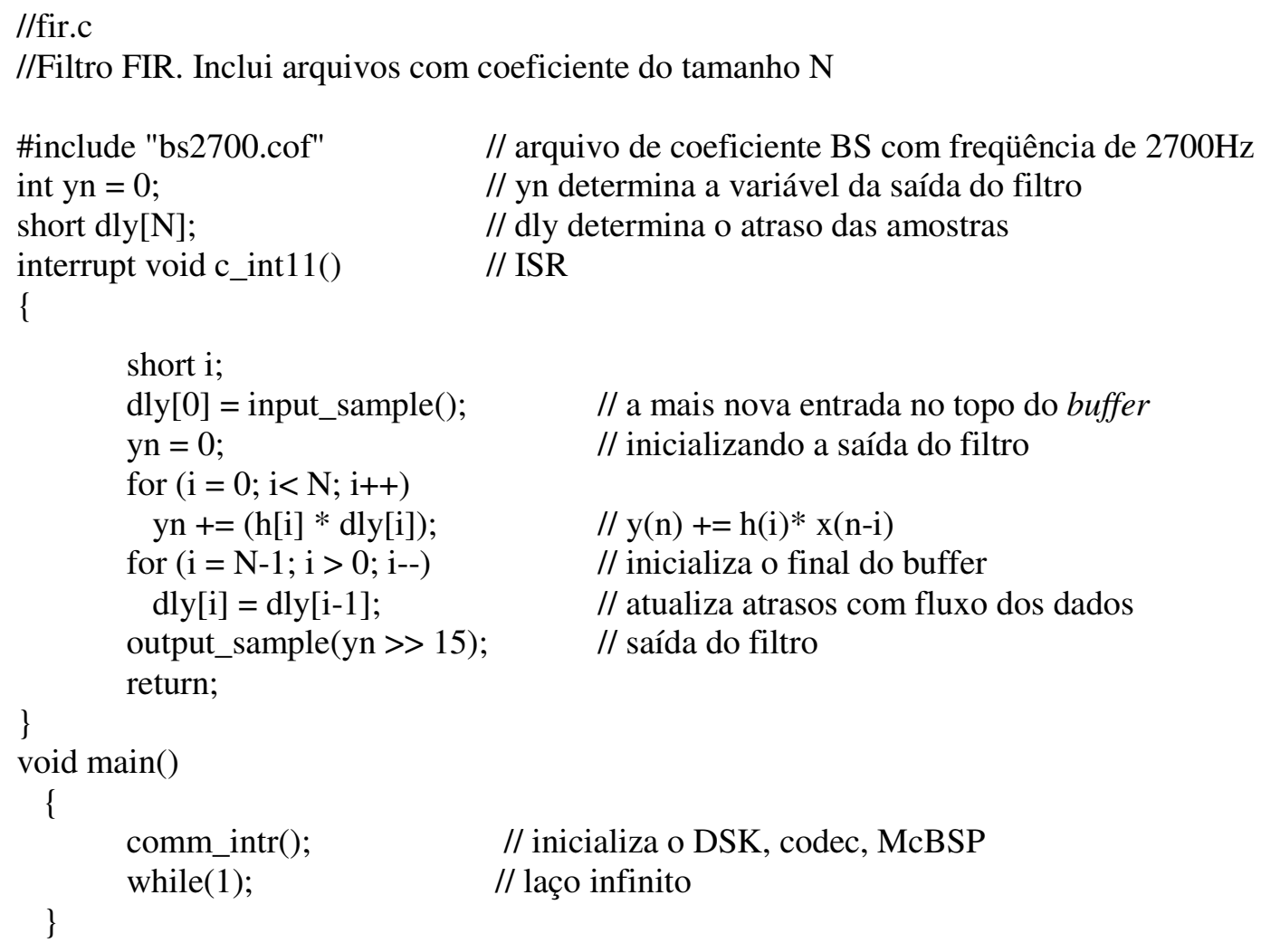

//bs2700.cof coeficientes do filtro FIR rejeita- faixa

\#define N 89 // número de coeficientes

short h[N]=\{-14,23,-9,-6,0,8,16,-58,50,44,-147,119,67,-245, $200,72,-312,257,53,-299,239,20,-165,88,0,105$, $-236,33,490,-740,158,932,-1380,392,1348,-2070$, $724,1650,-2690,1104,1776,-3122,1458,1704,29491$, $1704,1458,-3122,1776,1104,-2690,1650,724,-2070$, $1348,392,-1380,932,158,-740,490,33,-236,105,0$, $88,-165,20,239,-299,53,257,-312,72,200,-245,67$, $119,-147,44,50,-58,16,8,0,-6,-9,23,-14\}$;

\section{Considerações sobre o programa}

$\mathrm{O}$ arquivo bs2700.cof incluso no código fir.c especifica as características que contêm os coeficientes do filtro FIR rejeita-faixa centrado em $2700 \mathrm{~Hz}$. 
O buffer $d l y[N]$, apresentado no código fir.c, é criado para as amostras atrasadas. A mais nova amostra de entrada, $x(n)$, é adquirida através de dly[0] e armazenada no começo do buffer. Os coeficientes são armazenados em outro buffer, $h[N]$, com $h[0]$ no começo do buffer dos coeficientes. As amostras e os coeficientes são organizados nos seus respectivos buffers, como foi apresentado anteriormente nas Tabelas 3.3.1 e 3.3.2.

No código fir.c pode-se observar a utilização de dois loops dentro da rotina de interrupção. O primeiro loop implementa a equação de convolução com $N$ coeficientes e $N$ amostras atrasadas, num tempo $n$ especifico. Neste tempo $n$ a saída é:

$$
y(n)=h(0) x(n)+h(1) x(n-1)+\ldots+h(N-2) x(n-(N-2))+h(N-1) x(n-(N-1))
$$

As amostras atrasadas são atualizadas dentro do segundo loop para que sejam utilizadas no cálculo de $y(n)$, no tempo de $n+1$, ou $y(n+1)$. Sabe-se que a amostra de entrada mais recentemente adquirida, neste exemplo, sempre se encontra no começo do buffer de amostras. Assim a posição de memória que antes tinha a amostra $x(n)$ agora contém a amostra mais recentemente adquirida $x(n+1)$ e conseqüientemente a saída $y(n+1)$, no tempo de $n+1$.

\section{Criação do projeto}

Para criar este projeto no Code Composer Studio ${ }^{\mathrm{TM}}$ IDE, é preciso adicionar os arquivos necessários à construção do projeto Fir, como fora feito nos exemplos anteriores.

1. Crie o arquivo denominado fir.pjt clicando em Project $\rightarrow$ File

2. Selecione Project $\rightarrow$ Add Files to Project no CCS. Abra a pasta Fir do CD que acompanha o presente trabalho, e adicione ao projeto os dois arquivos ".c", fir.c e c6xdskinit.c.

3. Novamente, selecione Project $\rightarrow$ Add Files to Project. Abra a pasta Fir e adicione o arquivo do tipo assembly, vectors_11.asm.

4. Repita o passo 3 e adicione o arquivo $c 6 x d s k . c m d$.

5. Repita o passo 3 e adicione na pasta Libraries do projeto o arquivo rts6700.lib. 
6. Carregue na pasta Includes do projeto os arquivos de cabeçalho. Ou seja, clique em Project $\rightarrow$ Scan All File Dependecies e observe a adição dos seguintes arquivos; bs2700.cof, c6x.h, c6xdsk.h, c6xdskinit. e c6xinterrupts.h.

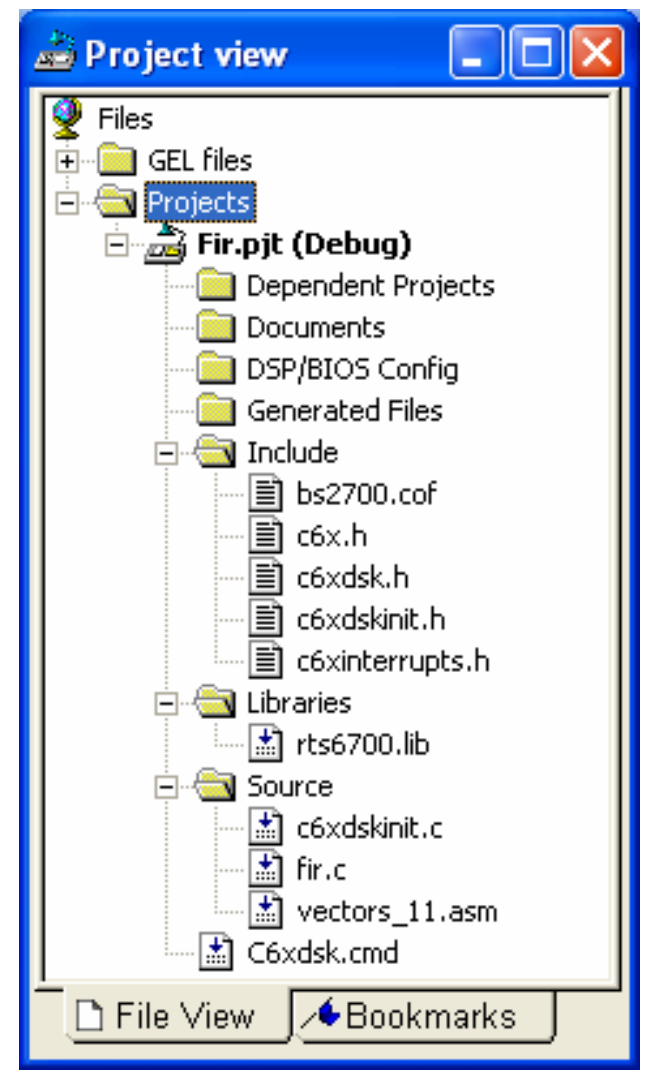

Figura 3.3.1.1 - Visualização do projeto.

\section{Configuração do compilador e do linker}

Em seguida é necessário configurar os parâmetros do compilador e do linker:

1. Clique em Project $\rightarrow$ Build Options.

2. Na janela Build Options $\rightarrow$ Compiler.

3. Na lista Category $\rightarrow$ Basic.

4. Em Basic escolha as seguintes opções:

a. Target Version $\rightarrow$ Default.

b. Generate Debug Info $\rightarrow$ Full Symbolic Debug (-g).

c. Opt Speed vs Size $\rightarrow$ Speed Most Critical (no ms).

d. Opt Level $\rightarrow$ None. 


\section{e. Program Level Opt $\rightarrow$ None.}

Verifique na janela Buil Options a seleção dos parâmetros $-g-k-s$.

5. Clique em Linker na janela Build Options

6. Na lista Category $\rightarrow$ Basic.

7. Em Basic ajuste as seguintes opções:

f. Habilite Suppress Banner (-q).

g. Habilite Exhaustively Reas Libraries (-x)

h. Em Otput Filename (-o) coloque o nome do arquivo de saída, ou seja, fir.out.

i. $\quad$ Em Autoint Model selecione Run-Time Autoinitialization (-c).

8. Clique em Ok e feche a janela Build Options

\section{Geração do executável e carregamento do programa}

1. Selecione Project $\rightarrow$ Build, para que o projeto possa ser construído.

2. Carregue o executável através do comando File $\rightarrow$ Load Program, selecionando o arquivo fir.out.

3. Faça o debug do programa através de Debug $\rightarrow$ Run.

\section{Construção gráfica no $C C S$}

Para construir os gráficos no domínio do tempo e da frequiência é necessário que você:

1. Selecione View $\rightarrow$ Graph $\rightarrow$ Time/Frequency. Ao abrir Graph Property Dialog faça as seguintes modificações:

- Start Adress $\rightarrow h$, como pode ser verificado no código fir.c.

- Acquisition Buffer Size $\rightarrow$ 89, representando o tamanho do buffer.

- DisplayData Size $\rightarrow 128$.

- DSP Data Size $\rightarrow$ 16-bit signed integer.

- $\quad$ Sampling Rate $(\mathrm{Hz}) \rightarrow 8000$. 


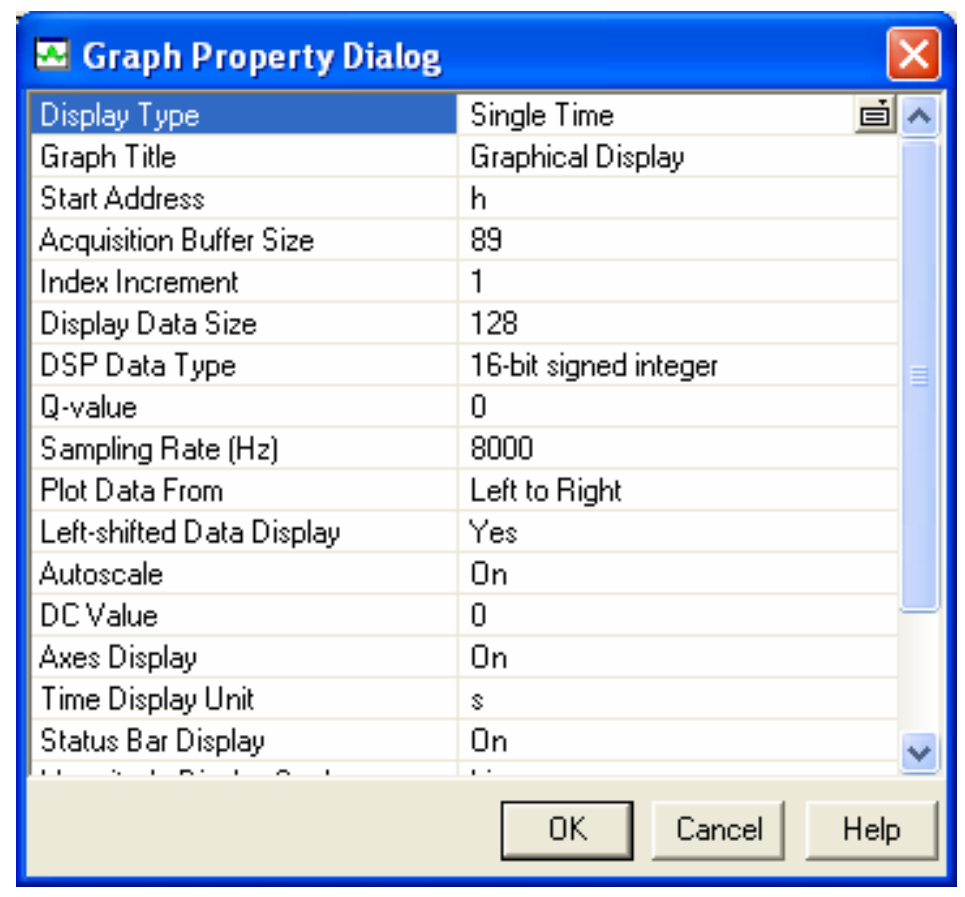

Figura 3.3.1.2 - Janela Graph Property Dialog com modificações.

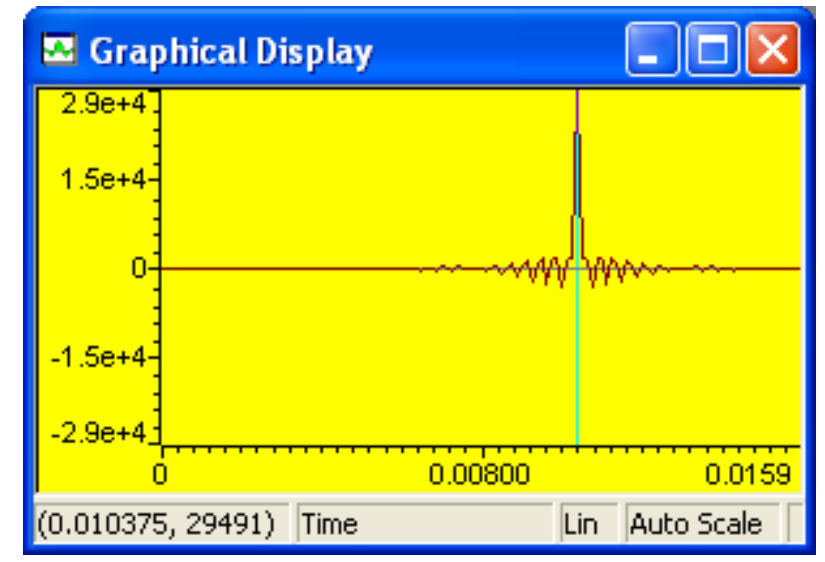

Figura 3.3.1.3 - Resposta impulsional.

Para o domínio da freqüência se devem modificar algumas características na janela Graph Property Dialog. Logo:

2. Selecione View $\rightarrow$ Graph $\rightarrow$ Time/Frequency. Ao abrir Graph Property Dialog faça as seguintes modificações:

- Selecione em DisplayType $\rightarrow$ FFT Magnitude.

- $\quad$ FFT Framesize $\rightarrow 89$. 


\begin{tabular}{|c|c|c|c|c|}
\hline \multicolumn{3}{|c|}{ \# Graph Property Dialog } & & $\times$ \\
\hline Display Type & \multicolumn{2}{|c|}{ FFT Magnitude } & 百 & $\bar{\wedge}$ \\
\hline Graph Title & \multicolumn{4}{|c|}{ Graphical Display } \\
\hline Signal Type & \multicolumn{4}{|l|}{ Real } \\
\hline Start Address & \multicolumn{4}{|l|}{$\mathrm{h}$} \\
\hline Acquisition Buffer Size & \multicolumn{4}{|l|}{89} \\
\hline Index Increment & \multicolumn{4}{|l|}{1} \\
\hline FFT Framesize & \multicolumn{4}{|l|}{89} \\
\hline FFT Order & \multicolumn{4}{|l|}{8} \\
\hline FFT Windowing Function & \multicolumn{4}{|l|}{ Rectangle } \\
\hline Display Peak and Hold & \multicolumn{4}{|l|}{ Off } \\
\hline DSP Data Type & \multicolumn{4}{|c|}{ 16-bit signed integer } \\
\hline Q-value & \multicolumn{4}{|l|}{0} \\
\hline Sampling Rate [Hz] & \multicolumn{4}{|l|}{8000} \\
\hline Plot Data From & \multicolumn{4}{|c|}{ Left to Right } \\
\hline Left-shifted Data Display & \multicolumn{4}{|c|}{ Yes } \\
\hline \multirow{2}{*}{ Autoscale } & \multicolumn{3}{|l|}{ On } & $\checkmark$ \\
\hline & OK & Cancel & Help & \\
\hline
\end{tabular}

Figura 3.3.1.4 - Janela Graph Property Dialog com modificações para a FFT.

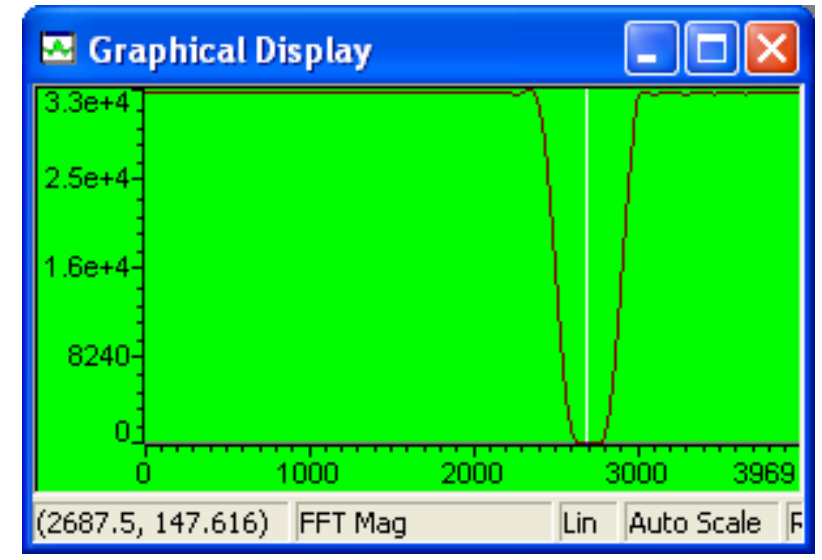

Figura 3.3.1.5 - FFT do filtro rejeita-faixa.

Verifica na Figura 3.3.1.5 que a faixa de rejeição do filtro está centrada em $2700 \mathrm{~Hz}$.

\section{Projeto utilizando o MATLAB}

A seguir será explorada a ferramenta de projeto de filtros que o software MATLAB 7.0 disponibiliza.

1. Digite sptool na linha de comando do MALAB; 
2. Ao abrir a janela SPTool:startup.stp selecione Filter $\rightarrow$ Firbp (design) $\rightarrow$ New.

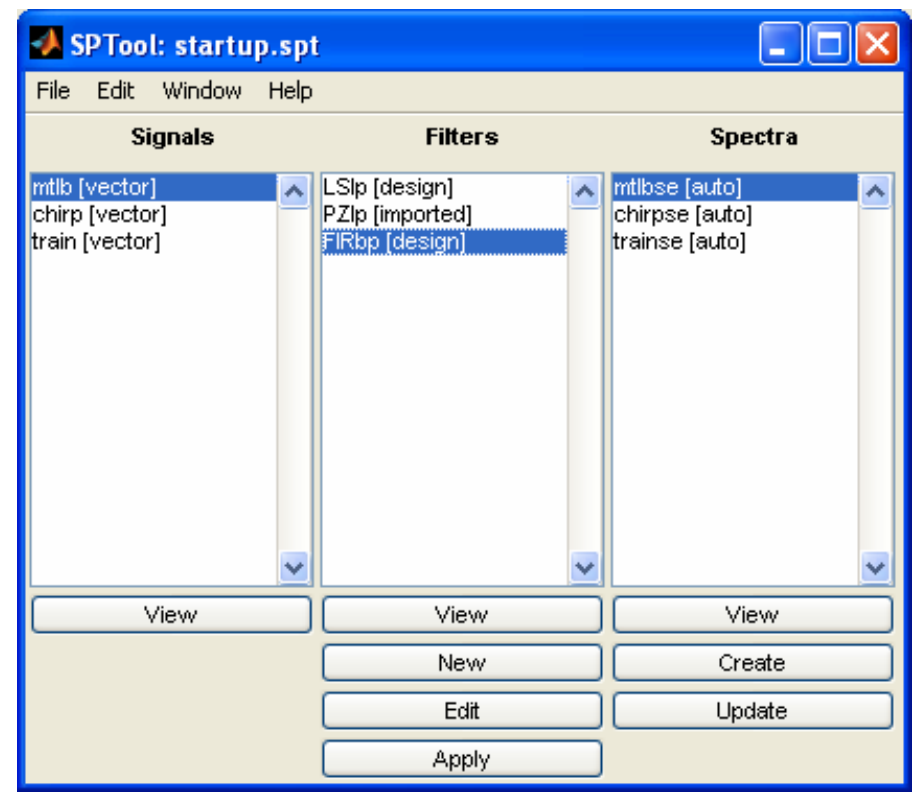

Figura 3.3.1.6 - Janela SPTool:startup.stp.

3. Na janela Filter Designer determine as características necessárias para o filtro FIR rejeita-faixa, como pode ser verificado na Figura (3.3.1.6).

- Sampling frequency $\rightarrow 8000$.

- Algorithm $\rightarrow$ Kaiser Window FIR.

- Order $\rightarrow$ 88. Observe que o Algorithm utilizado é a Kaiser, cujo comprimento é determinado por $N=M+1, \log$ o número de Order é 88 , resultando $N=89$.

- $F c 1 \rightarrow 2500$ e $F c 2 \rightarrow 2900$, determinando a faixa onde existe uma probabilidade do filtro estar centrado.

- Beta $\rightarrow$ 4. O parâmetro $\beta$ é utilizado para controlar tanto a largura do lobo principal quanto a razão entre os lobos principal e secundário.

4. Mude o nome do filtro para $b s 2700$ através dos comandos Edit $\rightarrow$ Name. na janela SPTool:startup.stp. 


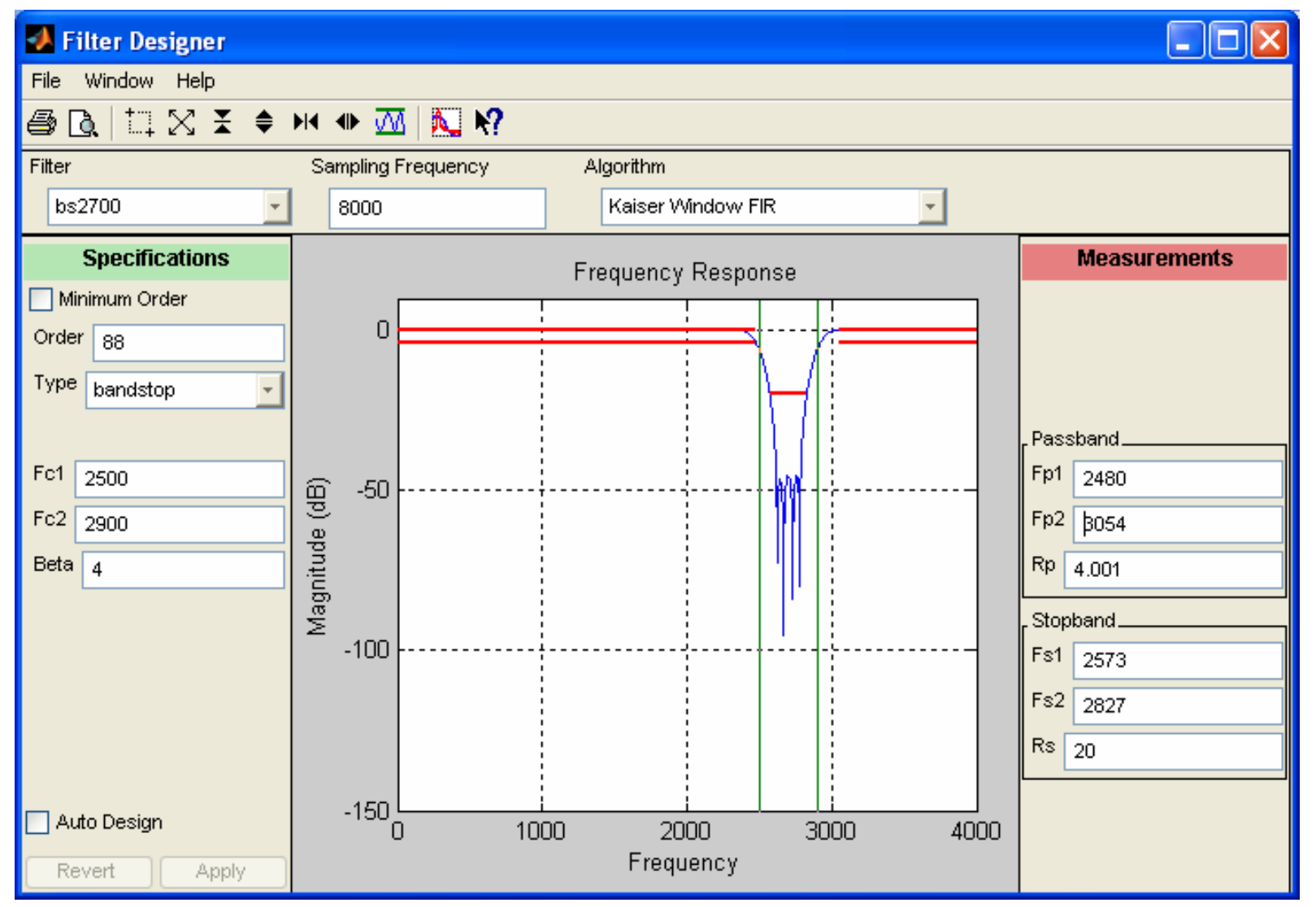

Figura 3.3.1.7 - Características do filtro FIR rejeita-faixa centrado em $2700 \mathrm{~Hz}$.

\section{Selecione File $\rightarrow$ Export $\rightarrow$ Filter:bs 2700 [design] $\rightarrow$ Export to workspace}

6. Com a finalidade de encontrar os coeficientes da função de transferência acesse a área de trabalho do Matlab e escreva os seguintes comandos:

$>$ bs2700.tf.num;

>round (bs2700.tf.num $\left.* 2^{\wedge} 15\right)$

Logo se observa que os coeficientes escalados perto de $2^{15}$ do filtro FIR rejeitafaixa, listados dentro da área de trabalho do Matlab, são os mesmos apresentados no arquivo de coeficientes bs2700.cof.

\section{Resultados Experimentais}

Ao se injetar na entrada da placa DSK, conector IN (J7), um ruído pseudorandômico, gerado a partir do programa que se encontra no anexo I (ruido.m), e implementando o filtro em estudo, obteve-se por meio do Osciloscópio - Agilent 5AG21A, conector OUT (J6), uma resposta em freqüência muito próxima da que fora obtida teoricamente. 


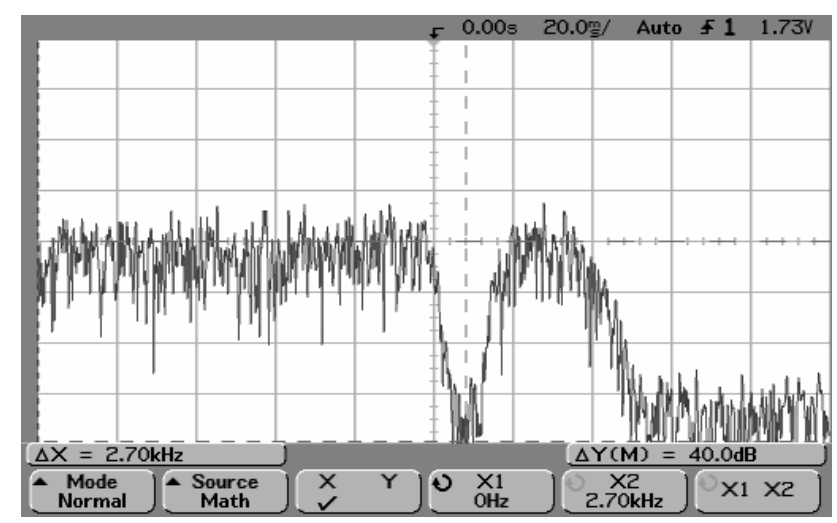

Figura 3.3.1.8 - Resposta em freqüência da saída do filtro FIR rejeita-faixa centrado em $2700 \mathrm{~Hz}$, obtida com um osciloscópio.

O decaimento da magnitude observado a partir da freqüência de aproximadamente $3500 \mathrm{~Hz}$, ocorre por conta do próprio codec do DSK que é um circuito passa-baixa com frequiência de corte de $3500 \mathrm{~Hz}$.

A Figura 3.3.1.9 mostra a resposta do filtro construída a partir de quatorze pontos obtidos experimentalmente com o auxílio do osciloscópio. Foi utilizado o método de interpolação PCHIP (Piecewise Cubic Hermite Interpolating Polynomial). O código fonte gerador da resposta em frequiência observada na Figura 3.3.1.9, implementado na ferramenta MATLAB 7.0, encontra-se no anexo I.

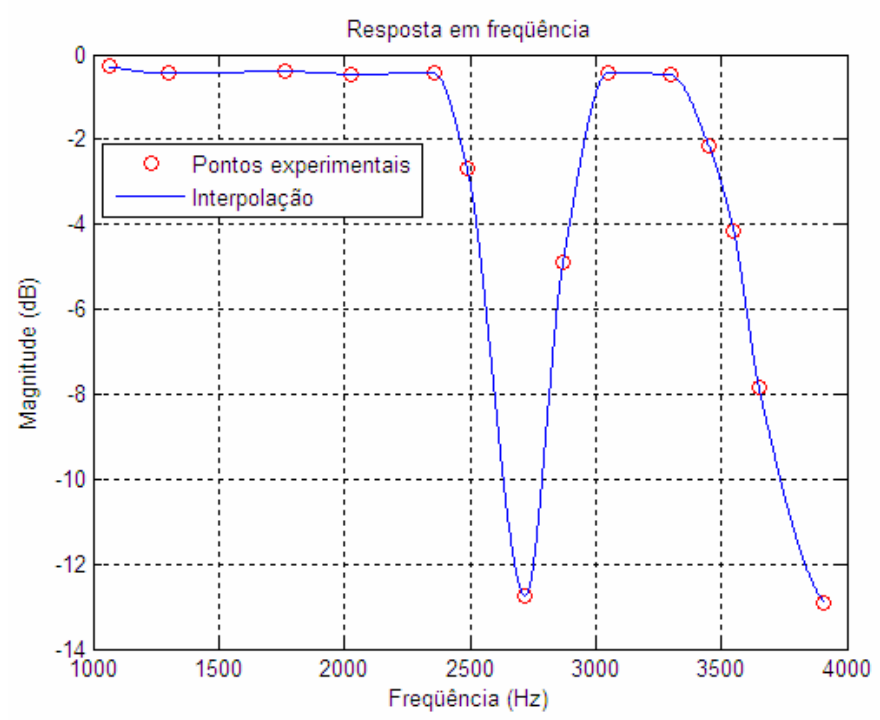

Figura 3.3.1.9 - Resposta em freqüência da saída do filtro FIR rejeita-faixa centrado em $2700 \mathrm{~Hz}$, obtido por meio da interpolação. 


\subsubsection{Exemplo 2: Filtro Passa-Faixa}

Esse exemplo analisa as características do filtro FIR passa-faixa a partir da modificação do arquivo dos coeficientes incluso no código fir.c. Logo troca-se bs2700.cof por bp1750.cof como pode ser verificado abaixo.
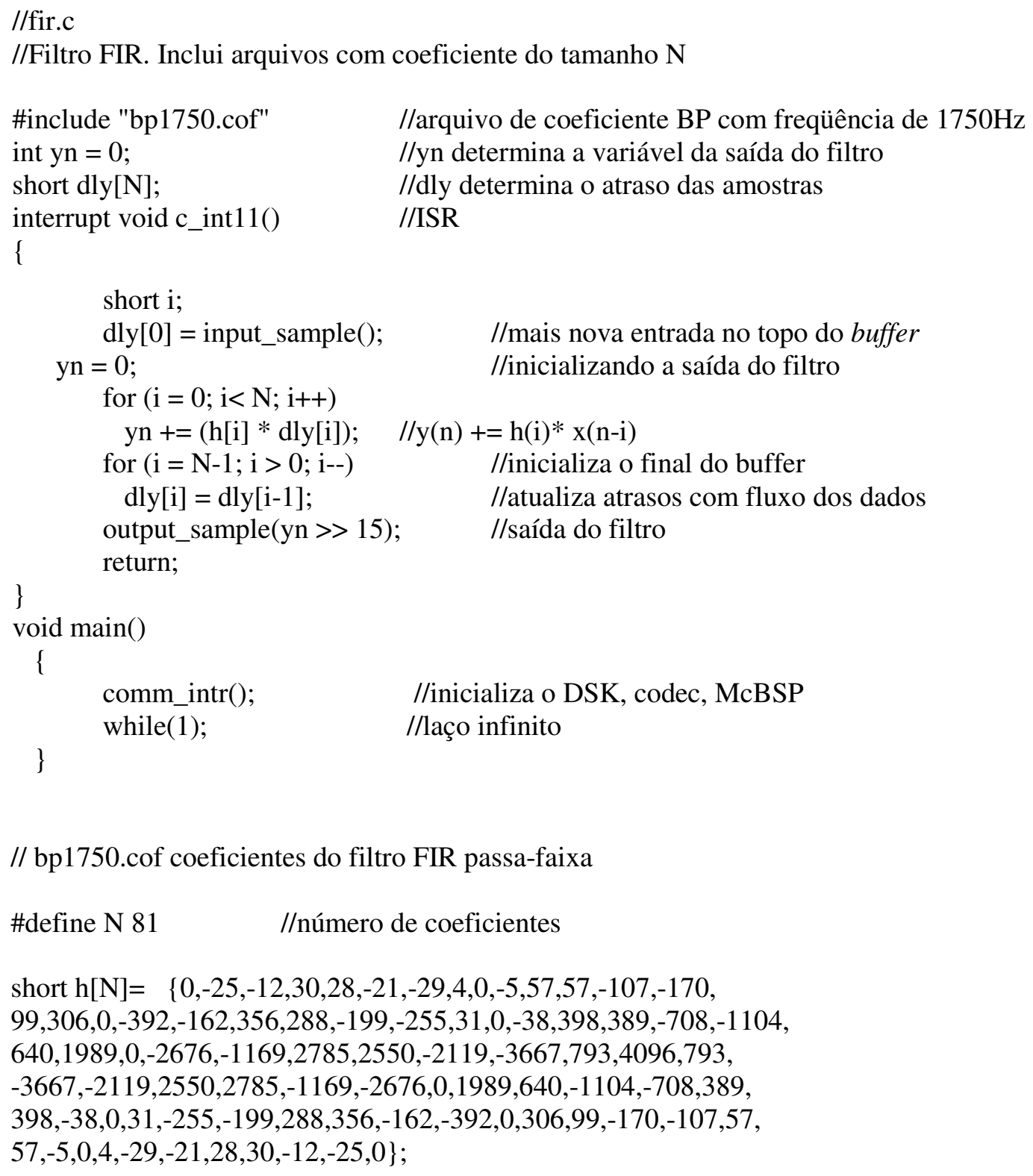

$\mathrm{O}$ arquivo bp1750.cof especifica as características do filtro FIR, onde a quantidade de coeficientes utilizados é $N=81$, para representar o filtro passa-faixa, centrado em $1750 \mathrm{~Hz}$. 


\section{Criação do projeto}

Após a modificação proposta no código fir.c, cria-se o projeto como pode ser visto na Figura 3.3.2.1.

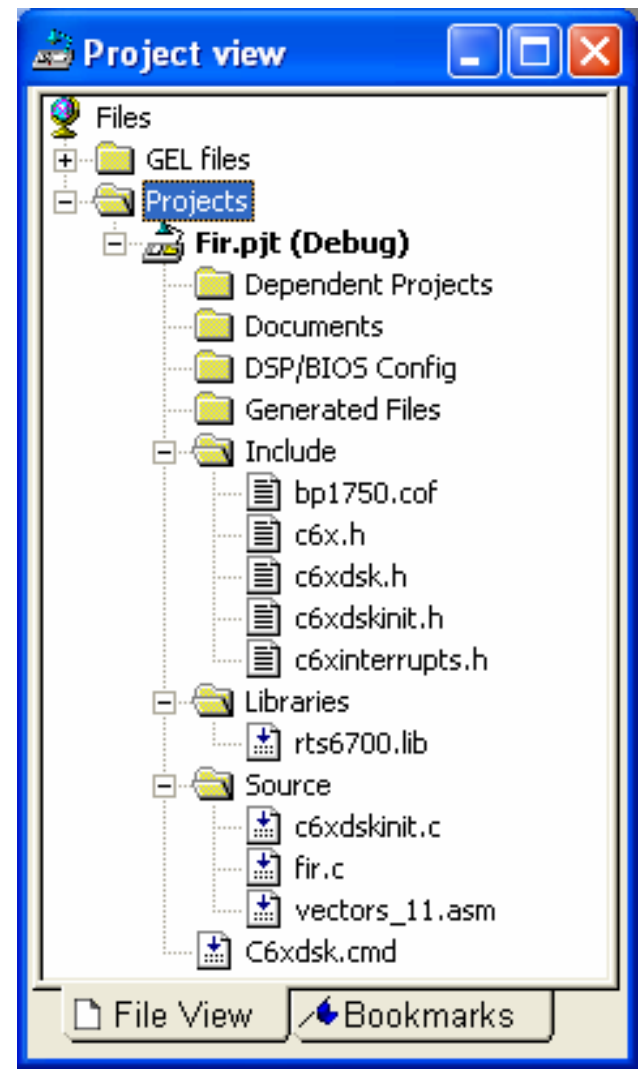

Figura 3.3.2.1 - Visualização do projeto

Para gerar o executável e carregar o programa utilizam-se as mesmas configurações dos parâmetros do compilador e do linker do exemplo anterior.

\section{Construção gráfica no $C C S$}

Para construir os gráficos no domínio do tempo e da frequiência é necessário que você:

1. Selecione View $\rightarrow$ Graph $\rightarrow$ Time/Frequency.

- $\quad$ Start Adress $\rightarrow h$

- Acquisition Buffer Size $\rightarrow 81$.

- DisplayData Size $\rightarrow 128$. 
- DSP Data Size $\rightarrow$ 16-bit signed integer.

- $\quad$ Sampling Rate $(\mathrm{Hz}) \rightarrow 8000$.

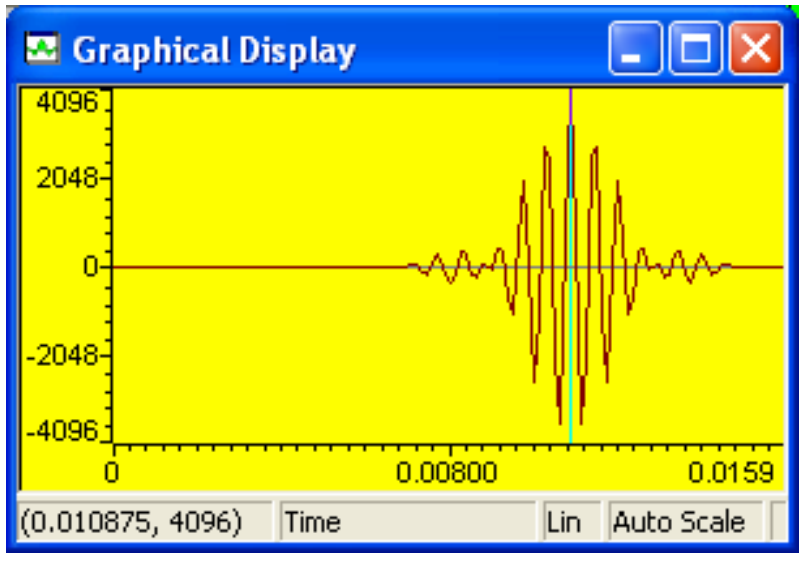

Figura 3.3.2.2 - Resposta impulsional.

Para o domínio da freqüência devem-se modificar algumas características na janela Graph Property Dialog. Logo:

2. Selecione View $\rightarrow$ Graph $\rightarrow$ Time/Frequency.

- Selecione em DisplayType $\rightarrow$ FFT Magnitude.

- $\quad$ FFT Framesize $\rightarrow 81$.

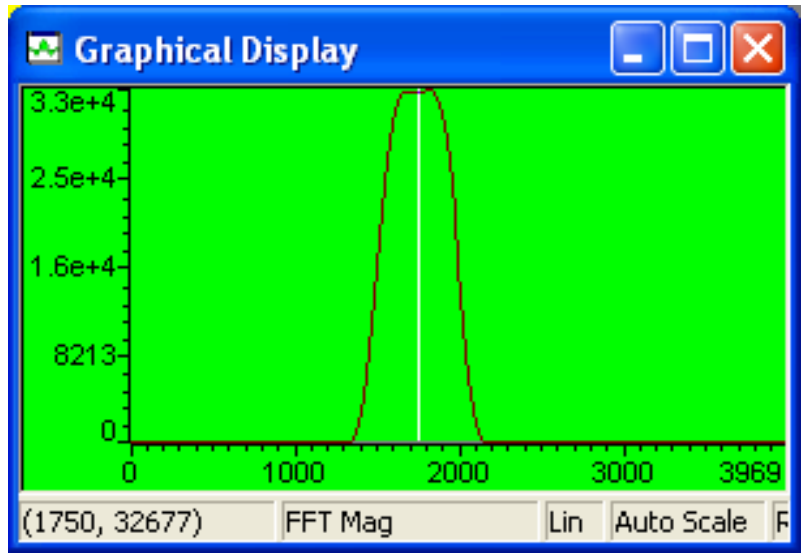

Figura 3.3.2.3 - FFT do filtro passa-faixa centrado em $1750 \mathrm{~Hz}$. 


\section{Projeto utilizando o MATLAB}

Utilize a ferramenta sptool, como no exemplo anterior, e determine as seguintes características do filtro FIR passa-faixa na janela Filter Designer:

- Sampling frequency $\rightarrow 8000$.

- Algorithm $\rightarrow$ Kaiser Window FIR.

- Order $\rightarrow 80$.

- $F c 1 \rightarrow 1500$ e $F c 2 \rightarrow 2000$, determinando a faixa onde existe uma probabilidade do filtro estar centrado.

- Beta $\rightarrow 5$.

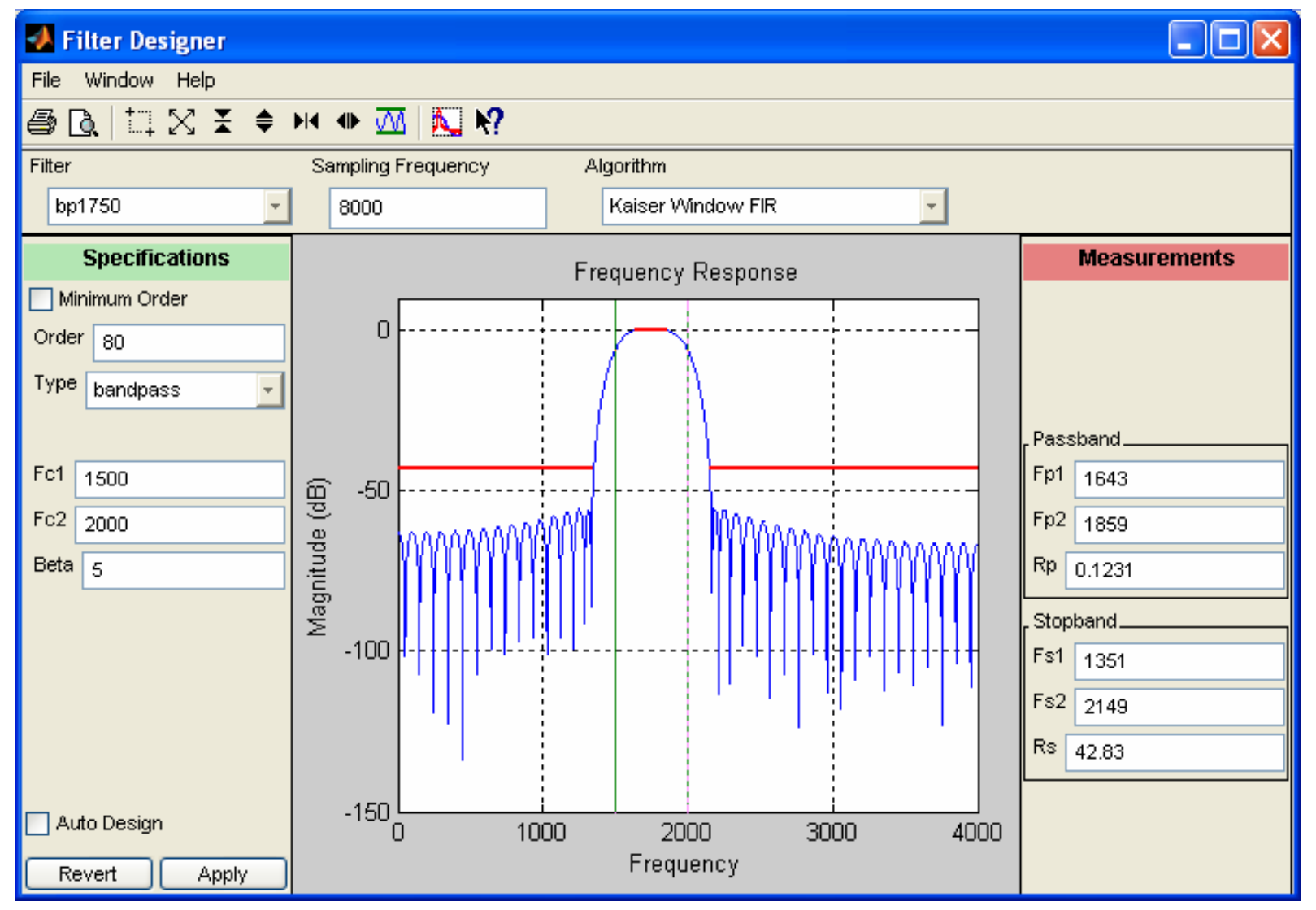

Figura 3.3.2.4 - Características do filtro FIR passa-faixa centrado em $1750 \mathrm{~Hz}$. 
Exporte o arquivo Filter:bp1750 [design] para a área de trabalho do MATLAB e verifique no mesmo, através dos comandos abaixo, a obtenção dos coeficientes contidos no arquivo bp1750.cof.

> bp1750.tf.num;

>round (bp1750.tf.num $\left.* 2^{\wedge} 15\right)$

\section{Resultados Experimentais}

Ao se injetar na entrada do $D S K$, conector IN (J7), o mesmo ruído pseudorandômico, ruído.m, utilizado no exemplo anterior, obteve-se com o auxílio do Osciloscópio - Agilent 5AG21A, que se encontra conectado com a saída da placa DSK, conector OUT (J6), uma resposta em freqüência, Figura 3.3.2.5, próxima à obtida teoricamente para o filtro FIR passa-faixa centrada em $1750 \mathrm{~Hz}$, Figura 3.3.2.6, que é implementado através da ferramenta do MATLAB 7.0, e o seu código fonte encontra-se no Anexo I.

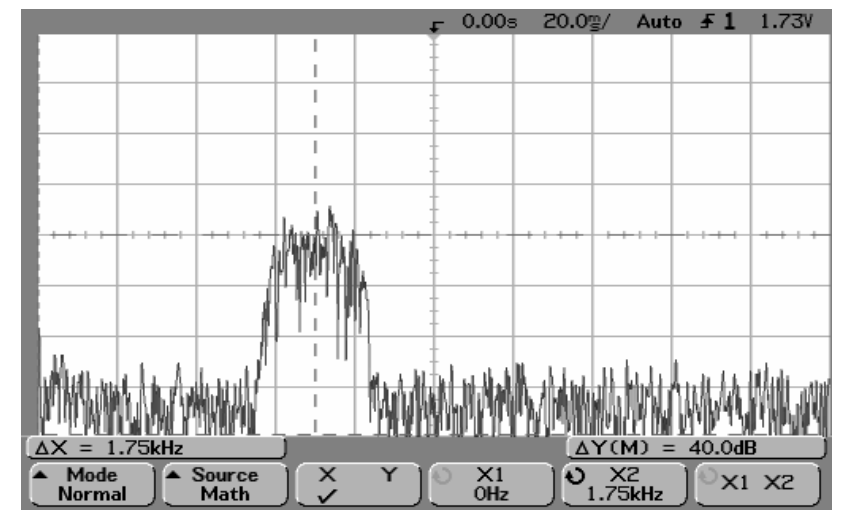

Figura 3.3.2.5 - Resposta em freqüência da saída do filtro FIR passa-faixa centrado em $1750 \mathrm{~Hz}$, obtido com um osciloscópio. 


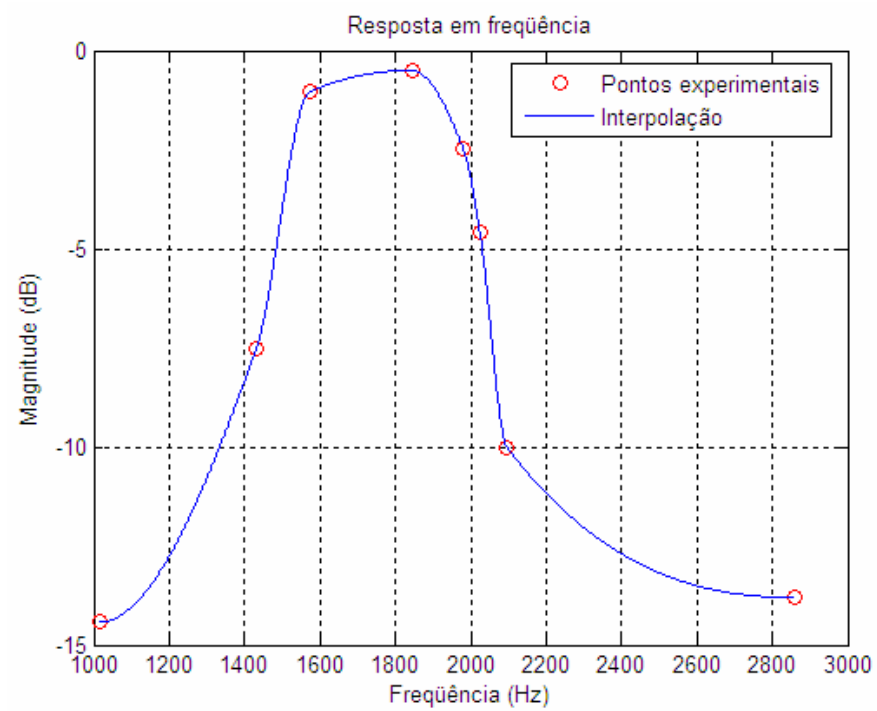

Figura 3.3.2.6 - Resposta em freqüência da saída do filtro FIR passa-faixa centrado em $1750 \mathrm{~Hz}$, obtido por meio da interpolação.

\subsubsection{Exemplo 3: Implementação de dois filtros FIR rejeita-faixa para a recuperação de uma entrada de voz corrompida.}

Esse exemplo analisa o funcionamento simultâneo de dois filtros FIR rejeita-faixa que recuperam uma entrada de voz que inicialmente está corrompida, através da implementação do código Notch2.c e da utilização de alguns recursos do CCS.

//Notch2.c

//Implementação de dois filtros FIR do tipo rejeita-faixa para a remoção dos ruídos.

\#include "BS900.cof"

\#include "BS2700.cof"

short dly $1[N]=\{0\}$; short dly $2[\mathrm{~N}]=\{0\}$; int y1out $=0$, y2out $=0$; short out_type $=1$;

interrupt void c_int11()

\{ short i;

$$
\begin{array}{ll}
\text { dly1[0] }=\text { input_sample }() ; & / / \text { mais nova entrada no topo do buffer } \\
\text { y1out }=0 ; & \text { // inicio da saída do primeiro filtro } \\
\text { y2out }=0 ; & / / \text { inicio da saída do segundo filtro } \\
\text { for }(\mathrm{i}=0 ; \mathrm{i}<\mathrm{N} ; \mathrm{i}++) & \\
\text { y1 out }+=\mathrm{h} 900[\mathrm{i}] * \text { dly1[i]; } & / / \mathrm{y} 1(\mathrm{n})+=\mathrm{h} 900(\mathrm{i}) * \mathrm{x}(\mathrm{n}-\mathrm{i})
\end{array}
$$




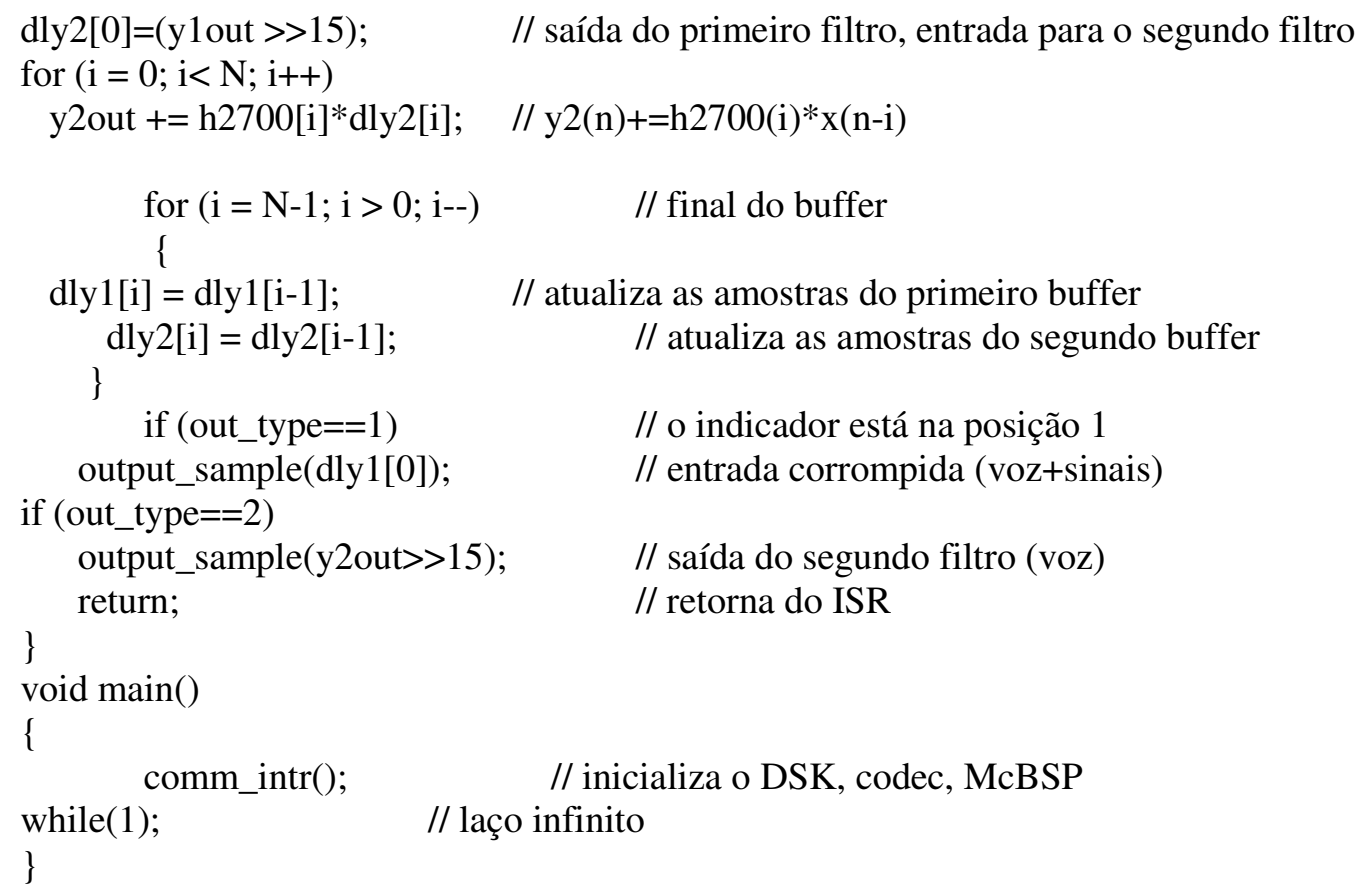

//BS900.cof coeficientes do filtro FIR rejeita- faixa centrado em $900 \mathrm{~Hz}$ \#define N $89 \quad$ // tamanho do filtro

//BS2700.cof coeficientes do filtro FIR rejeita- faixa centrado em $2700 \mathrm{~Hz}$

\#define N 89 // tamanho do filtro

short h2700[N]= $\{5255,-4173,-3204,-4194,27,-845,-2073,1043$, $-403,-1301,1233,-404,-917,1214,-495,-672,1139,-584,-483,1065$, $-660,-330,983,-721,-197,913,-765,-76,835,-810,30,776,-845,124$, $703,-874,222,630,-891,311,559,-904,399,483,31861,483,399,-904$, $559,311,-891,630,222,-874,703,124,-845,776,30,-810,835,-76,-765$, $913,-197,-721,983,-330,-660,1065,-483,-584,1139,-672,-495,1214$, $-917,-404,1233,-1301,-403,1043,-2073,-845,27,-4194,-3204,-4173,5255\}$;

Verifica-se no código Notch2.c que se utiliza um buffer para cada amostra atrasada de cada filtro. A saída do primeiro filtro rejeita-faixa centrado em $900 \mathrm{~Hz}$, torna-se a entrada do segundo filtro rejeita-faixa centrado em $2700 \mathrm{~Hz}$. 


\section{Criação do projeto}

O projeto Notch2.pjt é construído como verificado na figura (3.3.3.1), e depois utilizando as mesmas configurações dos parâmetros do compilador e do linker como fora feito nos exemplos anteriores presente neste tutorial, o executável é gerado e o programa é carregado.

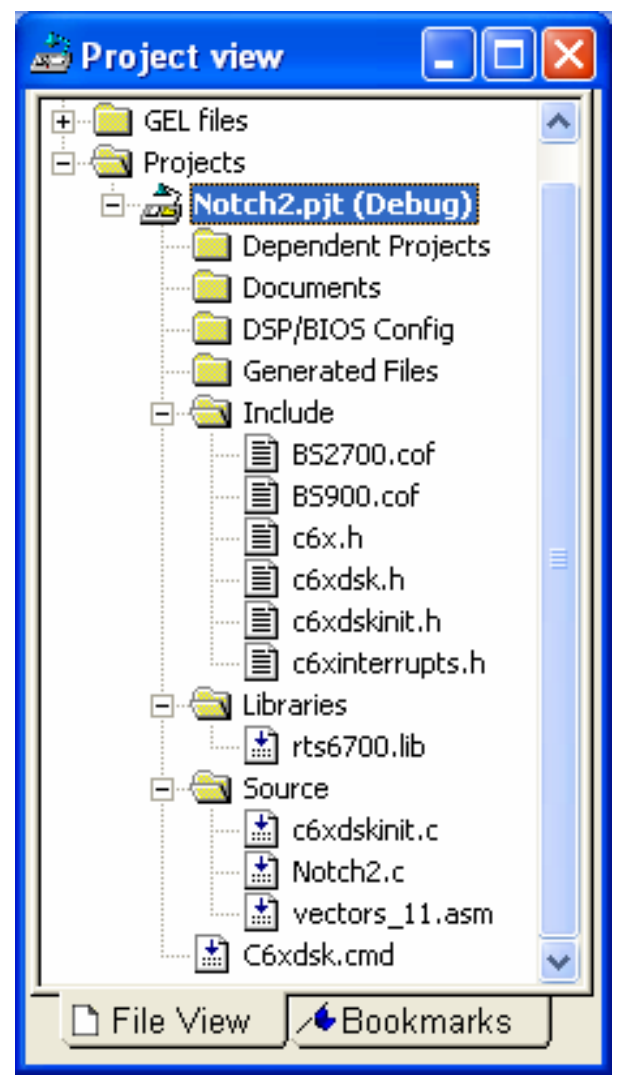

Figura 3.3.3.1 - Visualização do projeto.

\section{Resultados Experimentais}

Após a construção do projeto aplicou-se à entrada $J 7$ do $D S K$ o sinal de voz corrompido, corruptvoice.wav, que se encontra-se no diretório notch2 do $\mathrm{CD}$ que acompanha esse trabalho. 


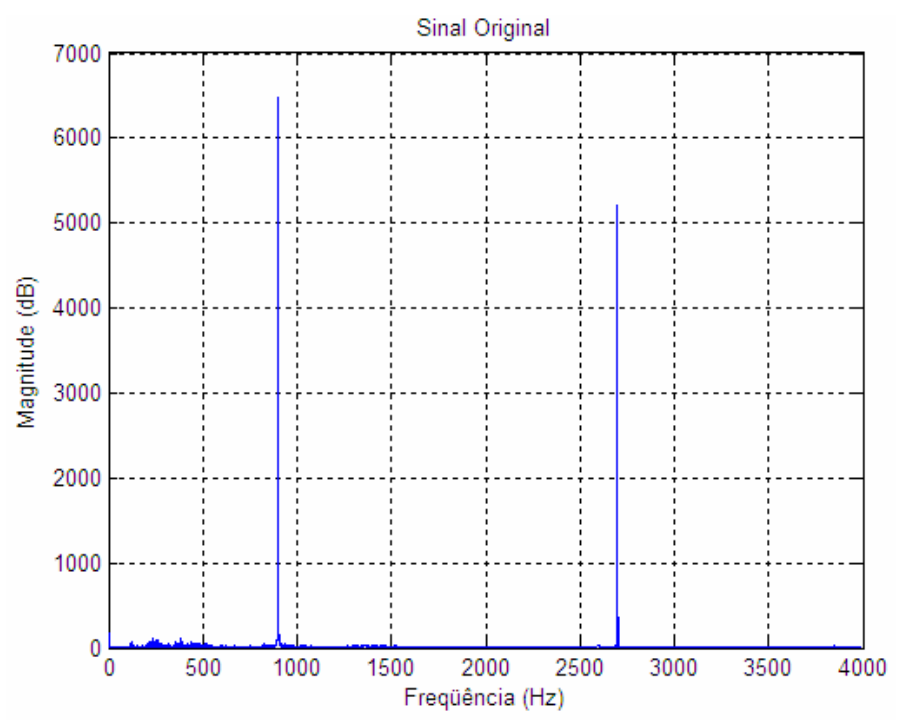

Figura 3.3.3.2 - Espectro do sinal de voz corrompido por dois sinais senoidais centrados em $900 \mathrm{~Hz}$ e $2700 \mathrm{~Hz}$.

O sinal de voz corrompido, Figura 3.3.3.2, cujo código fonte fora implementado na ferramenta MATLAB 7.0, encontra-se no anexo I, apresenta dois sinais senoidais centrados em 900 e $2700 \mathrm{~Hz}$, adicionados ao sinal de voz original. Ao passar por dois filtros rejeita-faixa, cujas freqüências são as mesmas dos ruídos senoidais presentes no sinal corrompido, obtém-se uma saída recuperada que pode ser capturada por meio da saída J6 do DSK.

Ao se aplicar como entrada do filtro o mesmo ruído pseudo-randômico, ruído.m, utilizado nos exemplos anteriores, obteve-se com o auxílio do Osciloscópio - Agilent 5AG21A, uma resposta em freqüência que explicita as faixas de rejeição impostas pelos dois filtros conectados em série (Figura 3.3.3.3).

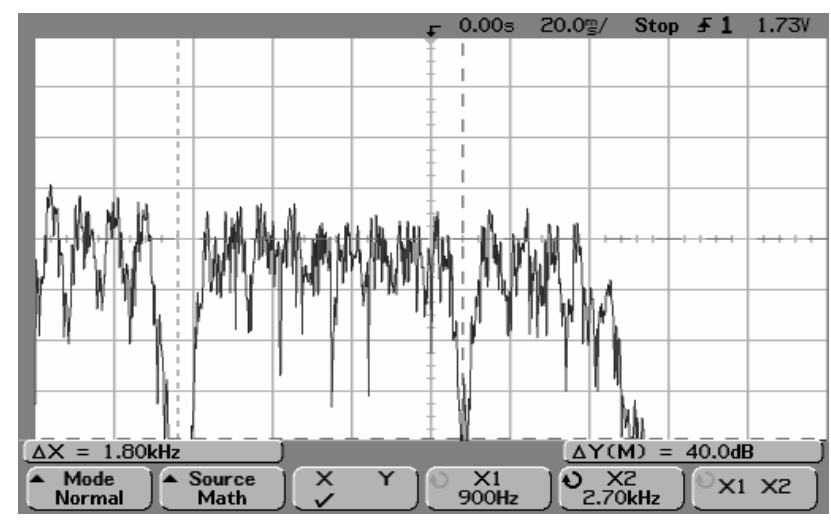

Figura 3.3.3.3 - Resposta em freqüência da saída dos filtros FIR rejeita-faixas em série centrados em $900 \mathrm{~Hz}$ e $27000 \mathrm{~Hz}$, obtida no osciloscópio. 


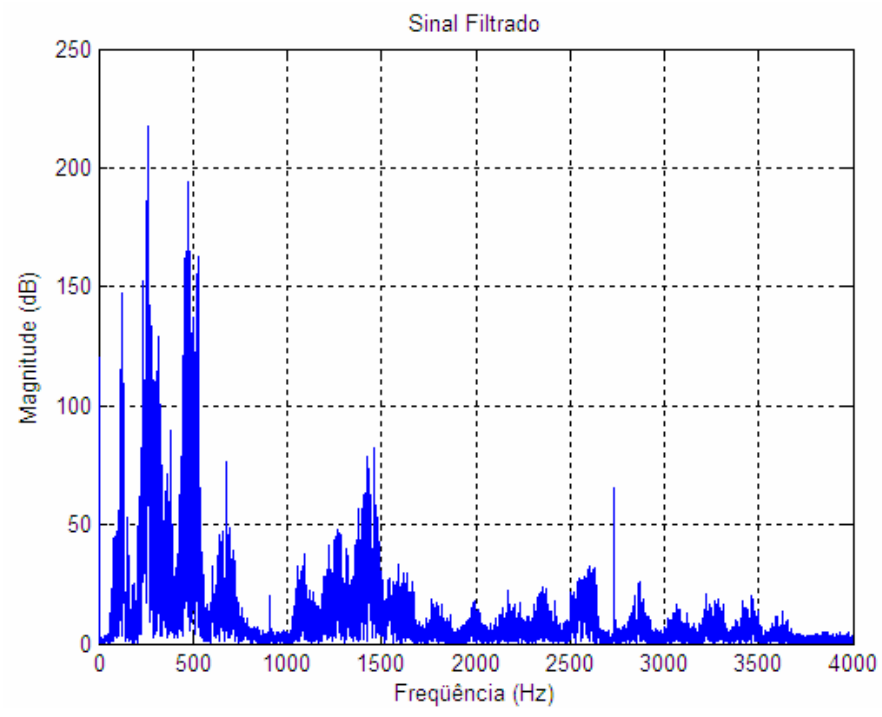

Figura 3.3.3.4 - Resposta em freqüência do sinal recuperado. 


\section{4 - TUTORIAL 3: FILTROS COM RESPOSTA IMPULSIONAL INFINITA (IIR)}

\subsection{OBJETIVO}

- Introdução a estruturas de filtros IIR: forma direta do tipo I, forma direta do tipo II, forma cascata e forma paralela.

- Introdução aos conceitos de transformação bilinear.

- Projeto e implementação de filtros com resposta impulsional infinita (IIR)

- Programação de exemplos usando código C e o TMS320C6711 DSK

Esse tutorial tem por finalidade apresentar os conceitos básicos sobre filtros com resposta impulsional infinita, filtros recursivos. Projetar dois exemplos de filtro IIR a partir da estrutura de forma direta do tipo II em cascata no TMS320C6711 DSK.

\subsection{INTRODUÇÃO}

\subsection{Filtros com Resposta Impulsional Infinita (IIR)}

Um filtro IIR é aquele cujas respostas aos impulsos são de duração infinita. Este tipo de filtro também é conhecido como recursivo, uma vez que a sua saída $y(n)$ depende dos sinais de entrada corrente, e dos sinais de saída passados [Marven \& Ewers, 1996].

$$
\begin{aligned}
y(n) & =b_{0} x(n)+b_{1} x(n-1)+\ldots+b_{L-1}(n-N+1)-a_{1} y(n-1)-\ldots-a_{M} y(n-M) \\
& =\sum_{k=0}^{N-1} b_{k} x(n-k)-\sum_{m=1}^{M} a_{m} y(n-m)
\end{aligned}
$$

A transformada $\mathrm{Z}$ da equação de diferenças do filtro do tipo recursivo, equação (4.1), considerando todas as condições iniciais nulas é representada por:

$$
\begin{aligned}
Y(z)= & b_{0} X(z)+b_{1} z^{-1} X(z)+b_{2} z^{-2} X(z)+\ldots+b_{N-1} z^{-(N-1)} X(z) \\
& -a_{1} z^{-1} Y(z)-a_{2} z^{-2} Y(z)-\ldots-a_{M} z^{-M} Y(z)
\end{aligned}
$$

Assim:

$$
Y(z)=\left(\sum_{k=0}^{N-1} b_{k} z^{-k}\right) X(z)+\left(\sum_{m=1}^{M} a_{m} z^{-m}\right) Y(z)
$$

A função de transferência do filtro recursivo é: 


$$
H(z)=\frac{Y(z)}{X(z)}=\frac{\sum_{k=0}^{N-1} b_{k} z^{-k}}{1+\sum_{m=1}^{M} a_{m} z^{-m}}=\frac{B(z)}{1+A(z)}
$$

A partir da equação (4.4) verifica-se que o filtro do tipo IIR é composto por dois filtros do tipo FIR $A(z)$ e $B(z)$ [Chen \& Sorensen, 1997].

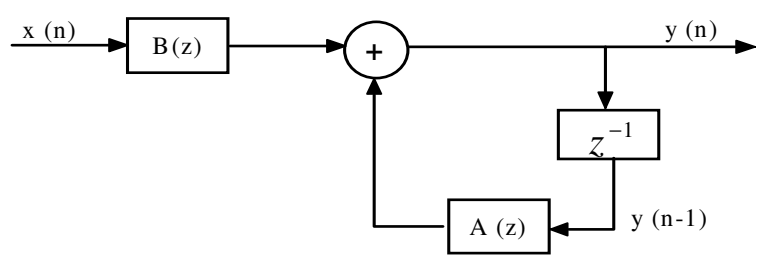

Figura 4.1.1 - Filtro IIR composto por dois filtros FIR.

Considerando $M=N-1$ na equação (4.2) obtém-se:

$$
H(z)=\frac{Y(z)}{X(z)}=\frac{b_{0}+b_{1} z^{-1}+b_{2} z^{-2}+\ldots+b_{M} z^{-M}}{1+a_{1} z^{-1}+a_{2} z^{-2}+\ldots+a_{M} z^{-M}}=\frac{N(z)}{D(z)}
$$

Multiplicando o numerador e o denominador por $z^{M}, H(z)$ torna-se:

$$
H(z)=\frac{Y(z)}{X(z)}=\frac{b_{0} z^{M}+b_{1} z^{M-1}+b_{2} z^{M-2}+\ldots+b_{M}}{z^{M}+a_{1} z^{M-1}+a_{2} z^{M-2}+\ldots+a_{M}}=C \prod_{i=1}^{M} \frac{z-z_{i}}{z-p_{i}}
$$

A função de transferência, equação (4.6), possui $M$ zeros e $M$ pólos. Caso todos os coeficientes $a_{i}$ sejam nulos a função de transferência será composta apenas por $M$ pólos na origem do plano $z$ representando um filtro FIR que é não-recursivo. O filtro IIR é considerado estável quando os seus pólos encontram-se dentro do circulo unitário.

Existem várias estruturas que representam um filtro do tipo IIR, dentre elas estão a forma direta do tipo I, forma direta do tipo II, forma cascata, e forma paralela.

A Figura 4.1.2 representa um filtro IIR na forma direta do tipo I, obtida a partir da equação (4.2). 


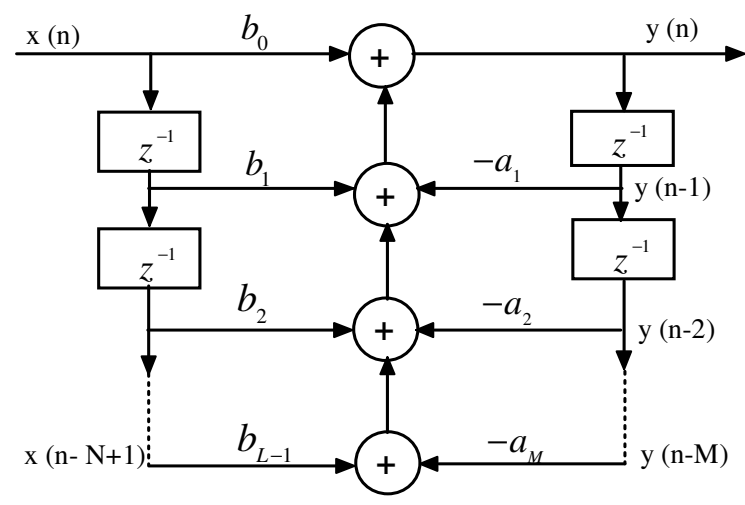

Figura 4.1.2 - Forma direta do Tipo I do filtro IIR.

Este tipo de filtro pode ser interpretado como a cascata de duas funções de transferência onde $H_{1}(z)=N(z)$ e $H_{2}(z)=\frac{1}{D(z)}$, assim:

$$
H(z)=H_{1}(z) H_{2}(z)
$$

O que representa um filtro de ordem $N$ com $2 N$ elementos atrasados, representados por $z^{-1}$. Caso o filtro utilizado seja de segunda ordem com $N=2$, o qual possui 4 elementos atrasados, onde, $H_{1}(z)=b_{0}+b_{1}(z)+b_{2}(z)$ e $H_{1}(z)=b_{0}+b_{1} z^{-1}+b_{2} z^{-2}$ e $H_{2}(z)=1 /\left(1+a_{1} z^{-1}+a_{2} z^{-2}\right)$, obtém-se:

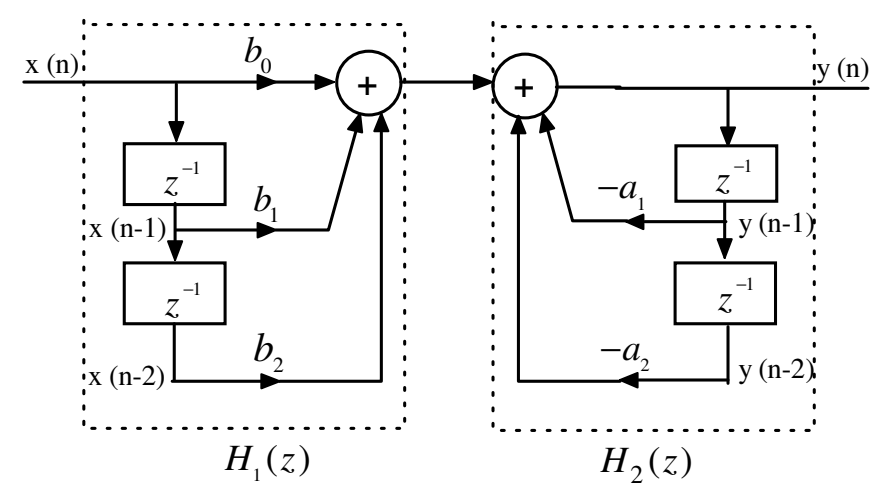

Figura 4.1.3 - Forma direta do Tipo I de segunda ordem.

Como a equação (4.7) é comutativa então a Figura 4.1.3 pode ser representada como: 


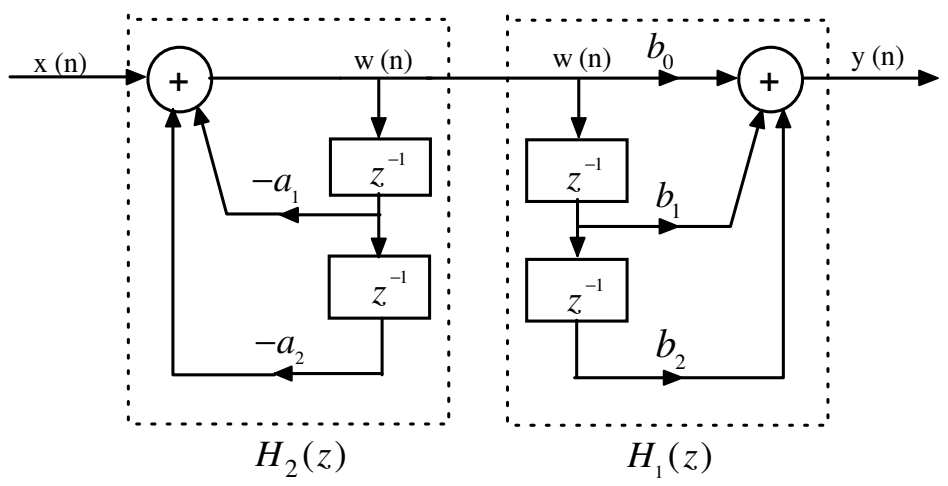

Figura 4.1.4 - Forma direta do Tipo I de segunda ordem $H(z)=H_{2}(z) H_{1}(z)$.

A existência do sinal intermediário $w(n)$, comum entre ambos os sinais de buffers $H_{1}(z)$ e $H_{2}(z)$, elimina a necessidade da utilização de dois buffers separados. Logo, eles podem ser combinados em um, e compartilhado por ambos os filtros, como pode ser verificado abaixo:

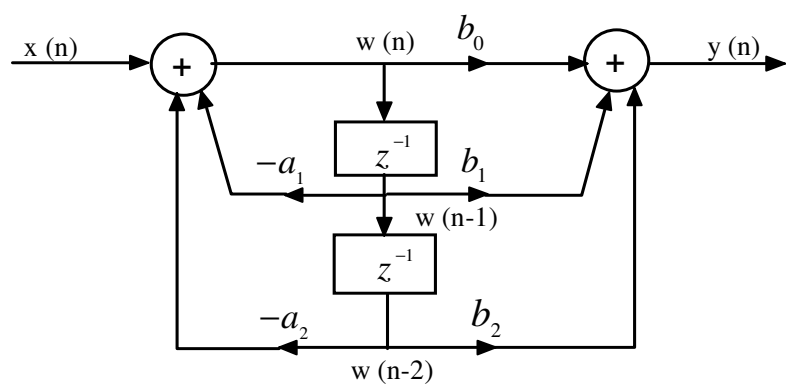

Figura 4.1.5 - Forma direta do Tipo II de segunda ordem.

Verifica-se que para esta realização necessita-se apenas de três locações de memória o que a diferencia da estrutura observada na Figura 4.1.3, afinal para esta seriam requisitadas seis alocações de memória. Este tipo de estrutura é classificado como filtro IIR na forma direta do tipo II. Sua saída $y(n)$ é representada por [Tretter, 1995]:

$$
y(n)=b_{0} w(n)+b_{1} w(n-1)+b_{2} w(n-2)
$$

Onde:

$$
w(n)=x(n)-a_{1} w(n-1)-a_{2} w(n-2)
$$

Aplicando a transformada $\mathrm{Z}$ em ambas as equações. 


$$
\begin{aligned}
& Y(z)=W(z)\left(b_{0}+b_{1} z^{-1}+b_{2} z^{-2}\right) \\
& X(z)=W(z)\left(1+a_{1} z^{-1}+a_{2} z^{-2}\right)
\end{aligned}
$$

A função de transferência é representada por:

$$
H(z)=\frac{Y(z)}{X(z)}=\frac{b_{0}+b_{1} z^{-1}+b_{2} z^{-2}}{1+a_{1} z^{-1}+a_{2} z^{-2}}
$$

De forma geral têm-se:

$$
\begin{gathered}
w(n)=x(n)-\sum_{m=1}^{M} a_{m} w(n-m) \\
y(n)=\sum_{k=0}^{N-1} b_{k} w(n-k)
\end{gathered}
$$

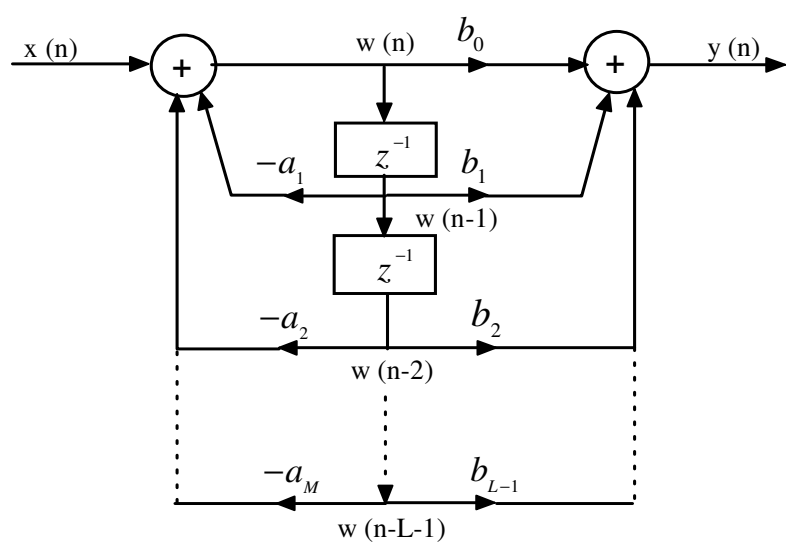

Figura 4.1.6 - Forma direta do tipo II.

A realização em cascata de um filtro IIR é composta pelo produto de funções de transferência simples de primeira ou de segunda ordem. Essas funções são obtidas a partir da fatoração polinomial do numerador e do denominador de uma função de transferência $H(z)$ qualquer. Considerando a função de transferência $H(z)$ dada em (4.6), esta pode ser expressa como [Bateman \& Yates,1991]:

$$
H(z)=C H_{1}(z) H_{2}(z) \ldots H_{K}(z)=C \prod_{k=1}^{K} H_{k}(z)
$$

Onde $k$ corresponde ao número total de seções. Cada seção pode ser representada por uma estrutura de forma direta do tipo II. 


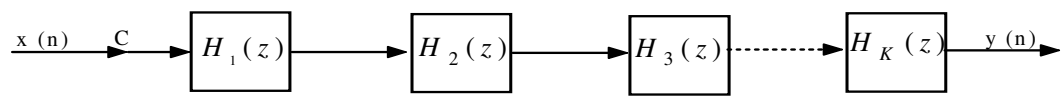

Figura 4.1.7 - Forma cascata de um filtro IIR.

Considerando um filtro IIR de quarta ordem a função de transferência do tipo cascata vai ser da forma [Parks \& Burrus, 1987]:

$$
H(z)=\frac{Y(z)}{X(z)}=\frac{\left(b_{01}+b_{11} z^{-1}+b_{21} z^{-2}\right)\left(b_{02}+b_{12} z^{-1}+b_{22} z^{-2}\right)}{\left(1+a_{11} z^{-1}+a_{21} z^{-2}\right)\left(1+a_{12} z^{-1}+a_{22} z^{-2}\right)}
$$

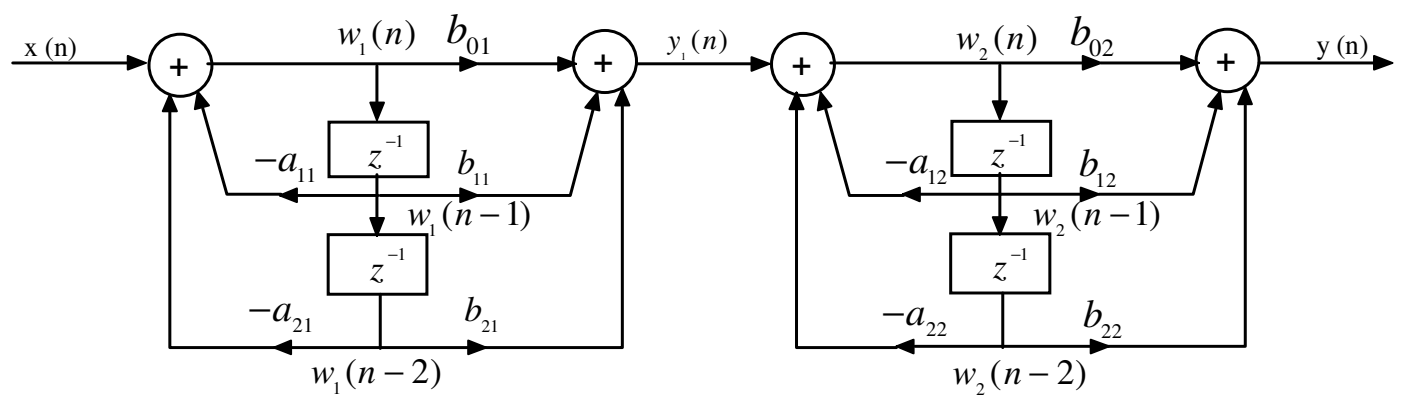

Figura 4.1.8 - Filtro IIR de quarta ordem com duas seções na forma direta do tipo II em cascata.

Diferentes ordens e casamentos, agrupamentos entre zeros e pólos, matematicamente não afeta o resultado da saída $y(n)$. Entretanto do ponto de vista prático a disposição de cada seção de segunda ordem pode minimizar o ruído de quantização, afinal a saída da primeira seção torna-se a entrada da segunda. Com o resultado da saída intermediária $y_{1}(n)$ armazenado em um dos registradores, o truncamento da saída intermediária torna-se insignificante. Conclui-se que a implementação da estrutura cascata é muito menos sensível a erros de quantização de coeficientes do que a estrutura de forma direta do tipo II.

Outra estrutura bastante utilizada em filtros digitais do tipo IIR é a forma paralela cuja função de transferência é obtida a partir da decomposição em frações parciais de (4.6), sendo representada por:

$$
H(z)=C+H_{1}(z)+H_{2}(z) \ldots+H_{K}(z)
$$

Cada função de transferência presente na forma paralela pode ser de primeira ou de segunda ordem. 


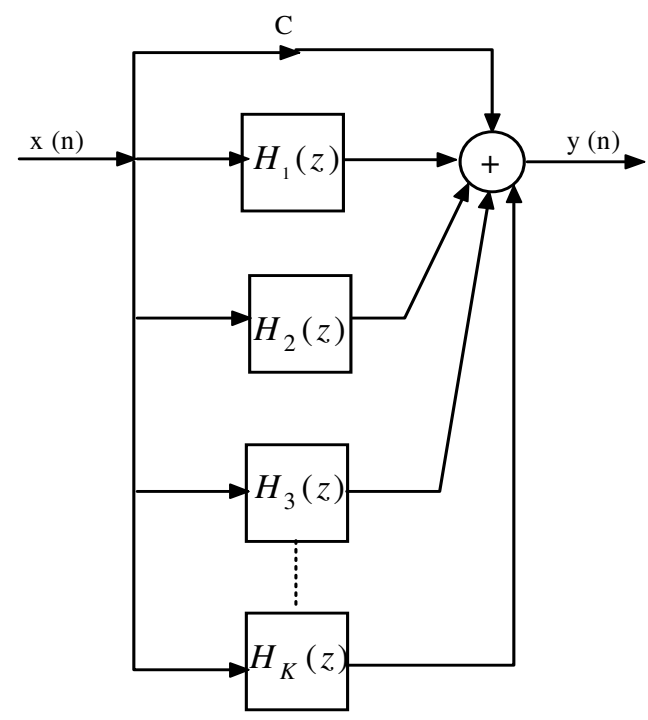

Figura 4.1.9 - Forma paralela de um filtro IIR.

\subsection{Transformação Bilinear}

A transformação bilinear é uma técnica de mapeamento, ou transformação, ponto a ponto do plano $s$ analógico para o plano $z$, convertendo, assim, os pólos e zeros analógicos em digitais, conservando a magnitude da resposta em frequiência do filtro analógico, uma vez que não ocorre o aliasing, e introduzindo uma distorção na fase. Esta transformação é definida por:

$$
s=K \frac{z-1}{z+1}
$$

Para manter a mesma ordem dos sistemas tanto no sistema analógico quanto no digital é necessário que os polinômios sejam de primeiro grau, como pode ser observado em (4.17). A constante $K$ é normalmente determinada como $K=2 / T$, onde $T$ representa uma variável amostrada. Ao escolher, por conveniência, $T=2$, a transformação bilinear fica reduzida a [Williams, 1986]:

$$
s=\frac{z-1}{z+1}
$$

Logo a transformação permite que:

- A região a esquerda no plano $s$, o que corresponde a $\sigma<0$, esteja dentro do círculo unitário no plano $z$.

- A região a direita no plano $s$, o que corresponde a $\sigma>0$, esteja fora do círculo unitário no plano $z$. 
- O eixo imaginário $j w$ no plano $s$ encontra-se sobre o círculo unitário no plano $z$.

Um filtro analógico estável deve ser transformado em um filtro digital estável. Logo verifica-se que o método da transformada bilinear consiste apenas em mapear a metade esquerda do plano $s$.

Se $w_{A}$ e $w_{D}$ representam respectivamente as freqüências analógica e digital, então $s=j w_{A}$ e $z=e^{j w_{D} T}$. Substituindo em (4.18):

$$
j w_{A}=\frac{e^{j w_{D} T}-1}{e^{j w_{D} T}+1}=\frac{e^{j w_{D} T / 2}\left(e^{j w_{D} T / 2}-e^{-j w_{D} T / 2}\right)}{e^{j w_{D} T / 2}\left(e^{j w_{D} T / 2}+e^{j w_{D} T / 2}\right)}
$$

Acarretando em:

$$
w_{A}=\operatorname{tg} \frac{w_{D} T}{2}
$$

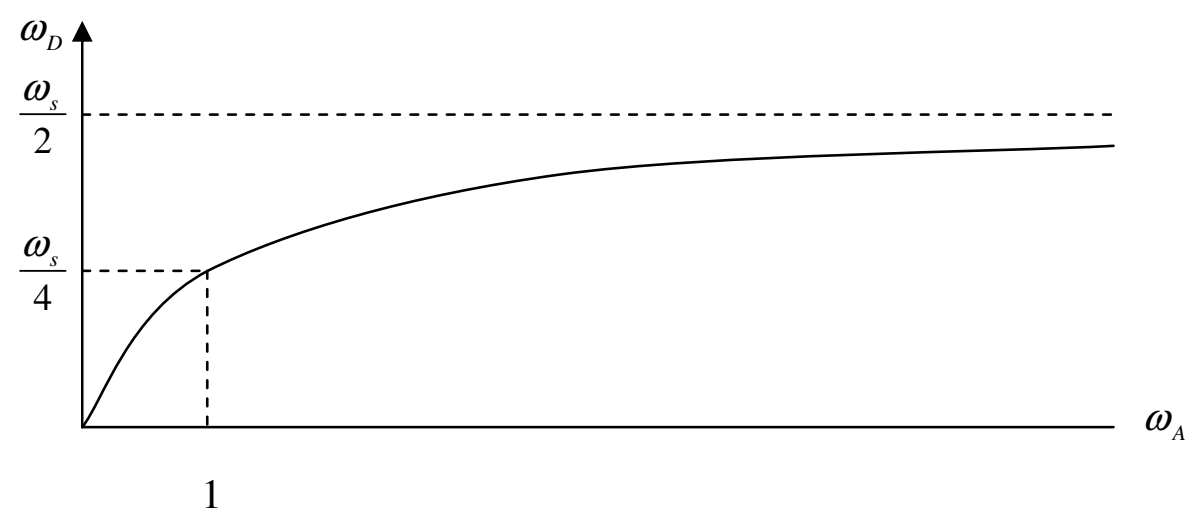

Figura 4.2.1. - Relação entre freqüências analógicas e digitais.

Observa-se na figura acima que a partir de $w_{A}>1$, a qual corresponde a região entre $w_{s} / 4$ e $w_{s} / 2$ para $w_{D}$, onde $w_{s}$ é a frequiência amostrada em radianos, a região é considerada completamente não-linear. Esta não-linearidade corresponde a uma grande distorção no módulo ou na magnitude na freqüência do filtro digital, também conhecida como efeito warping. 


\subsection{EXEMPLOS DE FILTROS COM RESPOSTA IMPULSIONAL INFINITA (IIR)}

Dois exemplos utilizando a forma direta do tipo II em cascata foram desenvolvidos para ilustrar a implementação de filtros IIR.

\subsubsection{Exemplo 1: Filtro Passa-Baixa}

Esse exemplo analisa as características do filtro IIR do tipo passa-baixa através da implementação do código IIR.c e da utilização de alguns recursos do CCS.

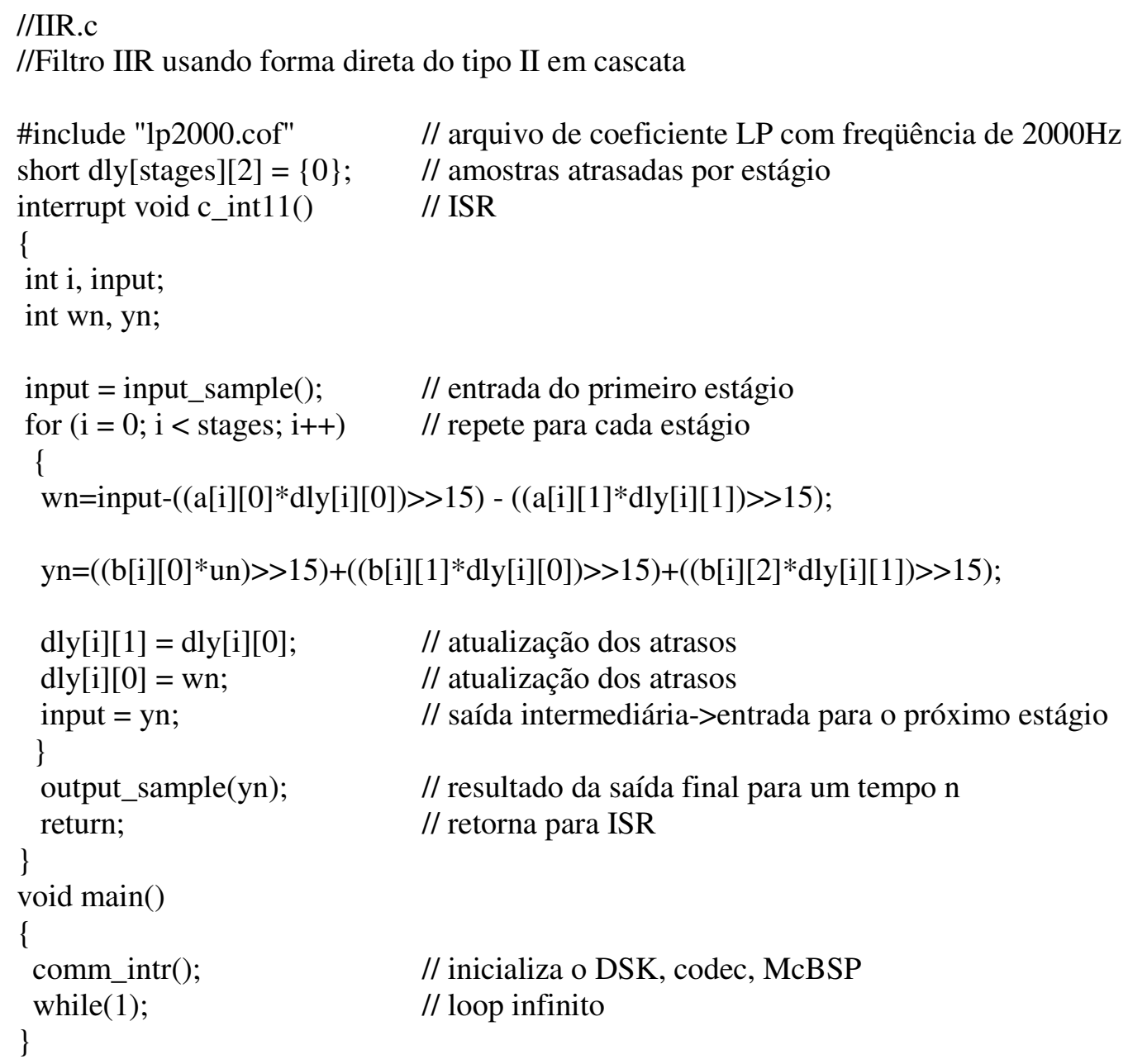


$\{32768,65518,32765\}$,

$\{32768,64542,31788\}\}$;

int b[stages][2] =

$\{0,318\}$,

$\{0,3015\}$,

$\{0,9362\}$,

$\{0,22070\} \quad\}$; //b30, b31, b32 para o terceiro estágio

//b40, b41, b42 para o quarto estágio

//coeficientes do denominador

//a11, a12 para o primeiro estágio

//a21, a22 para o segundo estágio

//a31, a32 para o terceiro estágio

//a41, a42 para o quarto estágio

\section{Considerações sobre o programa}

O arquivo lp2000.cof incluso no código IIR.c contém os coeficientes de um filtro IIR de oitava ordem.

O programa IIR.c implementa um filtro genérico usando, em cascata, seções de segunda ordem. Logo, se observa a associação de duas equações em cada seção [Lynn \& Fuerst,1994]:

$$
\begin{gathered}
w(n)=x(n)-a_{1} w(n-1)-a_{2} w(n-2) \\
y(n)=b_{0} w(n)+b_{1} w(n-1)+b_{2} w(n-2)
\end{gathered}
$$

O loop que há dentro do código do programa é processado quatro vezes (número de seções) para cada valor de $n$, ou período de amostragem. Para o primeiro estágio, $x(n)$ é a entrada amostrada recém adquirida. Assim, a saída do estágio $y(n)$ será a entrada $x(n)$ da próxima seção.

Os coeficientes $a[\mathrm{i}][0]$ e $a[\mathrm{i}][1]$ corresponde a $a_{1}$ e $a_{2}$ respectivamente, onde $i$ represente cada estágio. Os atrasos dly[i][0] e dly[i][1] correspondem a $w(n-1)$ e $w(n-2)$ respectivamente.

\section{Criação do projeto}

Para criar este projeto no Code Composer Studio ${ }^{\mathrm{TM}}$ IDE, é preciso adicionar os arquivos necessários à construção do projeto IIR, que se encontra no material fornecido, como fora feito nos exemplos do tutorial 2. 


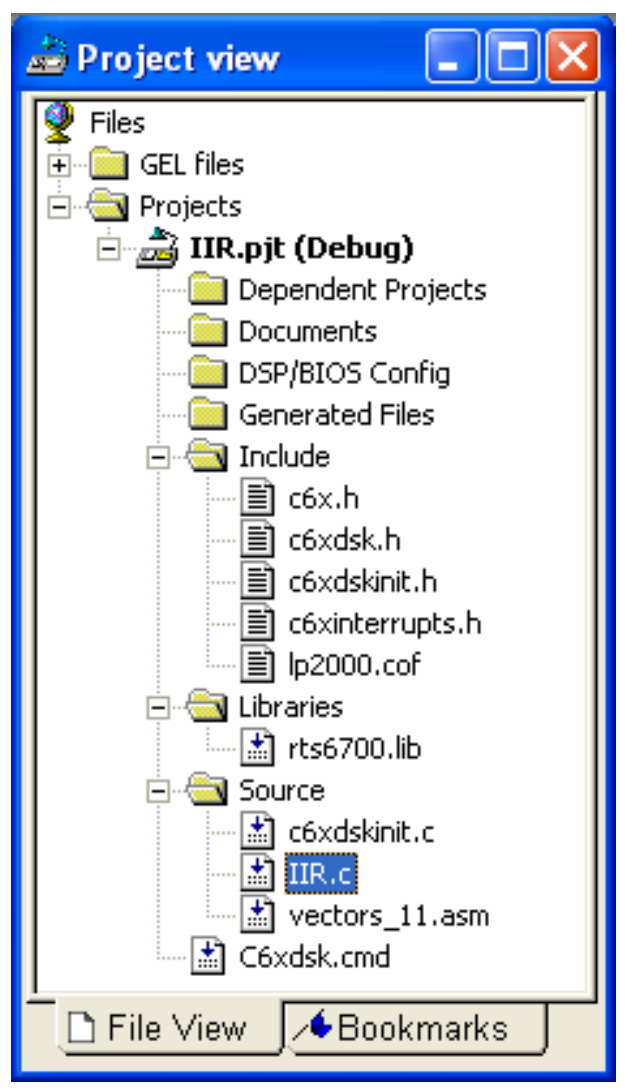

Figura 4.3.1.1 - Visualização do projeto.

Para gerar o executável e carregar o programa utilizam-se as mesmas configurações dos parâmetros do compilador e do linker como fora feito no tutorial 2.

\section{Resultados Experimentais}

Ao se implementar no conector IN (J7) da placa do DSK o ruído pseudorandômico, ruido.m, anexoI, como entrada deste filtro IIR passa-baixa com frequiência de corte igual a $2000 \mathrm{~Hz}$ obteve-se com o auxílio do Osciloscópio - Agilent 5AG21A, que se encontra conectado na saída da placa do DSK, conector OUT (J6), a resposta apresentada na Figura 4.3.1.2.

A Figura 4.3.1.3 representa a resposta do filtro construída por meio de interpolação cujo código fonte, que fora implementado na ferramenta MATLAB 7.0, encontra-se no anexo I. 


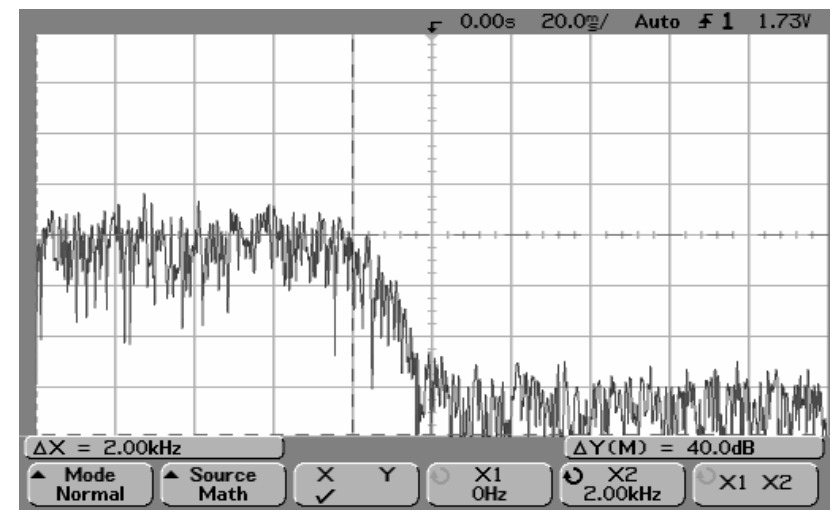

Figura 4.3.1.2 - Resposta em freqüência da saída do filtro IIR passa-baixa com freqüência de corte de $2000 \mathrm{~Hz}$, obtida no osciloscópio.

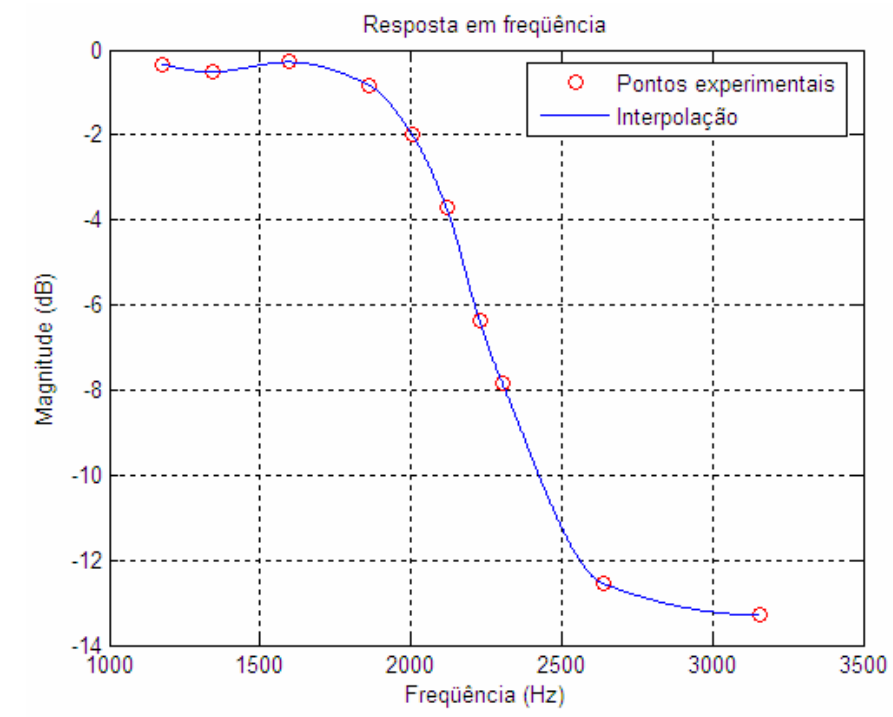

Figura 4.3.1.3 - Resposta em freqüência da saída do filtro IIR passa-baixa com freqüência de corte de $2000 \mathrm{~Hz}$, obtida por meio da interpolação.

\subsubsection{Exemplo 2: Filtro Passa-Faixa}

Esse exemplo analisa as características do filtro IIR do tipo passa-faixa com frequiência centrada em $2000 \mathrm{~Hz}$ a partir da modificação do arquivo dos coeficientes incluso no código IIR.c, ou seja, troca-se lp2000.cof por bp2000.cof como fora feito no exemplo 2 do tutorial 2. 
// lp2000.cof Coeficientes do filtro IIR passa-faixa com frequiência centrada em $2000 \mathrm{~Hz}$ // Os coeficientes a's e b's do MATLAB são os b's e a's utilizadados aqui

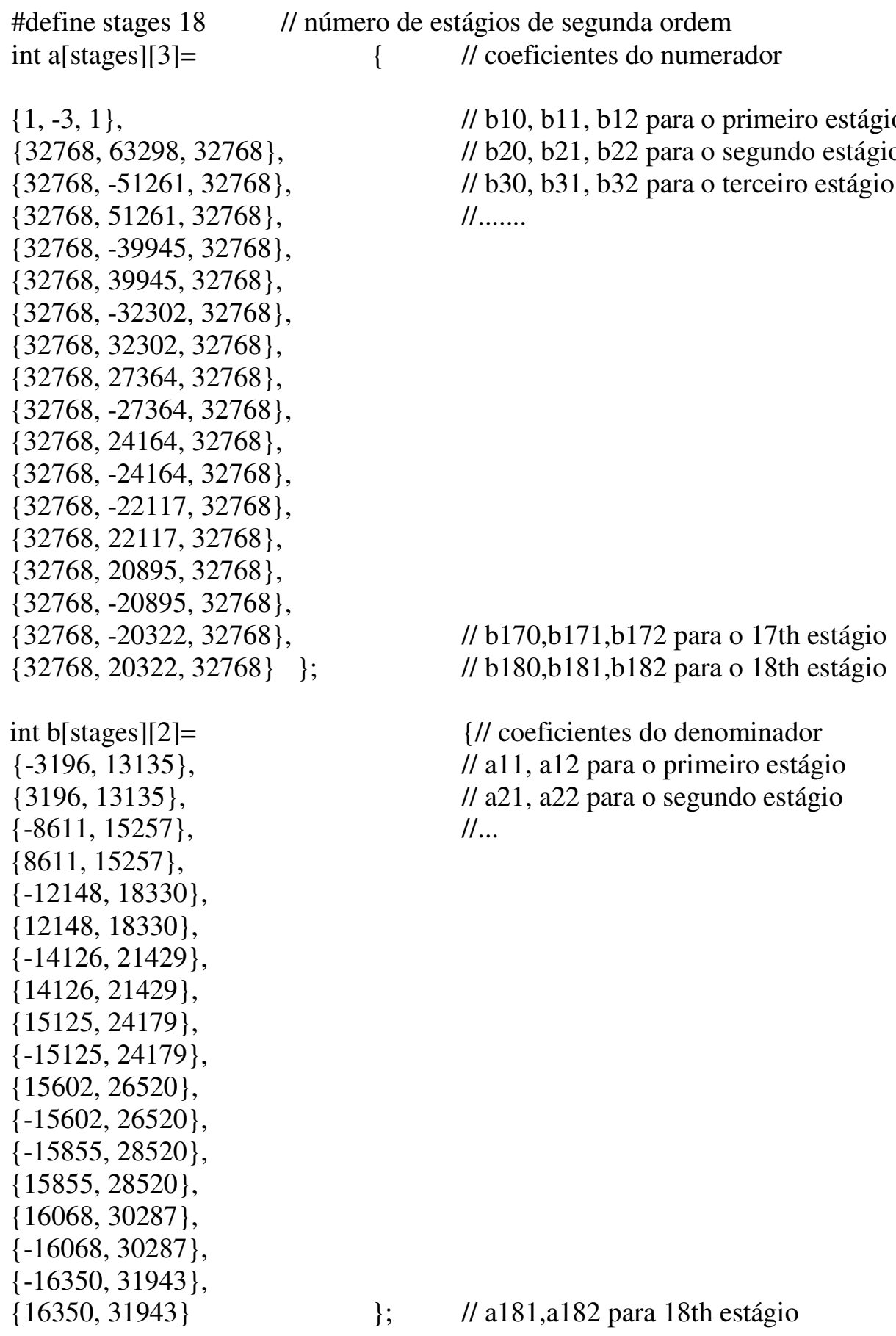

O arquivo bp2000.cof representa dezoito seções, ou seja, 36th- ordem. 


\section{Criação do projeto}

Após a modificação proposta no código IIR.c cria-se o seguinte projeto;

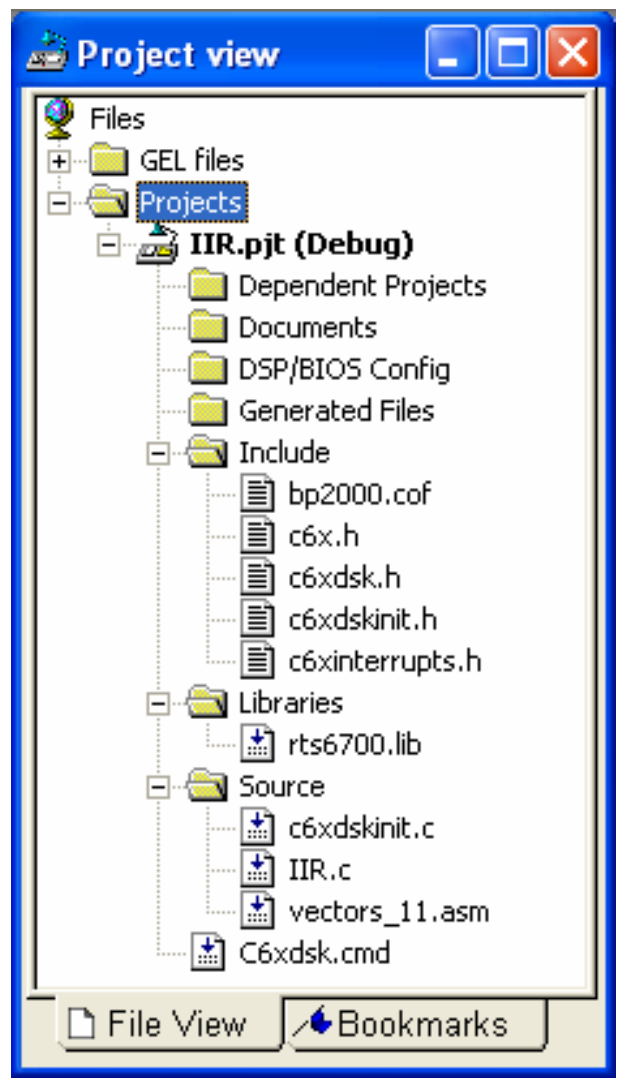

Figura 4.3.2.1 - Visualização do projeto.

Para gerar o executável e carregar o programa utilizam-se as mesmas configurações dos parâmetros do compilador e do linker como fora feito no exemplo anterior.

\section{Resultados Experimentais}

A Figura 4.3.2.2 mostra a resposta em freqüência do filtro obtida com o auxílio do Osciloscópio - Agilent 5AG21A. 


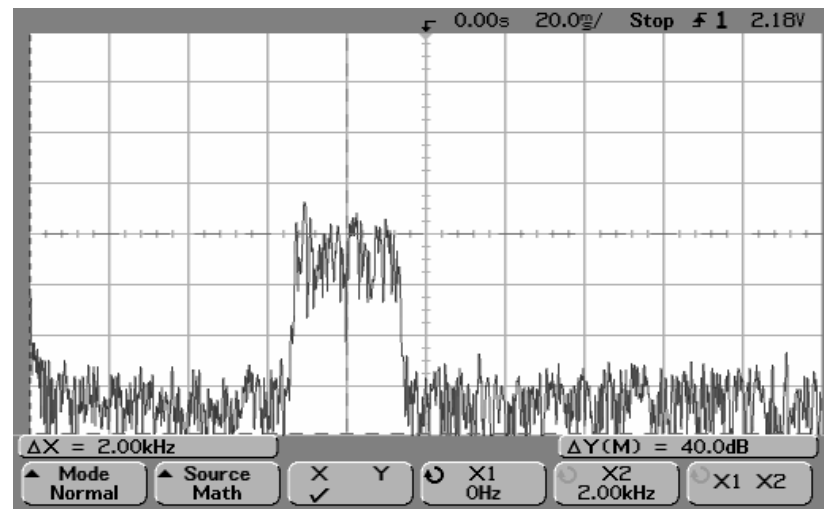

Figura 4.3.2.2 - Resposta em freqüência da saída do filtro IIR passa-faixa centrado em $2000 \mathrm{~Hz}$, obtida no osciloscópio.

\section{Construção gráfica no Matlab}

Utilize a ferramenta sptool, e determine as seguintes características do filtro IIR passa-faixa na janela Filter Designer:

- Sampling frequency $\rightarrow 8000$.

- Algorithm $\rightarrow$ Chebyshev Type II IIR.

- Order $\rightarrow 18$.

- $F c 1 \rightarrow 1600$ e $F c 2 \rightarrow 2400$, determinando a faixa onde existe uma probabilidade do filtro estar centrado.

- $\quad R s \rightarrow 101.5$ 


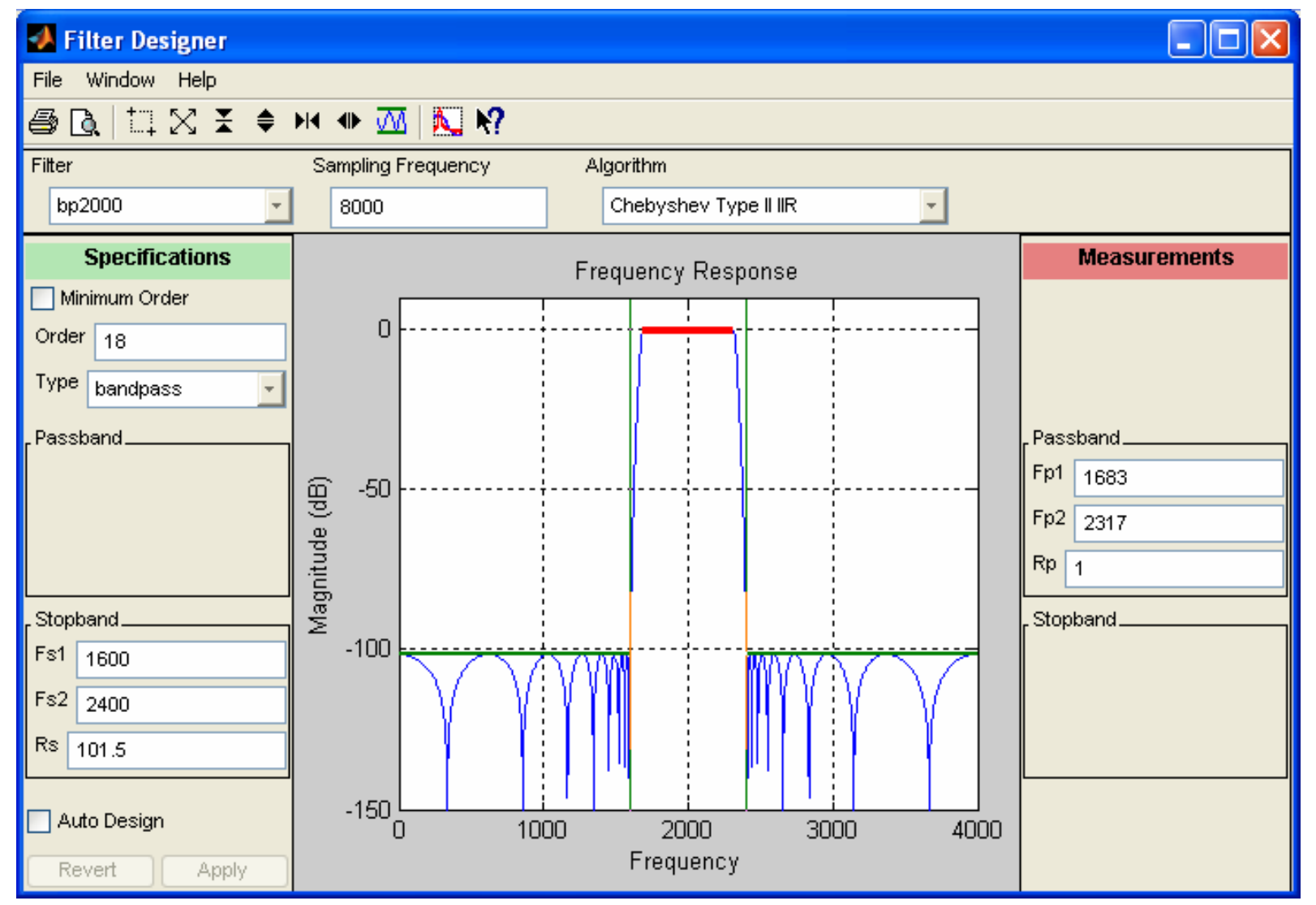

Figura 4.3.2.3 - Características do filtro IIR passa-faixa centrado em $2000 \mathrm{~Hz}$.

Exporte o arquivo Filter:bp2000 [design] para a área de trabalho do Matlab e verifique no mesmo, através dos comandos abaixo, a obtenção dos coeficientes contidos no arquivo bp2000.cof.

$$
\begin{aligned}
& >>[z, p, k]=t f 2 z p(b p 2000 . t f . n u m, b p 2000 . t f . d e n) ; \\
& >>s e c \_o r d \_s e c=z p 2 \operatorname{sos}(z, p, k) ; \\
& >>s e c \_o r d \_s e c=r o u n d\left(s e c \_o r d \_s e c * 2^{\wedge} 15\right)
\end{aligned}
$$

O primeiro comando acha as raízes do numerador e do denominador, ou seja, os pólos e os zeros, e converte-os em um formato de seções de segunda ordem para a implementação.

Logo se observa que os coeficientes, escalados por $2^{15}$, do filtro IIR passa-faixa listados dentro da área de trabalho do Matlab são os mesmos apresentados no arquivo de coeficientes bp2000.cof. 


\section{5 - TUTORIAL 4: TRANSFORMADA RÁPIDA DE FOURIER (FFT)}

\subsection{OBJETIVO}

- Introdução aos conceitos da Transformada de Fourier Discreta

- Introdução à transformada rápida de Fourier usando raiz 2 e raiz 4.

- Decimação na freqüência e no tempo.

- Programação de exemplos usando código C e o TMS320C6711 DSK

Esse tutorial tem por finalidade apresentar os conceitos sobre a transformada rápida de Fourier (FFT), um algoritmo muito eficiente que é utilizado para converter um sinal no domínio do tempo em um sinal equivalente no domínio da frequiência, baseado na transformada discreta de Fourier (DFT). Projetar dois exemplos no TMS320C6711 DSK.

\subsection{INTRODUÇÃO}

\subsubsection{Transformada Discreta de Fourier (DFT)}

A transformada discreta de Fourier (DFT) converte uma sequiência discreta no domínio do tempo numa sequiência equivalente no domínio da freqüência.

Para uma sequiência complexa $x(n)$ de tamanho $N$ a transformada de Fourier Discreta é representada por:

$$
X\left(w_{k}\right) \triangleq \sum_{n=0}^{N-1} x(n) e^{-j w_{k} t_{n}}=\sum_{n=1}^{N-1} x(n) e^{-j 2 \pi k n / N}, \quad \mathrm{k}=0,1,2, \ldots \mathrm{N}-1
$$

Onde:

$$
\begin{aligned}
& t_{n} \triangleq \mathrm{nT}=\mathrm{n} \text {-ésimo instante de amostragem }(\mathrm{s}) \\
& w_{k} \triangleq k \Omega=\text { k-ésima amostra de frequencia }(\mathrm{rad} / \mathrm{s}) \\
& \mathrm{T} \triangleq 1 / \mathrm{f}_{\mathrm{s}}=\text { intervalo de amostragem do tempo }(\mathrm{s}) \\
& \Omega \triangleq 2 \pi \mathrm{f}_{\mathrm{s}} / \mathrm{N}=\text { intervalo de amostragem da frequencia }(\mathrm{rad} / \mathrm{s})
\end{aligned}
$$

Logo $X\left(w_{k}\right)$ é a $k$-ésima amostra do espectro na frequiência $w_{k}$. Então a $k$-ésima amostra de $X\left(w_{k}\right)$ do espectro de $x$ é definido como produto interno de $x$ com a $k$-ésima senóide DFT. 
Ao considerar o fator $W_{N}=e^{-j 2 \pi / N}$, o qual representa a fase, a equação (5.1) pode ser escrita da seguinte forma:

$$
X\left(w_{k}\right) \triangleq \sum_{n=0}^{N-1} x(n) W_{N}^{k n}, \quad k=0,1, \ldots, N-1
$$

Logo:

$$
X\left(w_{k}\right)=x(0)+x(1) W_{N}^{k}+x(2) W_{N}^{2 k}+\ldots+x(N-1) W_{N}^{(N-1) k}
$$

A Equação 5.3 mostra que é possível calcular os $k$ elementos $X\left(w_{k}\right)$ por meio do produto entre uma matriz $N \times N$ e um vetor $N \times 1$, conforme mostra a Equação 5.4.

$$
\left[\begin{array}{c}
X\left(w_{0}\right) \\
X\left(w_{1}\right) \\
X\left(w_{2}\right) \\
\vdots \\
\mathrm{X}\left(\mathrm{W}_{\mathrm{N}-1}\right)
\end{array}\right]=\left[\begin{array}{cccc}
\mathrm{W}_{\mathrm{N}}^{0} & \mathrm{~W}_{\mathrm{N}}^{0} & \cdots & \mathrm{W}_{\mathrm{N}}^{0} \\
\mathrm{~W}_{\mathrm{N}}^{0} & \mathrm{~W}_{\mathrm{N}}^{1} & \cdots & \mathrm{W}_{\mathrm{N}}^{(\mathrm{N}-1)} \\
\mathrm{W}_{\mathrm{N}}^{0} & \mathrm{~W}_{\mathrm{N}}^{2} & \cdots & \mathrm{W}_{\mathrm{N}}^{2(\mathrm{~N}-1)} \\
\vdots & \vdots & \ddots & \vdots \\
\mathrm{W}_{\mathrm{N}}^{0} & \mathrm{~W}_{\mathrm{N}}^{(\mathrm{N}-1)} & \cdots & \mathrm{W}_{\mathrm{N}}^{(\mathrm{N}-1)^{2}}
\end{array}\right]\left[\begin{array}{c}
x(0) \\
x(1) \\
x(2) \\
\vdots \\
\mathrm{x}(\mathrm{N}-1)
\end{array}\right]
$$

Cada valor complexo de $x(n)$ em (5.3), é composto por $N$ multiplicações complexas e $(N-1)$ adições complexas, para calcular todos os $N$ valores da DFT são necessárias $N^{2}$ multiplicações complexas e $N(N-1)$ adições complexas.

Caso a propriedade distributiva seja aplicada, a Equação 5.2 poder ser expressa em termos de operações reais, obtendo-se:

$$
\begin{aligned}
X\left(w_{k}\right)=\sum_{n=0}^{N-1} & {\left[\left(\operatorname{Re}\{\mathrm{x}(\mathrm{n})\} \operatorname{Re}\left\{W_{N}^{k n}\right\}-\operatorname{Im}\{\mathrm{x}(\mathrm{n})\} \operatorname{Re}\left\{W_{N}^{k n}\right\}\right)\right.} \\
& \left.+\mathrm{j}\left(\operatorname{Re}\{\mathrm{x}(\mathrm{n})\} \operatorname{Im}\left\{W_{N}^{k n}\right\}+\operatorname{Im}\{\mathrm{x}(\mathrm{n})\} \operatorname{Re}\left\{W_{N}^{k n}\right\}\right)\right], \quad \mathrm{k}=0,1, \ldots, \mathrm{N}-1
\end{aligned}
$$

Onde uma multiplicação complexa é composta por quatro multiplicações reais e duas adições reais, e cada adição complexa possue duas adições reais. Tem-se para cada valor de $k, 4 N$ multiplicações reais e $(4 N-2)$ adições reais. Conseqüentemente, para $N$ valores a transformada discreta de Fourier de $x(n)$ requer $4 N^{2}$ multiplicações reais e $N(4 N-2)$ adições reais.

Para reduzir esta quantidade de operações em 1965, Cooley e Tukey, propuseram uma eficiente técnica algorítmica denominada transformada rápida de Fourier (FFT) baseada na transformada discreta de Fourier mas que requer bem menos cálculos, já que a 
FFT reduz a complexidade dos cálculos de $N^{2}$ para $N \log _{2} N$. A Figura 5.2.1.1 mostra o comportamento das funções $f(N)=N^{2}$ e $f(N)=N \log _{2} N$ a medida que $N$ cresce [Mitra \& Kaiser, 1993].

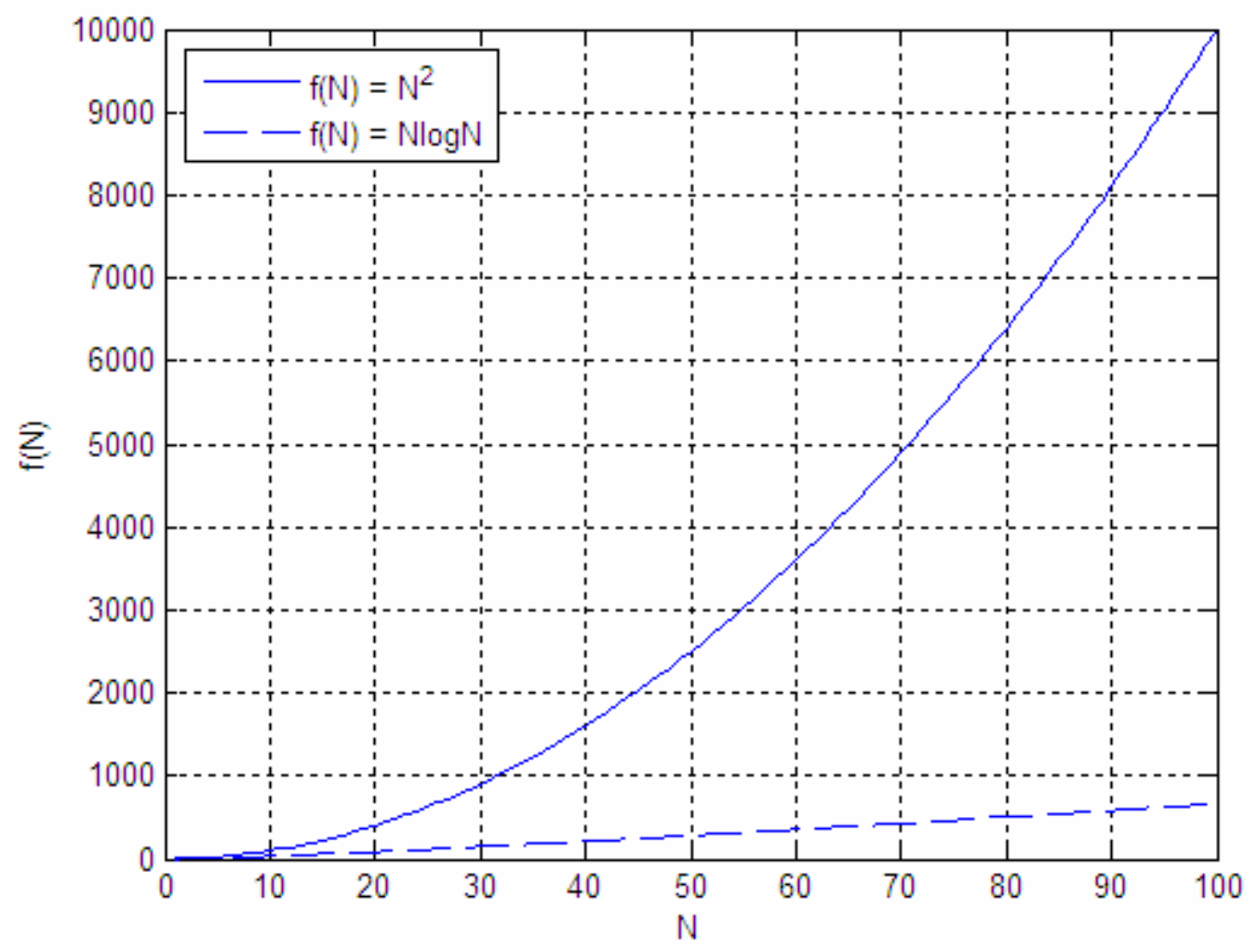

Figura 5.2.1.1 - Comparação entre as funções $f(N)=N^{2}$ e $f(N)=N \log _{2} N$.

A redução da complexidade da FFT requisita a utilização da simetria e da periodicidade, propriedades de $W_{N}^{k n}$.

A periodicidade de $W$ é determinada como:

$$
W_{N}^{k+N}=W_{N}^{k}
$$

A simetria de $W$ expressa-se por meio de:

$$
W_{N}^{k+N / 2}=-W_{N}^{k}
$$

Considerando $N=8$ e $k=2$ aplicando a propriedade da periodicidade $W^{10}=W^{2}$ e da simetria $W^{6}=-W^{2}$, obtém-se o diagrama da Figura 5.2.1.2. 


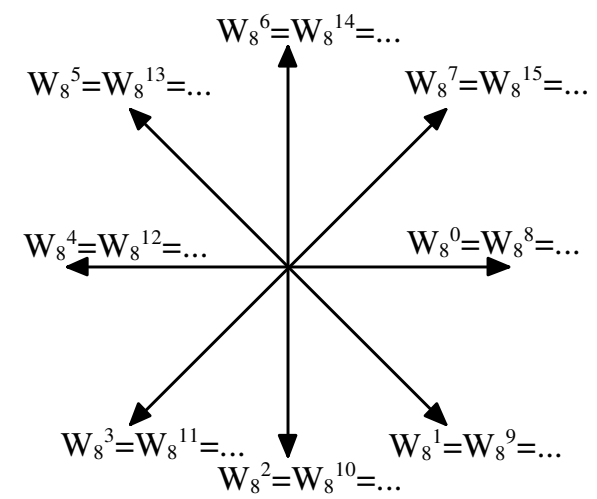

Figura 5.2.1.2 - Visualização das propriedades de simetria e de periodicidade.

Na base 2, a FFT decompõem a DFT de $N$ pontos em duas DFT's menores compostas por $N / 2$ pontos cada.

Logo para otimizar o processamento de uma DFT existem vários tipos de algoritmos rápidos cujo conjunto é conhecido como algoritmos de FFT.

\subsubsection{Desenvolvimento do algoritmo raiz-2 com decimação no tempo}

Decimação no tempo é o processo no qual a seqüência de entrada $x(n)$ é decomposta em seqüências menores.

Supondo que o comprimento $N$ da sequiência $x(n)$ seja uma potência de dois, $N=2^{l}$, onde $l$ representa o número de estágios, pode-se decompor $x(n)$ em duas outras seqüências menores, uma com os elementos de $x(n)$ para $n$ par e outra com elementos $x(n)$ para $n$ ímpar, conforme mostra a Equação 5.8 [Mitra,1998].

$$
X\left(w_{k}\right)=\sum_{n=0}^{(N / 2)-1} x(2 n) W_{N}^{2 n k}+\sum_{n=0}^{(N / 2)-1} x(2 n+1) W_{N}^{(2 n+1) k}
$$

Considerando $W_{N}^{2}=W_{N / 2}$,

$$
W_{N}^{2}=e^{-2 j(2 \pi / N)}=e^{-j 2 \pi /(N / 2)}=W_{N / 2}
$$

Substituindo (5.9) em (5.8),

$$
X\left(w_{k}\right)=\sum_{n=0}^{(N / 2)-1} x(2 n) W_{N / 2}^{n k}+W_{N}^{k} \sum_{n=0}^{(N / 2)-1} x(2 n+1) W_{N / 2}^{n k}
$$


Onde:

$$
\begin{aligned}
& C\left(w_{k}\right)=\sum_{n=0}^{(N / 2)-1} x(2 n) W_{N / 2}^{n k} \\
& D\left(w_{k}\right)=\sum_{n=0}^{(N / 2)-1} x(2 n+1) W_{N / 2}^{n k}
\end{aligned}
$$

Desta forma:

$$
X\left(w_{k}\right)=C\left(w_{k}\right)+W_{N}^{k} D\left(w_{k}\right)
$$

A Equação 5.12 representa duas DFTs com tamanho $N / 2$, acarretando em apenas $(N / 2)^{2}$ multiplicações complexas para cada somatório. Entretanto a seqüência composta por elementos de índice ímpar requer também $N$ multiplicações por $W_{N}^{k}$. Assim a Equação 5.12 implica em $2(N / 2)^{2}+N=\left(N^{2} / 2\right)+N$ multiplicações complexas. Após estas multiplicações são realizadas $2\left[(N / 2)^{2}-N / 2\right]+N=N^{2} / 2$ adições. Estas características são aplicadas de uma forma recursiva em cada uma das DFTs até que obtenham-se DFTs de comprimento 1, o que reduz de forma bastante significativa a complexidade dos cálculos [Johnson, 1989].

Ao considerar $w_{k}>(N / 2)-1$ e utilizando a propriedade de simetria (Equação 5.7), a Equação 5.12 resulta em,

$$
X\left(w_{k+N / 2}\right)=C\left(w_{k}\right)-W_{N}^{k} D\left(w_{k}\right)
$$

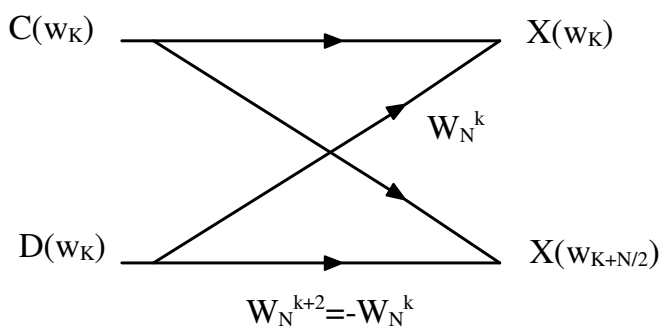

Figura 5.2.2.1 - Célula Básica do algoritmo de FFT com decimação no tempo.

Este tipo de célula básica, também conhecida como borboleta, neste caso, utiliza uma única multiplicação complexa, resultando num algoritmo com $\frac{N}{2} \log _{2} N$ multiplicações complexas. 
Logo para $N=8$ tem-se:

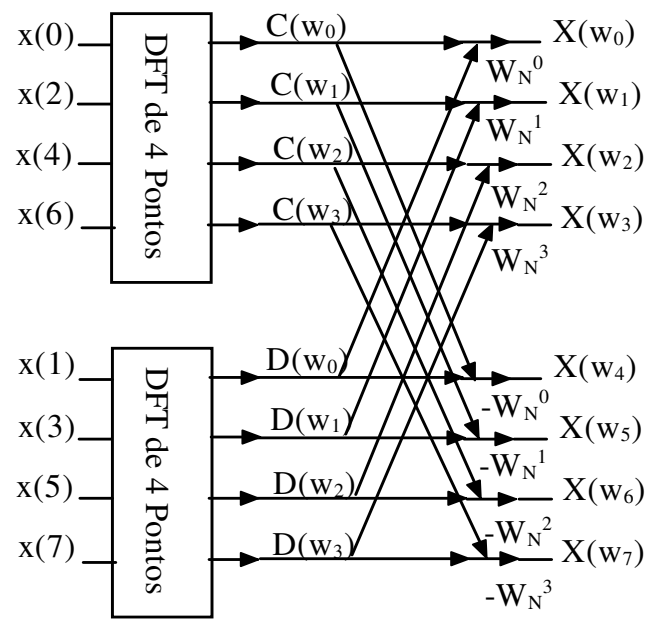

Figura 5.2.2.2 - Decomposição de uma DFT com 8 pontos em duas DFTs de 4 pontos com decimação no tempo.

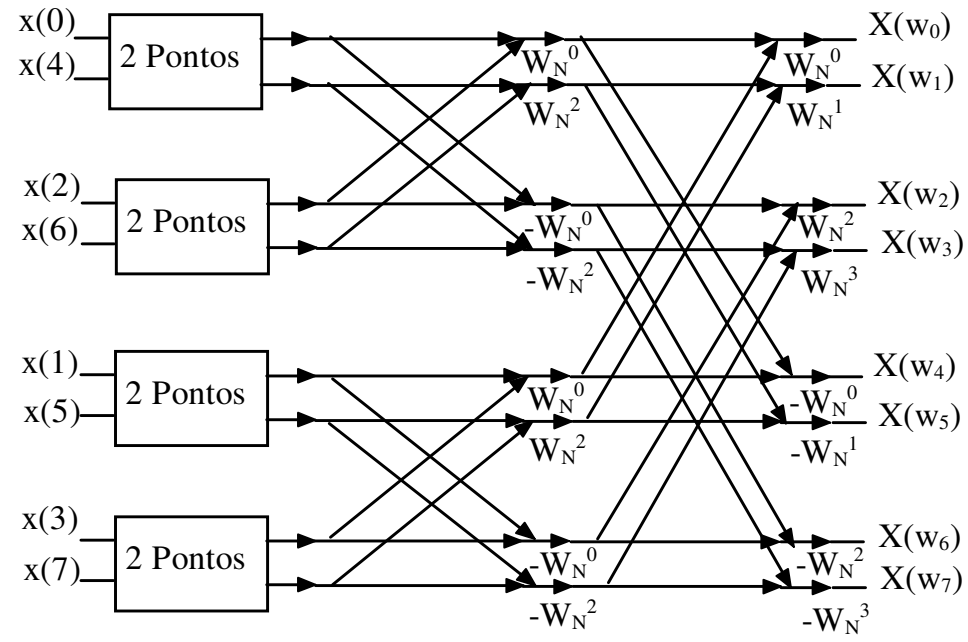

Figura 5.2.2.3 - Decomposição de duas DFTs de 4 pontos em quatro DFTs de 2 pontos com decimação no tempo. 


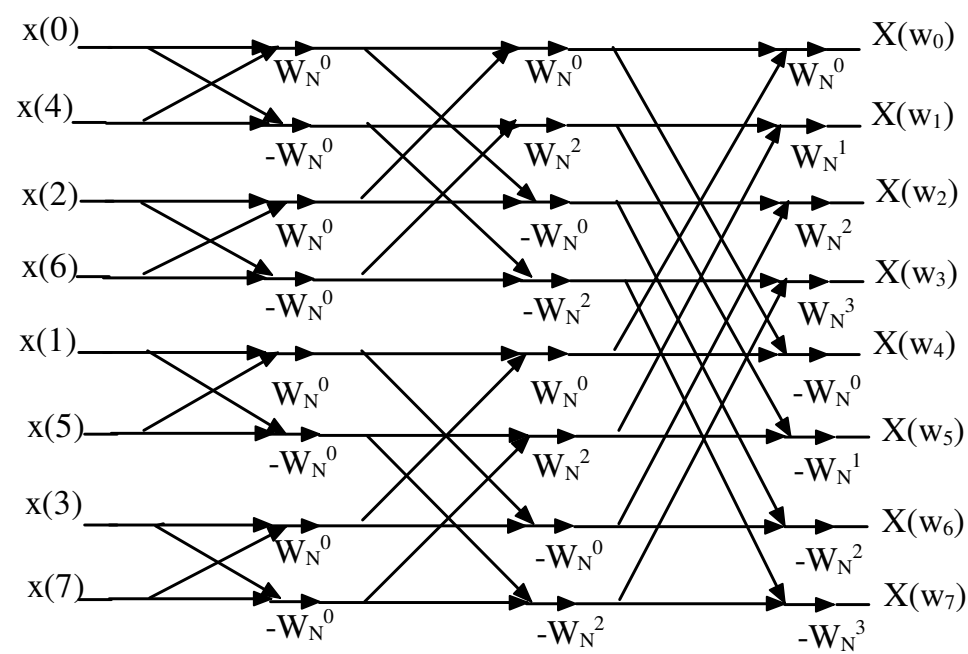

Figura 5.2.2.4 - FFT de oito pontos usando decimação no tempo.

\subsubsection{Desenvolvimento do algoritmo raiz-2 com decimação na freqüência}

O algoritmo raiz de 2 com decimação na frequiência corresponde a divisão da seqüência de saída $X\left(w_{k}\right)$ em seqüências cada vez menores.

Ao dividir a seqüência $x(n)$ da Equação (5.2) em duas partes iguais obtém-se:

$$
X\left(w_{k}\right)=\sum_{n=0}^{(N / 2)-1} x(n) W_{N}^{n k}+\sum_{n=N / 2}^{N-1} x(n) W_{N}^{n k}
$$

Considerando $n=n+N / 2$ no segundo somatório,

$$
\begin{aligned}
X\left(w_{k}\right) & =\sum_{n=0}^{(N / 2)-1} x(n) W_{N}^{n k}+\sum_{n=0}^{(N / 2)-1} x(n+N / 2) W_{N}^{n k} W_{N}^{k N / 2} \\
& =\sum_{n=0}^{(N / 2)-1} x(n) W_{N}^{n k}+\left(W_{N}^{k N / 2}\right) \sum_{n=0}^{(N / 2)-1} x(n+N / 2) W_{N}^{n k}
\end{aligned}
$$

Como $W_{N}^{k N / 2}=(-1)^{k}$ a equação (5.15) reduz-se a;

$$
X\left(w_{k}\right)=\sum_{n=0}^{(N / 2)-1}\left[x(n)+(-1)^{k} x\left(n+\frac{N}{2}\right)\right] W_{N}^{n k}
$$

Separando os termos pares e ímpares de $X\left(w_{k}\right)$ obtém-se:

$$
\begin{aligned}
X\left(w_{2 k}\right) & =\sum_{n=0}^{(N / 2)-1}\left[x(n)+x\left(n+\frac{N}{2}\right)\right] W_{N}^{2 n k} \\
X\left(w_{2 k+1}\right) & =\sum_{n=0}^{(N / 2)-1}\left[x(n)-x\left(n+\frac{N}{2}\right)\right] W_{N}^{n} W_{N}^{2 n k}
\end{aligned}
$$

Para $k=0,1,2, \ldots,(N / 2)-1$. 
Ao admitir que $W_{N}^{2}=W_{N / 2}$ e considerando,

$$
\begin{aligned}
& g(n)=x(n)+x(n+N / 2) \\
& h(n)=x(n)-x(n-N / 2)
\end{aligned}
$$

As Equações (5.17) e (5.18) podem ser escritas como DFTs de $(N / 2)$ pontos,

$$
\begin{gathered}
X\left(w_{2 k}\right)=\sum_{n=0}^{(N / 2)-1} g(n) W_{N / 2}^{n k} \\
X\left(w_{2 k+1}\right)=\sum_{n=0}^{(N / 2)-1} h(n) W_{N}^{n} W_{N / 2}^{n k}
\end{gathered}
$$

Primeiramente são calculadas as seqüências $g(n)$ e $h(n)$, então é calculado $h(n) W_{N}^{n}$, e finalmente calculam-se os $(N / 2)$ pontos, acarretando na obtenção das saídas dos termos pares e ímpares respectivamente.

Sendo considerado $a(n)=g(n)$ e $b(n)=h(n) W_{N}^{n}$ a célula básica da decimação na freqüência é representada por:

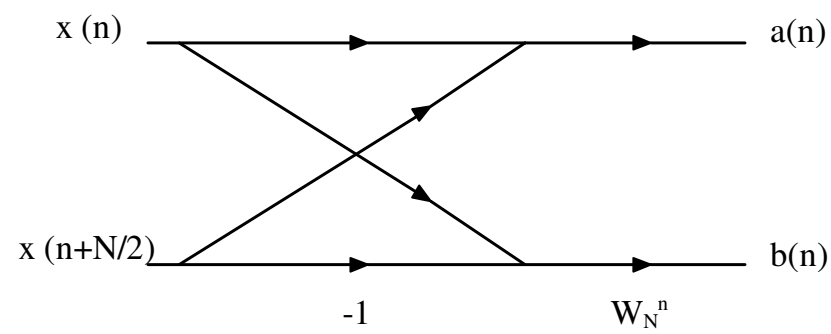

Figura 5.2.3.1 - Célula Básica do algoritmo de FFT com decimação na freqüência.

Este tipo de procedimento pode ser repetido para cada uma das DFTs de $(N / 2)$ pontos, gerando DFTs de comprimento $(N / 4)$, e este gerando DFTs de comprimento $(N / 8)$, e assim por diante. 
Logo para $N=8$, tem-se:

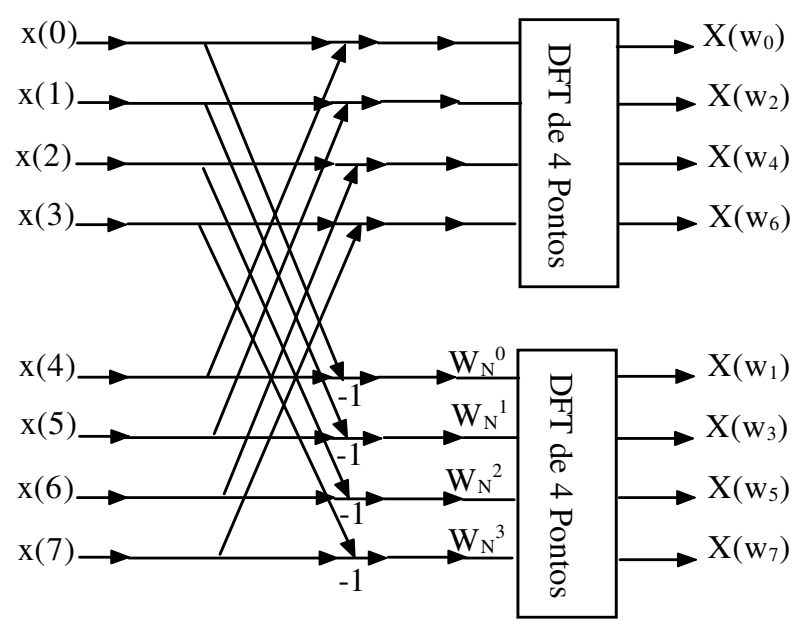

Figura 5.2.3.2 - Decomposição de uma DFT com 8 pontos em duas DFTs de 4 pontos com decimação na freqüência.

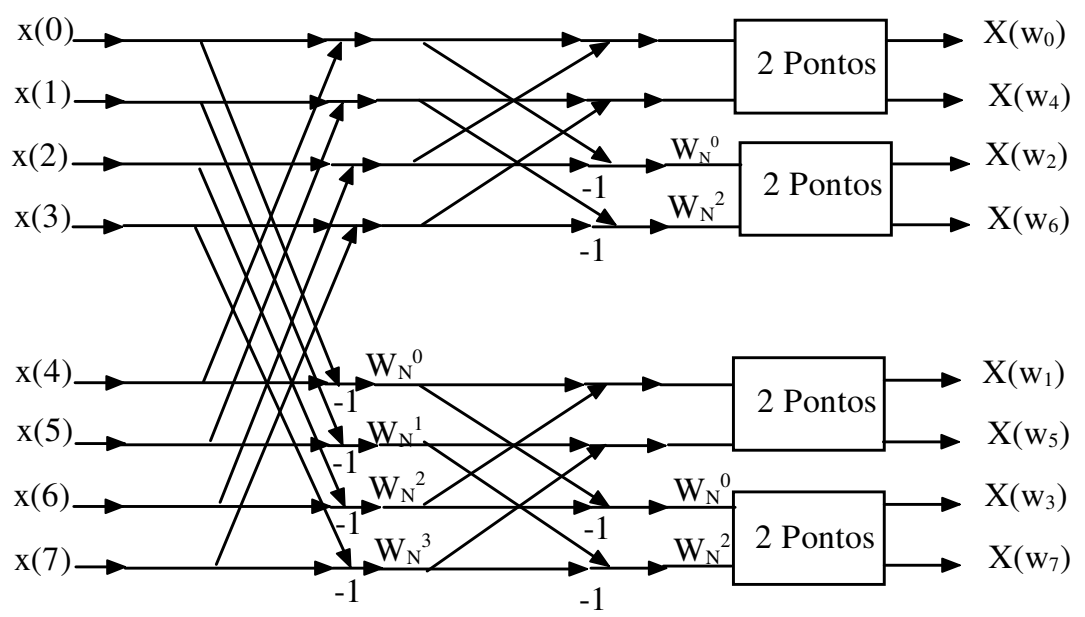

Figura 5.2.3.3 - Decomposição de duas DFTs de 4 pontos em quatro DFTs de 2 pontos com decimação na freqüência. 


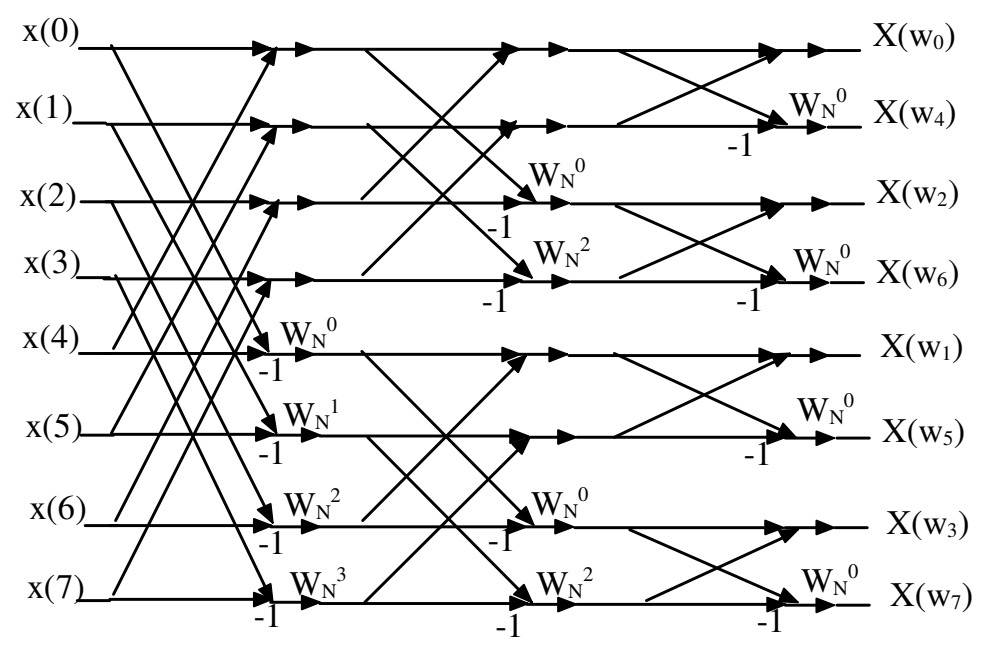

Figura 5.2.3.4 - FFT de oito pontos usando decimação na freqüência.

A Figura 5.2.3.4 requer $(N / 2) \log _{2} N$ multiplicações complexas e $N \log _{2} N$ adições complexas. Logo o número de cálculos realizados na decimação na frequiência corresponde ao da decimação no tempo.

\subsubsection{Algoritmo de raiz-4}

Quando o algoritmo utilizado for de raiz de 4 cujo comprimento é $N=2^{2 l}$, a DFT (5.2) é decomposta em quatro seqüências.

$$
X\left(w_{k}\right)=\sum_{n=0}^{(N / 4)-1} x(n) W_{N}^{n k}+\sum_{n=N / 4}^{(N / 2)-1} x(n) W_{N}^{n k}+\sum_{n=N / 2}^{(3 N / 4)-1} x(n) W_{N}^{n k}+\sum_{n=3 N / 4}^{N-1} x(n) W_{N}^{n k}
$$

Considerando $n=n+N / 4, \quad n=n+N / 2, \quad n=n+3 N / 4$ no segundo, terceiro e quarto somatório respectivamente obtém-se;

$$
\begin{aligned}
X\left(w_{k}\right) & =\sum_{n=0}^{(N / 4)-1} x(n) W_{N}^{n k}+W_{N}^{k N / 4} \sum_{n=0}^{(N / 4)-1} x(n+N / 4) W_{N}^{n k} \\
& +W_{N}^{k N / 2} \sum_{n=0}^{(N / 4)-1} x(n+N / 2) W_{N}^{n k}+W_{N}^{3 k N / 4} \sum_{n=0}^{(N / 4)-1} x(n+3 N / 4) W_{N}^{n k}
\end{aligned}
$$

Onde,

$$
\begin{aligned}
& W^{k N / 4}=(-j)^{k} \\
& W^{k N / 2}=(-1)^{k} \\
& W^{3 k N / 4}=(j)^{k}
\end{aligned}
$$

Assim (5.23) fica reduzida a, 


$$
X\left(w_{k}\right)=\sum_{n=0}^{(N / 4)-1}\left[x(n)+(-j)^{k} x(n+N / 4)+(-1)^{k} x(n+N / 2)+(j)^{k} x(n+3 N / 4)\right] W_{N}^{n k}
$$

Uma vez que $W_{N}^{4}=W_{N / 4},(5.25)$ pode ser escrita como;

$$
\begin{aligned}
X\left(w_{4 k}\right) & =\sum_{n=0}^{(N / 4)-1}[x(n)+x(n+N / 4)+x(n+N / 2)+x(n+3 N / 4)] W_{N / 4}^{n k} \\
X\left(w_{4 k+1}\right) & =\sum_{n=0}^{(N / 4)-1}[x(n)-j x(n+N / 4)-x(n+N / 2)+j x(n+3 N / 4)] W_{N}^{n} W_{N / 4}^{n k} \\
X\left(w_{4 k+2}\right) & =\sum_{n=0}^{(N / 4)-1}[x(n)-x(n+N / 4)+x(n+N / 2)-x(n+3 N / 4)] W_{N}^{2 n} W_{N / 4}^{n k} \\
X\left(w_{4 k+3}\right) & =\sum_{n=0}^{(N / 4)-1}[x(n)+j x(n+N / 4)-x(n+N / 2)-j x(n+3 N / 4)] W_{N}^{3 n} W_{N / 4}^{n k}
\end{aligned}
$$

Verifica-se que quanto menor o comprimento da DFT da célula básica de um algoritmo de FFT, mais otimizado ele torna-se, exceto para algoritmos de raízes múltiplos de dois, onde se pode obter um número de multiplicações progressivamente inferior ao dos algoritmos de raiz de 2 .

\subsubsection{Transformada Inversa Discreta de Fourier (IDFT)}

A transformada inversa discreta de Fourier converte a seqüência no domínio da freqüência numa freqüência equivalente no domínio do tempo [Bellanger, 1989].

$$
\begin{gathered}
x[n]=\frac{1}{N} \sum_{k=0}^{N-1} X\left[w_{k}\right] e^{j 2 \pi k n / N} \\
{\left[\begin{array}{c}
x(0) \\
x(1) \\
x(2) \\
\vdots \\
\mathrm{x}(\mathrm{N}-1)
\end{array}\right]=\frac{1}{N}\left[\begin{array}{cccc}
\mathrm{W}_{\mathrm{N}}^{0} & \mathrm{~W}_{\mathrm{N}}^{0} & \ldots & \mathrm{W}_{\mathrm{N}}^{0} \\
\mathrm{~W}_{\mathrm{N}}^{0} & \mathrm{~W}_{\mathrm{N}}^{-1} & \ldots & \mathrm{W}_{\mathrm{N}}^{-(\mathrm{N}-1)} \\
\mathrm{W}_{\mathrm{N}}^{0} & \mathrm{~W}_{\mathrm{N}}^{-2} & \ldots & \mathrm{W}_{\mathrm{N}}^{-2(\mathrm{~N}-1)} \\
\vdots & \vdots & \ddots & \vdots \\
\mathrm{W}_{\mathrm{N}}^{0} & \mathrm{~W}_{\mathrm{N}}^{-(\mathrm{N}-1)} & \ldots & \mathrm{W}_{\mathrm{N}}^{-(\mathrm{N}-1)^{2}}
\end{array}\right]\left[\begin{array}{c}
X\left(w_{0}\right) \\
X\left(w_{1}\right) \\
X\left(w_{2}\right) \\
\vdots \\
\mathrm{X}\left(\mathrm{W}_{\mathrm{N}-1}\right)
\end{array}\right]}
\end{gathered}
$$




\subsection{EXEMPLOS DE TRANSFORMADA DISCRETA DE FOURIER (DFT) E TRANSFORMADA RÁPIDA DE FOURIER (FFT)}

Dois exemplos são realizados nesta seção, o primeiro ilustra a DFT de duas entradas distintas, e o segundo exemplo implementa um algoritmo com duas entradas diferentes para ilustrar a FFT formulada por Danielson e Lanczos.

\subsubsection{Exemplo 1: DFT de uma Seqüência de números reais com saída para a janela do CCS}

Esse exemplo tem como objetivo ilustrar a transformada discreta de Fourier (DFT) de uma sequiência de $N$-pontos através da implementação do código $d f t . c$ e da utilização de alguns recursos do CCS.

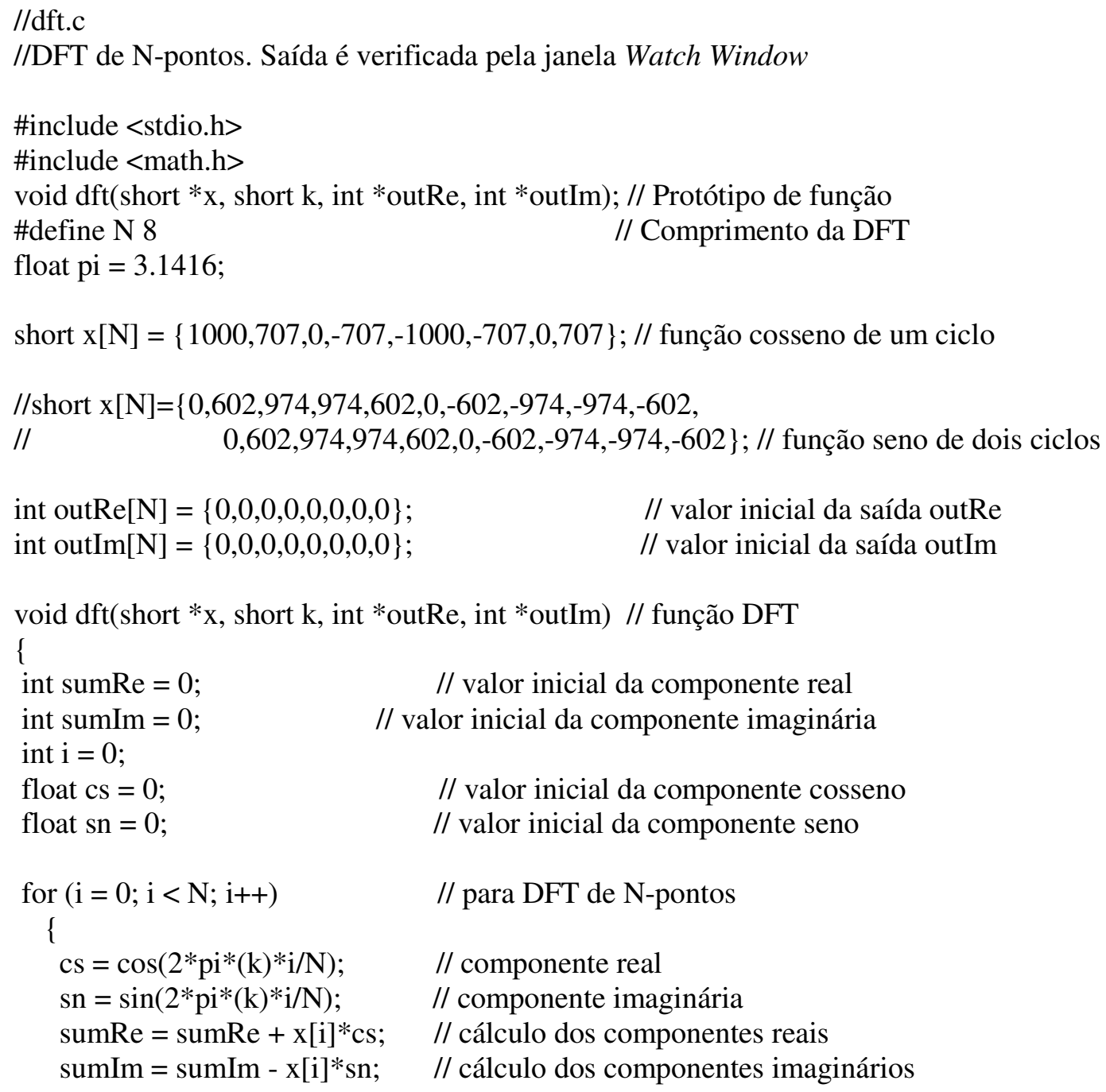




$$
\begin{array}{ll}
\text { outRe }[\mathrm{k}]=\text { sumRe; } & \text { // cálculo dos componenetes reais } \\
\operatorname{outIm}[\mathrm{k}]=\text { sumIm; } & \text { // cálculo dos componentes imaginários }
\end{array}
$$

\}

void main()

\{

int $\mathrm{j}$;

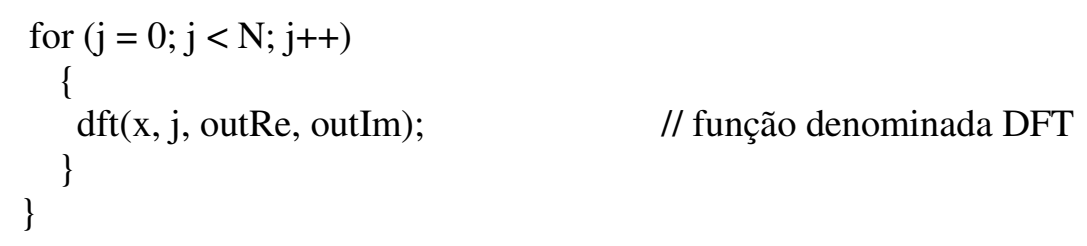

\section{Considerações sobre o programa}

A DFT da seqüência de uma entrada $x(n)$ é calculada por,

$$
X\left(w_{k}\right)=\sum_{n=0}^{N-1} x(n) W_{N}^{k n}, \quad k=0,1, \ldots, N-1
$$

Onde $W_{N}=e^{-j 2 \pi / N}$ são constantes de giro. Logo, esta equação pode ser decomposta em dois outros somatórios um com componentes reais e outro contendo componentes imaginários,

$$
\begin{aligned}
& \operatorname{Re}\left\{X\left(w_{k}\right)\right\}=\sum_{n=0}^{N-1} x(n) \cos (2 \pi n k / N) \\
& \operatorname{Im}\left\{X\left(w_{k}\right)\right\}=\sum_{n=0}^{N-1} x(n) \operatorname{sen}(2 \pi n k / N)
\end{aligned}
$$

Assim ao utilizar uma sequiência de números reais com um número inteiro de ciclos $m$, tem-se $X\left(w_{k}\right)=0$ para todo o $k$ exceto para $k=m$ e $k=N-m$.

O programa. dft.c possui duas entradas $x(n)$ distintas, em ambos os casos a frequiência de amostragem é considerada como $F_{s}=8000 \mathrm{~Hz}$.

A primeira entrada é um sinal cosseno de comprimento $N=8$, ou seja, composta por um único ciclo, multiplicado por 1000 e cuja freqüência $f=1000 \mathrm{kHz}$, uma vez que $f=F_{s}($ numero de ciclos) $/ \mathrm{N}=1 \mathrm{kHz}$, assim,

$$
x(n)=1000 \times \cos (2 \pi n 1 / 8)=x(n)=1000 \times \cos (\pi n / 4)
$$


Logo através da implementação na ferramenta MATLAB 7.0, do código que se encontra no anexo I, obtém-se $x[N]=\{1000,707,0,-707,-1000,-707,0,707\}$, como pode ser verificado graficamente na Figura 5.3.1.1.

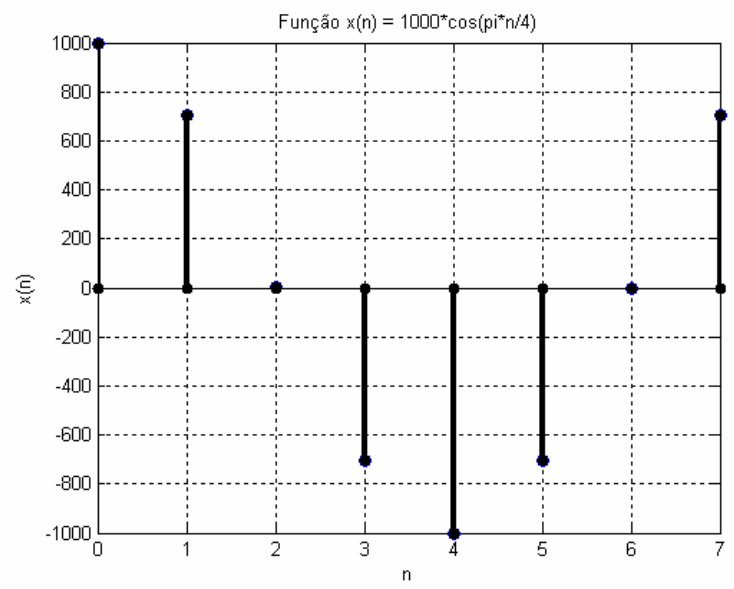

Figura 5.3.1.1 - Gráfico da função $x(n)=1000 * \cos \left(\frac{\pi}{4} n\right)$; Freqüência do sinal $f=1000 \mathrm{~Hz}$ e Freqüência de amostragem $F_{s}=8000 \mathrm{~Hz}$.

As Figuras 5.3.1.2 e 5.3.1.3 representam graficamente os valores da componente real da DFT, (outRe), obtidos a partir do cálculo de $\operatorname{Re}\left\{X\left(w_{k}\right)\right\}$, e dos valores da componente imaginária da DFT, (outIm), calculados por $\operatorname{Im}\left\{X\left(w_{k}\right)\right\}$.

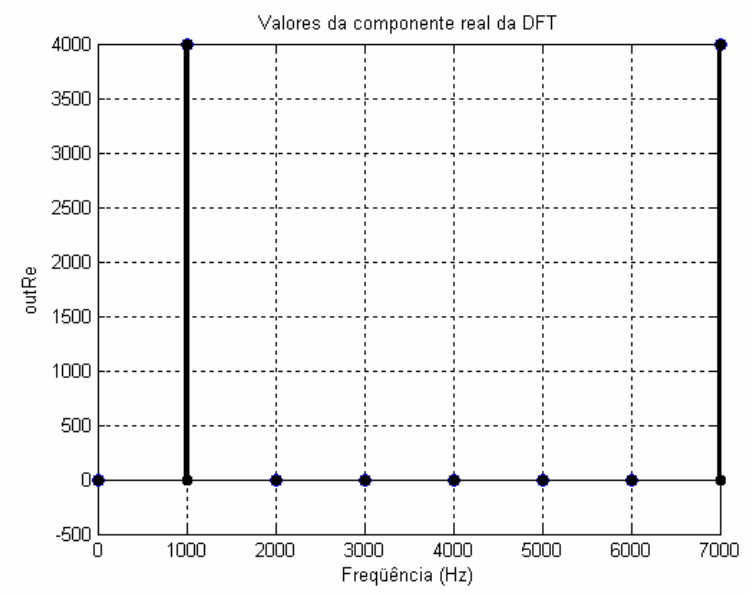

Figura 5.3.1.2 - Valores da componente real (outRe) da DFT de $N=8$ gerada no MATLAB. 


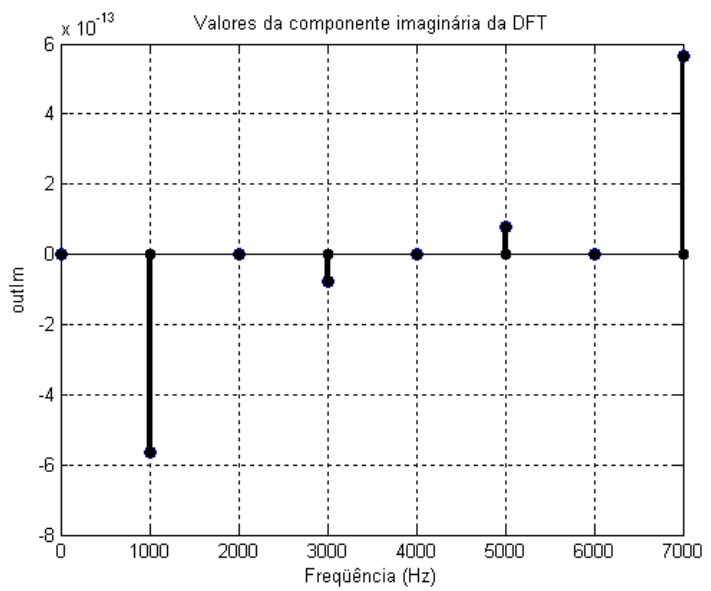

Figura 5.3.1.3 - Valores da componente imaginária (outlm) da DFT de $N=8$ gerada no MATLAB.

Verifica-se que por ser um sinal cosseno, a parte imaginária possui valores muito pequenos quando comparada aos valores da componente real, sendo assim considerada quase zero.

Os picos da parte real, como definidos anteriormente, ocorrem em $k=m=1$, outRe[1], e $k=N-m=8-1=7$, outRe[7], como pode ser verificado na Figura 5.3.1.2.

A segunda entrada composta no programa DFT.c é um sinal seno de comprimento $N=20$, composto por dois ciclos, multiplicado por 1000 , cuja freqüência $f=800 \mathrm{~Hz}$, assim,

$$
x(n)=1000 \times \operatorname{sen}(2 \pi n 2 / 20)=x(n)=1000 \times \cos (\pi n / 5)
$$

Logo, através da implementação na ferramenta MATLAB 7.0, do código que se encontra no anexo I, como pode ser visto na Figura 5.3.1.4 os valores obtidos pelo seno são:

$x[N]=\{0,602,974,974,602,0,-602,-974,-974,-602,0,602,974,974,602,0,-602,-974,-974,-602\}$

Ao contrário do sinal cosseno, o sinal seno possui a parte real próxima de zero quando comparada à parte imaginária como pode ser observado nas Figuras 5.3.1.5 e 5.3.1.6.

Os picos da parte imaginária ocorrem em $k=m=2$, outIm[2], e $k=N-m=18$, outIm [18], como pode ser verificado na Figura 5.3.1.6. 


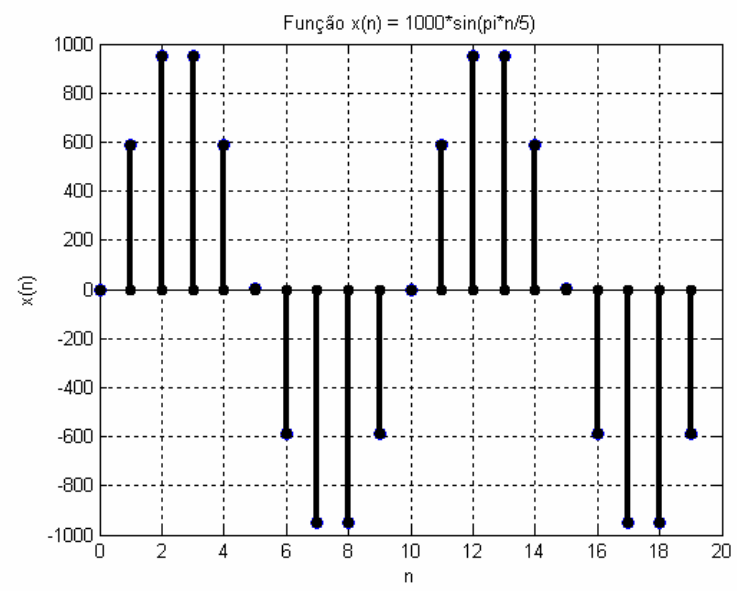

Figura 5.3.1.4 - Gráfico da função $x(n)=1000 \times \operatorname{sen}\left(\frac{\pi}{5} n\right)$; Freqüência do sinal $f=800 \mathrm{~Hz}$ e Freqüência de amostragem $F_{s}=8000 \mathrm{~Hz}$.

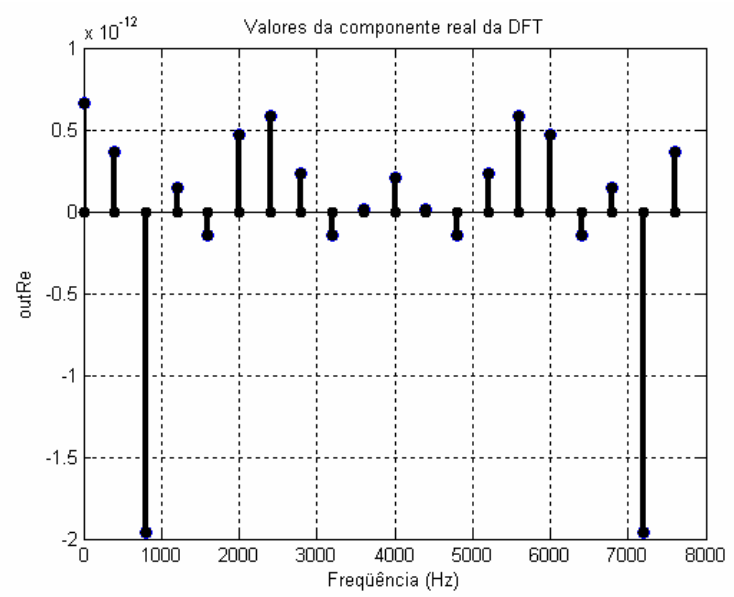

Figura 5.3.1.5 - Valores da componente real (outRe) da DFT de $N=20$ gerada no MATLAB.

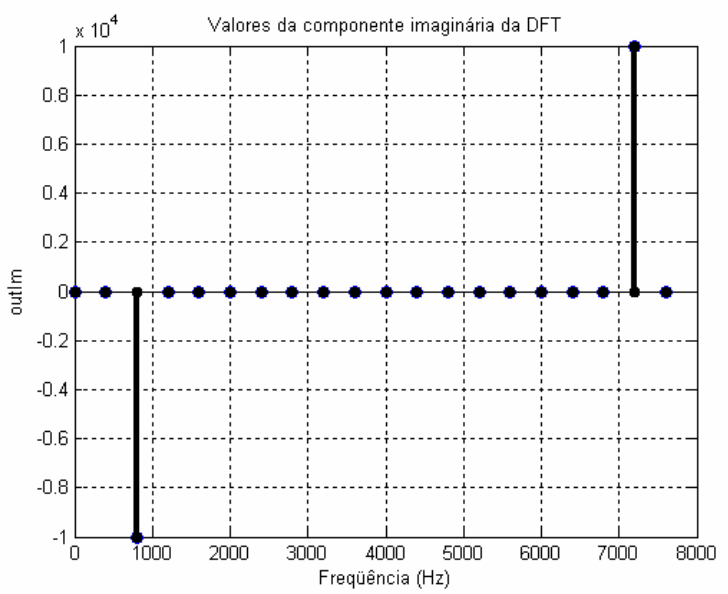

Figura 5.3.1.6 - Valores da componente imaginária (outlm) da DFT de $N=20$ gerada no MATLAB. 


\section{Criação do projeto}

Para criar este projeto no Code Composer Studio ${ }^{\mathrm{TM}}$ IDE, é preciso adicionar os arquivos necessários à construção do projeto DFT, como fora feito nos exemplos anteriores.

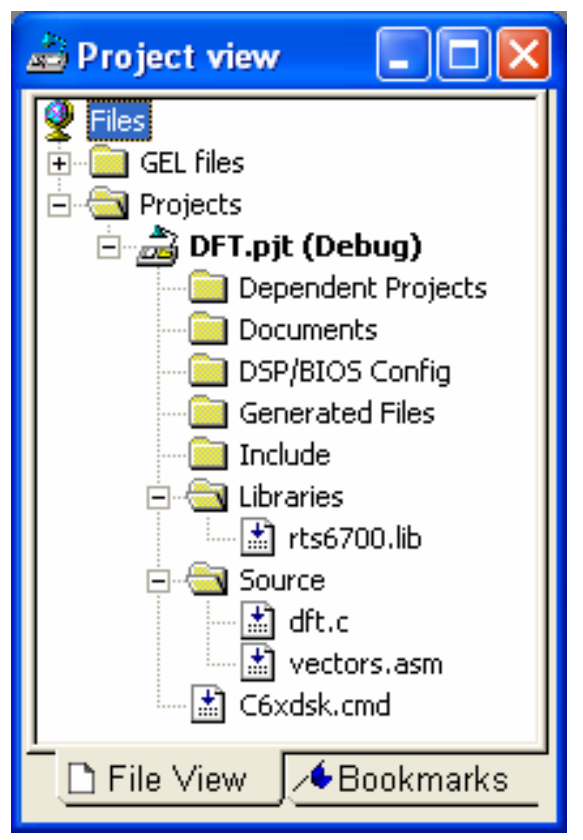

Figura 5.3.1.7 - Visualização do projeto.

Para gerar o executável e carregar o programa utilizam-se as mesmas configurações dos parâmetros do compilador e do linker como fora feito no terceiro tutorial.

\section{Obtenção da DFT no CCS}

Para obter a DFT no CCS é necessário que você:

1. Selecione View $\rightarrow$ Watch Window. Ao abrir a janela clique na aba Watch 1 e escreva outRe e outIm. 


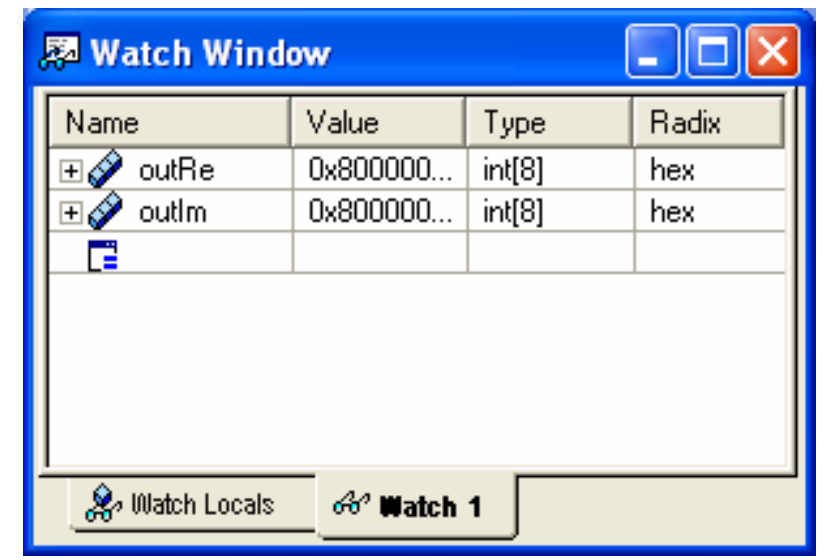

Figura 5.3.1.8 - Visualização da janela Watch Window para $N=8$.

Como a função cosseno corresponde à primeira entrada, então se observa na Figura 5.3.1.8 que a coluna Type refere-se ao comprimento da DFT.

Logo ao expandir na coluna Name outRe e outIm obtém-se os valores respectivos das componentes real e imaginária da DFT.

\begin{tabular}{|c|c|c|c|c|c|}
\hline \multicolumn{3}{|c|}{ Watch Window } & $=$ & $\square$ & $x$ \\
\hline Name & Value & Type & Radix & & $\Delta$ \\
\hline - $\forall$ outRe & 0x8000009C & int[8] & hex & & \\
\hline$\vartheta[0]$ & 0 & int & dec & & \\
\hline$\bullet[1]$ & 3996 & int & dec & & \\
\hline$\ominus[2]$ & 0 & int & dec & & \\
\hline$\bullet[3]$ & 0 & int & dec & & \\
\hline$\bullet[4]$ & 0 & int & dec & & \\
\hline$\bullet[5]$ & 0 & int & dec & & \\
\hline$\vartheta[6]$ & 0 & int & dec & & \\
\hline$\theta[7]$ & 3996 & int & dec & & \\
\hline$\nabla \otimes$ outlm & $0 \times 800000 \mathrm{BC}$ & int[8] & hex & & \\
\hline$\vartheta[0]$ & 0 & int & dec & & \\
\hline$\bullet[1]$ & 0 & int & dec & & \\
\hline$\bullet[2]$ & 1 & int & dec & & \\
\hline$\bullet[3]$ & 0 & int & dec & & \\
\hline$\theta[4]$ & 0 & int & dec & & \\
\hline$\vartheta[5]$ & 0 & int & dec & & \\
\hline$\theta[6]$ & 0 & int & dec & & \\
\hline$\theta[7]$ & 0 & int & dec & & $\nabla$ \\
\hline \& of llatch Locals & or Watch 1 & & & & \\
\hline
\end{tabular}

Figura 5.3.1.9 - Componentes real (outRe) e imaginária (outlm) da DFT de $N=8$. 

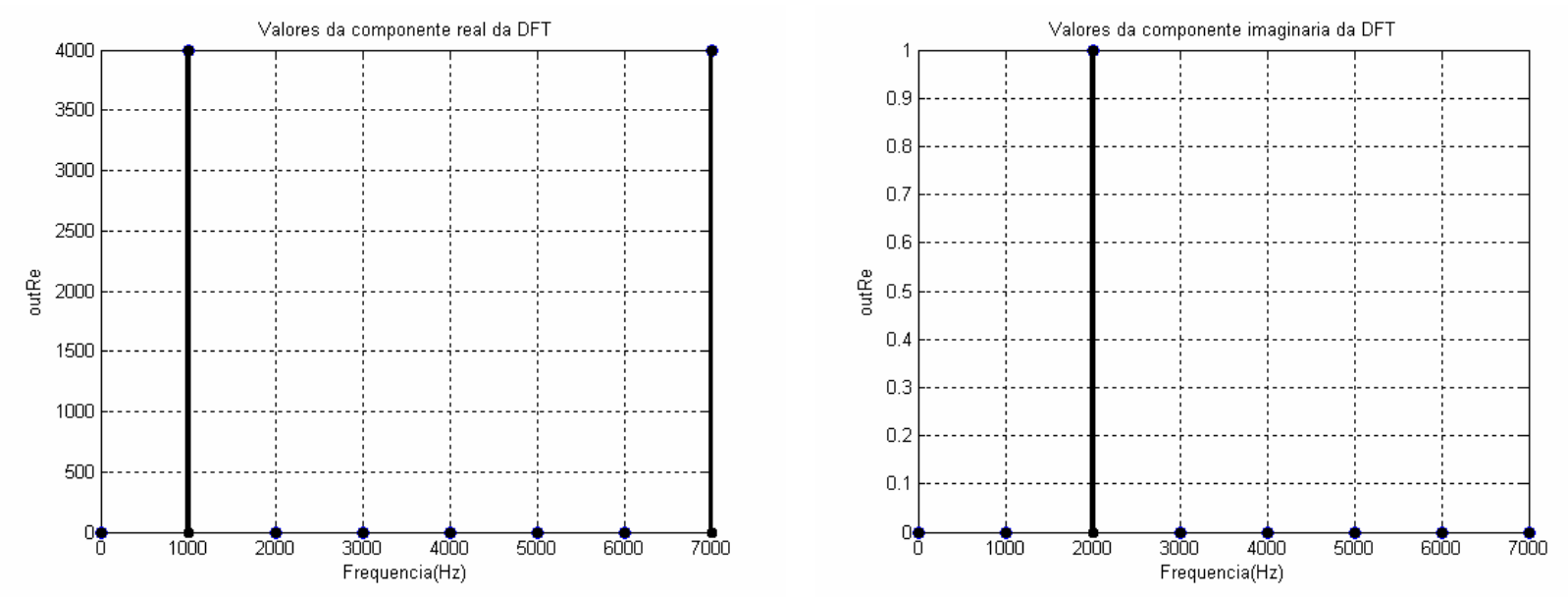

Figura 5.3.1.10 - Componentes real (outRe) e imaginária (outlm) da DFT de $N=8$ geradas no MATLAB.

A Figura 5.3.1.11 mostra a análise da complexidade da função "dft" por meio do Profile Viewer apresentado no Capítulo 2, Tutorial 1, Exemplo 5.

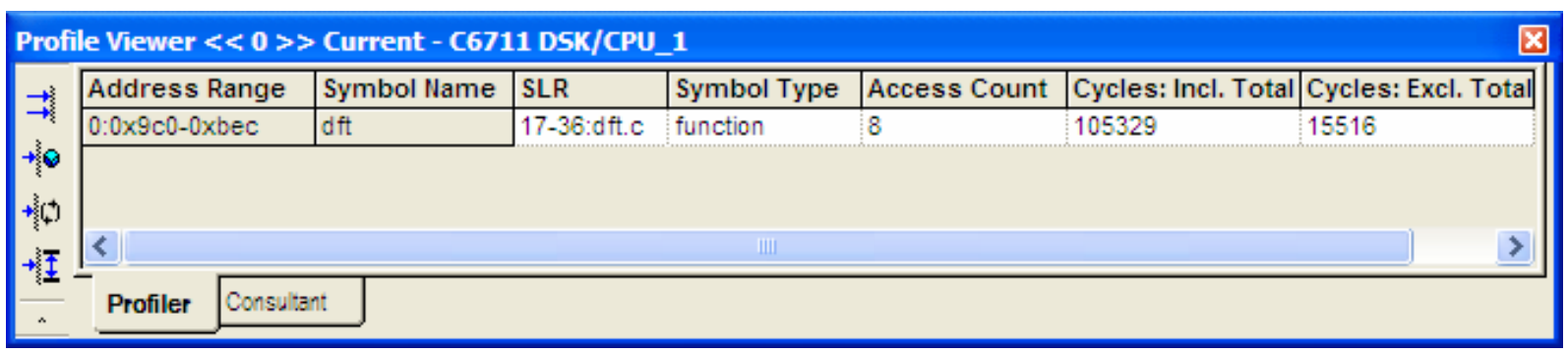

Figura 5.3.1.11 - Complexidade da função dft.c de uma DFT de comprimento $N=8$.

A função $d f t . c$ neste caso foi acessada 8 vezes, foram necessários 15516 ciclos para execução da função, entretanto incluindo as sub-rotinas foram necessários 105329 ciclos.

Considerando o sinal seno como entrada, e fazendo as modificações necessárias no código dft.c é possível obter: 


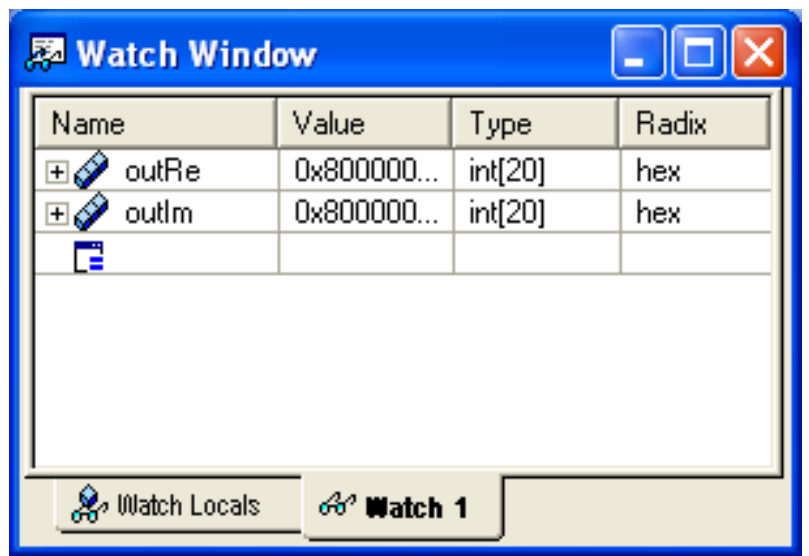

Figura 5.3.1.12 - Visualização da janela Watch Window para $N=20$.

\begin{tabular}{|c|c|c|c|c|}
\hline \multicolumn{4}{|l|}{ Watch Window } & \multirow{2}{*}{$\underline{x}$} \\
\hline Name & Value & Type & Radix & \\
\hline$\square \otimes$ outRe & $0 \times 80000028$ & int[20] & hex & \\
\hline$\vartheta[0]$ & 0 & int & dec & \\
\hline$\theta[1]$ & -7 & int & dec & \\
\hline$\bullet[2]$ & -5 & int & dec & \\
\hline$\ominus[3]$ & 4 & int & dec & \\
\hline$\theta[4]$ & 2 & int & dec & \\
\hline$\bullet[5]$ & 1 & int & dec & \\
\hline$\vartheta[6]$ & 5 & int & dec & \\
\hline$\theta[7]$ & 2 & int & dec & \\
\hline$\bullet[8]$ & 1 & int & dec & \\
\hline$\bullet[9]$ & 1 & int & dec & \\
\hline$\bullet[10]$ & 0 & int & dec & \\
\hline$\bullet[11]$ & 2 & int & dec & \\
\hline$\bullet[12]$ & 2 & int & dec & \\
\hline$\bullet[13]$ & 3 & int & dec & \\
\hline$\bullet[14]$ & 4 & int & dec & \\
\hline$\bullet[15]$ & 0 & int & dec & \\
\hline$\bullet[16]$ & 3 & int & dec & \\
\hline$\bullet[17]$ & 2 & int & dec & \\
\hline$\bullet[18]$ & 0 & int & dec & \\
\hline$\bullet[19]$ & -8 & int & dec & $\nabla$ \\
\hline of Watch Locals & of Watch 1 & & & \\
\hline
\end{tabular}

Figura 5.3.1.13 - Valores da componente real (outRe) da DFT de $N=20$. 


\begin{tabular}{|c|c|c|c|c|}
\hline \multicolumn{4}{|l|}{ Watch Window } & \multirow{2}{*}{$\underline{x}$} \\
\hline Name & Value & Type & Radix & \\
\hline$\pm \otimes$ out $\operatorname{Re}$ & $0 \times 80000028$ & int[20] & hex & \\
\hline$-\otimes$ outlm & $0 \times 80000078$ & int[20] & hex & \\
\hline$\vartheta[0]$ & 0 & int & dec & \\
\hline$\bullet[1]$ & 0 & int & dec & \\
\hline$\ominus[2]$ & -10232 & int & dec & \\
\hline$\bullet[3]$ & -1 & int & dec & \\
\hline$\Leftrightarrow[4]$ & 0 & int & dec & \\
\hline$\vartheta[5]$ & 0 & int & dec & \\
\hline$\bullet[6]$ & 0 & int & dec & \\
\hline$\ominus[7]$ & 1 & int & dec & \\
\hline$\ominus[8]$ & 0 & int & dec & \\
\hline$\bullet[9]$ & -1 & int & dec & \\
\hline$\diamond[10]$ & 0 & int & dec & \\
\hline$\bullet[11]$ & -1 & int & dec & \\
\hline$\bullet[12]$ & 0 & int & dec & \\
\hline$\bullet[13]$ & 0 & int & dec & \\
\hline$\bullet[14]$ & 0 & int & dec & \\
\hline$\bullet[15]$ & 0 & int & dec & \\
\hline$\diamond[16]$ & 0 & int & dec & \\
\hline$\bullet[17]$ & 1 & int & dec & \\
\hline$\bullet[18]$ & 10232 & int & dec & \\
\hline$\bullet[19]$ & 1 & int & dec & $\checkmark$ \\
\hline \&o Watch Locals & of Watch 1 & & & \\
\hline
\end{tabular}

Figura 5.3.1.14 - Valores da componente imaginária (outlm) da DFT de $N=20$.
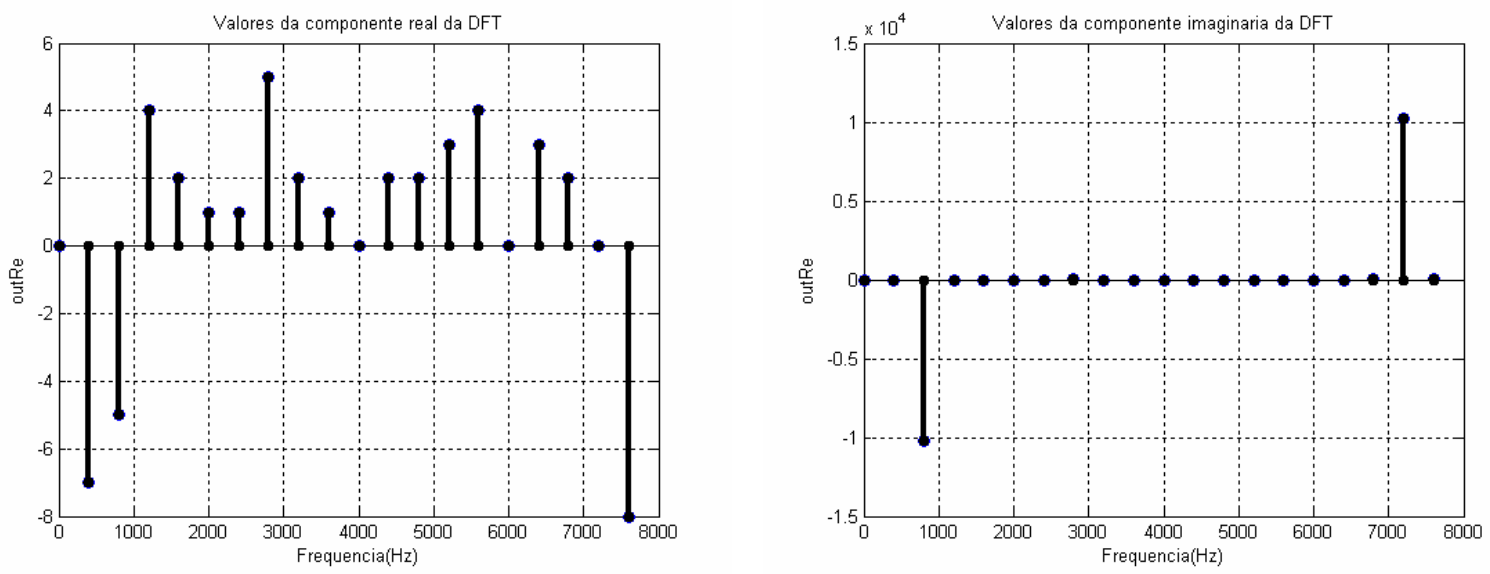

Figura 5.3.1.15 - Componentes real (outRe) e imaginária (outIm) da DFT de $N=20$ geradas no MATLAB.

A Figura 5.3.1.16 mostra a análise da complexidade da função "dft".

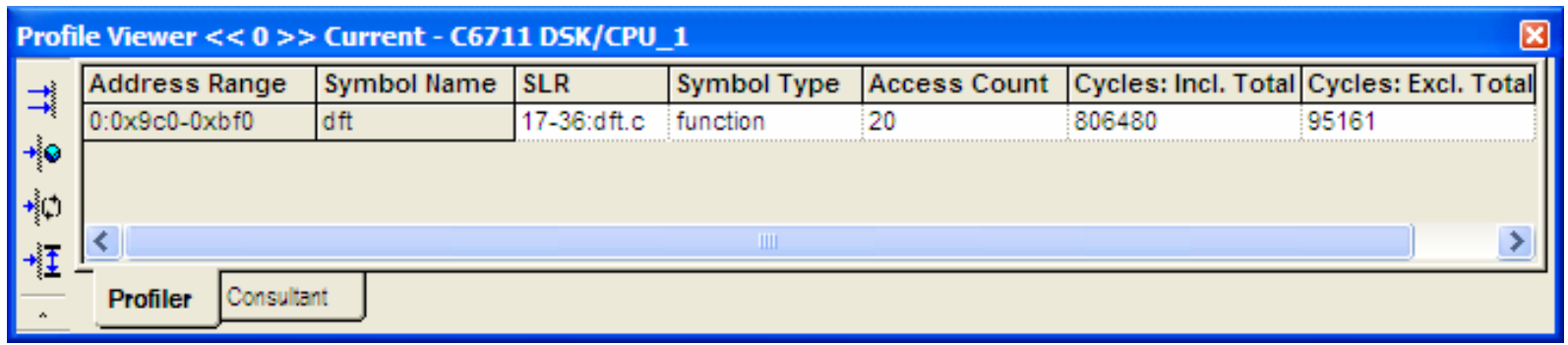

Figura 5.3.1.16 - Complexidade da função dft.c de uma DFT de comprimento $N=20$. 
A função $d f t . c$ para o sinal seno foi acessada 20 vezes, foram necessários 95161 ciclos para execução da função, entretanto ao incluir as sub-rotinas foram necessários 806480 ciclos.

Devido à limitação na precisão do $D S P$ o gráfico da componente imaginária da função cosseno obtida, Figura 5.3.1.10, é diferente do gráfico apresentado na parte teórica, Figura 5.3.1.3, mas ambos quando comparados a componente real tendem a zero. Este tipo de limitação também pode ser observado quando comparados os gráficos da componente real do sinal seno, Figura 5.3.1.15 e Figura 5.3.1.5.

\subsubsection{Exemplo 2: FFT formulada por Danielson -Lanczos.}

Esse exemplo tem como objetivo ilustrar a transformada rápida de Fourier (FFT) através da implementação do código fft.c, algoritmo este formulado por DanielsonLanczos, de uma seqüência de $N$ - pontos, utilizando alguns recursos do CCS.

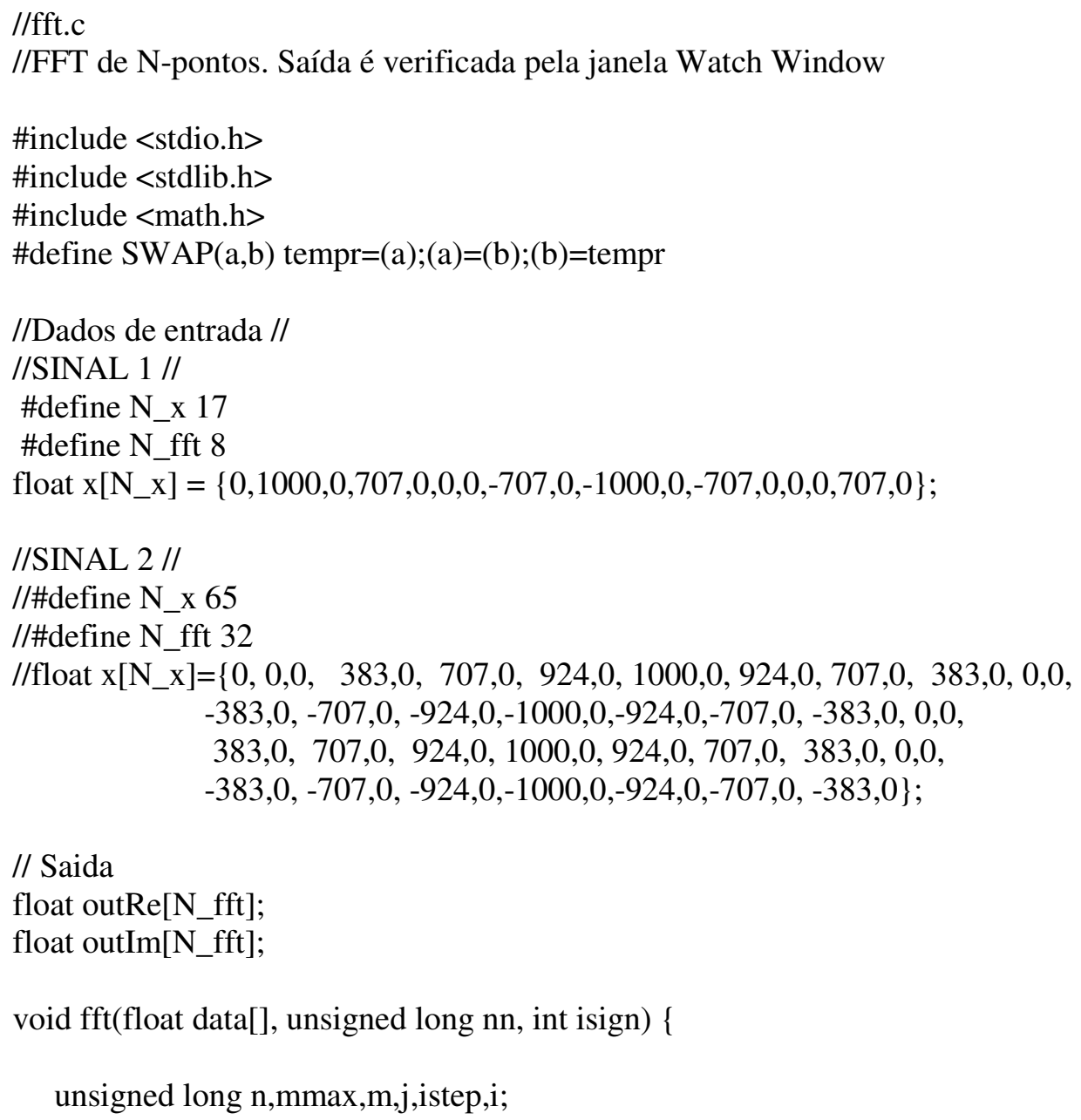

// Saida

float outRe[N_fft];

float outIm[N_fft];

void fft(float data[], unsigned long $\mathrm{nn}$, int isign) \{

unsigned long n,mmax,m,j,istep,i; 
double wtemp,wr,wpr,wpi,wi,theta;

float tempr,tempi;

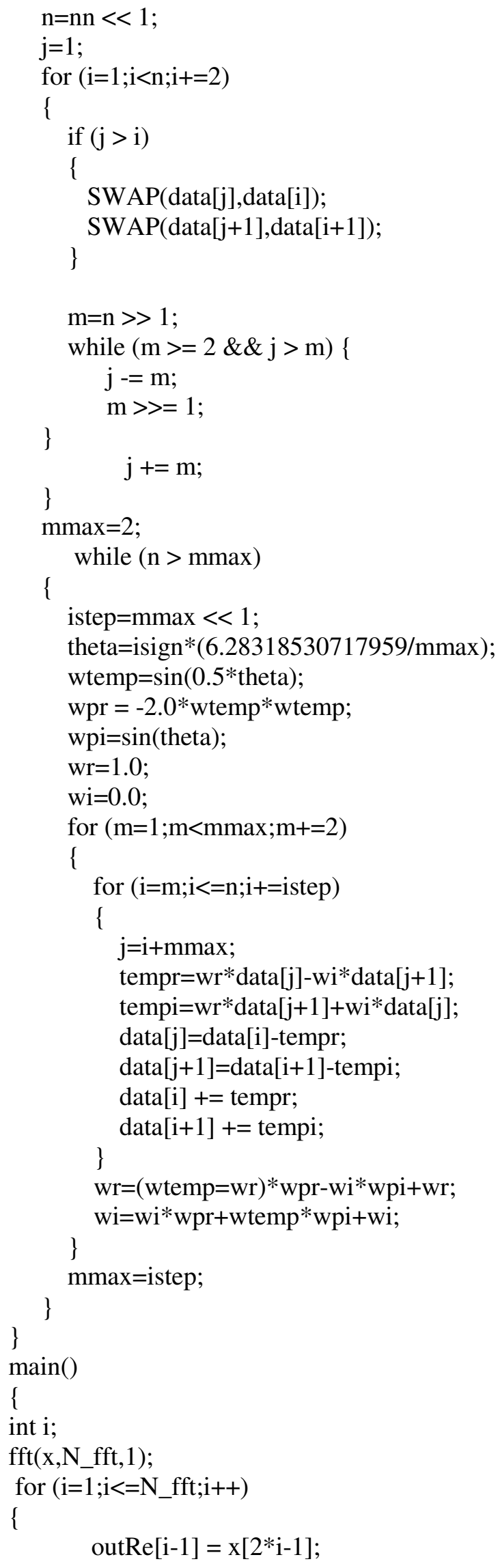




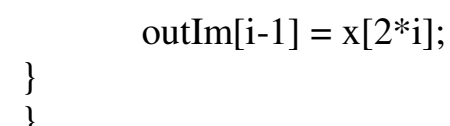

\section{Considerações sobre o programa}

Sabe-se que Danielson e Lanczos mostraram que a DFT poderia ser reescrita como a soma de duas outras, uma formada por pontos pares (e), e outra por pontos ímpares (o), cada uma de tamanho $N / 2$, como fora feito em (5.8). Logo a Equação (5.12) é representada por.

$$
F_{k}=F_{k}^{e}+W_{N}^{k} F_{k}^{o}
$$

A aplicação deste Teorema só é possível quando $N$ é potência de 2, caso a FFT em questão não tenha potência de dois, zeros serão acrescentados até que FFT atinja a próxima potência de dois.

Uma vez que $N$ da FFT é uma potência de dois o Teorema de Danielson e Lanczos é utilizado até que o comprimento desta seja igual a um. Neste caso uma forma de solucionar o principal problema, ou seja, o de combinar as transformadas de ordem 2 , depois as de ordem 4 e assim sucessivamente, seria combinar os pares adjacentes de elementos, depois combinar elementos resultantes em pares adjacentes e assim por diante. Este tipo de combinação, entre pares adjacentes, é possível através da reordenação dos elementos.

Logo ao aplicar-se sucessivas divisões entre pares e ímpares até obter uma transformada de 1 termo:

$$
F_{k}^{\text {eoeеoео...еeе }}=f_{n}
$$

Neste caso $f_{n}$ não depende de $k$, então é preciso descobrir quem é $n$ no conjunto original. Substituindo os e's e os o's por 0's e 1's, respectivamente, um número binário é obtido. $\mathrm{O}$ valor de $n$ é exatamente este número com a ordem dos bits invertida. Isto acontece porque as subdivisões sucessivas em pares e ímpares são testes sucessivos de bits de baixa ordem $n$.

A primeira divisão entre pares e ímpares de um sinal de 8 pontos, como o SINAL 1, do código fft.c, $\{f(0), f(1), f(2), f(3), f(4), f(5), f(6), f(7)\}$ resulta em dois conjuntos $\{f(0), f(2), f(4), f(6)$,$\} e \{f(1), f(3), f(5), f(7)\}$, já a divisão destes resultará em quatro 
conjuntos $\{f(0), f(4)\},\{f(2), f(6)\},\{f(1), f(5)\},\{f(3), f(7)\}$. Este tipo de reordenação é verificado na primeira parte do código fft.c.

Tabela 5.3.1 - Reordenação utilizando a inversão de Bits

\begin{tabular}{|l|l|l|l|}
\hline $\begin{array}{c}\text { Conjunto } \\
\text { Original }\end{array}$ & Índice & \multicolumn{1}{|c|}{$\begin{array}{c}\text { Conjunto } \\
\text { Reordenado }\end{array}$} & Índice \\
\hline $\mathrm{f}(0)$ & 000 & $\mathrm{f}(0)$ & 000 \\
\hline $\mathrm{f}(1)$ & 001 & $\mathrm{f}(4)$ & 100 \\
\hline $\mathrm{f}(2)$ & 010 & $\mathrm{f}(2)$ & 010 \\
\hline $\mathrm{f}(3)$ & 011 & $\mathrm{f}(6)$ & 110 \\
\hline $\mathrm{f}(4)$ & 100 & $\mathrm{f}(1)$ & 001 \\
\hline $\mathrm{f}(5)$ & 101 & $\mathrm{f}(5)$ & 101 \\
\hline $\mathrm{f}(6)$ & 110 & $\mathrm{f}(3)$ & 011 \\
\hline $\mathrm{f}(7)$ & 111 & $\mathrm{f}(7)$ & 111 \\
\hline
\end{tabular}

A segunda parte do código fft.c possui um laço externo que é executado $\log _{2} N$ vezes e calcula, em ordem, a transformada do comprimento $2,4,8, \ldots, N$. Para cada estágio deste processo, dois laços internos aninhados escalam sobre as transformadas já computadas e os elementos de cada um transformam, implementando desta forma o Teorema de Danielson-Lanczos. A operação é feita mais eficiente por chamadas externas de restrição para senos e cossenos trigonométricos ao laço exterior, aonde ele é feito somente $\log _{2} N$ vezes. A computação de senos e cossenos de ângulos múltiplos são através da simples relação de recorrência no laço interno.

$\mathrm{O}$ código fft.c tem como entrada o número de pontos de dados complexos $n n$, o array de dados (data[1...2*nn]), e isign, o qual deve ser ajustado para \pm 1 o que representa o sinal de $i$ na exponencial em (5.1). Quando isign for igual a -1 a rotina calculará a transformada inversa sem multiplicação da mesma pelo termo $1 / N$, equação (5.27).

O array de entrada contém um comprimento de $2 \times n n$, onde cada valor complexo ocupa duas localizações consecutivas, ou seja, data[1] é a parte real de $f_{0}$, e data [2] a parte imaginária do mesmo, e assim consecutivamente até data[2*nn-1] que representa a parte real de $f_{N-1}$ e data[2*nn] que é a parte imaginária deste. 
O array de saída contém o espectro complexo de Fourier com $N$ valores de freqüência. Ou seja, a parte real e imaginária da freqüência zero (componentes de $F_{0}$ ) estão localizados em data[1] e data[2], logo a menor frequiência positiva tem suas componentes real e imaginária localizadas em data[3]e data[4], com o aumento da magnitude as partes real e imaginária são armazenadas em data[5] e data[6], assim sucessivamente até data[nn-1], data [nn]. Consequentemente a menor freqüência negativa diferente de zero tem parte real em data[2*nn-1] e a parte imaginária em data[2*nn], a próxima freqüência é armazenada em data[2*nn-3], data [2*nn-2], e assim sucessivamente até data[nn+3] e data[nn+4]. Logo data[nn+1] e data[nn+2] contém as partes reais e imaginárias das freqüências mais positivas e mais negativas, acarretando desta forma num ponto de alias.

O SINAL 1 observado no código fft.c é o mesmo sinal cosseno utilizado no exemplo anterior no código dft.c., como apresentado na Figuras (5.3.1.1), (5.3.1.2) e (5.3.1.3).

O SINAL 2 a ser processado é um sinal seno de comprimento $N=32$, multiplicado por 1000 , cuja freqüência é $f=500 \mathrm{~Hz}$, assim,

$$
x(n)=1000 \times \operatorname{sen}(2 \pi n 2 / 32)=x(n)=1000 \times \cos (\pi n / 8)
$$

Através da implementação na ferramenta MATLAB 7.0, do código que se encontra no anexo I, obtém-se:

$$
\begin{aligned}
x[N]= & \{0,0,0,383,0,707,0,924,0,1000,0,924,0,707,0,383,0,0,0,-383,0,-707,0,-924, \\
& 0,-1000,0,-924,0,-707,0,-383,0,0,0,383,0,707,0,924,0,1000,0,924,0,707,0,383, \\
& 0,0,0,-383,0,-707,0,-924,0,-1000,0,-924,0,-707,0,-383,0\}
\end{aligned}
$$

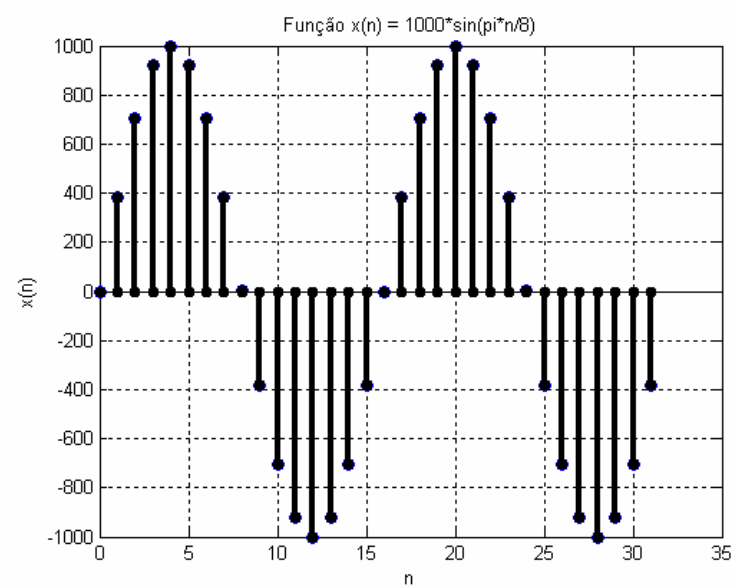

Figura 5.3.2.1 -Gráfico da função $x(n)=1000 * \sin \left(\frac{\pi}{8} n\right)$; Freqüência do sinal $f=500 \mathrm{~Hz}$ e Freqüência de amostragem $F_{s}=8000 \mathrm{~Hz}$. 
A Figura 5.3.2.2 representa graficamente os valores das componentes real da FFT, (outRe), e dos valores da componente imaginária desta FFT, (outIm).
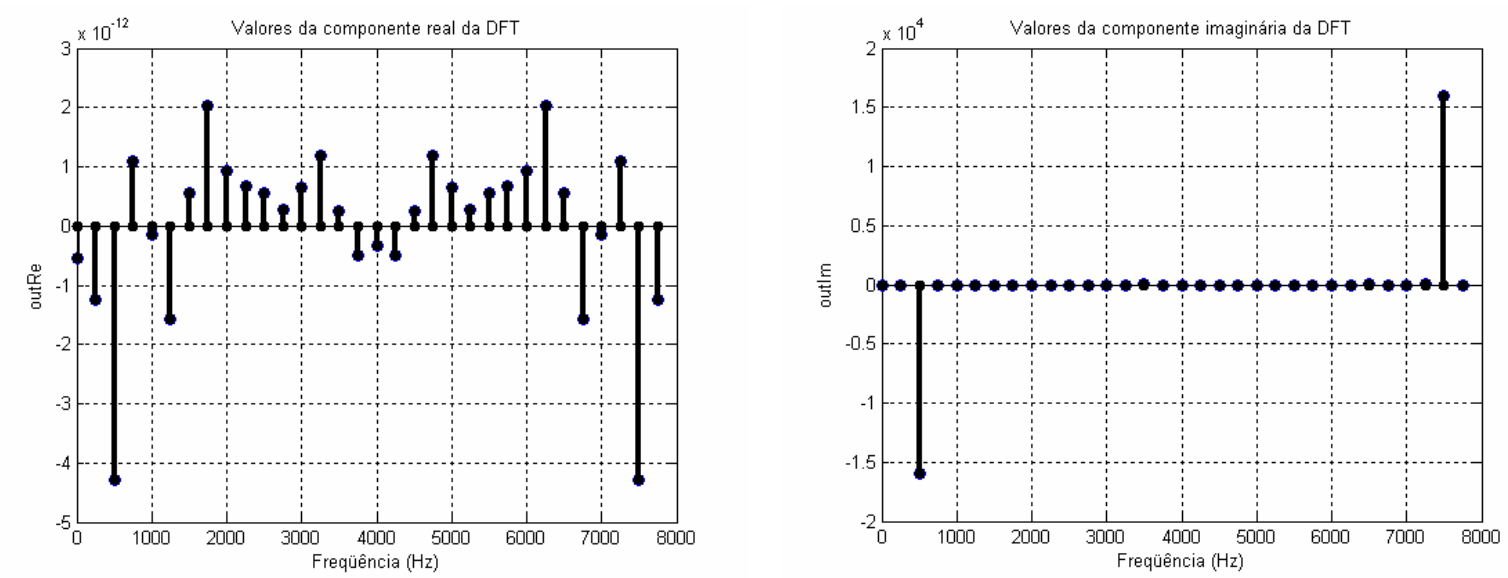

Figura 5.3.2.2 - Componentes real (outRe) e imaginária (outlm) da FFT de $N=32$ geradas no MATLAB.

\section{Criação do projeto}

Para criar este projeto no Code Composer Studio ${ }^{\mathrm{TM}}$ IDE, é preciso adicionar os arquivos necessários à construção do projeto FFT, ou seja, fft.c, vector.asm, C6xdsk.cmd e rts6700.lib, que estão presente na pasta $F F T$ do $c d$ fornecido.

Após a construção do projeto gere o executável e carregue o programa utilizando as mesmas configurações dos parâmetros do compilador e do linker como fora feito no projeto da DFT.

\section{Obtenção da FFT no $C C S$}

Para obter a FFT no CCs é necessário que você realize os mesmos comandos realizados na DFT e assim selecione a janela Watch Window, indicando na barra Watch 1 outRe e outIm. Logo ao expandir a coluna Name, outRe e outIm obtém-se os valores respectivos das componentes real e imaginária da FFT.

Logo ao considerar o SINAL 1, obtém-se a seguinte resposta. 


\begin{tabular}{|c|c|c|c|c|}
\hline \multicolumn{4}{|c|}{ Watch Window } & \multirow{2}{*}{$\underline{x}$} \\
\hline Name & Value & Type & Radix & \\
\hline$\nabla \hat{y}$ outRe & $0 \times 80000000$ & float... & hex & \\
\hline$\theta[0]$ & 0.0 & float & float & \\
\hline$\bullet[1]$ & 3999.698 & float & float & \\
\hline$\bullet[2]$ & 0.0 & float & float & \\
\hline$\bullet[3]$ & 0.302002 & float & float & \\
\hline$\bullet[4]$ & 0.0 & float & float & \\
\hline$\bullet[5]$ & 0.302002 & float & float & \\
\hline$\vartheta[6]$ & 0.0 & float & float & \\
\hline$\bullet[7]$ & 3999.698 & float & float & \\
\hline$-\otimes y_{\text {out } I m}$ & Cx800000F0 & float... & hex & \\
\hline$\vartheta[0]$ & 0.0 & float & float & \\
\hline$\theta[1]$ & $7.958079 \mathrm{e}-13$ & float & float & \\
\hline$\bullet[2]$ & 0.0 & float & float & \\
\hline$\bullet[3]$ & $-2.273737 e-12$ & float & float & \\
\hline$\vartheta[4]$ & 0.0 & float & float & \\
\hline$\bullet[5]$ & $-7.958079 \mathrm{e}-13$ & float & float & \\
\hline$\vartheta[6]$ & 0.0 & float & float & \\
\hline$\theta[7]$ & $2.273737 e-12$ & float & float & $\checkmark$ \\
\hline \multicolumn{2}{|c|}{ \&o Watch Locals ar Watch 1} & & & \\
\hline
\end{tabular}

Figura 5.3.2.3 - Componentes real (outRe) e imaginária (outlm) da FFT de $N=8$.

A Figura 5.3.2.4 mostra a análise da complexidade da função "fft".

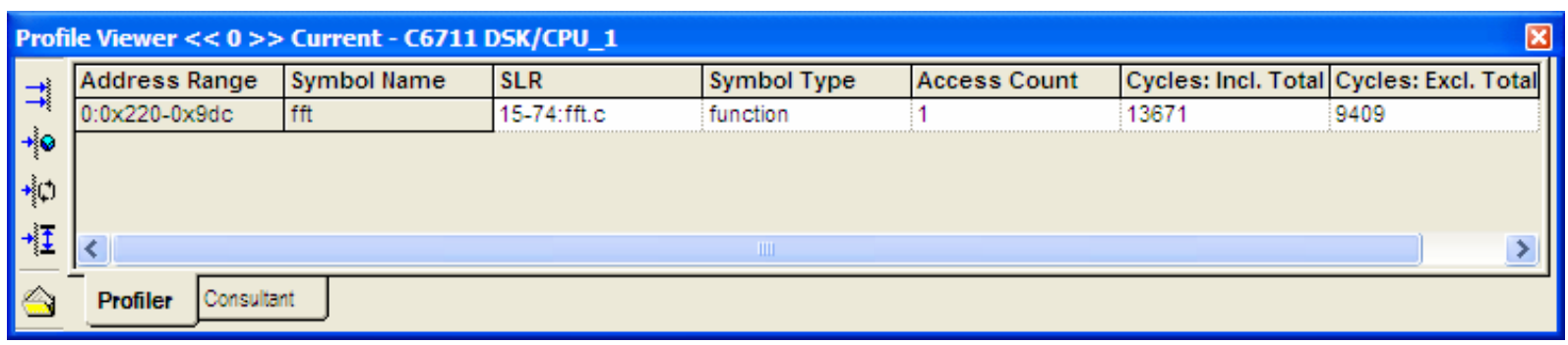

Figura 5.3.2.4 - Complexidade da função fft.c de uma FFT de comprimento $N=8$.

Logo pode ser verificada na Figura 5.3.2.4 a diminuição tanto do Cycles: Incl.Total quanto do Cycles: Excl.Total, ou seja, dos custos dos ciclos de clock, quando comparada com a Figura 5.3.1.11 que representa a complexidade da função dft.c de uma DFT de comprimento de $N=8$.

Fazendo as modificações necessárias no código fft.c e implementando o sinal seno, SINAL 2, obtém-se as seguintes componentes: 


\begin{tabular}{|c|c|c|c|c|}
\hline \multicolumn{4}{|c|}{ Watch Window } & \multirow{2}{*}{$\underline{\underline{x}}$} \\
\hline Name & Value & Type & Radix & \\
\hline$\square \hat{y}$ outRe & $0 \times 80000104$ & float.. & hex & \\
\hline$\vartheta[0]$ & 0.0 & float & float & \\
\hline$\bullet[1]$ & 0.0 & float & float & \\
\hline$\bullet[2]$ & 0.0002475658 & float & float & \\
\hline$\bullet[3]$ & 0.0 & float & float & \\
\hline$\Leftrightarrow[4]$ & 0.0 & float & float & \\
\hline$\bullet[5]$ & 0.0 & float & float & \\
\hline$\theta[6]$ & $9.289657 \mathrm{e}-05$ & float & float & \\
\hline$\bullet[7]$ & 0.0 & float & float & \\
\hline$\bullet[8]$ & 0.0 & float & float & \\
\hline$\bullet[9]$ & 0.0 & float & float & \\
\hline$\diamond[10]$ & $-9.289657 e-05$ & float & float & \\
\hline$\diamond[11]$ & 0.0 & float & float & \\
\hline$\bullet[12]$ & 0.0 & float & float & \\
\hline$\bullet[13]$ & 0.0 & float & float & \\
\hline$\bullet[14]$ & -0.0002475658 & float & float & \\
\hline$\bullet[15]$ & 0.0 & float & float & \\
\hline$\bullet[16]$ & 0.0 & float & float & \\
\hline$\diamond[17]$ & 0.0 & float & float & \\
\hline$\bullet[18]$ & -0.0002475658 & float & float & \\
\hline$\bullet[19]$ & 0.0 & float & float & \\
\hline$\diamond[20]$ & 0.0 & float & float & \\
\hline$\bullet[21]$ & 0.0 & float & float & \\
\hline$\diamond[22]$ & $-9.289657 \mathrm{e}-05$ & float & float & \\
\hline$\bullet[23]$ & 0.0 & float & float & \\
\hline$\bullet[24]$ & 0.0 & float & float & \\
\hline$\bullet[25]$ & 0.0 & float & float & \\
\hline$\bullet[26]$ & $9.289657 \mathrm{e}-05$ & float & float & \\
\hline$\diamond[27]$ & 0.0 & float & float & \\
\hline$\bullet[28]$ & 0.0 & float & float & \\
\hline$\bullet[29]$ & 0.0 & float & float & \\
\hline$\diamond[30]$ & 0.0002475658 & float & float & \\
\hline$\bullet[31]$ & 0.0 & float & float & - \\
\hline \&o Watch Lo & or Watch 1 & & & \\
\hline
\end{tabular}

Figura 5.3.2.5 - Valores da componente real (outRe) e da FFT de $N=32$. 


\begin{tabular}{|c|c|c|c|c|}
\hline \multicolumn{4}{|c|}{ Watch Window } & \multirow{2}{*}{$\frac{x}{\Delta}$} \\
\hline Name & Value & Type & Radix & \\
\hline$\nabla \hat{y}_{\text {out } / \mathrm{m}}$ & C×80000184 & float.. & hex & \\
\hline$\vartheta[0]$ & 0.0 & float & float & \\
\hline$\bullet[1]$ & 0.0 & float & float & \\
\hline$\bullet[2]$ & 16001.26 & float & float & \\
\hline$\bullet[3]$ & 0.0 & float & float & \\
\hline$\ominus[4]$ & 0.0 & float & float & \\
\hline$\Leftrightarrow[5]$ & 0.0 & float & float & \\
\hline$\Leftrightarrow[6]$ & 1.36691 & float & float & \\
\hline$\bullet[7]$ & 0.0 & float & float & \\
\hline$\Leftrightarrow[8]$ & 0.0 & float & float & \\
\hline$\Leftrightarrow[9]$ & 0.0 & float & float & \\
\hline$\bullet[10]$ & 2.574918 & float & float & \\
\hline$\bullet[11]$ & 0.0 & float & float & \\
\hline$\Leftrightarrow[12]$ & 0.0 & float & float & \\
\hline$\bullet[13]$ & 0.0 & float & float & \\
\hline$\bullet[14]$ & 2.463379 & float & float & \\
\hline$\bullet[15]$ & 0.0 & float & float & \\
\hline$\bullet[16]$ & 0.0 & float & float & \\
\hline$\diamond[17]$ & 0.0 & float & float & \\
\hline$\bullet[18]$ & -2.463379 & float & float & \\
\hline$\bullet[19]$ & 0.0 & float & float & \\
\hline$\bullet[20]$ & 0.0 & float & float & \\
\hline$\bullet[21]$ & 0.0 & float & float & \\
\hline$\bullet[22]$ & -2.574918 & float & float & \\
\hline$\bullet[23]$ & 0.0 & float & float & \\
\hline$\bullet[24]$ & 0.0 & float & float & \\
\hline$\bullet[25]$ & 0.0 & float & float & \\
\hline$\bullet[26]$ & -1.36691 & float & float & \\
\hline$\diamond[27]$ & 0.0 & float & float & \\
\hline$\bullet[28]$ & 0.0 & float & float & \\
\hline$\Leftrightarrow[29]$ & 0.0 & float & float & \\
\hline$\diamond[30]$ & -16001.26 & float & float & \\
\hline$\bullet[31]$ & 0.0 & float & float & - \\
\hline \&os Watch 1 & of Watch & & & \\
\hline
\end{tabular}

Figura 5.3.2.6 - Valores da componente imaginária (outlm) da FFT de $N=32$.

A Figura 5.3.1.16 mostra a análise da complexidade da função "fft".

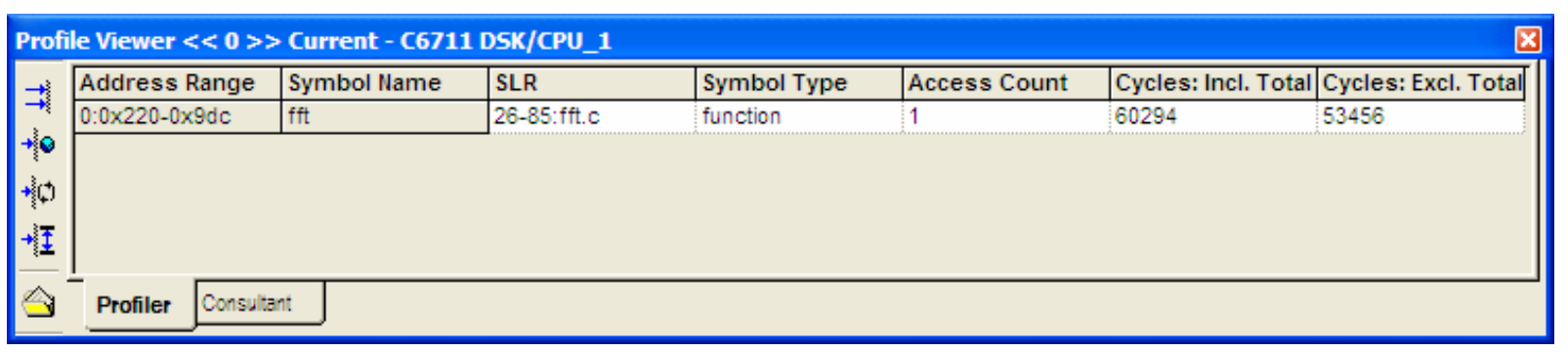

Figura 5.3.2.7 - Complexidade da função fft.c de uma FFT de comprimento $N=32$. 


\section{6 - TUTORIAL 5: FILTROS ADAPTATIVOS}

\subsection{OBJETIVO}

- Introdução do conceito sobre estruturas adaptáveis

- Estudo do Algoritmo do gradiente estocástico - Least Mean Square

- Programação de identificação de sistema utilizando C e o TMS320C6711 DSK

Esse tutorial tem por finalidade apresentar o conceito sobre filtros adaptativos, de suas estruturas e características básicas, de algoritmos adaptativos, e aplicações importantes. Projetar um exemplo de filtro adaptativo utilizando processador DSP de ponto flutuante, TMS320C6711 DSK.

\subsection{INTRODUÇÃO}

\subsubsection{Filtros adaptativos}

Nos filtros digitais convencionais FIR e IIR, como visto anteriormente, os parâmetros do processo que determinam as características dos filtros já são conhecidos e podem variar com o tempo, uma vez que a natureza da variação é também conhecida. Entretanto muitos problemas práticos não podem ser solucionados com a implementação dos filtros digitais fixos ou por não possuir informação suficiente para projetar o filtro com coeficientes fixos, havendo assim uma grande incerteza com relação a alguns parâmetros, ou porque os critérios do projeto mudam durante a operação. Para tanto um tipo especial de filtro que modifica a sua resposta automaticamente, adaptando-se a uma dada situação, para que seu desempenho melhore durante a operação, denominado de filtro adaptativo, é utilizado.

O filtro adaptativo IIR possui a mesma performance que o filtro adaptativo FIR com baixa complexidade, entretanto caso os pólos existentes se locomovam para fora do círculo unitário durante o processo de adaptação, o filtro adaptativo IIR torna-se potencialmente instável. Logo, o filtro adaptativo não-recursivo, ou combinador linear adaptativo (CLA), é utilizado na maioria dos filtros adaptativos e é o elemento mais importante em sistemas de aprendizado e processos adaptativos em geral [Widrow, 1985]. 
A saída do CLA, para um conjunto fixo de pesos, é a combinação linear dos elementos de entrada. Caso os pesos estejam em processo de adaptação, sendo também função dos componentes de entrada, a saída do combinador deixa de ser uma função linear da entrada.

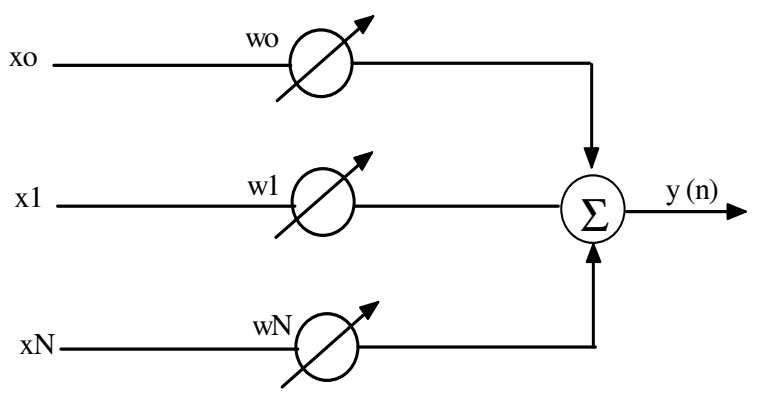

Figura 6.2.1.1 - Forma geral de um combinador linear adaptativo.

Logo a Equação 6.1 é a relação de entrada e saída de um filtro adaptativo FIR.

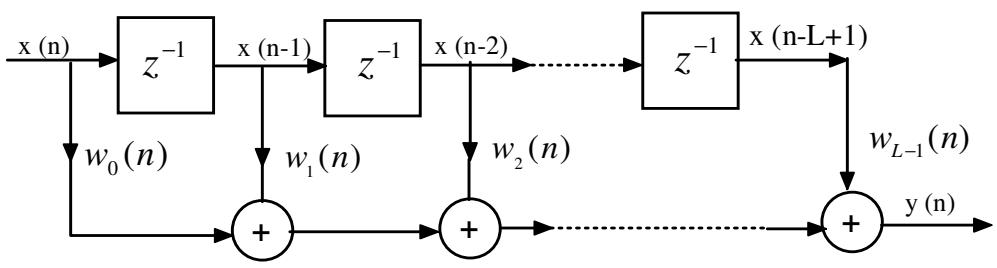

Figura 6.2.1.2 - Diagrama de um filtro adaptativo FIR.

$$
y(n)=\sum_{i=0}^{L-1} w_{i}(n) x(n-i)=\mathbf{w}^{\mathbf{T}}(n) \mathbf{x}(n)
$$

Onde $w_{i}(n)$ representa os $i^{\prime} s$ coeficientes ajustáveis ou pesos para um tempo especifico $n$. O vetor de coeficientes $\mathbf{w}(n)$ constitui de $L$ coeficientes.

$$
\begin{gathered}
\mathbf{w}(n)=\left[w_{0}(n) w_{1}(n) \ldots w_{L-1}(n)\right]^{T} \\
\mathbf{x}(n)=[x(n) \mathrm{x}(n-1) \ldots w(n-L+1)]^{T}
\end{gathered}
$$

No processo de adaptação o vetor de pesos do combinador linear é ajustado, de acordo com alguns critérios estatísticos, de tal forma que à minimizar o sinal de erro, $e(n)$, ou seja, que produza uma saída $y(n)$ o mais próximo possível do sinal desejado $d(n)$. 


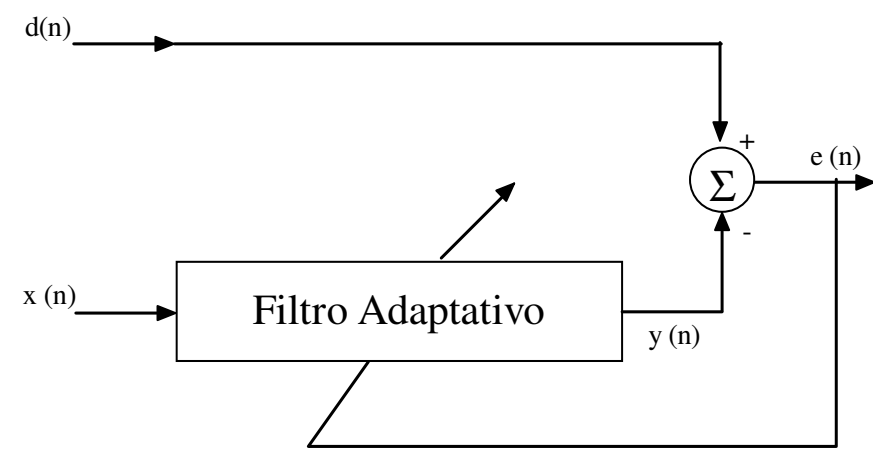

Figura 6.2.1.3 - Estrutura Básica de um filtro Adaptativo.

Onde,

$$
e(n)=d(n)-y(n)
$$

A atualização dos coeficientes é feita através do critério de minimização do erro quadrático médio acarretando, desta forma, no processo de minimização do critério predeterminado. Para a obtenção do erro quadrático médio calcula-se o valor esperado da seguinte forma;

$$
\xi=E\left[e^{2}(n)\right]
$$

Onde $E[$.$] é o operador que retorna o valor esperado.$

Substituindo as Equações 6.1 e 6.4 na Equação 6.5, obtém-se:

$$
\xi=E\left[d^{2}(n)\right]+\mathbf{w}^{\mathbf{T}}(n) \mathbf{R} \mathbf{w}(n)-2 \mathbf{w}^{\mathbf{T}}(n) \mathbf{p}
$$

A matriz $L \times L$ de autocorrelação do vetor de amostras do sinal de entrada é representada por,

$$
\mathbf{R}=E\left[\mathbf{x}(n) \mathbf{x}^{\mathbf{T}}(n)\right]=\left[\begin{array}{cccc}
r_{x x}(0) & r_{x x}(1) & \ldots & r_{x x}(L-1) \\
r_{x x}(1) & r_{x x}(0) & & \\
\vdots & & \ddots & r_{x x}(1) \\
r_{x x}(L-1) & & r_{x x}(1) & r_{x x}(0)
\end{array}\right]
$$

Os termos da diagonal principal da matriz $\mathbf{R}$ são os quadrados dos componentes da entrada, e os termos fora desta diagonal indicam a correlação entre os elementos de entrada.

O vetor $\mathbf{p}$ da Equação 6.6 representa o vetor $L \times 1$ de correlação cruzada.

$$
\xi=E[d(n) \mathbf{x}(n)]=\left[\begin{array}{llll}
r_{d x}(0) & r_{d x}(1) & \ldots & r_{d x}(L-1)
\end{array}\right]^{T}
$$

Este vetor quantifica a dependência entre o sinal desejado e cada elemento do valor de sinais de entrada. Onde a função de autocorrelação é definida como;

$$
r_{d x}(k)=E[d(n) x(n-k)]
$$


Onde $\mathrm{k}=0,1, \ldots, \mathrm{L}-1$. Logo se verifica que a equação (6.6) é uma função convexa garantindo, desta forma, a existência de um mínimo local. Uma maneira de se determinar o mínimo da superfície de erro quadrático é através do método o gradiente [Widrow, 1985].

$$
\nabla(\xi)=\frac{\partial \xi}{\partial \mathbf{w}(n)}=0
$$

Assim para a função de erro definida em (6.6) obtém-se o vetor de coeficiente ótimo $\mathbf{w}^{0}$.

$$
\mathbf{w}^{0}=\mathbf{R}^{-1} \mathbf{p}
$$

Esta equação é conhecida como Wiener-Hopf, e o filtro com coeficientes ótimos dados nesta Equação 6.9 é chamado de filtro de Wiener.

Ao substituir a Equação 6.11 em 6.6 obtém-se o erro médio quadrático mínimo, resultando, desta forma, num $y(n)$ com uma estimativa bastante próxima de $d(n)$.

Uma maneira bastante intuitiva de se construir este algoritmo é inicializar os coeficientes com um valor qualquer, e a cada iteração dar pequenos passos contrários ao gradiente de desempenho. Deste modo a cada iteração se terá uma melhor aproximação de $\mathbf{w}^{0}$ [Born, 2000].

\subsubsection{Algoritmo LMS - Least Mean Square}

O algoritmo LMS é importante pela simplicidade e facilidade de computação. Se o sistema adaptativo é um combinador linear adaptativo, e o vetor de entrada $x(n) \mathrm{e}$ a resposta desejada $d(n)$ estão disponíveis a cada iteração, o algoritmo LMS é geralmente a melhor escolha para muitas aplicações de sinais [Widrow,1985].

Este algoritmo utiliza o valor instantâneo do erro quadrado, $e^{2}(n)$, como estimativa da função de custo por $E\left[e^{2}(n)\right]$. Logo,

$$
\nabla(n)=\frac{\partial^{2} e(n)}{\partial \mathbf{w}(\mathbf{n})}=-2 e(n) \mathbf{x}(n)
$$

Como ao gradiente é o vetor que aponta no sentido máximo da função de custo, desloca-se o vetor de pesos na direção oposta com o objetivo de procurar o mínimo. Assim o algoritmo LMS, ou algoritmo de gradiente estocástico, é expresso como:

$$
\mathbf{w}(n+1)=\mathbf{w}(n)+2 \mu e(n) \mathbf{x}(n)
$$


Nas implementações práticas a constante $2 \mu$ é usualmente substituídas por $\mu$. A constante $\mu$ é denominada de ganho (ou passo) de adaptação, e tem como características o controle de estabilidade e da velocidade de convergência do algoritmo.

Para que haja estabilidade no algoritmo é preciso que o valor do ganho de adaptação obedeça a seguinte desigualdade [Opeheim, 1993],

$$
0<\mu<\frac{1}{L P_{x}}
$$

Onde $L$ é comprimento e a potência do sinal de entrada $x(n)$ é $P_{x}$. O valor de $P_{x}$ é calculado através de um simples método recursivo que estima a potência de um sinal de amostras.

Uma importante técnica para otimizar a velocidade de convergência enquanto é mantida a independência da potência do sinal é conhecida como algoritmo normalizado de LMS, ou seja, NLMS [Nascimento, 2005].

$$
\mathbf{w}(n+1)=\mathbf{w}(n)+\mu e(n) \mathbf{x}(n)
$$

Neste caso $\mu$ é normalizado por $L$ e pela potência do sinal $x(n)$, ou seja,

$$
\mu=\frac{\alpha}{L \hat{P}_{x}}
$$

Onde $\alpha$ é uma constante positiva de valor inferior a uma unidade, e $\hat{P}_{x}$ é a estimativa da potência do sinal de referência, ou seja, de $x(n)$ no tempo $n$.

Por definição, em [Kuo \& Gan, 2005], tem-se;

$$
\hat{P}_{x}=(1-\beta) \hat{P}_{x}(n-1)+\beta x^{2}(n)
$$

Onde $\beta<1$, afinal $\beta=1 / N$, sendo $N$ o comprimento da janela.

A Equação 6.15 apresenta melhor comportamento que o LMS simples na presença de sinais de voz por adaptar o ganho em função da potência do sinal. Este tipo de sinal apresenta grande variação de potência ao longo do tempo, tornando bastante difícil à escolha de um valor fixo para o ganho de adaptação: caso o ganho seja muito pequeno o algoritmo aproxima-se da solução parando a adaptação antes de atingir uma posição razoável devido à precisão finita. Por outro lado se o valor da potência estimada for zero ou muito pequeno, o ganho de adaptação é suficientemente elevado e o algoritmo torna-se instável. Para tanto, nas implementações básicas são utilizados softwares limitados.

A Equação 6.13 pode ser reescrita na forma escalar [Haykin, 1991].

$$
w_{i}(n+1)=w_{i}(n)+\mu e(n) x(n-i)
$$


Onde $\mathrm{i}=0,1, \ldots, \mathrm{L}-1$. Este tipo de algoritmo requer somente $2 L$ multiplicações e adições, sendo, desta forma, considerado o algoritmo mais eficiente em termos de cálculos e armazenamento. A complexidade do algoritmo é considerada mais baixa quando comparada com outros algoritmos adaptativos tais como Kalman e o algoritmo recursivo de mínimo quadrado, RLS. Logo o algoritmo LMS é o mais amplamente utilizado para aplicações práticas.

\subsubsection{Estruturas Adaptativas}

Nesta secção serão introduzidas quatro aplicações de estruturas básicas que são utilizadas para diferentes aplicações na filtragem adaptativa.

\section{- Identificação de Sistemas}

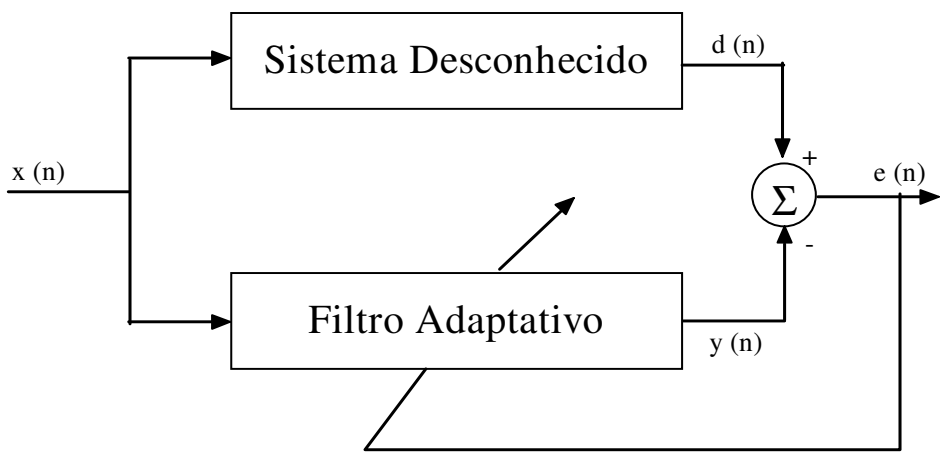

Figura 6.2.3.1 - Identificação de Sistema utilizando filtro adaptativo.

Como verificado na Figura 6.2.3.1, a mesma entrada $x(n)$ excita tanto o sistema desconhecido quanto o filtro adaptativo, que se encontra em paralelo. O sinal de erro definido na Equação 6.4 retorna para o filtro adaptativo e é utilizado para atualizar os coeficientes do filtro adaptativo até que a saída seja $y(n)=d(n)$. Quando isto acontece o processo adaptativo finaliza e $e(n)$ aproxima-se de zero. 
- Modelamento de Inversão

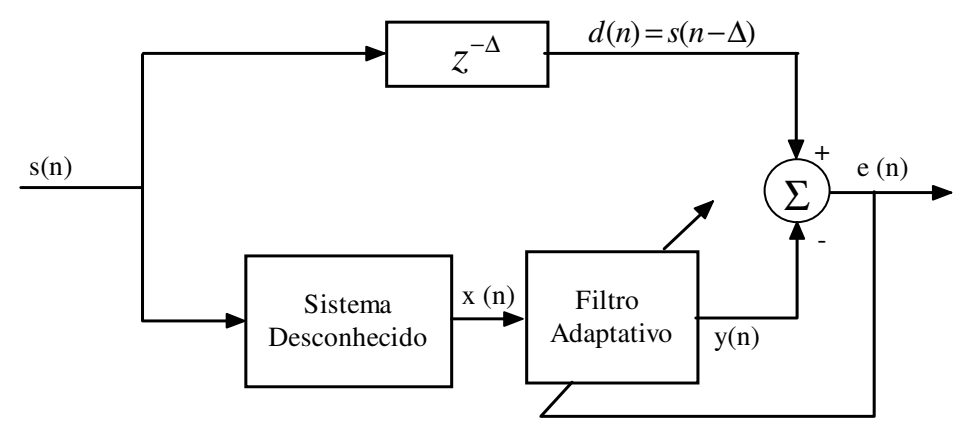

Figura 6.2.3.2 - Sistema de modelamento de inversão utilizando um filtro adaptativo.

Neste tipo de estrutura, Figura 6.2.3.2, o sistema desconhecido encontra-se em cascata com o filtro adaptativo. O sinal desejado $d(n)$ é obtido através do sinal atrasado $s(n)$ usando a unidade de atraso $z^{-\Delta}$, onde $\Delta \simeq L / 2$. O objetivo do atraso é para compensar o atraso de propagação ocorrido através do sistema desconhecido e do filtro adaptativo. $\mathrm{O}$ atraso permite que o filtro adaptativo convirja para um filtro causal, o qual é o inverso do sistema desconhecido. O filtro adaptativo equaliza o sistema desconhecido, ou canal, recuperando, conseqüentemente, a versão atrasada do sinal, $s(n)$, na saída do filtro, $y(n)$.

Caso $s(n)$ tenha um espectro plano e um ruído pequeno, o filtro pode se adaptar para um modelo inverso preciso de um sistema desconhecido.

\section{- Cancelamento de ruído}

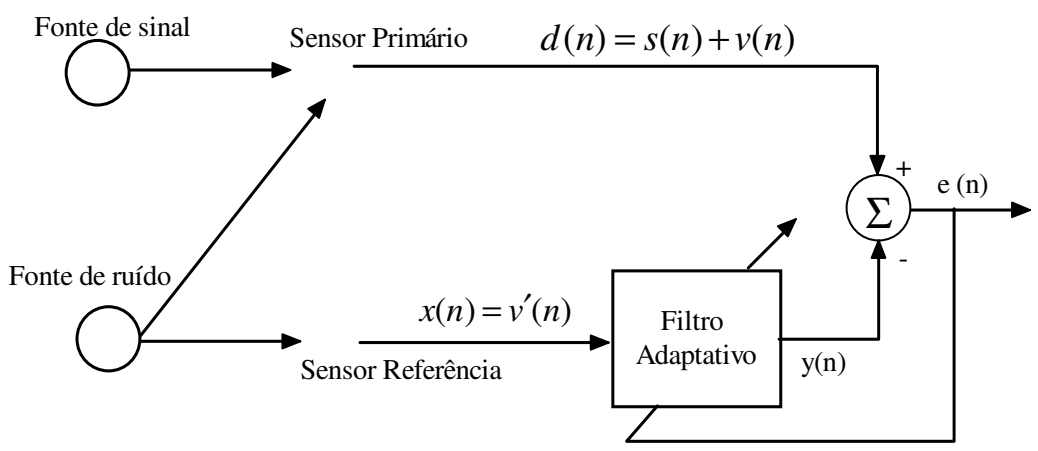

Figura 6.2.3.3 - Estrutura de um Cancelamento de Ruído. 
O sinal primário, $d(n)$, adquirido pelo sensor primário, Figura 6.2.3.3, contém o sinal desejado, $s(n)$, e um ruído indesejável, $v(n)$. Para remover este ruído, o sensor de referência é utilizado para obter um ruído $v^{\prime}(n)$, o qual é utilizado na entrada do filtro adaptativo $x(n)$. Como $v^{\prime}(n)$ e $s(n)$ não são correlatados o filtro adaptativo pode ser somente ajustar o ruído referência $v^{\prime}(n)$ de tal forma que produza uma saída $y(n)$ que se aproxime do ruído $v(n)$. Assim o componente $v(n)$ é cancelado por $y(n)$, acarretando na convergência gradual do sinal $e(n)$ aproximando-o para o sinal limpo $s(n)$.

\section{- Predição Adaptativa}

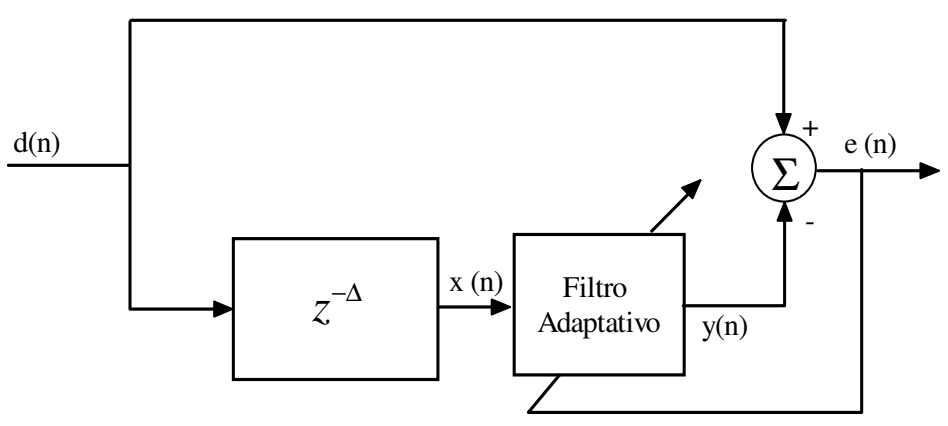

Figura 6.2.3.4 - Estrutura de Predição Adaptativa.

O sinal desejado, $d(n)$,é atrasado por $\Delta$ amostras, logo $x(n)=d(n-\Delta)$ é o sinal de entrada do filtro adaptativo, o qual adapta os coeficientes para minimizar o sinal de erro, $e(n)$. Este filtro adaptativo consiste em disponibilizar a melhor predição do valor presente dum sinal aleatório. $\mathrm{O}$ valor presente do sinal serve de resposta desejada para um filtro adaptativo. É verificado na Figura 6.2.3.4 que o sinal de referência do filtro consiste apenas nos valores passados do processo.

Em alguns casos o sinal de saída do filtro adaptativo serve como saída do sistema, nestes casos o filtro funciona como preditor. Em outros casos, o erro de predição é utilizado como saída, e assim o filtro funciona como um filtro de erro de predição. 


\subsection{EXEMPLOS DE FILTROS ADAPTATIVOS}

\subsubsection{Exemplo 1: FIR adaptativo para identificação de sistemas.}

Esse exemplo implementa um filtro adaptativo utilizando o algoritmo do gradiente estocástico, ou algoritmo de erro médio quadrático, no código ADAPTC.C.

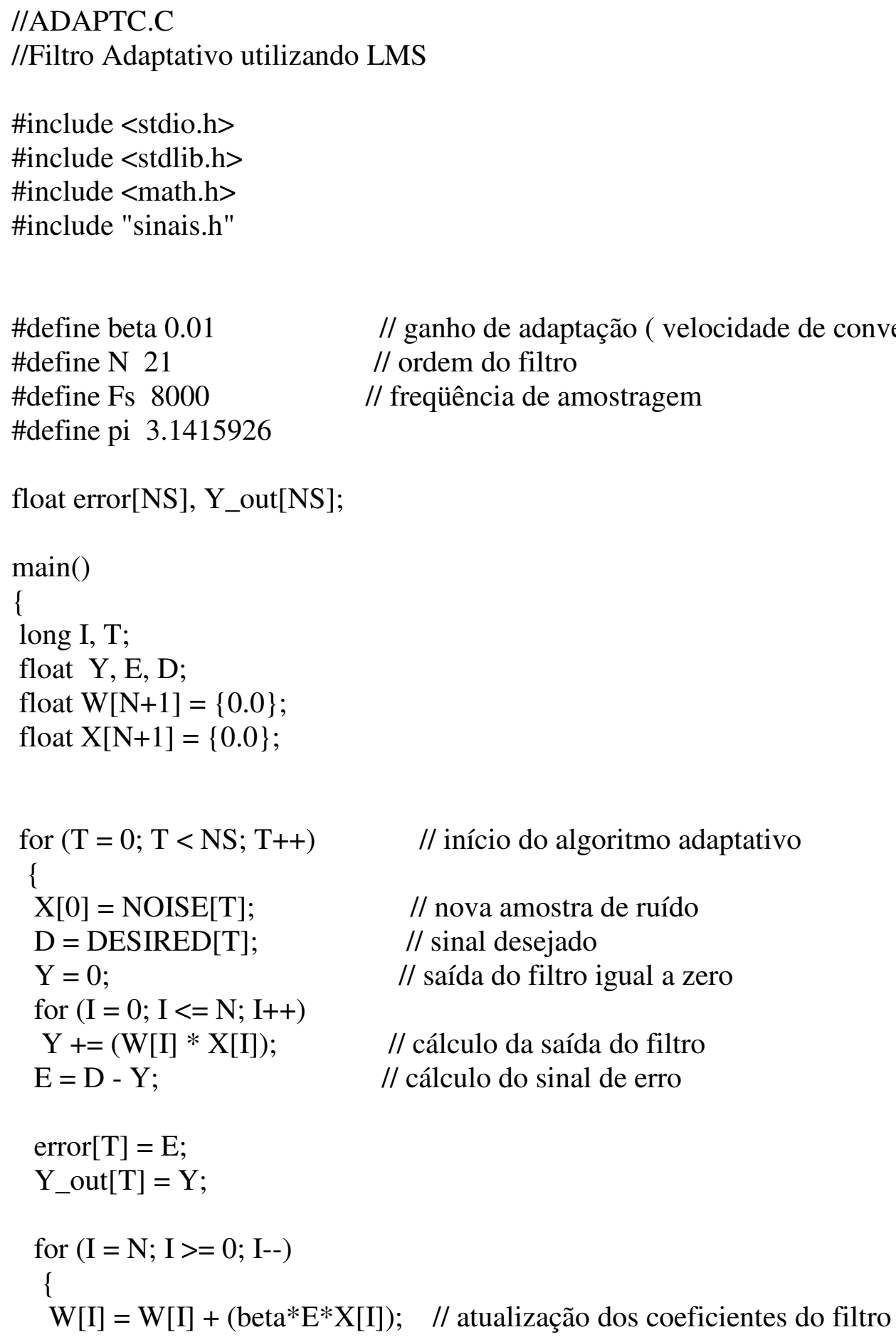




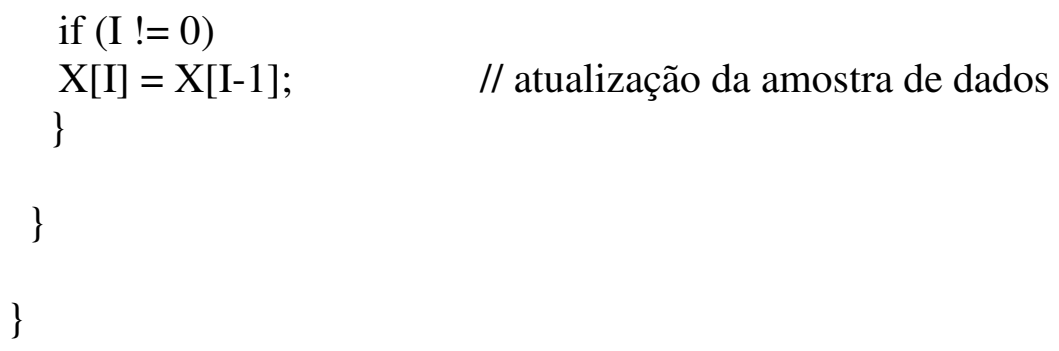

\section{Criação do projeto}

A criação deste projeto no Code Composer Studio ${ }^{\mathrm{TM}}$ IDE requer a adição de arquivos composto na pasta de FiltroAdapt do cd fornecido; ADAPTC.C, vector.asm, C6xdsk.cmd, rts6700.lib, e sinais.h.

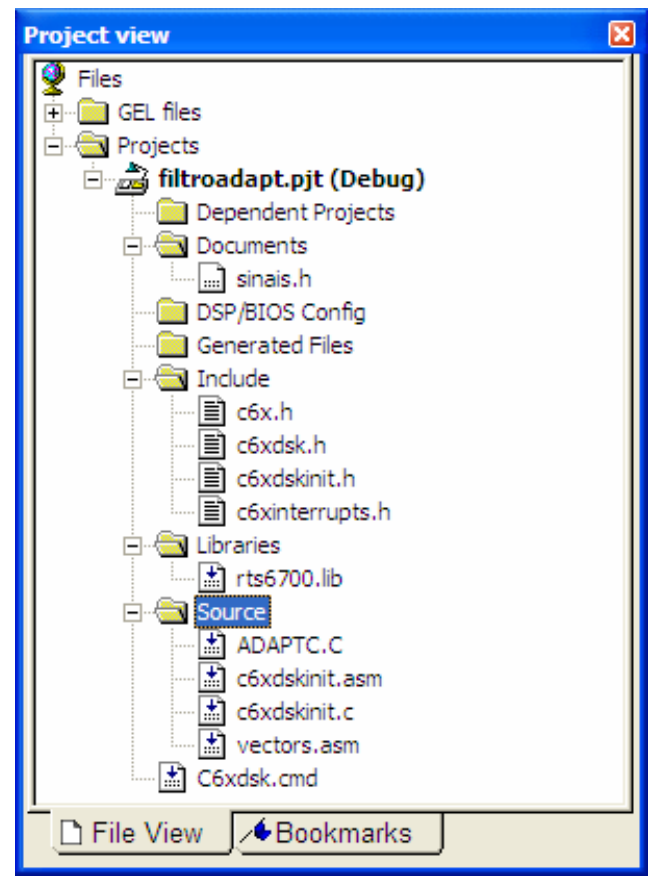

Figura 6.3.1.1 - Visualização do projeto.

Após a construção do projeto filtroadapt.pjt, gere o executável e carregue o programa utilizando as mesmas configurações dos parâmetros do compilador e do linker como fora feito nos exemplos do Tutorial 4. 


\section{Construção gráfica no $C C S$}

Para construir os gráficos no domínio do tempo e da frequiência é necessário que você:

1. Selecione View $\rightarrow$ Graph $\rightarrow$ Time/Frequency. Ao abrir Graph Property Dialog faça as seguintes modificações:

- Start Adress - uppeer display $\rightarrow$ DESIRED, como pode ser verificado no código fir.c.

- Start Adress - lower display $\rightarrow$ Y_out.

- Acquisition Buffer Size $\rightarrow$ 128, representando o tamanho do buffer.

- DisplayData Size $\rightarrow 40$.

- DSP Data Size $\rightarrow$ 32-bit float point.

- $\quad$ Sampling Rate $(\mathrm{Hz}) \rightarrow 8000$.

\begin{tabular}{|l|l|}
\hline Q G Graph Property Dialog & \\
\hline Display Type & Dual Time \\
\hline Graph Title & Graphical Display \\
\hline Interleaved Data Sources & No \\
\hline Start Address - upper display & DESIRED \\
\hline Start Address - lower display & Y_out \\
\hline Acquisition Buffer Size & 128 \\
\hline Index Increment & 1 \\
\hline Display Data Size & 40 \\
\hline DSP Data Type & 32 -bit floating point \\
\hline Sampling Rate [Hz] & 8000 \\
\hline Plot Data From & Left to Right \\
\hline Left-shifted Data Display & Yes \\
\hline Autoscale & On \\
\hline DCValue & 0 \\
\hline Axes Display & On \\
\hline Time Display Unit & s \\
\hline Status Bar Display & On \\
\hline Magnitude Display Scale & Linear \\
\hline Data Plot Style & Line \\
\hline Grid Style & Zero Line \\
\hline Cursor Mode & Data Cursor \\
\hline
\end{tabular}

Figura 6.3.1.2 - Janela Graph Property Dialog com modificações. 


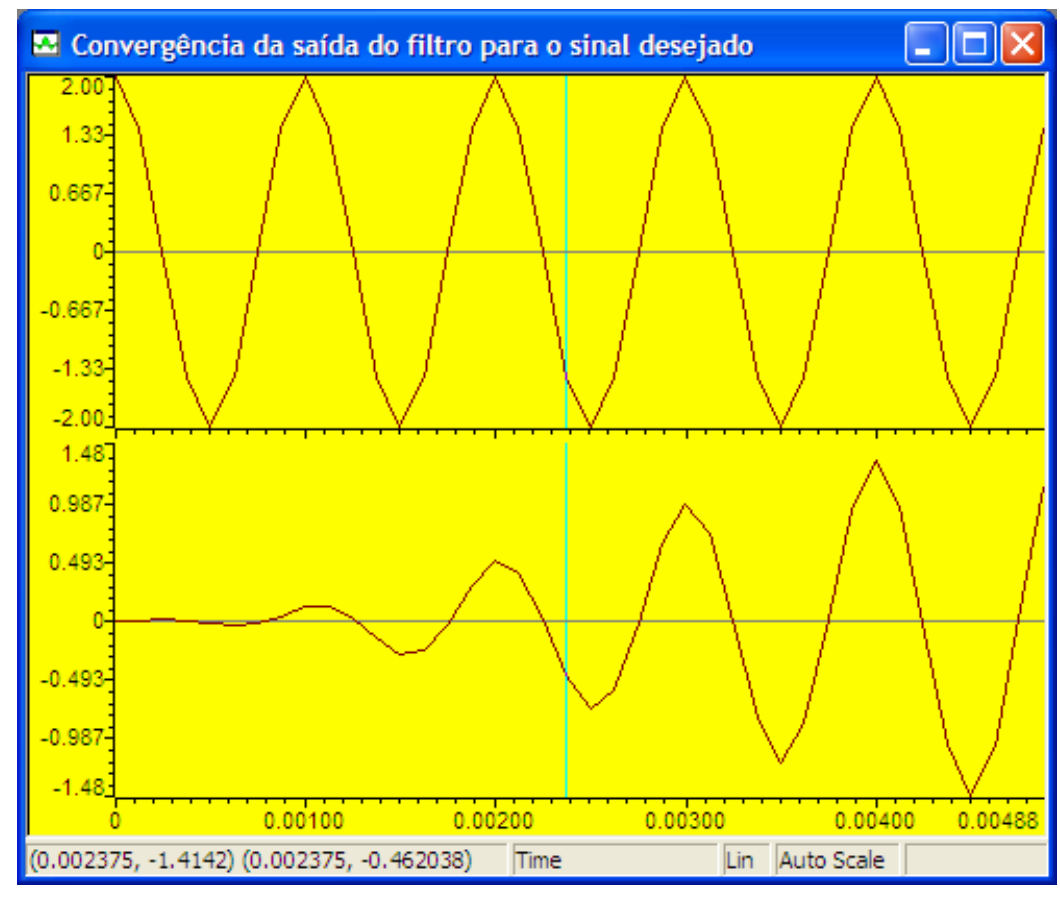

Figura 6.3.1.3 - Sinal de cima: Sinal desejado (DESIRED); Sinal de baixo saída do filtro (Y_out). 


\section{7 - CONCLUSÃO}

A motivação inicial desse trabalho era de abordar o tema DSP's sob a óptica da família TMS320C6x, desenvolvida pela Texas Instruments para dar suporte a disciplina de processamento digital de sinais (PDS).

Primeiramente partiu-se de conceitos gerais a respeito das características inerentes a qualquer DSP, em seguida fez-se uma abordagem sobre o pacote DSK, (DSP starter kit), que oferece as ferramentas de suporte de software e hardware da família de processadores que é alvo deste trabalho, em conjunto com práticas de laboratório que demonstraram os comandos necessários para a construção e implementação de projetos no ambiente oferecido pelo Code Composer Studio (CCS), ferramenta que acompanha o TMS320C6x.

Posteriormente, a partir da conceituação de alguns tópicos em processamento digital de sinais, tais como filtro FIR, filtros IIR, transformada discreta de Fourier (DFT), transformada rápida de Fourier, e filtros adaptativos, e em posse dos conhecimentos adquiridos no primeiro tutorial fora possível criar, construir e implementar práticas de laboratório.

Observou-se que a conclusão obtida ao final do desenvolvimento de cada experimento fora bastante satisfatória uma vez que apresentou ao leitor uma série de experimentos que consolidaram a teoria abordada em cada capítulo e ao mesmo tempo formaram a base para o desenvolvimento de outras aplicações em DSP's. Sendo assim, pode-se afirmar que o presente trabalho atende a uma necessidade de ordem acadêmica e ao mesmo tempo de mercado, uma vez que tais dispositivos constituem uma solução tecnológica presente em uma diversidade muito grande de dispositivos comerciais.

Por fim, trabalhos futuros poderiam desenvolver-se no sentido de adaptar os experimentos aqui apresentados para DPS's mais modernos, bem como incorporar novas práticas que poderiam surgir de necessidades específicas detectadas pelo professor da disciplina de Processamento Digital de Sinais. 


\section{REFERÊNCIA BIBLIOGRÁFICA}

(Ahmed \& Natarajan, 1983) - Ahmed, N., Natarajan, T. Discrete-Time Signal and Systems, Reston Publishing, Reston, VA, 1983.

(Aziz, Sorensen \& Van Der Spiegel, 1996) - Aziz, P, M., Sorensen, H. V., Van Der Spiegel, J. An Overview of Sigma Delta Converters, IEEE Signal Processing, Piscataway, Jan.1996.

(Bateman \& Yates, 1991) - Bateman, A.,Yates, W. Digital Signal Processsing Design, Computer Science Press, New York,1991.

(Bellanger, 1989) - Bellanger, M. Digital Processsing of Signals, Wiley, New York,1989.

(Born, 2000) - Born, R.S., Filtros Adaptativos Aplicados a Sinais Biomédicos. Monografia de Curso de Bacharelado em Informática. Instituto de Física e Matemática da Universidade Federal de Pelotas, 2000.

(Candy \& Temes, 1992) - Candy, J. C., Temes, G. Oversampling Delta-Sigma Data Converters: Theory, Design and Simulation, IEEE Press, Piscataway, New Jersey,1992.

(Chassaing, 1999) - Chassaing, R. Digital Signal Processsing Laboratory Experiments Using $C$ and the TMS320C31, Wiley, New York,1999.

(Chassaing, 2000) - Chassaing, R. DSP Applications Using C and the TMS320C6x DSK. New York, NY: John Wiley. 2000.

(Chassaing \& Horning, 1990) -Chassaing, R., Horning, D.W. Digital Signal Processsing Laboratory Experiments Using C and the TMS320C5, Wiley, New York,1990.

(Chen \& Sorensen, 1997) - Chen, J., Sorensen, H. V. A Digital Signal Processing Laboratory Using the TMS320C30, Prentice Hall, Upper Saddle River, New Jersey, 1997.

(Dahnoum, 2000) - Dahnoum, N. DSP Implementation Using the TMS320C6x Processors, Prentice Hall, Upper Saddle River, New Jersey, 2000.

(Eyre, 2001) - Eyre, J. The Newest Breed Trede off Speed, Energy Consumption, and cost to vie for an ever bigger piece of the action, IEEE Spetrum, June 2001.

(Gold \& Radere, 1969) - Gold, B., Rader, C. M. Digital Signal Processing, Prentice Hall, Upper Saddle River, New Jersey, 1969.

(Gray \& Markel, 1973) - Gray, A. H., Markel, J.D. Digital Lattice and Ladder Filter Synthesis, IEEE Trasactions on Acoustics, Speech, and Signal Processing, Vol. ASSP-21, 1973, pp 491-500.

(Gray \& Markel, 1975) - Gray, A. H., Markel, J.D. A Normalized Digital Filter Structure, IEEE Trasactions on Acoustics, Speech, and Signal Processing, Vol. ASSP-23, 1975, pp 268-277. 
(Jackson, 1969) - Jackson, L.B. An Analysis of Limit Cycles due to Multiplicative Rouding in Recursive Digital Filters, Proceeding of the $7^{\text {th }}$ Allerton Conference on Circuit and System Theory, 1969, pp 69-78.

(Jackson, 1996) - Jackson, L.B. Digital Filters abd Signal Processing, Kluwer Academic, Norwell, MA, 1996.

(Johnson, 1989) - Johnson, J. R. Introdution to Digital Signal Processing, Prentice Hall, Upper Saddle River, New Jersey, 1989.

(Hamming, 1983) - Hamming, R. W. Digital Filters, Prentice Hall, Upper Saddle River, New Jersey, 1983.

(Haykin, 1991) -Haykin, S. Adaptive Filter Theory, $2^{\text {nd }}$. Edition, Prentice-Hall. 1991.

(Kaiser, 1974) - Kaiser, J. F. Some practical considerations in the realization of linear digital filters, Proceedings of the $3^{\text {rd }}$ Allerton Conference on Circuit System Theory, Oct. 1965, pp. 621-633.

(Kehtarnavaz \& Keramat, 2001) - Kehtarnavaz, N., Keramat, M. DSP System Design Using the TMS320C6000, Prentice Hall, Upper Saddle River, New Jersey, 2001.

(Kehtarnavaz \& Simsek, 2000) - Kehtarnavaz, N., Simsek, B. C6x-Based Digital Signal Processing, Prentice Hall, Upper Saddle River, New Jersey, 2000.

(Kernigan \& Ritchie, 1998) - Kernigan, B.W., Ritchie, D. M.The C Programming Language, Prentice Hall, Upper Saddle River, New Jersey, 2001.

(Kuo \& Gan, 2005) - Kuo, S.M., Gan, W. Digital Signal Processors. Prentice-Hall. 2005.

(Lynn \& Fuerst, 1994) - Lynn, P. A., Fuerst, W. Introdution Digital Signal Processsing with Computer Application, Wiley, New York,1994.

(Lyons, 1997) - Lyons, R. G. Understanding Digital Signal Processing, AddissonWesley, Reading, MA, 1996.

(Marven \& Ewers, 1996) - Marven, C., Ewers, G. A Simple Approach to Digital Signal Processing, Wiley, New York,1999.

(Matlab, 2004) - Mathworks®, Using Matlab. Version 7. The Mathworks, Inc., 2004.

(Mitra, 1998) -Mitra, S. K. Digital Signal Processing: A Computer-Based Approach, McGraw-Hill, New York,1998.

(Mitra \& Kaiser, 1993) -Mitra, S. K., Kaiser, J. F.Handbook for Digital Signal Processsing, Wiley, New York,1993.

(Nascimento, 2005) - Nascimento, V.H. Implementação de Filtros Adaptativos em Aritmética de Ponto Fixo II. 2005. 
(Norsworthy, Schreier \& Temes, 1999) - Norsworthy, S., Schreier R., G. Temes, DeltaSigma Data Converters: Theory, Design and Simulation, IEEE Press, Piscataway, New Jersey,1997.

(Oppenheim \& Schafer, 1989) - Oppenheim, A. V., Schafer, R. Discrete-Time Signal Processing, Prentice Hall, Upper Saddle River, New Jersey, 1989.

(Oppenheim, 1993) - Openheim, R.W. Digital Signal Processing, Prentice-Hall. 1993.

(Orfanidis, 1996) - Orfanidis, S. J. Introdution to Signal Processing, Prentice Hall, Upper Saddle River, New Jersey, 1993.

(Parks \& Burrus, 1987) - Parks, T. W., Burrus, C. S. Digital Filter Design, Wiley, New York,1997.

(Piedra \& Fritsh, 1996) - Piedra, R. M., Fritsh, A. Digital Signal Processing Comes of Age, IEEE Spetrum, June 2001.

(Porat, 1997) - Porat, B. A Course in Digital Signal Processsing, Wiley, New York,1997.

(Proakis \& Manolakis, 1996) - Proakis, J. G., Manolakis, D. G. Digital Signal Processing: Principles, Algorithms and Application, Prentice Hall, Upper Saddle River, New Jersey, 1996.

(Rabiner \& Gold, 1975) - Rabiner, L.R., Gold, B. Theory and Application of Digital Signal Processing, Prentice Hall, Upper Saddle River, New Jersey, 1975.

(Solomon, 1988) - Solomon, C. W. Switched-capacitor Filters, IEEE Spectrum, June 1988.

(Stearns \& David, 1993) - Stearns, S. D., David, R. A. Signal Processing in Fortrans and C, Prentice Hall, Upper Saddle River, New Jersey, 1993.

(Tretter, 1995) - Tretter, S. A. Communication System Using DSP Algorithms, , Plenum Press, New York, 1995.

(TMS320C6000, 1999) - TMS320C6000 Assembly Language Tools User's Guide, SPRU198D, Texas Instruments, Dallas, Texas, 1999.

(TMS320C6000C, 1998) - TMS320C6000 CPU and Instruction Set Reference Guide, SPRU198D, Texas Instruments, Dallas, Texas, 1998.

(TMS320C6000, 2000) - TMS320C6000 Programmer's Guide, SPRU198D, Texas Instruments, Dallas, Texas, 2000.

(TMS320C6000O, 1999) - TMS320C6000 Optimizing C Compiler User's Guide, SPRU198D, Texas Instruments, Dallas, Texas, 1999. 
(TMS320C6211, 2000) - TMS320C6211 Fixed-point Digital Signal ProcessorTMS320C6711 Floating-point Digital Signal Processor, Texas Instruments, Dallas, Texas, 2000.

(Williams, 1986) - Williams, C. S. Designing Digital Filters, Prentice Hall, Upper Saddle River, New Jersey, 1986.

(Widrow \& Stearns, 1986) - Widrow, B., Stearns, S. Adaptive Signal Processing, PrenticeHall. 1985.

(Young, 1985) -Young, T. Linear Systems and Digital Signal Processing, Prentice Hall, Upper Saddle River, New Jersey, 1985. 


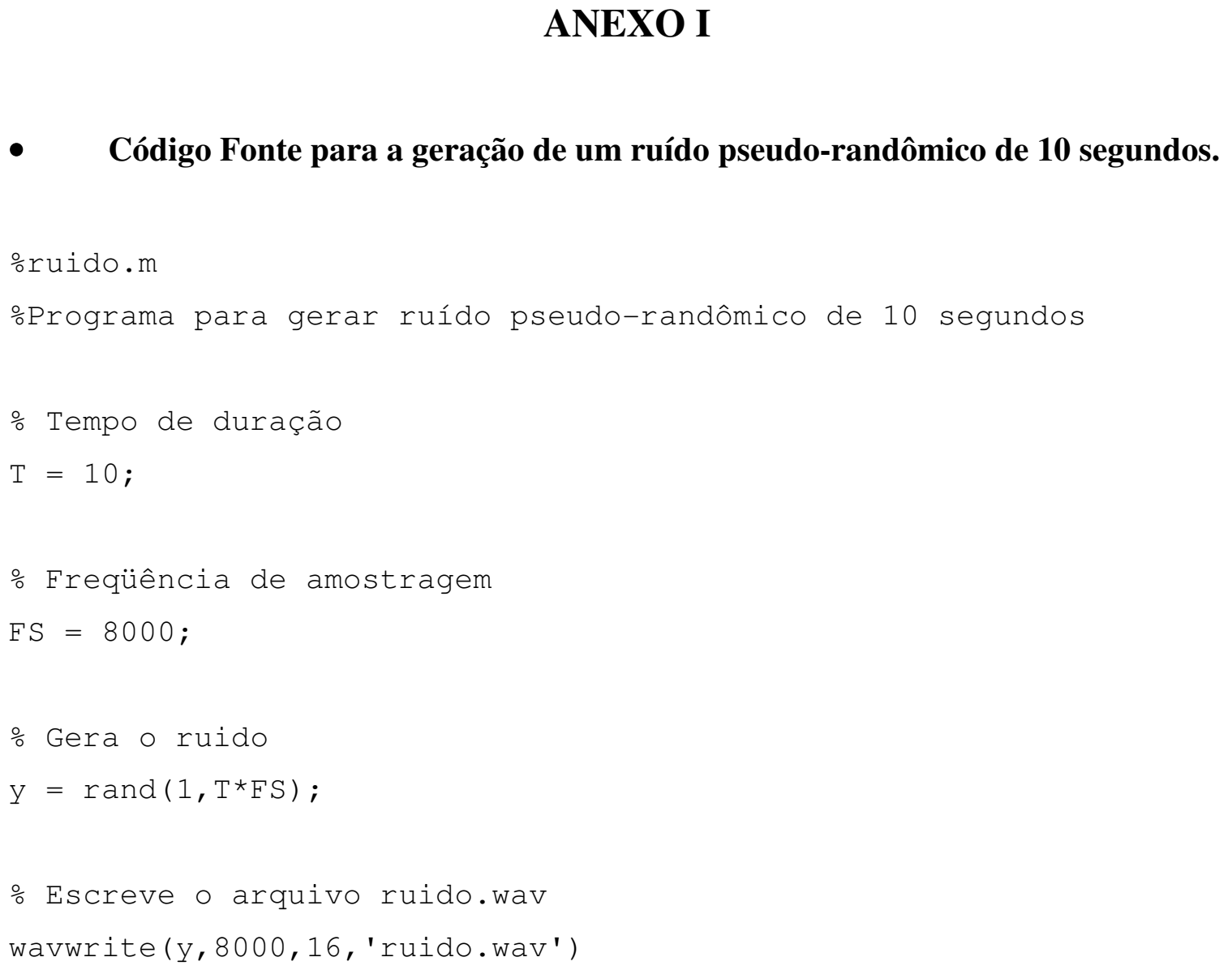

- Código Fonte para a implementação da resposta em freqüência da saída do filtro FIR rejeita-faixa centrado em $2700 \mathrm{~Hz}$.

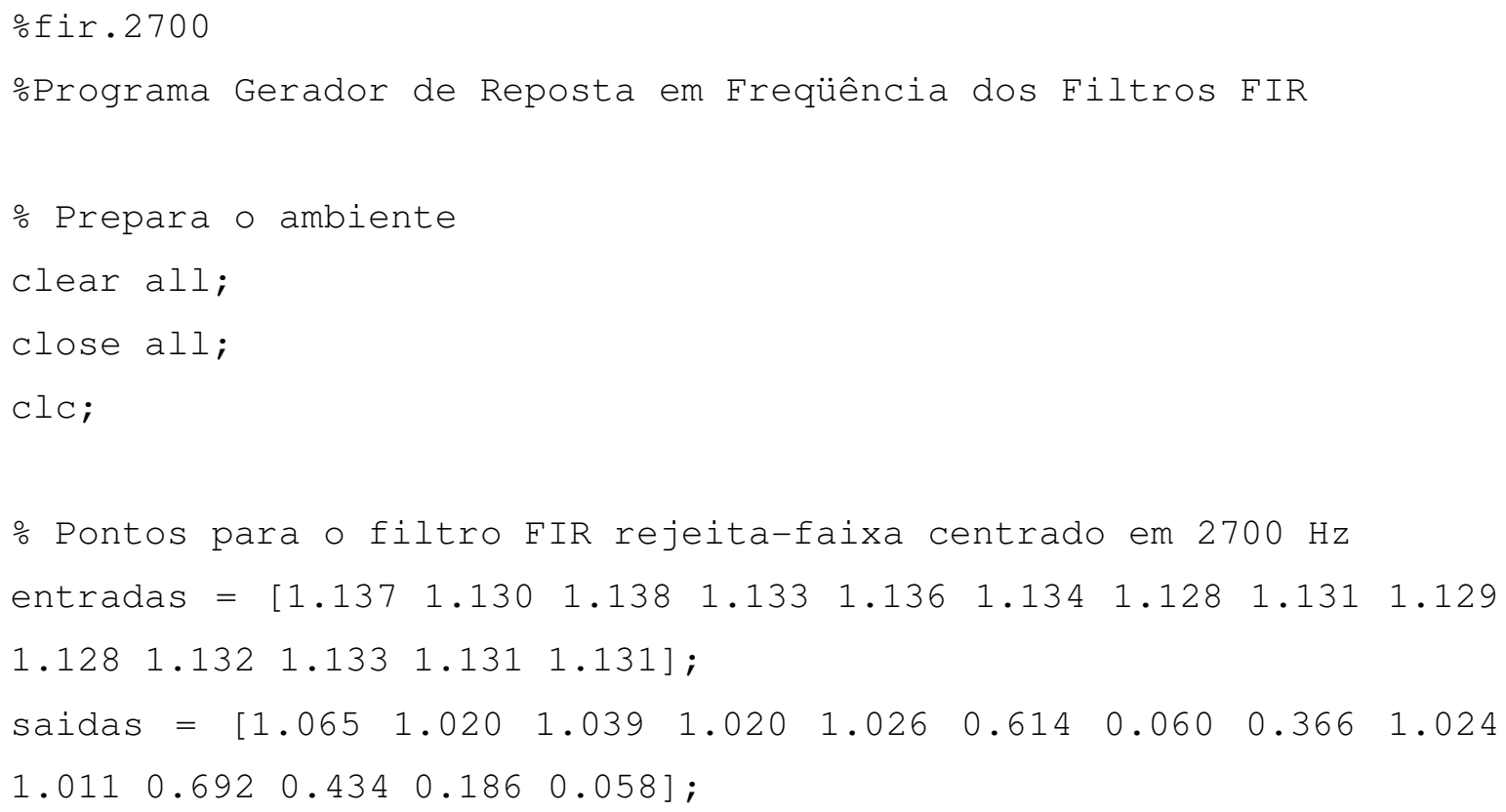


\% Resposta em freqüência do filtro

Ganho $=10 * \log 10($ saidas./entradas);

$\mathrm{xx}=\min ($ frequencias) $: \max ($ frequencias) ;

yy $=$ pchip(frequencias, Ganho, xx);

plot (frequencias, Ganho, 'ro' , xx, yy)

ylabel ('Magnitude (dB)')

xlabel ('Freqüência (Hz)')

title('Resposta em freqüência')

grid on

legend('Pontos experimentais', 'Interpolação')

- Código Fonte para a implementação da resposta em freqüência da saída do filtro FIR passa-faixa centrado em $1750 \mathrm{~Hz}$.

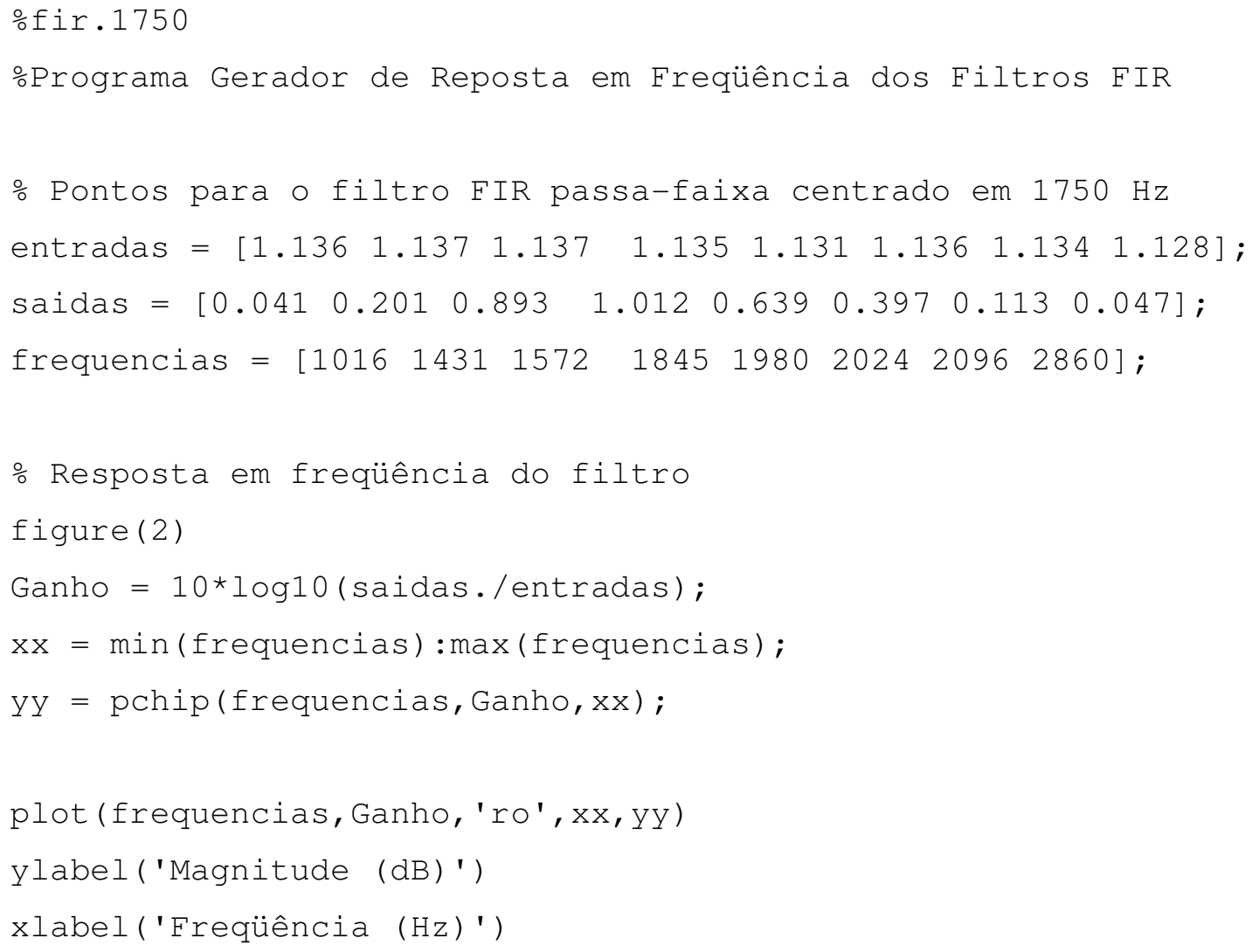


title('Resposta em freqüência')

grid on

legend('Pontos experimentais', 'Interpolação')

- Código Fonte para a implementação da resposta em freqüência da saída do filtro IIR passa-baixa centrado em $1750 \mathrm{~Hz}$.

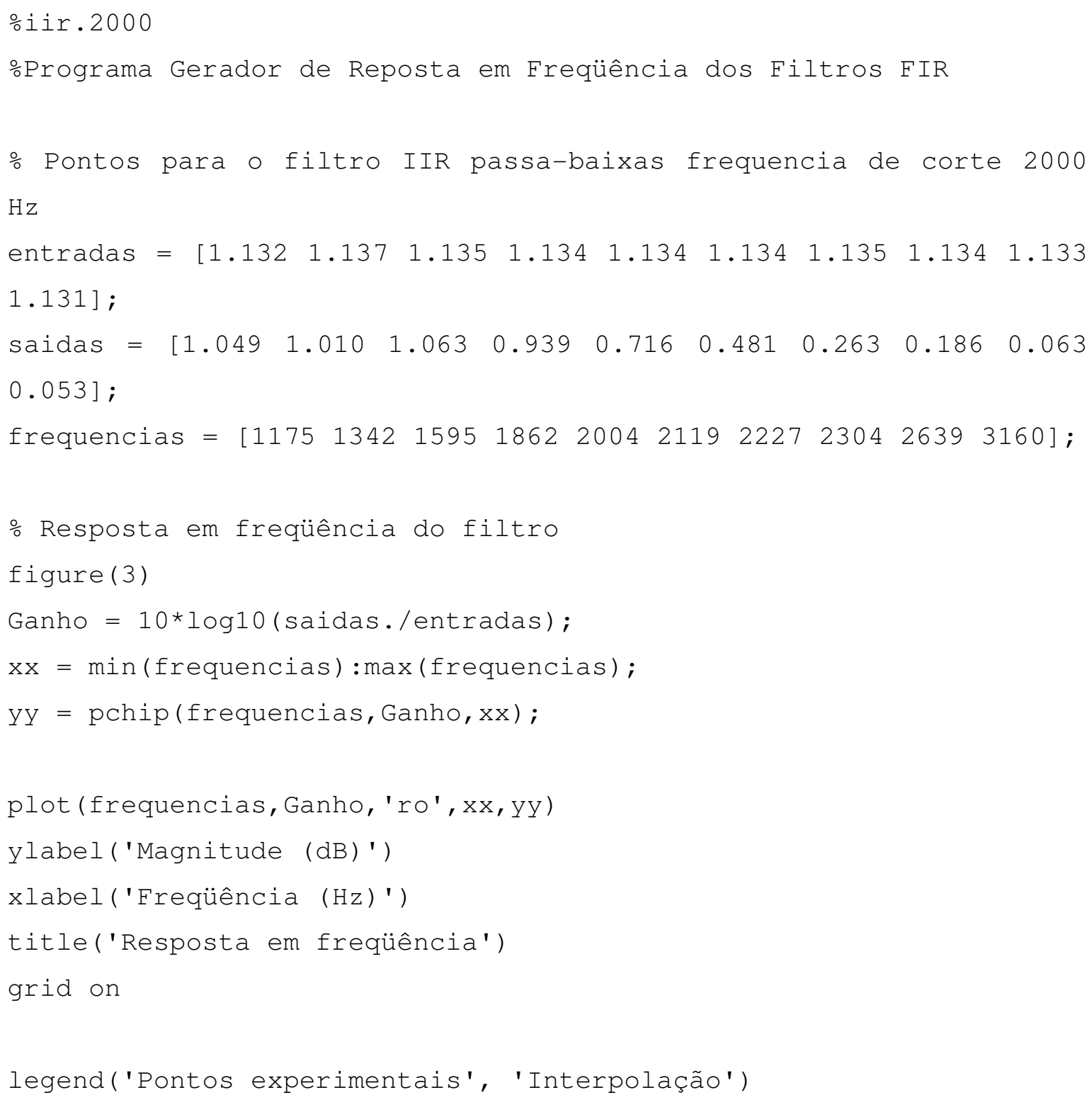


- Código Fonte para a geração do espectro do sinal corrompido por dois sinais senoidais centrados em $900 \mathrm{~Hz}$ e $2700 \mathrm{~Hz}$, e a FFT do sinal recuperado.

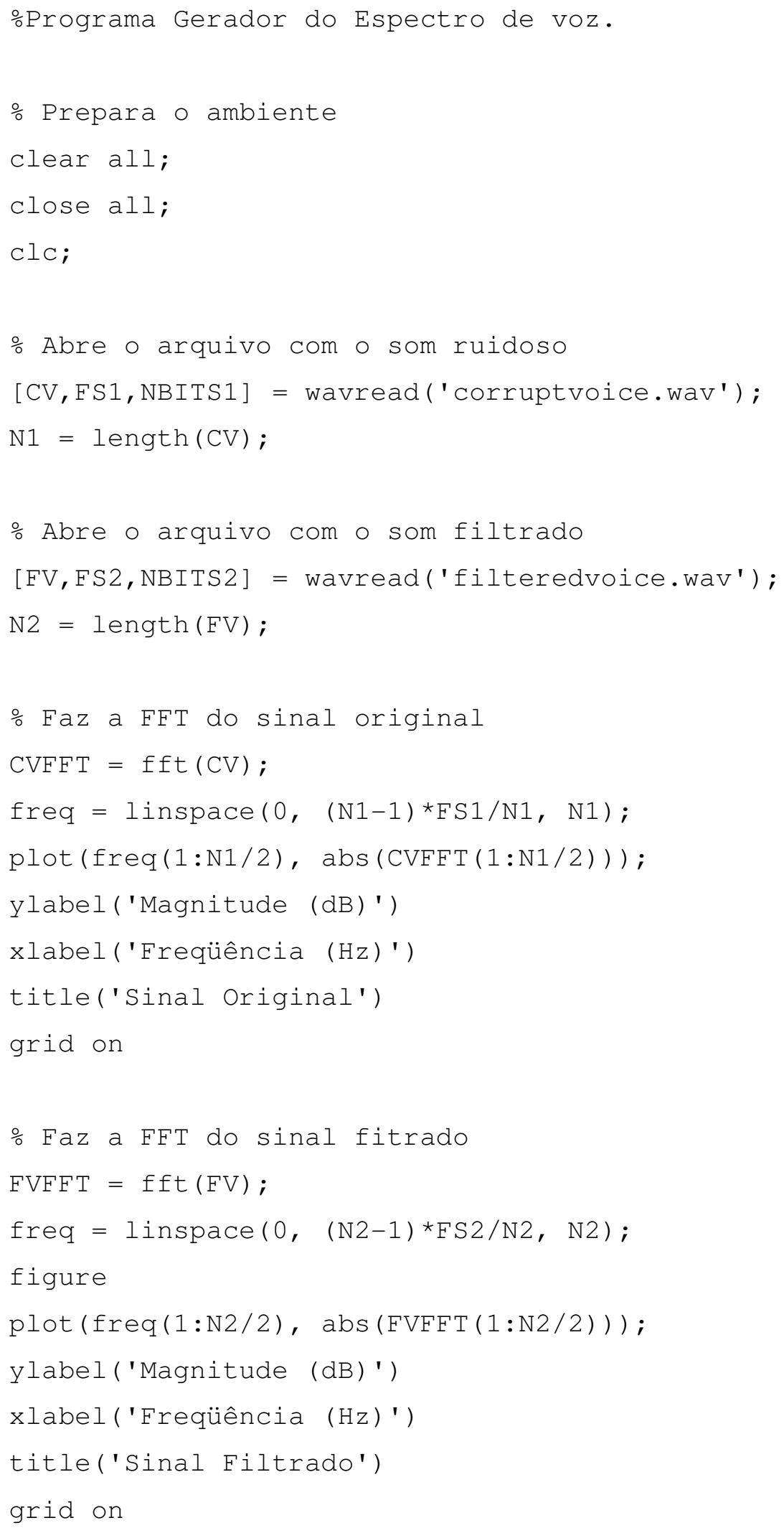




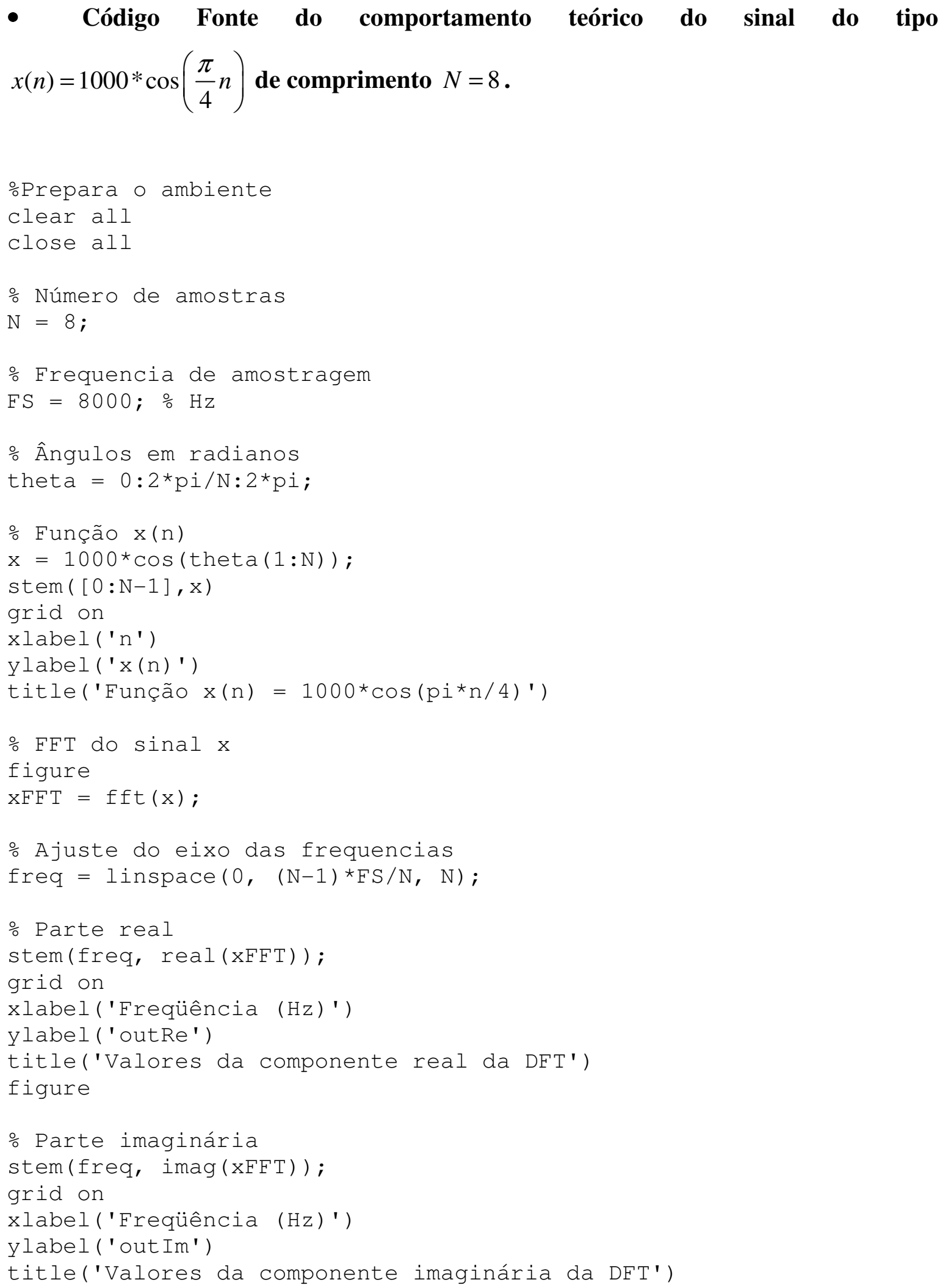


- Código Fonte do comportamento teórico do sinal do tipo $x(n)=1000 * \sin \left(\frac{\pi}{5} n\right)$ de comprimento $N=20$.

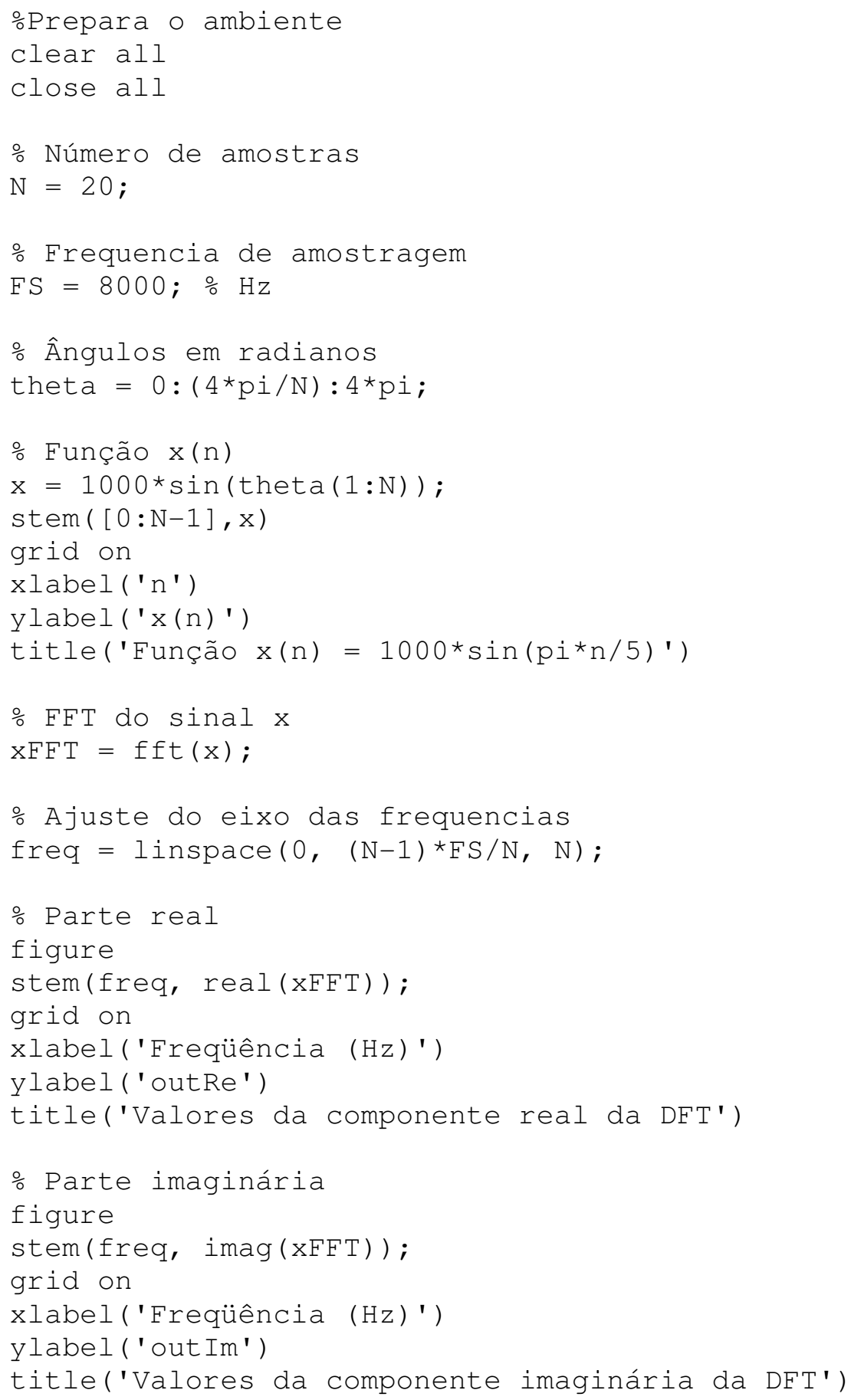


- Código Fonte do comportamento teórico do sinal do tipo $x(n)=1000 * \sin \left(\frac{\pi}{8} n\right)$ de comprimento $N=32$.

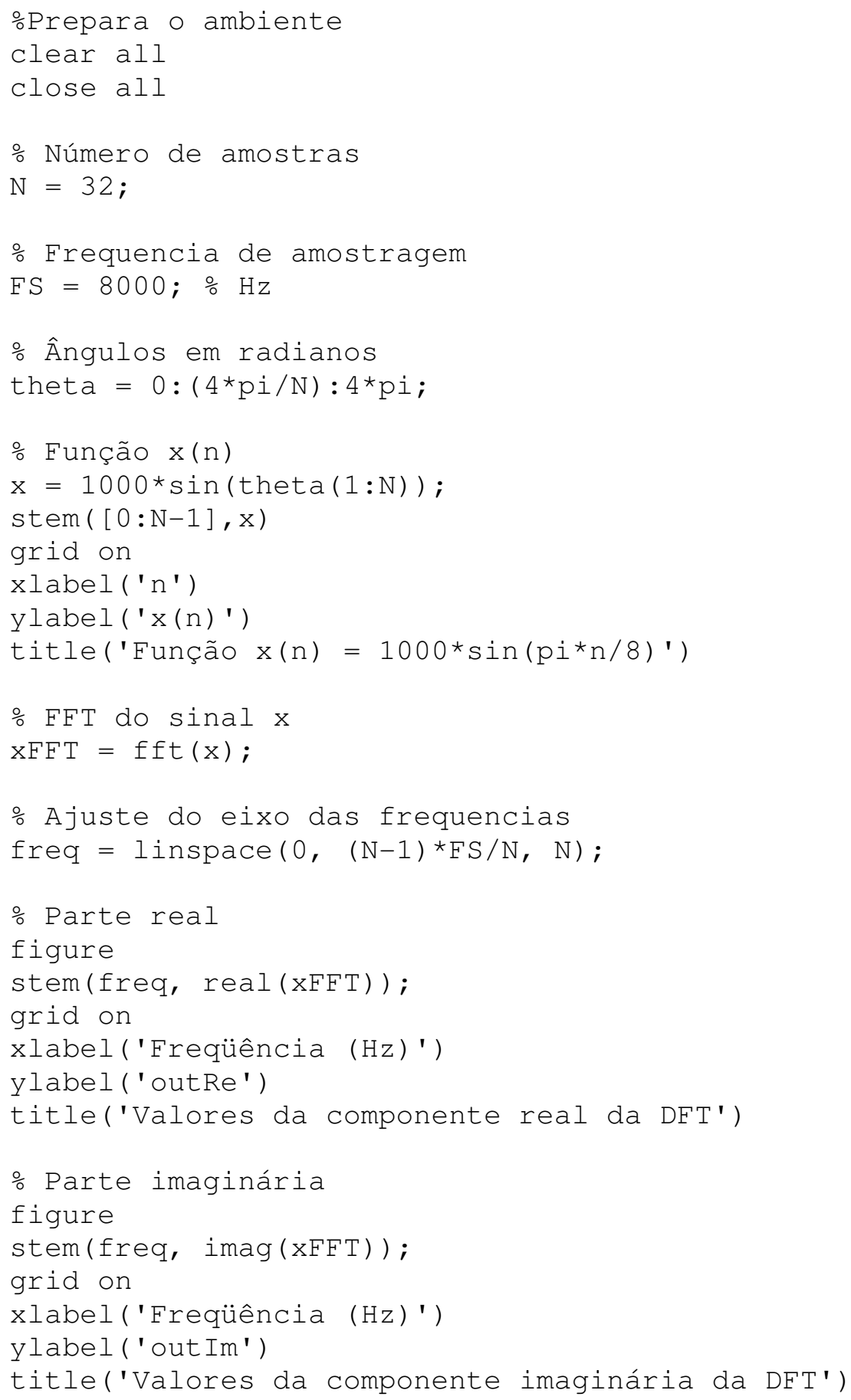

